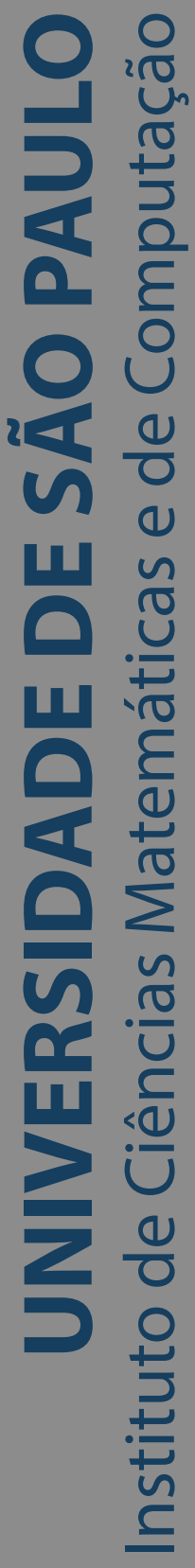

Subsídios à integração de ferramentas de avaliação automática e sistemas de gerenciamento de aprendizagem

\title{
Draylson Micael de Souza
}

Tese de Doutorado do Programa de Pós-Graduação em Ciências de Computação e Matemática Computacional (PPG-CCMC) 

Assinatura:

\section{Draylson Micael de Souza}

Subsídios à integração de ferramentas de avaliação automática e sistemas de gerenciamento de aprendizagem

Tese apresentada ao Instituto de Ciências Matemáticas e de Computação - ICMC-USP, como parte dos requisitos para obtenção do título de Doutor em Ciências - Ciências de Computação e Matemática Computacional. VERSÃO REVISADA

Área de Concentração: Ciências de Computação e Matemática Computacional

Orientadora: Profa. Dra. Ellen Francine Barbosa 
Ficha catalográfica elaborada pela Biblioteca Prof. Achille Bassi e Seção Técnica de Informática, ICMC/USP, com os dados fornecidos pelo(a) autor(a)

de Souza, Draylson
Subsídios à integração de ferramentas de avaliação
automática e sistemas de gerenciamento de
aprendizagem / Draylson de Souza; orientador Ellen
Barbosa. - São Carlos, 2017.
195 p.
Tese (Doutorado - Programa de Pós-Graduação em
Ciências de Computação e Matemática Computacional) --
Instituto de Ciências Matemáticas e de Computação,
Universidade de São Paulo, 2017.
1. Ferramentas de avaliação automática de
trabalhos de programação. 2. Sistemas de
gerenciamento de aprendizagem. 3. Ensino e
aprendizagem de programação. 4. Arquitetura. 5.
Middleware. I. Barbosa, Ellen, orient. II. Título.




\section{Draylson Micael de Souza}

\section{Subsidies to the integration of automated assessment tools and learning management systems}

Doctoral dissertation submitted to the Institute of Mathematics and Computer Sciences - ICMC-USP, in partial fulfillment of the requirements for the degree of the Doctorate Program in Computer Science and Computational Mathematics. FINAL VERSION

Concentration Area: Computer Science and Computational Mathematics

Advisor: Profa. Dra. Ellen Francine Barbosa 

Primeiramente, agradeço a Deus, pois foi Ele que me deu condições e me conduziu até onde estou.

Em seguida, agradeço ao meu pai Noel Antonio de Souza e a minha mãe Maria Izabel Teixeira de Souza, pois dedicaram as suas vidas para que eu e meu irmão tivéssemos boas oportunidades.

Agradeço aos demais familiares que me deram apoio, em especial ao meu irmão Drayton Mizael de Souza, contribuindo para o meu bem-estar e crescimento pessoal.

Agradeço também aos amigos e colegas que me apoiaram, muitas vezes agindo como família.

Agradeço à minha orientadora Ellen Francine Barbosa, pois me deu apoio acadêmico e pessoal durante praticamente toda a minha vida acadêmica.

Agradeço ao professor Michael Kölling e a University of Kent at Canterbury (UKC) que me aceitaram para um estágio no exterior, contribuindo para o meu trabalho e para a minha formação pessoal.

Agradeço aos demais professores que contribuíram para a minha formação profissional e pessoal, sejam do ICMC-USP, de outras instituições ou dos tempos de escola.

Destes mesmos lugares, agradeço aos demais funcionários e servidores que me prestaram serviços de forma atenciosa e dedicada.

Agradeço à Universidade de São Paulo (USP), mais especificamente ao Instituto de Ciências Matemáticas e de Computação (ICMC) e, em especial, aos grupos de pesquisa de Engenharia de Software (LabES) e de Computação Aplicada à Educação (CAEd) por me proporcionarem um excelente formação profissional e pessoal.

Por fim, agradeço a Fundação de Amparo à Pesquisa do Estado de São Paulo - FAPESP (Processos 2012/04352-6 e BEPE 2015/10670-9), pelo apoio financeiro ao longo da minha vida acadêmica. 

"Educação nunca foi despesa.

Sempre foi investimento com retorno garantido."

(Sir Arthur Lewis) 



\section{RESUMO}

SOUZA, D. M. Subsídios à integração de ferramentas de avaliação automática e sistemas de gerenciamento de aprendizagem. 2017. 195 p. Tese (Doutorado em Ciências - Ciências de Computação e Matemática Computacional) - Instituto de Ciências Matemáticas e de Computação, Universidade de São Paulo, São Carlos - SP, 2017.

A avaliação de trabalhos práticos de programação é uma tarefa dispendiosa. Diversas ferramentas têm sido propostas e desenvolvidas a fim de automatizar as tarefas repetitivas realizadas pelos professores na avaliação de trabalhos práticos de programação e fornecer um feedback mais rápido e adequado aos alunos. No entanto, a adição de uma nova ferramenta aumenta a sobrecarga de novas informações e ambientes que os alunos têm que lidar. De forma análoga, a ferramenta de avaliação é mais um recurso que o professor tem de configurar, manter e ensinar os alunos a utilizar. Por este motivo, vários trabalhos vêm sendo conduzidos a fim de integrar ferramentas de avaliação para trabalhos de programação em sistemas de gestão da aprendizagem (Learning Management Systems - LMSs). A integração de ferramentas em LMSs promove sua adoção em disciplinas de computação, uma vez que estarão em concordância com o LMS já familiar aos alunos e professores, dispensando a necessidade de adotar, aprender e gerenciar a submissão e correção de trabalhos em um outro ambiente. No entanto, tais trabalhos consistem apenas em modelos conceituais abstratos, não propõem uma integração com vários LMSs ou não tratam certas dificuldades específicas encontradas quando integrando ferramentas de avaliação. Nessa perspectiva, este trabalho tem como objetivo o desenvolvimento da arquitetura IMPACTLE, uma solução que permite a integração de diferentes ferramentas de avaliação para trabalhos de programação em vários LMSs. A ideia é que os alunos e professores possam acessar as funcionalidades das ferramentas por meio dos LMSs em que já estão habituados, sem a necessidade de aprender a utilizar e adotar uma nova ferramenta. Protótipos da arquitetura IMPACTLE foram instanciados e experimentos foram realizados envolvendo a utilização de diferentes ferramentas de avaliação por meio de LMSs. De modo geral, observou-se que a utilização da IMPACTLE possibilita que professores e alunos realizem as tarefas relacionadas às atividades de programação de forma mais eficiente, eficaz e efetiva por meio dos LMSs.

Palavras-chave: Ferramentas de avaliação automática de trabalhos de programação. Sistemas de gerenciamento de aprendizagem. Ensino e aprendizagem de programação. Arquitetura. Middleware. 



\section{ABSTRACT}

SOUZA, D. M. Subsidies to the integration of automated assessment tools and learning management systems. 2017. 195 p. Tese (Doutorado em Ciências - Ciências de Computação e Matemática Computacional) - Instituto de Ciências Matemáticas e de Computação, Universidade de São Paulo, São Carlos - SP, 2017.

The assessment of programming assignments is a costly task. Several tools have been proposed and developed in order to automate the repetitive tasks performed by instructors in the assessment of programming assignments and provide a faster and more adequate feedback to students. However, adding a new tool increases the overload of new information and environments that students have to deal with. Similarly, the assessment tool is one more resource that the instructor has to configure, maintain and teach students to use, spending time and effort that could be used in other pedagogical activities. For this reason, several works have been conducted to integrate assessment tools for programming assignments in learning management systems (LMSs). The integration of assessment tools into LMSs promotes their adoption in computing courses, since they will be in agreement with the LMS already familiar to students and instructors, without the need to adopt, learn and manage the submission and correction of assignments in another environment. However, these works consist only of abstract conceptual models, do not propose integration with several LMSs, or do not address certain specific difficulties faced when integrating assessment tools. In this perspective, this work aims at the proposition of the IMPACTLE architecture, a solution that allows the integration of different assessment tools for programming assignments in LMSs. The idea is that students and teachers can access the features of the tools through the LMSs they are already used to, without the need to learn how to use and adopt a new tool. Architecture prototypes were instantiated and experiments were carried out involving the use of different assessment tools through LMSs. In general, we noticed that the use of IMPACTLE enables instructors and students perform tasks related to programming activities in a more efficient, efficacious and effective way through the LMSs.

Keywords: Assessment tools for programming assignments. Learning management systems. Teaching and learning of programming. Architecture. Middleware. 



\section{LISTA DE ILUSTRAÇÕES}

Figura 1 - Integração de ferramentas de avaliação automática em LMSs . . . . . . . . 27

Figura 2 - Dificuldades em programação: Procedimento de seleção dos artigos . . . . 32

Figura 3 - Dificuldades em programação: Procedimento de extração dos dados . . . . 33

Figura 4 - Dificuldades em programação: Fases do mapeamento sistemático . . . . . . 33

Figura 5 - Dificuldades em programação: Número de publicações por ano . . . . . . . 34

Figura 6 - Defeitos em comandos: Frequência absoluta . . . . . . . . . . . . . 44

Figura 7 - Defeitos em comandos: Frequência relativa . . . . . . . . . . 45

Figura 8 - Defeitos em comandos: Categorias e subcategorias com maior número de defeitos associados . . . . . . . . . . . . . . 46

Figura 9 - Defeitos em expressões: Frequência absoluta . . . . . . . . . . . . . 47

Figura 10 - Defeitos em expressões: Frequência relativa . . . . . . . . . . . . . . 47

Figura 11 - Defeitos em expressões: Categorias e subcategorias com maior número de defeitos associados . . . . . . . . . . . . . . 48

Figura 12 - Comparação entre os defeitos e as dificuldades em programação . . . . . . 49

Figura 13 - Ferramentas de avaliação: Procedimento de seleção dos artigos . . . . . . . 54

Figura 14 - Ferramentas de avaliação: Procedimento de extração dos dados . . . . . . . 54

Figura 15 - Ferramentas de avaliação: Fases do mapeamento sistemático . . . . . . . . 55

Figura 16 - Ferramentas de avaliação: Número de artigos por ano . . . . . . . . . . . 58

Figura 17 - Ferramentas de avaliação: Número de artigos por base eletrônica . . . . . . 58

Figura 18 - Principais funcionalidades identificadas em ferramentas de avaliação . . . . 65

Figura 19 - Principais linguagens apoiadas pelas ferramentas de avaliação . . . . . . . . 67

Figura 20 - Interfaces entre as ferramentas de avaliação e outros ambientes . . . . . . . 67

Figura 21 - Arquitetura SOA de Amelung, Krieger e Rosner (2011) . . . . . . . . . . . 74

Figura 22 - Arquitetura GLUE! . . . . . . . . . . . . . . . . 76

Figura 23 - Arquitetura IMPACTLE: Visão geral . . . . . . . . . . . . . . . . . 91

Figura 24 - Arquitetura IMPACTLE: Extensão e demais recursos de um LMS . . . . . . 94

Figura 25 - Arquitetura IMPACTLE: Comportamento das extensões . . . . . . . . . . . 96

Figura 26 - Arquitetura IMPACTLE: Estrutura do adaptadores . . . . . . . . . . . . . . 98

Figura 27 - Arquitetura IMPACTLE: Comportamento dos adaptadores . . . . . . . . 101

Figura 28 - Arquitetura IMPACTLE: Estrutura do middleware . . . . . . . . . . . . . . 103

Figura 29 - Arquitetura IMPACTLE: Comportamento do middleware . . . . . . . . . . 106

Figura 30 - Arquitetura IMPACTLE: Visão de casos de uso (Professor) . . . . . . . . . 107

Figura 31 - Arquitetura IMPACTLE: Visão de casos de uso (Aluno) . . . . . . . . . . . 109 
Figura 32 - Arquitetura IMPACTLE: Visão lógica . . . . . . . . . . . . . . . 111

Figura 33 - Arquitetura IMPACTLE: Visão de processos (Submissão de uma solução) 115

Figura 34 - Arquitetura IMPACTLE: Visão de implementação . . . . . . . . . . . . . 116

Figura 35 - Arquitetura IMPACTLE: Visão física . . . . . . . . . . . . . . . . . . . 119

Figura 36 - Protótipo arquitetural do middleware . . . . . . . . . . . . . . . . . . . 121

Figura 37 - Extensão para o MoOdLE . . . . . . . . . . . . . . . . . . 123

Figura 38 - Extensão para o BLUEJ . . . . . . . . . . . . . . . . . . . . 124

Figura 39 - Experimento 1: Eficiência . . . . . . . . . . . . . . . . . 134

Figura 40 - Experimento 1: Eficácia . . . . . . . . . . . . . . . . 136

Figura 41 - Experimento 1: Efetividade . . . . . . . . . . . . . . . 138

Figura 42 - Experimento 1: Resultados da percepção dos participantes . . . . . . . . 140

Figura 43 - Experimento 2: Resultados . . . . . . . . . . . . . . . . . . . 146

Figura 44 - Experimento 2: Percepção dos participantes . . . . . . . . . . . . . . . . 149

Figura 45 - Experimento 2: Opinião dos participantes sobre a abordagem . . . . . . . . 150

Figura 46 - Arquitetura IMPACTLE: Visão lógica detalhada (Subsistemas) . . . . . . . 172

Figura 47 - Arquitetura IMPACTLE: Visão lógica detalhada (LMSs) ～. . . . . . . . . 173

Figura 48 - Arquitetura IMPACTLE: Visão lógica detalhada (Middleware) . . . . . . 176

Figura 49 - Arquitetura IMPACTLE: Visão lógica detalhada (Adaptador) . . . . . . . . 180

Figura 50 - Arquitetura IMPACTLE: Visão de processos detalhada (Definição de um trabalho $\ldots \ldots \ldots \ldots \ldots$. . . . . . . . . . . . . . . 182

Figura 51 - Arquitetura IMPACTLE: Visão de processos detalhada (Seleção de questão de uma base de questões) . . . . . . . . . . . . . . . . . . . . 184

Figura 52 - Arquitetura IMPACTLE: Visão de processos detalhada (Geração de dados de teste para uma questão $\ldots \ldots$. . . . . . . . . . . . . . 185

Figura 53 - Arquitetura IMPACTLE: Visão de processos detalhada (Submissão de uma solução $\ldots \ldots \ldots \ldots$. . . . . . . . . . . . . . . . 187

Figura 54 - Arquitetura IMPACTLE: Visão de processos detalhada (Avaliação automática centrada no professor $\ldots \ldots \ldots$. . . . . . . . . . . 188

Figura 55 - Arquitetura IMPACTLE: Visão de processos detalhada (Avaliação manual centrada no professor $\ldots$. . . . . . . . . . . . . . . . . . . 189

Figura 56 - Arquitetura IMPACTLE: Visão de processos detalhada (Avaliação automática centrada no aluno $\ldots \ldots \ldots$. . . . . . . . . . . . . . . . 190

Figura 57 - Arquitetura IMPACTLE: Visão de processos detalhada (Processamento de uma requisição em espera) . . . . . . . . . . . . . . . . . . . 192

Figura 58 - Arquitetura IMPACTLE: Visão de processos detalhada (Obtenção dos resultados de uma requisição em processamento) . . . . . . . . . . . . . 193

Figura 59 - Arquitetura IMPACTLE: Visão de processos detalhada (Obtenção dos resultados de uma requisição pronta) . . . . . . . . . . . . . . . . . . . . . . 194 
Quadro 1 - Artigos sobre o ensino e a aprendizagem de programação . . . . . . . . . 31

Quadro 2 - Conceitos de programação identificados como difíceis de se aprender e ensinar 35

Quadro 3 - Problemas relacionados às dificuldades de aprender conceitos de programação 35

Quadro 4 - Problemas relacionados às dificuldades motivacionais . . . . . . . . 37

Quadro 5 - Propostas para mitigar as dificuldades motivacionais . . . . . . . . . 37

Quadro 6 - Classificação de defeitos: Possíveis ações . . . . . . . . . . . . . . . . . 39

Quadro 7 - Classificação de defeitos: Tipos de comandos . . . . . . . . . . . . . 40

Quadro 8 - Classificação de defeitos: Exemplos de categorias de defeitos em comandos 40

Quadro 9 - Classificação de defeitos: Componentes de comandos . . . . . . . . . . . 40

Quadro 10 - Classificação de defeitos: Exemplos de subcategorias de defeitos em comandos 41

Quadro 11 - Classificação de defeitos: Tipos de expressões . . . . . . . . . . . . . . . . 41

Quadro 12 - Classificação de defeitos: Exemplo de categorias de defeitos em expressões 42

Quadro 13 - Classificação de defeitos: Exemplo de subcategorias de defeitos em expressões 42

Quadro 14 - Ferramentas de avaliação: Artigos incluídos no mapeamento sistemático . . 56

Quadro 15 - Ferramentas de avaliação: Artigos incluídos no mapeamento sistemático (continuação) . . . . . . . . . . . . . . . . . . 5 57

Quadro 16 - Ferramentas de avaliação para trabalhos de programação . . . . . . . . . . 59

Quadro 17 - Visão geral dos principais LMSs identificados . . . . . . . . . . . . . . . 69

Quadro 18 - LMSs: Funcionalidades de organização . . . . . . . . . . . . . . . 70

Quadro 19 - LMSs: Funcionalidades de conteúdo . . . . . . . . . . . . . . . . 70

Quadro 20 - LMSs: Funcionalidades de atividades . . . . . . . . . . . . . . . 70

Quadro 21 - LMSs: Funcionalidades de comunicação . . . . . . . . . . . . . . 71

Quadro 22 - Integração de ferramentas em LMSs: Limitações dos trabalhos identificados 79

Quadro 23 - Arquitetura IMPACTLE: Funcionalidades das extensões . . . . . . . . . . 93

Quadro 24 - Arquitetura IMPACTLE: Funcionalidades dos adaptadores . . . . . . . . . 97

Quadro 25 - Arquitetura IMPACTLE: Artefatos dos adaptadores . . . . . . . . . . . . 99

Quadro 26 - Arquitetura IMPACTLE: Funcionalidades do middleware . . . . . . . . . . 101

Quadro 27 - Arquitetura IMPACTLE: Casos de uso (Professor) . . . . . . . . . . . 108

Quadro 28 - Arquitetura IMPACTLE: Casos de uso (Aluno) . . . . . . . . . . . . . . 110

Quadro 29 - Arquitetura IMPACTLE: Subsistemas . . . . . . . . . . . . . . . . . . 110

Quadro 30 - Arquitetura IMPACTLE: Visão lógica (Componentes dos LMSs) . . . . . . 110

Quadro 31 - Arquitetura IMPACTLE: Visão lógica (Componentes do middleware) . 112

Quadro 32 - Arquitetura IMPACTLE: Visão lógica (Componentes do adaptador) . . . . 113 
Quadro 33 - Arquitetura IMPACTLE: Visão de processos (Principais processos) . . . 114

Quadro 34 - Arquitetura IMPACTLE: Visão de implementação (Unidades de implementação $\ldots \ldots \ldots \ldots$. . . . . . . . . . . . . . . 117

Quadro 35 - Arquitetura IMPACTLE: Visão de implementação (Artefatos) . . . . . . . 117

Quadro 36 - Arquitetura IMPACTLE: Visão física (Dispositivos) ～. . . . . . . . . . 118

Quadro 37 - Arquitetura IMPACTLE: Visão lógica detalhada (Subsistemas) . . . . . . . 172

Quadro 38 - Arquitetura IMPACTLE: Visão lógica detalhada (Componentes dos LMSs) 173

Quadro 39 - Arquitetura IMPACTLE: Visão lógica detalhada (Operações da extensão) 175

Quadro 40 - Arquitetura IMPACTLE: Visão lógica detalhada (Componentes do middleware $\ldots \ldots \ldots$. . . . . . . . . . . . . . 177

Quadro 41 - Arquitetura IMPACTLE: Visão lógica detalhada (Operações do serviço de administração $) \ldots \ldots \ldots$. . . . . . . . . . . . . 177

Quadro 42 - Arquitetura IMPACTLE: Visão lógica detalhada (Atributos de uma conta de

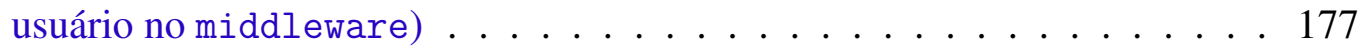

Quadro 43 - Arquitetura IMPACTLE: Visão lógica detalhada (Atributos de uma ferramenta no middleware $\ldots \ldots$. . . . . . . . . . . . . . . 177

Quadro 44 - Arquitetura IMPACTLE: Visão lógica detalhada (Operações do serviço de execução ． . . . . . . . . . . . . . . . . . . . 178

Quadro 45 - Arquitetura IMPACTLE: Visão lógica detalhada (Atributos de uma requisição) 178

Quadro 46 - Arquitetura IMPACTLE: Visão lógica detalhada (Componentes do adaptador) 179

Quadro 47 - Arquitetura IMPACTLE: Visão lógica detalhada (Interfaces no adaptador) . 179

Quadro 48 - Arquitetura IMPACTLE: Visão lógica detalhada (Operações do serviço

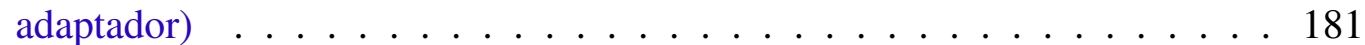

Quadro 49 - Arquitetura IMPACTLE: Visão lógica detalhada (Atributos de uma questão no adaptador $\ldots \ldots \ldots \ldots$. . . . . . . . . . . . . . 181

Quadro 50 - Arquitetura IMPACTLE: Visão de processos detalhada (Operações acionadas no processamento de uma requisição em espera) . . . . . . . . . . . 192

Quadro 51 - Arquitetura IMPACTLE: Visão de processos detalhada (Operações acionadas na obtenção dos resultados de requisições em processamento) . . . . . 194 
Tabela 1 - Número de códigos por número de defeitos . . . . . . . . . . . . . . 43

Tabela 2 - Experimento 1: Resultados de eficiência do Grupo A . . . . . . . . . 135

Tabela 3 - Experimento 1: Resultados de eficiência para o Grupo B . . . . . . . 135

Tabela 4 - Experimento 1: Resultados de eficácia para o Grupo A . . . . . . . . 137

Tabela 5 - Experimento 1: Resultados de eficácia para o Grupo B . . . . . . . . 137

Tabela 6 - Experimento 1: Resultados de efetividade para o Grupo A . . . . . . . . 139

Tabela 7 - Experimento 1: Resultados de efetividade para o Grupo B . . . . . . . . 139

Tabela 8 - Experimento 2: Resultados para o Grupo A . . . . . . . . . . . 147

Tabela 9 - Experimento 2: Resultados para o Grupo B . . . . . . . . . . 147 



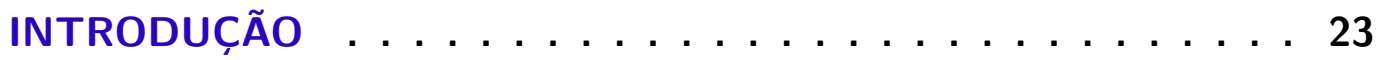

1.1

Contexto 23

1.2

Motivações 25

1.3

Objetivos 27

ENSINO E APRENDIZAGEM DE PROGRAMAÇÃO . . . . . . 29

Dificuldades no ensino e na aprendizagem de programação . . . . 30

2.2.1 Planejamento e condução do mapeamento sistemático . . . . . . 30

2.2.2 Categorias de dificuldades e trabalhos relacionados . . . . . . . . . 34

2.2.2.1 Dificuldades no ensino e na aprendizagem de conceitos de programação . . 34

2.2.2.2 Dificuldades no projeto de programas . . . . . . . . . . . . . . 35

2.2.2.3 Dificuldades no entendimento de programas . . . . . . . . . . . . 36

2.2.2.4 Dificuldades motivacionais. . . . . . . . . . . . . . . . . 36

2.2.2.5 Dificuldades em avaliar programas . . . . . . . . . . . . . 37

2.3 Defeitos mais frequentes nos programas dos alunos . . . . . . . 38

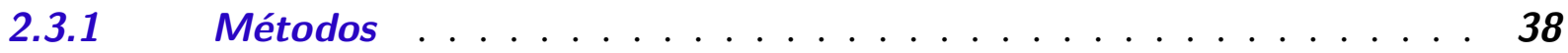

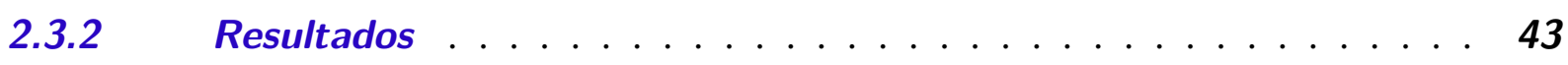

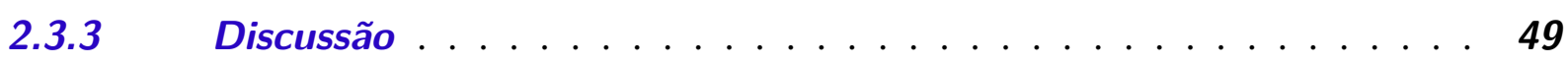

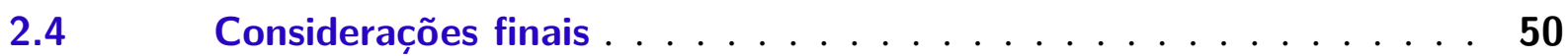

3 FERRAMENTAS DE AVALIAÇÃO, SISTEMAS DE GERENCIAMENTO DE APRENDIZAGEM E ARQUITETURAS DE SOFTWARE 51

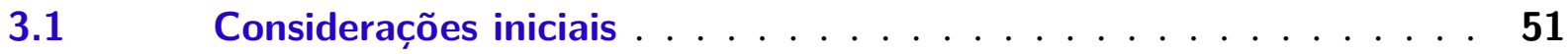

3.2 Ferramentas de avaliação para trabalhos práticos de programação . 52

3.2.1 Planejamento e execução do mapeamento sistemático . . . . . . . 52

3.2.2 Classificação das ferramentas de avaliação para trabalhos de programação . . . . . . . . . . . . . . . . . 58

3.2.2.1 Classificação por nível de automatização . . . . . . . . . . . . . . . . 59

3.2.2.2 Classificação por tipo de abordagem . . . . . . . . . . . . . 61

3.2.2.3 Classificação por ambiente de execução . . . . . . . . . . . . . . 62

3.2.3 Funcionalidades e características das ferramentas de avaliação . . 64 
$3.3 \quad$ Sistemas de gestão da aprendizagem . . . . . . . . . . . 68

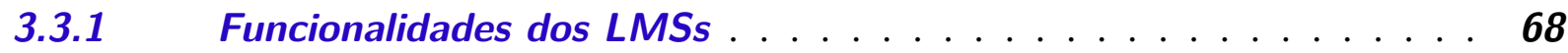

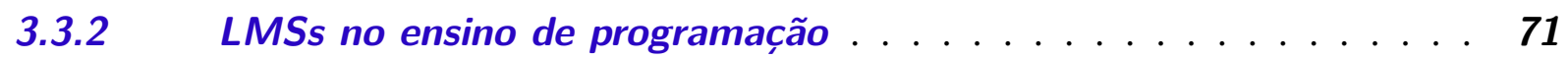

3.3.3 Integração de ferramentas externas em LMSs . . . . . . . . . . 73

3.3.3.1 Arquitetura SOA de Amelung, Krieger e Rosner (2011) . . . . . . . . . . 74

3.3.3.2 Sistema de gestão de aprendizagem $A+\ldots \ldots$. . . . . . . . . 75

3.3.3.3 Arquitetura GLUE! . . . . . . . . . . . . . . . . . . . 75

3.3.3.4 Protótipo de arquitetura para integração de conteúdos de aprendizagem inteligentes . . . . . . . . . . . . . . . . . 76

3.3.3.5 Acos server . . . . . . . . . . . . . . . . . . . 77

3.3.3.6 Outras iniciativas . . . . . . . . . . . . . . . . . . 77

3.3.3.7 Limitações . . . . . . . . . . . . . . . . . . . . . . . 78

$3.4 \quad$ Arquitetura de software $\ldots \ldots \ldots \ldots \ldots \ldots$

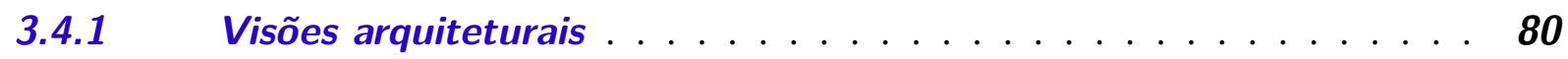

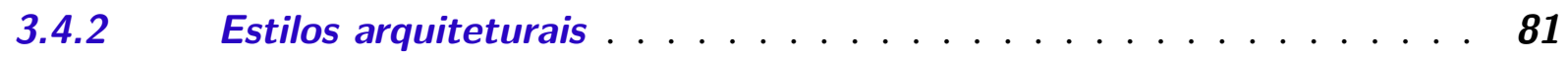

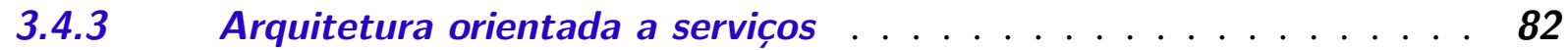

3.4.4 Avaliação de arquiteturas de software . . . . . . . . . . 83

$3.5 \quad$ Considerações finais . . . . . . . . . . . . . . . . . . . . . . 84

4 A ARQUITETURA IMPACTLE $\ldots \ldots \ldots \ldots \ldots$

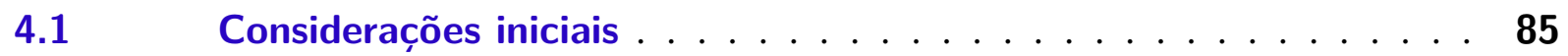

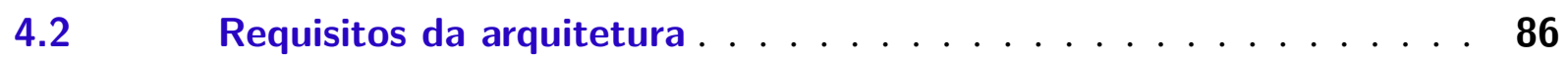

4.3 Decisões de projeto . . . . . . . . . . . . . . . . . . 87

4.3.1 Funcionalidades redundantes entre os LMSs e as ferramentas de

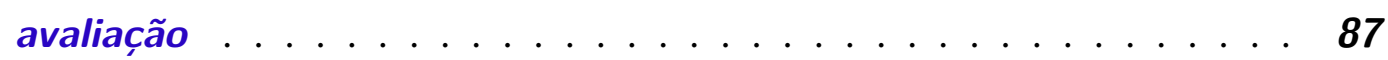

4.3.2 Diferentes contextos de atividades de programação . . . . . . . . . 89

4.3.3 Diferentes dados e artefatos de entrada . . . . . . . . . . . . . . 89

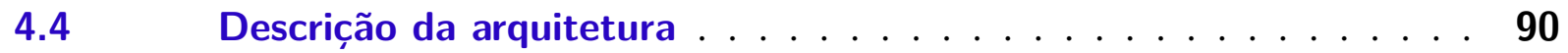

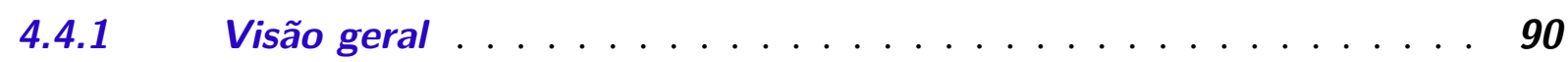

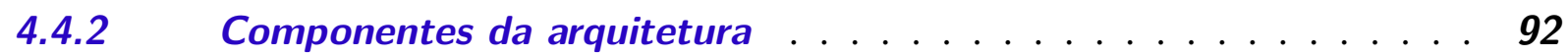

4.4.2.1 LMSs e extensões . . . . . . . . . . . . . . . . . . 92

4.4.2.2 Adaptadores ... . . . . . . . . . . . . . . . 95

4.4.2.3 O Middleware . . . . . . . . . . . . . . . . . . . . . 100

$4.5 \quad$ Visões da arquitetura . . . . . . . . . . . . . . . 105

4.5.1 Visão de casos de uso . . . . . . . . . . . . . . . . . 105

4.5.1.1 Casos de uso do professor . . . . . . . . . . . . . . . . . . . . . 105

4.5.1.2 Casos de uso do aluno . . . . . . . . . . . . . . . . . . . . . 109

4.5.2 Visão lógica . . . . . . . . . . . . . . . . . . . . . . 109

4.5.3 Visão de processos . . . . . . . . . . . . . . . . 113

4.5.4 Visão de implementação . . . . . . . . . . . . . . . 115 
$4.5 .5 \quad$ Visão física . . . . . . . . . . . . . . . . . . . 118

4.6 Protótipos arquiteturais ................. 118

4.6.1 O middleware . . . . . . . . . . . . . . . . . . . . 120

4.6.2 Adaptadores para ferramentas de avaliação . . . . . . . . . . . . . 120

4.6.3 A extensão para o Moodle . . . . . . . . . . . . . . . . . . . . 122

4.6.4 A extensão para o BlueJ . . . . . . . . . . . . . . . . . . . 122

4.7 Considerações finais . . . . . . . . . . . . . . . . 124

5 ASPECTOS DE USO E VALIDAÇÃO DA ARQUITETURA IMPACTLE . . . . . . . . . . . . . . . . . . . . 127

$5.1 \quad$ Considerações iniciais . . . . . . . . . . . . . . 127

5.2 Experimento 1: Definição, submissão e avaliação de trabalhos . . 128

$5.2 .1 \quad$ Visão geral . . . . . . . . . . . . . . . . . . 128

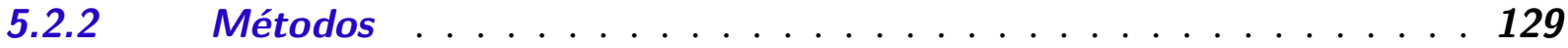

5.2.3 Resultados . . . . . . . . . . . . . . . . . 134

5.2.4 Discussões . . . . . . . . . . . . . . . . . . 140

5.3 Experimento 2: Desenvolvimento e correção de programas . . . . 141

5.3.1 Visão geral . . . . . . . . . . . . . . . . . . . . . . 142

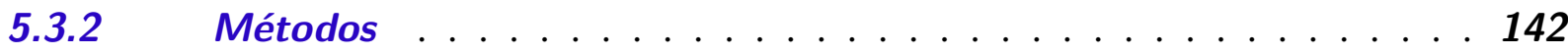

5.3.3 Resultados ..................... 146

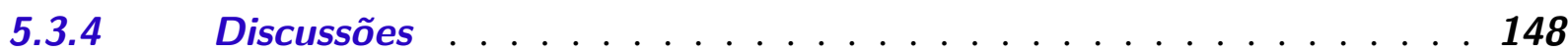

$5.4 \quad$ Considerações finais . . . . . . . . . . . . . . . . 150

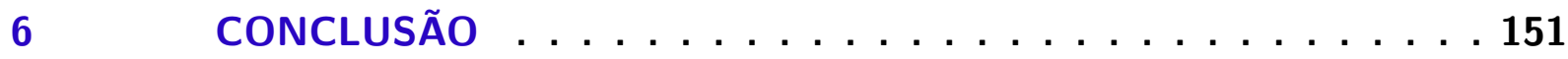

6.1 Caracterização da pesquisa realizada . . . . . . . . . . . . 151

$6.2 \quad$ Contribuições . . . . . . . . . . . . . . . . . . 152

$6.3 \quad$ Limitações . . . . . . . . . . . . . . . . . . . . 154

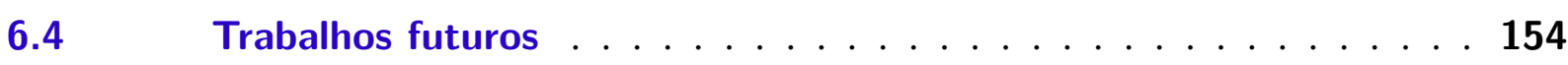

$6.5 \quad$ Publicações . . . . . . . . . . . . . . . 155

REFERÊNCIAS . . . . . . . . . . . . . . . . . . . . 157

APÊNDICE A A ARQUITETURA IMPACTLE - VISÕES LÓGICA E DE PROCESSOS . . . . . . . . . . . . . . 171

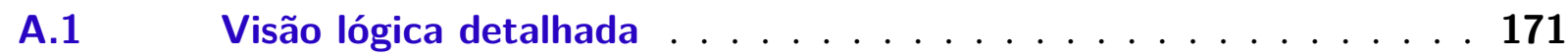

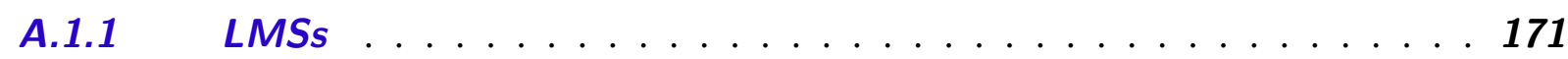

A.1.2 Middleware . . . . . . . . . . . . . . . . 174

A.1.3 Adaptadores . . . . . . . . . . . . . . 179

A.1.4 Ferramentas de avaliação . . . . . . . . . . . . . 181

A.2 Visão de processos detalhada . . . . . . . . . . . 182 
A.2.1 Definição de um trabalho prático . . . . . . . . . . . . 182

A.2.2 Seleção de questão de uma base de questões . . . . . . . . . . . 183

A.2.3 Geração de dados de teste para uma questão . . . . . . . . . . . 185

A.2.4 Submissão de uma solução . . . . . . . . . . . . . . . . 186

A.2.5 Avaliação automática centrada no professor . . . . . . . . . . 187

A.2.6 Avaliação manual centrada no professor . . . . . . . . . . 188

A.2.7 Avaliação automática centrada no aluno . . . . . . . . . 190

A.2.8 Processamento de uma requisição em espera . . . . . . . . . . 191

A.2.9 Obtenção dos resultados de uma requisição em processamento . . 193

A.2.10 Obtenção dos resultados de uma requisição pronta . . . . . . . . 194 


\section{1}

\section{INTRODUÇÃO}

\subsection{Contexto}

Fundamentos de programação é um dos principais tópicos ensinados nas disciplinas introdutórias dos cursos de computação (WATSON; LI, 2014). Mais do que aprender a sintaxe de uma linguagem de programação, em tais disciplinas os alunos devem desenvolver um pensamento computacional, que os permita resolver problemas por meio de habilidades como abstração, decomposição, generalização, avaliação e projeto de algoritmos (LÓPEZ; GARCÍA-PEÑALVO, 2016).

Em geral, as disciplinas de programação têm altas taxas de desistência e reprovação (WATSON; LI, 2014). Pesquisas têm sugerido que os motivos estão relacionados a vários problemas e dificuldades no ensino e na aprendizagem de programação (BOSSE; GEROSA, 2017). Do ponto de vista da aprendizagem, os problemas vão desde as dificuldades dos alunos em entender os conceitos abstratos de programação (HIDALGO-CÉSPEDES; MARÍN-RAVENTÓS; LARA-VILLAGRÁN, 2014) à falta de motivação entre os alunos em realizar as atividades de programação (SETTLE; VIHAVAINEN; SORVA, 2014). Do ponto de vista do ensino, os problemas vão desde as dificuldades dos professores em ilustrar os aspectos dinâmicos de programas e algoritmos (SORVA; KARAVIRTA; MALMI, 2013) às dificuldades em prover um feedback adequado aos alunos sobre a qualidade dos programas e algoritmos desenvolvido por eles (FALKNER et al., 2014).

Um dos aspectos essenciais relacionados à aprendizagem e ao ensino de programação é a avaliação dos trabalhos práticos de programação (MATTHÍASDÓTTIR; ARNALDS, 2015). É comum em disciplinas introdutórias de programação os alunos serem solicitados a desenvolverem programas a fim de exercitar as habilidades necessárias em programação (PARLANTE et al., 2014). Os resultados dessas avaliações são fundamentais para que os alunos possam melhorar a qualidade dos seus programas, aprendendo a partir dos seus próprios erros (AZIZ et al., 2015); 
bem como para que os professores possam identificar quais tópicos e conceitos devem ser mais enfatizados e exercitados ao longo do curso (KURVINEN et al., 2016).

No entanto, avaliar trabalhos práticos de programação é uma tarefa dispendiosa (SHAFFER; SHAFFER, 2013; CHRISTIAN; TRIVEDI, 2016). No melhor dos casos, os professores precisam, ao menos, compilar e executar cada um dos programas dos alunos com um conjunto de valores de entrada e verificar se os programas produzem as saídas esperadas para o problema em questão (SOUZA; FELIZARDO; BARBOSA, 2016). Além disso, o tempo e esforço excessivos na avaliação de tais trabalhos, principalmente em disciplinas com um grande número de alunos, fazem com que os resultados da avaliação sejam limitados (SHAFFER; SHAFFER, 2013), de forma que os alunos não são motivados a melhorarem os seus programas (AZIZ et al., 2015).

Nessa perspectiva, vários trabalhos envolvendo a proposta e o desenvolvimento de ferramentas de avaliação para trabalhos de programação têm sido conduzidos (CHRISTIAN; TRIVEDI, 2016; SOUZA; FELIZARDO; BARBOSA, 2016). O objetivo de tais ferramentas é automatizar algumas tarefas repetitivas realizadas pelos professores durante a avaliação (SOUZA; FELIZARDO; BARBOSA, 2016), além de permitir que os alunos possam receber um feedback mais rápido e detalhado sobre a qualidade dos seus programas (AZIZ et al., 2015; HOLTON; WALLACE, 2013). Em geral, ferramentas de avaliação fornecem tanto funcionalidades para que os professores definam trabalhos práticos de programação e avaliem as soluções dos alunos como funcionalidades para que os alunos submetam suas soluções e recebam um feedback detalhado sobre a qualidade das mesmas (SOUZA; FELIZARDO; BARBOSA, 2016). Em sua maioria, as ferramentas de avaliação para trabalhos de programação verificam automaticamente a correção dos programas dos alunos (SOUZA; FELIZARDO; BARBOSA, 2016) mas, em alguns casos, também verificam aspectos como desempenho, estilo de código, documentação (AZIZ et al., 2015) e até mesmo a qualidade dos testes desenvolvidos pelos alunos (EDWARDS, 2014).

Apesar dos benefícios observados, a adição de uma nova ferramenta aumenta a sobrecarga de novas informações e recursos que os alunos têm que lidar (RÖSSLING et al., 2010; BRUSILOVSKY et al., 2014). É comum que os alunos dispensem um empenho excessivo aprendendo a utilizar a ferramenta ao invés de se dedicarem à construção dos seus programas (RÖSSLING et al., 2010; SIRKIÄ; HAARANEN, 2015). De forma análoga, a ferramenta de avaliação é outro recurso que o professor tem de configurar, manter e ensinar os alunos a utilizar, desperdiçando tempo e esforço que poderia ser utilizado em outras atividades pedagógicas (RÖSSLING et al., 2010; KARAVIRTA; IHANTOLA; KOSKINEN, 2013).

Dentro deste contexto, o presente trabalho de doutorado tem como principais objetivos investigar e propor uma solução para que alunos e professores possam acessar as funcionalidades das ferramentas de avaliação para trabalhos de programação por meio dos ambientes de aprendizagem com os quais já estejam habituados, sem a necessidade de aprender a utilizar uma nova ferramenta. Em síntese, foram investigados mecanismos para a integração de diferentes ferramentas de avaliação para trabalhos de programação em vários ambientes de aprendizagem. 


\subsection{Motivações}

Sistemas de gestão da aprendizagem (Learning Management Systems - LMSs) são aplicações baseadas na web que permitem planejar, implementar e avaliar a aprendizagem de várias formas, incluindo funcionalidades para criar e disponibilizar conteúdo, monitorar a participação nos cursos e avaliar o desempenho dos alunos (BAKER, 2015). Os LMSs são úteis para atrair o interesse dos alunos, bem como ajudar as instituições a dinamizar a educação (PEREZ, 2011). Exemplos de LMSs incluem o MoodLE (Moodle Community, 2016), o CHAMILO (The Chamilo Association, 2017) e o BLACKBOARD (Blackboard Inc., 2017), entre outros.

Apesar de seus benefícios, LMSs não são, por padrão, desenvolvidos de forma adequada para atender às demandas de certas disciplinas dos cursos de computação (RÖSSLING et $a l .$, 2010; SIRKIÄ; HAARANEN, 2015), em especial, disciplinas que envolvem o ensino e a aprendizagem de programação. Essa carência está relacionada tanto a requisitos específicos da área como a interesses/necessidades especiais dos próprios professores, tais como (RÖSSLING et al., 2010; BRUSILOVSKY et al., 2014):

- Habilidade de integrar visualizações e simulações dinâmicas de algoritmos e estruturas de dados.

- Apoio à disponibilização de exemplos de código, os quais os alunos possam facilmente copiar para suas áreas de trabalho e realizar experimentos.

- Facilidade na utilização de código fonte em todas as entradas, como por exemplo, em fóruns ou blogs, com destaque sintático apropriado.

- Apoio a subáreas específicas da computação, tais como linguagens formais, modelagem e simulações.

- Apoio ao oferecimento de trabalhos extraclasse que solicitam aos alunos a submissão de código (opcionalmente com uma avaliação automática integrada).

Nesta perspectiva, vários trabalhos vêm sendo conduzidos a fim de integrar ferramentas de apoio à aprendizagem e ao ensino de computação (em especial, programação) em LMSs. Alario-Hoyos et al. (2013), por exemplo, propuseram a arquitetura GLUE!, que permite a integração de diferentes ferramentas colaborativas (tais como GooGLEDocs (Google, 2017), MEdiaWiki (Wikimedia Foundation, 2017) e DoodLE (Doodle, 2017)) em diferentes LMSs. Brusilovsky et al. (2014) identificaram por meio de uma pesquisa de opinião que a falta de integração delas com os LMSs adotados pelas instituições é uma das principais dificuldades dos professores e alunos em adotá-las e, por este motivo, propuseram um modelo conceitual para integração de ferramentas externas a LMSs. Já Sirkiä e Haaranen (2015) criaram um servidor para hospedagem de ferramentas externas para o ensino de computação. A ideia é que o servidor atue como um repositório de ferramentas externas, de forma que os professores possam selecionar 
as ferramentas que desejam utilizar e inserir um link para elas nas páginas dos seus cursos, disponibilizados por meio de LMSs.

Dentre os trabalhos que procuram apoiar o ensino e a aprendizagem de programação, destacam-se as iniciativas visando a introdução de ferramentas de avaliação para trabalhos práticos de programação em LMSs. Karavirta, Ihantola e Koskinen (2013), por exemplo, desenvolveram o LMS orientado a serviços $\mathrm{A}+$, projetado para que diferentes ferramentas externas para avaliação de programas e exercícios de programação sejam integradas a ele. Thiébaut (2015) desenvolveram o plugin VPL (Virtual Programming Lab), que permite a automatização da avaliação de trabalhos práticos de programação no LMS MoodLE (Moodle Community, 2016). Staubitz et al. (2016) desenvolveram o CODEOCEAN, uma ferramenta de avaliação para trabalhos práticos de programação projetada para ser utilizada em plataformas de MOOCs (Massive Open Online Courses) (ALMAN; JUMBA, 2017). De fato, Rößling et al. (2008), García-Peñalvo e Forment (2014) ressaltam que a comunidade acadêmica tem caminhado em direção ao uso de LMSs. Consequentemente, a integração de ferramentas em LMSs promove sua adoção em disciplinas de computação, uma vez que estarão em concordância com um LMS já familiar aos alunos e professores, dispensando a necessidade de adotar, aprender e gerenciar a submissão e correção de trabalhos em um outro (novo) ambiente.

A integração de ferramentas de avaliação para trabalhos de programação em LMSs inserese também como uma solução para minimizar os efeitos negativos da incorporação de mais uma ferramenta no processo de aprendizagem e ensino de programação (KARAVIRTA; IHANTOLA; KOSKINEN, 2013). Por meio do LMS, as funcionalidades das ferramentas de avaliação são integradas ao ambiente que os alunos já estão habituados a utilizar, diminuindo o esforço necessário para se aprender a utilizar a ferramenta (RÖSSLING et al., 2010; BRUSILOVSKY et al., 2014). De forma análoga, sem a necessidade de configurar, manter e ensinar os alunos a utilizar outra ferramenta, os professores podem investir tempo e esforço em outras atividades pedagógicas relevantes (RÖSSLING et al., 2010; SIRKIÄ; HAARANEN, 2015).

No entanto, a maioria dos trabalhos envolvendo a integração de ferramentas de avaliação para trabalhos de programação em LMSs consiste na integração de uma ferramenta específica em um LMS específico (RÖSSLING et al., 2010; SIRKIÄ; HAARANEN, 2015). Assim, ainda que as funcionalidades de uma determinada ferramenta estejam disponíveis por meio um LMS, para utilizá-las é necessário adotar o LMS em questão, o qual muitas vezes pode não ser o mesmo LMS adotado pelo professor ou pela instituição (SIRKIÄ; HAARANEN, 2015). Além disso, a integração entre diferentes ferramentas e sistemas é, em geral, difícil (BRUSILOVSKY et al., 2014). Uma solução que facilite tal integração pode aumentar a disponibilidade das ferramentas de avaliação em uma variedade maior de LMSs. Assim, os professores poderão encontrar as funcionalidades das ferramentas que desejam no LMS adotado por ele ou pela instituição. 


\subsection{Objetivos}

A partir do contexto e motivações apresentadas nas seções anteriores, este trabalho de doutorado tem como principal objetivo a proposição da arquitetura IMPACTLE (Integration Modules for Programming Assignment Checking Tools and Learning Environments), que visa integrar diferentes ferramentas de avaliação para trabalhos de programação em diferentes LMSs.

A Figura 1 sintetiza a proposta do trabalho, ilustrando uma solução em que: (i) ao integrar uma ferramenta de avaliação, vários LMSs têm acesso às suas funcionalidades; e (ii) ao adicionar um LMS ao sistema, este tem acesso às funcionalidades de todas as ferramentas previamente integradas.

Figura 1 - Integração de ferramentas de avaliação automática em LMSs

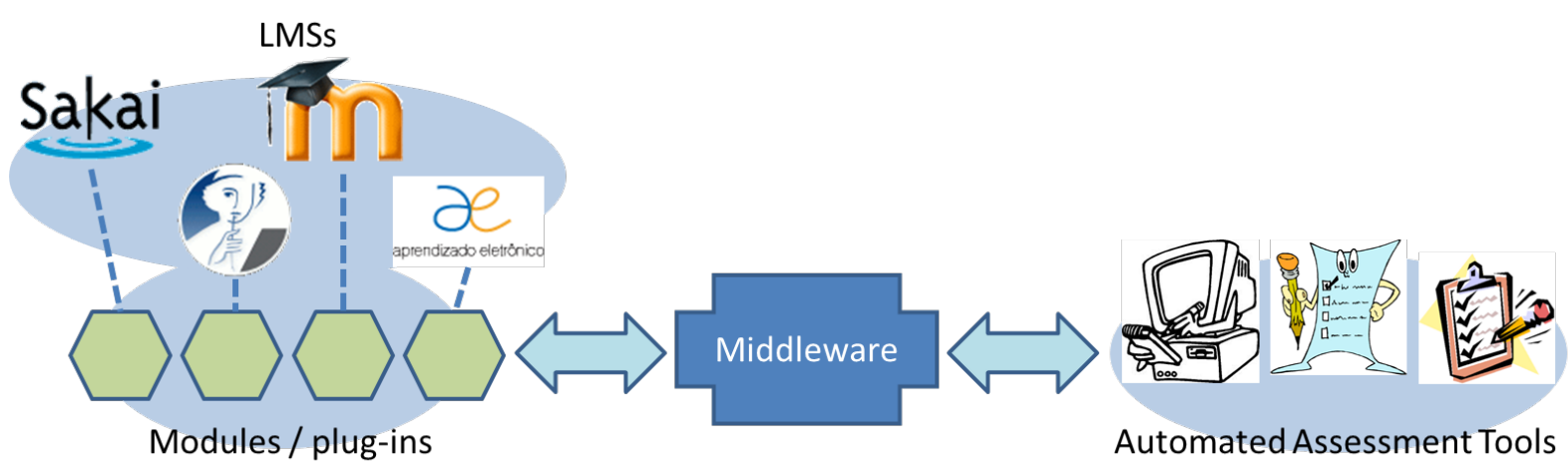

Fonte: Elaborada pelo autor.

A partir da integração de ferramentas de avaliação para trabalhos de programação, os LMSs poderão fornecer um feedback imediato e mais adequado aos alunos sobre a situação dos seus programas, ajudando-os a superar as suas dificuldades em programação e melhorar os seus programas. Por outro lado, uma vez que parte da avaliação é realizada automaticamente, o professor também terá seu esforço reduzido durante a avaliação dos trabalhos, podendo concentrar-se apenas nos aspectos que não puderam ser avaliados automaticamente. Tal solução também permite diminuir o esforço na integração de ferramentas de avaliação em LMSs e serve como apoio para desenvolvedores e pesquisadores na integração de novas ferramentas e LMSs.

Uma das principais dificuldades em realizar este trabalho consiste em identificar como as diferentes funcionalidades e capacidades das ferramentas de avaliação podem ser inseridas nos LMSs para melhor apoiar o processo de ensino e aprendizagem em programação. Cada ferramenta avalia os trabalhos dos alunos com diferentes critérios de avaliação, exige diferentes propriedades de configuração e retorna diferentes tipos de resultados. Desse modo, desenvolver uma arquitetura que permita o recebimento e envio dos diferentes tipos de dados das ferramentas, consiste em um dos principais desafios deste trabalho.

Ainda como parte do trabalho, protótipos instanciando os componentes da arquitetura foram desenvolvidos e experimentos foram conduzidos considerando estes protótipos na utiliza- 
ção de ferramentas de avaliação para trabalhos de programação em LMSs. O desenvolvimento de protótipos e a condução de experimentos tiveram por objetivo validar a arquitetura proposta. Além disso, indicativos sobre a efetividade do uso de ferramentas de avaliação por meio de LMSs também foram obtidos por meio desses experimentos.

Assim, os objetivos deste trabalho de doutorado estão principalmente relacionados às seguintes questões de pesquisa: (i) Como possibilitar acesso adequado às funcionalidades das ferramentas de avaliação para trabalhos de programação por meio de LMSs?; e (ii) Como a utilização de ferramentas de avaliação para trabalhos de programação por meio LMSs influenciam no tempo e esforço despendido na realização de tarefas por elas apoiadas?.

\subsection{Organização}

Neste capítulo, foram discutidos o contexto, as motivações e os objetivos deste trabalho de doutorado.

No Capítulo 2 são descritos os estudos conduzidos a fim de identificar as dificuldades dos alunos em programação e os tipos de defeitos mais cometidos por eles em seus programas.

No Capítulo 3 são descritos conceitos e pesquisas sobre os tópicos relacionados a este trabalho, em especial, a identificação e análise de ferramentas de avaliação para trabalhos de programação e de LMSs, bem como trabalhos relacionados visando a integração de ferramentas em LMSs.

No Capítulo 4 é apresentada a arquitetura IMPACTLE, como uma solução a fim de permitir o acesso às funcionalidades das ferramentas de avaliação para trabalhos de programação por meio de LMSs.

No Capítulo 5 são discutidas a condução e os resultados de experimentos realizados a fim de validar a arquitetura proposta e identificar os benefícios do uso de ferramentas de avaliação para trabalhos de programação integradas a LMSs.

Por fim, no Capítulo 6 são apresentadas as conclusões deste trabalho, as principais contribuições e perspectivas para a continuidade da pesquisa. 


\section{ENSINO E APRENDIZAGEM DE PROGRAMAÇÃO}

\subsection{Considerações iniciais}

Como discutido no Capítulo 1, vários trabalhos de pesquisa têm ressaltado a necessidade de integração de ferramentas de apoio ao ensino e à aprendizagem de programação em LMSs. Este trabalho insere-se nesta perspectiva, dando ênfase à integração de ferramentas de avaliação para trabalhos práticos de programação em LMSs. Uma das principais vantagens destas ferramentas é que elas propiciam o fornecimento de um feedback mais rápido e adequado aos alunos sobre a qualidade dos seus programas. A fim de obter indicativos sobre a importância desse feedback no ensino e aprendizagem de programação, estudos foram realizados para identificar as principais dificuldades dos alunos em programação e os benefícios que um feedback mais rápido e adequado proporcionam para minimizar essas dificuldades.

Assim, na Seção 2.2 é apresentado um mapeamento sistemático conduzido a fim de identificar as principais dificuldades no ensino e na aprendizagem de programação. Em seguida, na Seção 2.3 é apresentado um estudo que visa levantar os tipos de defeitos que são identificados e corrigidos pelos alunos com o auxílio de um feedback sobre os seus programas. Os tipos de defeitos mais frequentes foram comparados com as dificuldades identificadas no mapeamento sistemático apresentado na Seção 2.2. A ideia foi verificar quais das dificuldades discutidas na literatura podem ser minimizadas com o auxílio de um feedback fornecido pelas ferramentas de avaliação. 


\subsection{Dificuldades no ensino e na aprendizagem de progra- mação}

Nesta seção são descritos os métodos e resultados de um mapeamento sistemático realizado a fim de obter um panorama sobre os problemas e dificuldades no ensino e na aprendizagem de programação. O mapeamento sistemático foi conduzido em 2014 e os resultados obtidos foram publicados em:

- Souza, D. M.; Batista, M. H. S.; Barbosa, E. F. Problemas e Dificuldades no Ensino de Programação: Um Mapeamento Sistemático. Revista Brasileira de Informática na Educação. 24(1):39-52, 2016.

Os resultados do mapeamento sistemático serviram como base para o desenvolvimento da arquitetura proposta neste trabalho. O planejamento e condução do mapeamento são detalhados a seguir.

\subsubsection{Planejamento e condução do mapeamento sistemático}

O mapeamento sistemático conduzido está em conformidade com as diretrizes propostas por Kitchenham e Charters (2007). Um mapeamento sistemático começa com a fase de planejamento, que inclui a formulação das questões de pesquisa e a definição dos critérios de inclusão e exclusão, seguido pela busca e revisão dos estudos.

Uma abordagem comumente utilizada para formular as questões de pesquisa é a utilização dos critérios de PICO. Usando o PICO as questões de pesquisa são estruturadas em quatro aspectos: população (Population), intervenção (Intervention), comparação (Comparison) e resultados (Outcomes) (KITCHENHAM; CHARTERS, 2007).

- População: Estudos sobre o ensino e a aprendizagem de programação.

- Intervenção: Aspectos do ensino e da aprendizagem de programação.

- Comparação: Não se aplica ao contexto de mapeamento sistemático.

- Resultados: Problemas e dificuldades no ensino e na aprendizagem de programação.

Para identificar os problemas e dificuldades no ensino e na aprendizagem de programação foram consideradas duas questões de pesquisa:

- Questão Primária: Quais problemas no ensino e na aprendizagem de programação têm sido investigados? 
- Questão Secundária: Quais as soluções têm sido propostas para amenizar os problemas e dificuldades no ensino e na aprendizagem de programação?

Os termos e sinônimos considerados na construção da string de busca foram obtidos por meio da identificação dos principais termos nas questões de pesquisa (PICO) e palavras-chave em um grupo de artigos conhecidos sobre o ensino e a aprendizagem de programação, conforme apresentado no Quadro 1.

Quadro 1 - Artigos sobre o ensino e a aprendizagem de programação

\begin{tabular}{|l|l|l|}
\hline Autor(es) & Ano & Palavras-chave \\
\hline Panwong e Kemavuthanon (603-613) & 2014 & student, learning, programming, problem \\
\hline Bain e Barnes (2014) & 2014 & student, learning, programming, problem \\
\hline $\begin{array}{l}\text { Hidalgo-Céspedes, Marín-Raventós e } \\
\text { Lara-Villagrán (2014) }\end{array}$ & 2014 & student, learning, programming, difficult \\
\hline Piteira e Costa (2013) & 2013 & student, novice, programming, difficult \\
\hline Costa e Aparicio (2014) & 2014 & student, learning, programming, difficult \\
\hline Piteira e Costa (2012) & 2012 & student, novice, learning, programming, difficult, problem \\
\hline
\end{tabular}

Fonte: Elaborada pelo autor.

Ressalta-se que testes foram realizados considerando o grupo de controle e observou-se que somente o termo "learning" era suficiente para retornar os estudos sobre ambos o ensino e a aprendizagem de programação. Assim, a string de busca construída com base nos termos e sinônimos identificados foi:

(student OR novice) AND learning AND programming AND (difficulty OR problem)

Depois da definição dos termos de pesquisa, o processo de identificação da literatura relevante foi iniciado. A busca foi realizada considerando a base eletrônica SCOPUS, pois ela indexa as principais bases eletrônicas em Ciência da Computação.

Além disso, os seguintes filtros foram considerados: (1) publicações entre 2010 e 2014; (2) publicações da área de Ciência da Computação, eliminando os estudos provenientes de outras áreas.

Para a seleção dos artigos, os seguintes critérios de inclusão de artigos foram definidos para atender às questões de pesquisa:

- CI1: O artigo discute um problema ou dificuldade no ensino ou na aprendizagem de programação.

- CI2: O artigo apresenta uma possível solução para amenizar um problema ou dificuldade no ensino ou na aprendizagem de programação.

De forma análoga, o seguinte critério de exclusão de artigos foi definido para atender às questões de pesquisa: 
- CE1: O artigo não menciona algum problema ou alguma solução relacionada ao ensino ou à aprendizagem de programação.

Na Figura 2 é ilustrado o procedimento utilizado para a seleção dos artigos. Inicialmente, dois revisores realizaram a revisão dos metadados dos artigos. Foi realizada uma revisão minuciosa do título, resumo e palavras-chave dos estudos, bem como outros metadados que viessem a ser úteis para a classificação dos estudos. Estudos identificados como relevantes foram selecionados para leitura completa. Procurou-se eliminar o máximo possível de estudos irrelevantes, tomando cuidado para que nenhum estudo relevante fosse descartado.

Figura 2 - Dificuldades em programação: Procedimento de seleção dos artigos

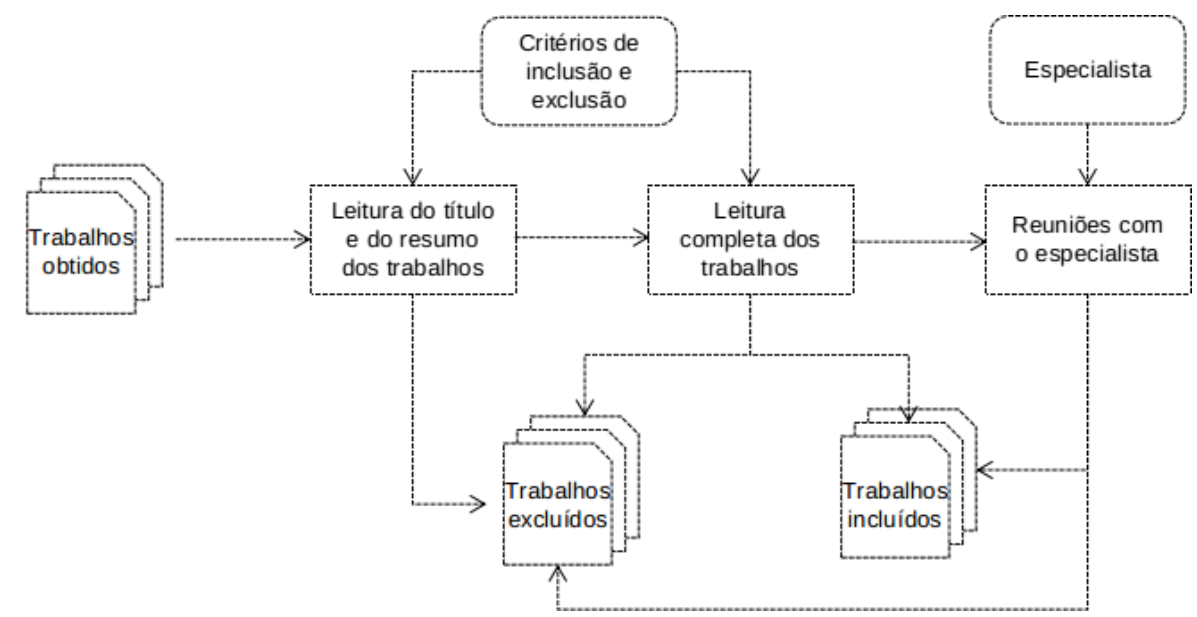

Fonte: Elaborada pelo autor.

Em seguida, o texto completo de cada estudo primário selecionado foi lido, decidindo se este deveria ser incluído ou excluído. Ocorrendo dúvida, o trabalho era colocado em espera, e sua inclusão ou exclusão era definida em reuniões com especialista. Os estudos primários incluídos na seleção final correspondem aos artigos relevantes que atendiam às questões de pesquisa abordadas no mapeamento.

Com relação à extração dos dados, um formulário foi elaborado para auxiliar a extração dos dados durante a leitura dos artigos. Na Figura 3 é ilustrado o procedimento utilizado para a extração. Para cada artigo, uma instância do formulário de extração foi preenchida com os dados presentes no artigo, como por exemplo, as dificuldades em programação discutidas pelos autores e as soluções propostas por eles para mitigar tais dificuldades. Com base nesses dados, categorias de dificuldades em programação foram definidas. Por fim, resumos e mapas sobre as dificuldades e soluções associadas a cada categoria foram elaborados.

O mapeamento sistemático foi conduzido com base no planejamento apresentado. Inicialmente, a string de busca foi adaptada segundo a notação da base eletrônica. Os campos de busca considerados foram o título e o resumo dos artigos. Na Figura 4 são ilustrados os resultados 
Figura 3 - Dificuldades em programação: Procedimento de extração dos dados

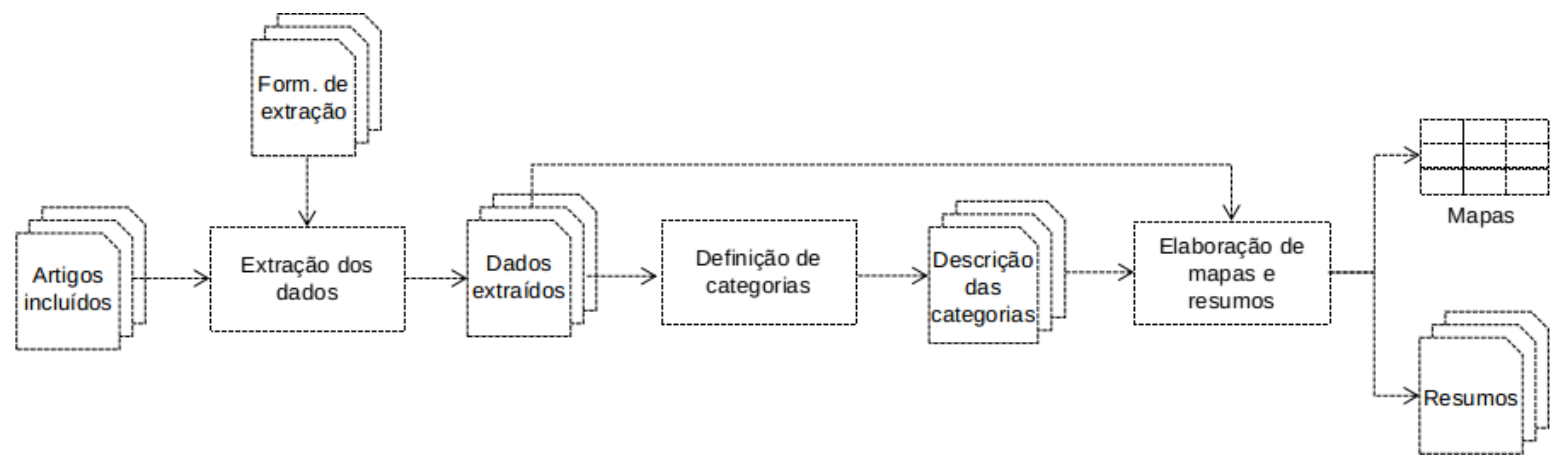

Fonte: Elaborada pelo autor.

obtidos em cada fase do mapeamento. Inicialmente, as strings de busca foram executadas nas bases eletrônicas, que retornaram um total de 519 resultados.

Figura 4 - Dificuldades em programação: Fases do mapeamento sistemático

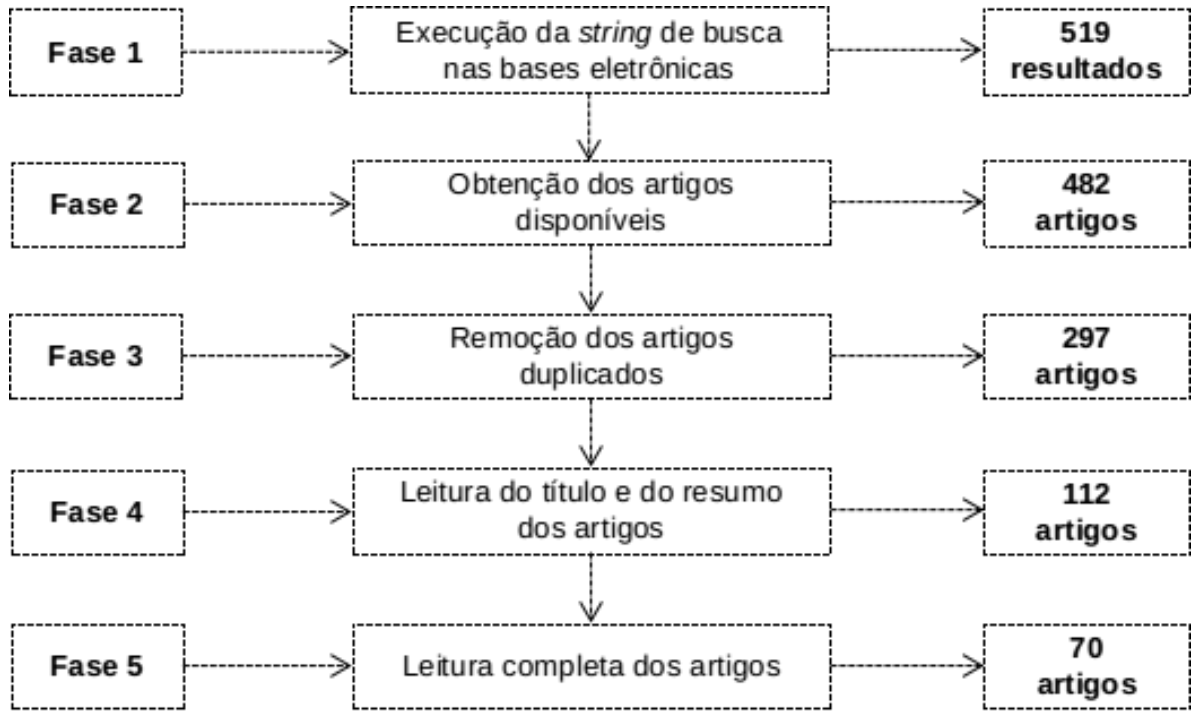

Fonte: Elaborada pelo autor.

A partir dos artigos retornados, notou-se que alguns resultados levavam a páginas ou trabalhos indisponíveis. Assim, dos 519 resultados retornados, 482 resultados consistiam em artigos disponíveis. Removendo os artigos duplicados, obteve-se um total de 297 artigos recuperados.

Durante o processo de seleção dos artigos, 112 artigos foram identificados como relevantes e pré-selecionados para serem lidos na íntegra. Após a leitura completa dos artigos pré-selecionados, 70 artigos foram incluídos nos resultados, com base nos critérios de inclusão e exclusão adotados.

No gráfico da Figura 5 é apresentado o número de publicações por ano. A maioria dos artigos selecionados foram publicados no ano de 2011. Ressalta-se que o número de publicações em 2014 é parcial. Uma vez que o mapeamento sistemático foi realizado em 2014, alguns artigos 
publicados neste ano ainda não estavam disponíveis.

Figura 5 - Dificuldades em programação: Número de publicações por ano

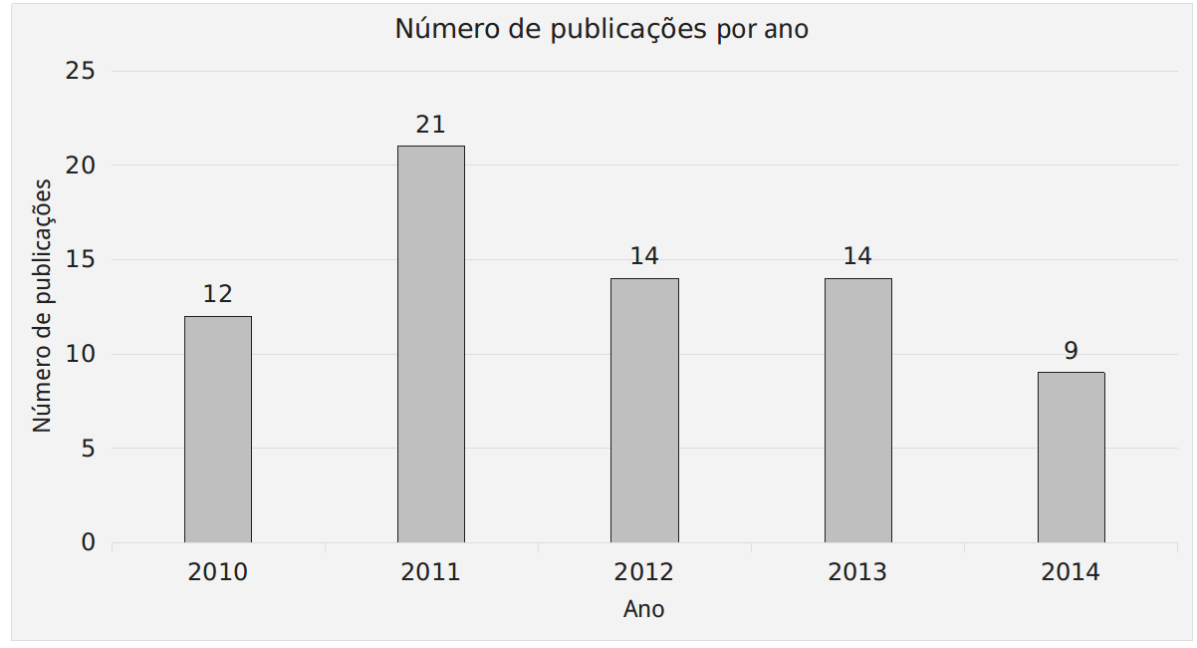

Fonte: Elaborada pelo autor.

Por fim, os artigos foram classificados considerando as dificuldades em programação abordadas. As categorias de dificuldades e os artigos associados a elas são detalhadas a seguir.

\subsubsection{Categorias de dificuldades e trabalhos relacionados}

Nesta seção, são detalhadas as dificuldades no ensino e na aprendizagem de programação descritas na literatura e sintetizados os principais trabalhos identificados por meio do mapeamento sistemático.

\subsubsection{Dificuldades no ensino e na aprendizagem de conceitos de programação}

Algumas pesquisas têm mostrado que os alunos têm mais dificuldades em aprender certos conceitos de programação do que outros (LAHTINEN ESSI ALA-MUTKA; JÄRVINEN, 2005; PITEIRA; COSTA, 2013). Ainda, o entendimento de determinados conceitos pode ser um grande desafio aos alunos (HIDALGO-CÉSPEDES; MARÍN-RAVENTÓS; LARA-VILLAGRÁN, 2014). Da mesma forma que os alunos têm dificuldades em aprender os conceitos de programação, os professores têm dificuldades em ensinar os conceitos de programação de maneira clara e didática (CAMP; WOODWARD, 2011).

No Quadro 2 são ilustrados alguns conceitos de programação identificados como difíceis de se aprender e ensinar. Por exemplo, estudos mostram dificuldades dos alunos em aprender os conceitos abstratos de programação, como tipos abstratos de dados (PITEIRA; COSTA, 2013) e conceitos orientados a objetos (classes, objetos, herança, entre outros.) (SCHULTE; BENNEDSEN, 2006). 
Quadro 2 - Conceitos de programação identificados como difíceis de se aprender e ensinar

\begin{tabular}{|l|l|}
\hline $\begin{array}{l}\text { Conceitos de programação identificados como difíceis de aprender } \\
\text { e ensinar }\end{array}$ & Referências \\
\hline \hline Recursão & Enström (2013), Al-fedaghi (2012) \\
\hline Variáveis multidimensionais (vetores e matrizes) & Enström (2013) \\
\hline Ponteiros e referências & Piteira e Costa (2013) \\
\hline Tipos abstratos de dados & Piteira e Costa (2013) \\
\hline Conceitos orientados a objetos (classes, objetos, herança, entre outros.) & $\begin{array}{l}\text { Schulte e Bennedsen (2006), Aris e Nazeer } \\
(2011)\end{array}$ \\
\hline Sintaxe das linguagens de programação & $\begin{array}{l}\text { Cambranes (2013), Ko e Lee (2013), Abid, } \\
\text { Zehra e Iftikhar (2011) }\end{array}$ \\
\hline
\end{tabular}

Fonte: Elaborada pelo autor.

No Quadro 3 são apresentados alguns problemas investigados na literatura que estão relacionados às dificuldades de aprender conceitos de programação. Por exemplo, alguns trabalhos sugerem que as dificuldades em aprender programação podem também estar relacionadas ao conhecimento do aluno em outras áreas, como matemática, lógica e inglês (AMBROSIO et $a l ., 2011)$. Estudos sugerem de que os alunos que têm melhores conhecimentos nessas áreas aprendem programação mais facilmente.

Quadro 3 - Problemas relacionados às dificuldades de aprender conceitos de programação

\begin{tabular}{|l|l|}
\hline $\begin{array}{l}\text { Problemas relacionados às dificuldades de aprender conceitos de } \\
\text { programação }\end{array}$ & Referências \\
\hline \hline $\begin{array}{l}\text { Sobrecarga de informações que os alunos precisam aprender (conceitos, } \\
\text { linguagens e ferramentas) }\end{array}$ & De-Oliveira-Brandão, Ribeiro e Brandão (2012) \\
\hline Falta de conhecimento dos alunos em matemática, lógica e inglês & Ambrosio et al. (2011) \\
\hline $\begin{array}{l}\text { Modelo mental em desacordo com o modelo da linguagem e/ou para- } \\
\text { digma }\end{array}$ & Kollmansberger (2010) \\
\hline
\end{tabular}

Fonte: Elaborada pelo autor.

Propostas que visam mitigar tais problemas incluem linguagens de programação pedagógicas (KAUČIČ; ASIČ, 2011; KO; LEE, 2013), ambientes de programação pedagógicos (COULL; DUNCAN, 2011; DE-OLIVEIRA-BRANDÃO; RIBEIRO; BRANDÃO, 2012; KOLLMANSBERGER, 2010; ABID; ZEHRA; IFTIKHAR, 2011), metáforas (HIDALGOCÉSPEDES; MARÍN-RAVENTÓS; LARA-VILLAGRÁN, 2014; HORVÁTH, 2011) e ferramentas de visualização (ENSTRÖM, 2013; AJAYI et al., 2010). Tais iniciativas procuram diminuir a sobrecarga de informação que os alunos precisariam lidar e apresentar os conceitos de programação de forma mais clara, didática e visual.

\subsubsection{Dificuldades no projeto de programas}

Além das dificuldades em aprender os conceitos de programação, alguns estudos sugerem que um dos maiores problemas está no projeto de programas (HELMINEN; MALMI, 2010). Muitas vezes os alunos conseguem responder corretamente questões sobre determinados conceitos de programação, mas não conseguem aplicar esse conhecimento na construção de programas válidos para um dado problema. 
Uma das sugestões identificadas na literatura que visa mitigar essa dificuldade é a utilização de estratégias de aprendizagem baseada em problemas (PBL - Problem-Based Learning) (ČISAR et al., 2013; AMBRÓSIO; COSTA, 2010; AMBROSIO et al., 2011). A PBL é uma abordagem de ensino em que os alunos aprendem por meio de experiências adquiridas durante a resolução de problemas. Em geral, os problemas não possuem necessariamente uma única solução a ser desenvolvida pelos alunos e o foco não é atingir uma determinada solução, mas adquirir conhecimentos e habilidades durante a resolução do problema. Outras características da PBL são a colaboração e comunicação, uma vez que, em geral, os problemas são solucionados em equipes.

Outra sugestão identificada é a utilização de scaffolding de instruções (HU; TSENG; LEE, 2013; HU; HUANG; LIU, 2012; JANTAN; ALJUNID, 2012). Em linhas gerais, scaffolding é um processo de aprendizagem em que o aluno recebe um apoio instrucional (exemplos, diretrizes, materiais, entre outros.) para realizar as atividades pedagógicas. Observa-se, porém, que este apoio vai sendo gradualmente removido conforme o aluno avança nas atividades.

Ambas as estratégias permitem desenvolver as habilidades dos alunos na resolução de problemas (BAIN; BARNES, 2014; BEGOSSO et al., 2012; GOMES; MENDES, 2010), ajudando-os a melhor interpretar os problemas e construir soluções para eles.

\subsubsection{Dificuldades no entendimento de programas}

Estas dificuldades estão relacionadas à falta de habilidade dos alunos em encontrar defeitos em seus próprios códigos e de rastrear o fluxo de execução dos programas (HELMINEN; MALMI, 2010). Alguns trabalhos também discutem a dificuldade dos alunos em criar abstrações em alto nível dos programas (AFFANDY et al., 2011).

Em geral, vários trabalhos propõem diferentes ferramentas de visualização de programas a fim de mitigar tais dificuldades (HELMINEN; MALMI, 2010; AFFANDY et al., 2011). Alguns trabalhos também sugerem que os alunos sejam incentivados a testar os seus programas, uma vez que a atividade de teste estimula os alunos a melhor entender os seus programas (BUFFARDI; EDWARDS, 2015; SOUZA; ISOTANI; BARBOSA, 2015).

\subsubsection{Dificuldades motivacionais}

Alguns trabalhos apontam que um dos problemas relacionados à aprendizagem de programação é a falta de motivação dos alunos em realizar as atividades de programação (IBRAHIM et al., 2010; HAATAINEN et al., 2013; ANDERSON et al., 2014; BRITO; SÁ-SOARES, 2014).

No Quadro 4 são enumerados alguns problemas identificados na literatura que estão relacionados às dificuldades motivacionais dos alunos em aprender programação. Nesse sentido, uma das linhas de pesquisa que visa melhor motivar os alunos em programação sugere que a falta de motivação está no fato de que, nos cursos de programação, os exemplos e atividades 
consistem apenas em toy programs, ou seja, programas relativamente simples, que não têm uma aplicação prática muito clara.

Quadro 4 - Problemas relacionados às dificuldades motivacionais

\begin{tabular}{|l|l|}
\hline Problemas relacionados às dificuldades motivacionais & Referências \\
\hline \hline Atividades consistem em toy programs & $\begin{array}{l}\text { Huang } \text { et al. (2011), Hartanto e Reye (2013), Anderson } \text { et } \\
\text { al. } \text { (2014) }\end{array}$ \\
\hline Falta de feedback aos alunos & Brito e Sá-Soares (2014) \\
\hline Dificuldades sociais e pessoais dos alunos & $\begin{array}{l}\text { Chang, Chen e Lin (2012), Corney, Teague e Thomas } \\
(2010), \text { Alberola e García-Fornes (2012), Haatainen et al. } \\
(2013)\end{array}$ \\
\hline
\end{tabular}

Fonte: Elaborada pelo autor.

Por sua vez, no Quadro 5 são sumarizadas algumas propostas encontradas na literatura visando mitigar as dificuldades motivacionais. Dentre as propostas que visam aumentar a motivação dos alunos em programação, encontra-se a utilização de ludificação (ou gamificação) (KHALEEL et al., 2015). Ludificação consiste na aplicação de técnicas de projeto de jogos em contextos não relacionados a jogos, como o contexto de aprendizagem. As técnicas podem envolver a competição entre os alunos, o oferecimento de recompensas por objetivos alcançados e meios de permitir que os alunos verifiquem a sua progressão em relação a vários níveis de conquistas definidos para o curso.

Quadro 5 - Propostas para mitigar as dificuldades motivacionais

\begin{tabular}{|l|l|}
\hline Propostas para mitigar as dificuldades motivacionais & Referências \\
\hline \hline $\begin{array}{l}\text { Resolução de problemas reais, como por exemplo, progra- } \\
\text { mação de robôs e brinquedos }\end{array}$ & $\begin{array}{l}\text { Huang } \text { et al. (2011), Hartanto e Reye (2013), Anderson } \text { et } \\
\text { al. (2014) }\end{array}$ \\
\hline Aumento da frequência de avaliações & Brito e Sá-Soares (2014) \\
\hline $\begin{array}{l}\text { Abordagens de aprendizagem envolvendo colaboração, re- } \\
\text { des sociais, sessões em grupo, entre outros }\end{array}$ & $\begin{array}{l}\text { Chang, Chen e Lin (2012), Corney, Teague e Thomas } \\
(2010), \text { Alberola e García-Fornes (2012), Haatainen } \text { et al. } \\
(2013)\end{array}$ \\
\hline Ludificação (ou gamificação) & Khaleel et al. (2015) \\
\hline "Jogos sérios" & Ibrahim et al. (2010, 2010), Karapinar et al. (2012) \\
\hline
\end{tabular}

Fonte: Elaborada pelo autor.

\subsubsection{Dificuldades em avaliar programas}

Estas dificuldades estão relacionadas aos professores e, basicamente, consistem em três problemas: (i) o esforço excessivo na avaliação de programas, especialmente quando o número de alunos é grande (SOUZA; FELIZARDO; BARBOSA, 2016); (ii) a necessidade em prover um feedback mais adequado e imediato aos alunos (SOUZA; ISOTANI; BARBOSA, 2015); e (iii) a ocorrência de plágio entre os alunos (CAMP; WOODWARD, 2011).

A maioria dos trabalhos que visam mitigar tais problemas propõem ferramentas para detecção de plágio e de apoio à avaliação de trabalhos de programação (CAMP; WOODWARD, 2011; SOUZA; ISOTANI; BARBOSA, 2015), diminuindo o esforço dos professores na avaliação das atividades e fornecendo um feedback sobre a qualidade dos programas dos alunos. 
Em complemento aos resultados deste mapeamento sistemático, um estudo foi realizado visando estudar os tipos de defeitos cometidos pelos alunos em seus programas. A ideia foi comparar os problemas de correção nos programas dos alunos com as dificuldades levantadas neste mapeamento sistemático. Tal estudo é descrito a seguir.

\subsection{Defeitos mais frequentes nos programas dos alunos}

Nesta seção é descrito um estudo realizado a fim de identificar os tipos de defeitos que foram mais frequentemente corrigidos pelos alunos com o auxílio de feedback automático sobre a correção dos seus programas. De fato, a correção é a principal característica dos programas verificada pela maioria das ferramentas de avaliação para trabalhos de programação (SOUZA; FELIZARDO; BARBOSA, 2016). Assim, ideia do estudo foi verificar os benefícios que um feedback mais rápido e adequado pode trazer para mitigar as dificuldades dos alunos em programação.

No estudo foram considerados os dados do projeto BLACKBOX (BROWN et al., 2014). Em síntese, BLACKBOX é uma coleção de dados que armazena as ações de milhares de alunos ao redor do mundo enquanto estão desenvolvendo os seus programas no ambiente de desenvolvimento BLUEJ (KÖLLING et al., 2003). De modo geral, foram observados projetos contendo testes JUNIT (JUnit, 2016) e analisadas as correções que os alunos fizeram em seus códigos quando o resultado de algum teste era falho. No total, foram consideradas 57.492 execuções de teste falhas e os defeitos associados a elas.

O estudo foi realizado no período de setembro/2015 a agosto/2016, como parte das atividades de um estágio no exterior na University of Kent at Canterbury, sob supervisão do Prof. Michael Kölling (Processo FAPESP/BEPE 2015/10670-9). O seguinte artigo descrevendo o estudo e seus resultados foi produzido e submetido para ser publicado em uma conferência relevante na área:

- Souza, D. M; Kölling, M.; Barbosa, E. F. The most common fixes students do to increase the correctness of their programs. Frontiers in Education (FIE 2017). Indianapolis, IN, pág. 1-10, Outubro, 2017.

O estudo e seus resultados são detalhados a seguir.

\subsubsection{Métodos}

Nesta seção é descrito o método utilizado na condução do estudo. Em síntese, o estudo foi conduzido em três etapas: coleta de dados, classificação dos defeitos e análise dos resultados. 


\section{Coleta de dados}

A estratégia adotada para identificar códigos incorretos e os seus defeitos foi escanear o histórico de execução de casos de teste, verificando os momentos em que um caso de teste mudou o seu estado de "error/failed" para "succeeded". Verificando as diferenças entre a versão de um código em que o teste foi bem sucedido e a versão em que o teste falhou, foi possível identificar os defeitos na versão falha do código.

Seguindo esta abordagem, foram obtidos 57.492 códigos fontes incorretos e seus defeitos. Ressalta-se que foram descartados os casos em que havia defeitos nos casos de teste. Os defeitos foram classificados de acordo com um esquema de classificação pré-definido, o qual é detalhado a seguir.

\section{Classificação de defeitos}

Um esquema de classificação foi proposto para contabilizar os tipos de defeitos mais frequentes. As categorias do esquema de classificação foram definidas com base na forma como o defeito foi corrigido, ou seja, elas classificam o defeito categorizando a correção aplicada sobre ele. Assim, cada categoria da classificação possui dois tipos de informação: (i) a ação realizada para corrigir o defeito; e (ii) o tipo do comando associado ao defeito. No Quadro 6 são sintetizadas as quatro possíveis ações definidas pelo esquema de classificação.

Quadro 6 - Classificação de defeitos: Possíveis ações

\begin{tabular}{|l|l|}
\hline Ações & Descrição \\
\hline \hline Inserção (I) & O comando está presente no código corrigido, mas não está presente no código incorreto. \\
\hline Remoção $(\mathrm{R})$ & O comando está presente no código incorreto, mas não está presente no código corrigido. \\
\hline Movimento $(\mathrm{M})$ & O comando está presente em ambos os códigos, mas em diferentes posições. \\
\hline Alteração (A) & O comando foi modificado. \\
\hline
\end{tabular}

Fonte: Elaborada pelo autor.

Os tipos de comando foram definidos com base na especificação da linguagem Java (Java Language Specification) (GOSLING et al., 2013). No Quadro 7 são ilustrados os 12 tipos de comandos definidos. Os tipos foram definidos agrupando os comandos que são relacionados ao mesmo conceito de programação.

Considerando as ações possíveis, para cada tipo de comando, quatro categorias foram definidas. Para exemplificar, no Quadro 8 são ilustradas as categorias relacionadas aos comandos de seleção.

Foram também definidas subcategorias para as categorias relacionadas à ação Alteração (A), classificando as diferentes alterações que poderiam ser realizadas. De forma análoga às categorias de alto nível, cada subcategoria tem dois tipos de informação: (i) a ação realizada; e (ii) o componente do comando que foi alterado. Foram consideradas as mesmas ações definidas 
Quadro 7 - Classificação de defeitos: Tipos de comandos

\begin{tabular}{|l|l|}
\hline Tipos de comandos & Descrição \\
\hline \hline Declaração de pacote (DP) & Comandos relacionados à declaração de pacotes \\
\hline Declaração de importação (DI) & $\begin{array}{l}\text { Comandos relacionados à importação de classes exter- } \\
\text { nas }\end{array}$ \\
\hline Declaração de classe (DC) & $\begin{array}{l}\text { Comandos relacionados à declaração de classes } \\
\text { Declaração de atributo (DA) } \\
\text { classes }\end{array}$ \\
\hline Declaração de método (DM) & $\begin{array}{l}\text { Comandos relacionados à declaração de métodos de } \\
\text { classes }\end{array}$ \\
\hline Comando de declaração de variáveis (CDV) & Comandos relacionados à declaração de variáveis locais \\
\hline Comando de expressão (CE) & $\begin{array}{l}\text { Expressões como comandos, tais como chamadas de } \\
\text { métodos e comandos de atribuição }\end{array}$ \\
\hline Comando de seleção (CS) & Comandos if-then, if-then-else e switch \\
\hline Comando de laço (CL) & Comandos while, do e for \\
\hline Comando de desvio incondicional (CDI) & Comandos break, continue e return \\
\hline Comando de tratamento de erros (CTE) & Comandos assert, try e throw \\
\hline Comando de controle de concorrência (CCC) & Comando synchronized \\
\hline
\end{tabular}

Fonte: Elaborada pelo autor.

Quadro 8 - Classificação de defeitos: Exemplos de categorias de defeitos em comandos

\begin{tabular}{|l|}
\hline Categorias \\
\hline \hline Inserção de comando de seleção (I-CS) \\
\hline Remoção de comando de seleção (R-CS) \\
\hline Movimento de comando de seleção (M-CS) \\
\hline Alteração de comando de seleção (A-CS) \\
\hline
\end{tabular}

Fonte: Elaborada pelo autor.

para as categorias de alto nível (inserção, remoção, movimento e alteração) e os possíveis componentes também foram definidos com base na especificação da linguagem Java (GOSLING et al., 2013). De acordo com cada tipo de comando, os possíveis componentes de comando são sintetizados no Quadro 9.

Quadro 9 - Classificação de defeitos: Componentes de comandos

\begin{tabular}{|l|l|}
\hline Componentes & Descrição \\
\hline \hline Bloco (B) & $\begin{array}{l}\text { Inclui blocos else em comandos if-then-else, blocos finally em coman- } \\
\text { dos try, entre outros. }\end{array}$ \\
\hline Cláusula catch (CC) & Cláusulas catch em comandos try \\
\hline Dimensionador (D) & Dimensionamento de arrays \\
\hline Expressão (E) & Expressões lógicas, relacionais, de atribuição, entre outros. \\
\hline Modificador (M) & $\begin{array}{l}\text { Modificadores (tais como public, private, static, final, entre outros.) em } \\
\text { variáveis, campos, métodos e declarações de classe }\end{array}$ \\
\hline Switch case (SC) & Cláusula case em um comando switch \\
\hline Tipo (T) & Tipos de variáveis, tipos de valores de retorno em métodos, entre outros. \\
\hline Tipo paramétrico (TP) & Tipos paramétricos em classes genéricas \\
\hline Declaração de variável (DV) & $\begin{array}{l}\text { Declaração de variáveis em comandos de declaração de variáveis, declarações } \\
\text { de métodos e comandos for }\end{array}$ \\
\hline
\end{tabular}

Fonte: Elaborada pelo autor.

Para exemplificar, no Quadro 10 são apresentadas as subcategorias para alteração de comandos de seleção.

Em adição às categorias relacionadas aos defeitos em comandos, observou-se a necessi- 
Quadro 10 - Classificação de defeitos: Exemplos de subcategorias de defeitos em comandos

\begin{tabular}{|l|}
\hline Categorias \\
\hline \hline Alteração de comando de seleção - Alteração de expressão (A-CS-A-E) \\
\hline Alteração de comando de seleção - Inserção de bloco (A-CS-I-B) \\
\hline Alteração de comando de seleção - Remoção de bloco (A-CS-R-B) \\
\hline Alteração de comando de seleção - Movimento de bloco (A-CS-M-B) \\
\hline
\end{tabular}

Fonte: Elaborada pelo autor.

dade de definir categorias para classificar os defeitos em expressões. A maioria dos trabalhos em um programa é realizada por meio da avaliação de expressões. Os resultados das expressões afetam o fluxo de controle e o fluxo de dados do programa, sendo importantes na determinação da sequência de execução em comandos. Assim, semelhantemente aos comandos, foram definidos os tipos de expressões (Quadro 11).

De forma análoga às demais categorias, para cada tipo de expressão as quatro ações (inserção, remoção, movimento e alteração) podem ser associadas. Para exemplificar, no Quadro 12 são ilustradas as categorias para expressões aritméticas.

Por fim, foram definidas subcategorias para as categorias de expressões relacionadas à alteração de expressões. Os possíveis componentes de uma expressão podem ser: (i) um Operador (0); (ii) componentes de comandos como um Dimensionador (D), um Modificador (M) ou um Tipo ( $\mathrm{T}$ ); e (iii) sub-expressões, incluindo todos os tipos de expressões descritas no Quadro 11. Associando as ações inserção, remoção, movimento e alteração, no Quadro 13 são ilustrados exemplos de subcategorias para a alteração de expressões aritmética.

Quadro 11 - Classificação de defeitos: Tipos de expressões

\begin{tabular}{|l|l|}
\hline Tipos de expressões & Descrição \\
\hline \hline Acesso à array (AAR) & Expressões relacionadas ao acesso de valores em um array \\
\hline Acesso à atributo (AAT) & $\begin{array}{l}\text { Expressões relacionadas ao acesso de valores de um atributo de uma } \\
\text { classe }\end{array}$ \\
\hline Criação de array (CAR) & Expressões relacionadas à instanciação de um array \\
\hline Criação de objeto (COB) & Expressões relacionadas à instanciação de uma classe \\
\hline Expressão aritmética (EAR) & Expressões relacionadas ao uso de operadores \\
\hline Expressão de atribuição (EAT) & Expressões relacionadas ao uso de operadores de atribuição \\
\hline Expressão bitwise (EBI) & Expressões relacionadas ao uso de operadores bitwise \\
\hline Expressão cast (ECA) & Expressões relacionadas ao uso de operadores cast \\
\hline Expressão condicional (ECO) & Expressões relacionadas ao uso do operador condicional (? : ) \\
\hline Expressão instanceof (EIN) & Expressões relacionadas ao uso do operador instanceof \\
\hline Expressão lambda (ELA) & Expressões relacionadas ao uso do símbolo -> \\
\hline Expressão lógica (ELO) & Expressões relacionadas ao uso de operadores lógicos \\
\hline Expressão parametrizada (EPA) & $\begin{array}{l}\text { Expressões relacionadas ao uso de parênteses para controlar a or- } \\
\text { dem de avaliação das expressões }\end{array}$ \\
\hline Expressão relacional (ERE) & Expressões relacionadas ao uso de operadores relacionais \\
\hline Expressão this (ETH) & Expressões relacionadas a uso da notação this \\
\hline Inicialização de array (IAR) & $\begin{array}{l}\text { Expressões relacionadas à inicialização de um array com uma } \\
\text { sequência de valores }\end{array}$ \\
\hline Invocação de método (IME) & Expressões relacionadas à invocação de métodos \\
\hline Literal (LI) & $\begin{array}{l}\text { Expressões relacionadas à literais tais como false, null, 1, entre } \\
\text { outros. }\end{array}$ \\
\hline Nome (NO) & Expressões relacionadas a variáveis, atributos e objetos \\
\hline Referência à método (RME) & Expressões relacionadas à referência de métodos \\
\hline & Fonte: Elaborada pelo autor. \\
\hline
\end{tabular}

Fonte: Elaborada pelo autor. 
Quadro 12 - Classificação de defeitos: Exemplo de categorias de defeitos em expressões

\begin{tabular}{|l|}
\hline Categorias \\
\hline \hline Inserção de expressão aritmética (I-EAR) \\
\hline Remoção de expressão aritmética (R-EAR) \\
\hline Movimento de expressão aritmética (M-EAR) \\
\hline Alteração de expressão aritmética (A-EAR) \\
\hline
\end{tabular}

Fonte: Elaborada pelo autor.

Quadro 13 - Classificação de defeitos: Exemplo de subcategorias de defeitos em expressões

\begin{tabular}{|l|}
\hline Categorias \\
\hline \hline Alteração de expressão aritmética - Alteração de operador (A-EAR-A-O) \\
\hline Alteração de expressão aritmética - Inserção de criação de array (A-EAR-I-CAR) \\
\hline Alteração de expressão aritmética - Remoção de criação de objeto (A-EAR-R-COB) \\
\hline Alteração de expressão aritmética - Movimento de literal (A-EAR-M-LI) \\
\hline Alteração de expressão aritmética - Alteração de expressão this (A-EAR-A-ETH) \\
\hline
\end{tabular}

Fonte: Elaborada pelo autor.

\section{Análise dos dados}

Com relação à análise dos dados, inicialmente foi contabilizado o número de defeitos por código fonte incorreto. O número de defeitos provê informações sobre o tamanho das modificações que os alunos precisaram fazer para corrigir os seus programas. Em seguida, duas análises foram realizadas: (i) análise dos defeitos em comandos, com base na contabilização dos defeitos associados a cada categoria de defeitos em comandos definidas no esquema de classificação proposto; e (ii) análise dos defeitos em expressões, com base na contabilização dos defeitos associados a cada categoria de defeitos em expressões definidas no esquema de classificação proposto.

Com relação à análise dos defeitos em comandos foram contabilizados e analisados o número de defeitos por tipo de comando. A ideia foi verificar qual tipo de comando teve o maior número de defeitos associados a ele.

Uma vez que a frequência absoluta dos defeitos associados a um certo tipo de comando pode estar relacionada à alta frequência desse tipo de comando nos códigos, foi analisada também a frequência relativa dos defeitos em comandos. Assim, foi contabilizada a quantidade de cada tipo de comando em todos os códigos sendo analisados e, em seguida, foi calculada a porcentagem de defeitos associados a cada tipo de comando em relação ao total de ocorrências do tipo de comando envolvido.

Para os tipos de comandos com maiores ocorrências de defeitos foram observados a quantidade de defeitos associados às categorias e subcategorias de defeitos para aqueles tipos de comandos, obtendo um visão mais aprofundada sobre quais foram os defeitos mais frequentes.

Por fim, com relação à análise dos defeitos em expressões, foram considerados procedimentos semelhantes aos da análise dos defeitos em comandos. Inicialmente, verificou-se a 
frequência absoluta e relativa de defeitos associados a cada tipo de expressão e, em seguida, observou-se a quantidade de defeitos associados às categorias e subcategorias de defeitos para as expressões com maior número de ocorrência de defeitos.

Os resultados obtidos seguindo os métodos descritos nesta seção são apresentados a seguir.

\subsubsection{Resultados}

No Quadro 1 é apresentado o número de códigos incorretos por quantidade de defeitos associados. Por exemplo, de todos os códigos fontes incorretos identificados, 2716 (7\%) deles tiveram três defeitos associados. A quantidade de códigos que tiveram no máximo três defeitos (20213) corresponde a 54\% de todos os códigos incorretos identificados. Apesar de haver códigos com mais de mil defeitos, 30087 (81\%) deles tiveram no máximo 13 defeitos. Ressalta-se, ainda, que 12754 (34\%) dos códigos incorretos identificados tiveram apenas um defeito.

Tabela 1 - Número de códigos por número de defeitos

\begin{tabular}{c|c|c|c|c}
\hline Defeitos & Códigos & $\begin{array}{c}\text { Códigos } \\
(\%)\end{array}$ & $\begin{array}{c}\text { Códigos } \\
\text { (Acumulativo) }\end{array}$ & $\begin{array}{c}\text { Códigos } \\
\text { (\%cumulativa) }\end{array}$ \\
\hline \hline 1 & 12754 & $34 \%$ & 12754 & $34 \%$ \\
\hline 2 & 4743 & $12 \%$ & 17497 & $47 \%$ \\
\hline 3 & 2716 & $7 \%$ & 20213 & $54 \%$ \\
\hline 4 & 2263 & $6 \%$ & 22476 & $60 \%$ \\
\hline 5 & 1615 & $4 \%$ & 24091 & $64 \%$ \\
\hline 6 & 1119 & $3 \%$ & 25210 & $67 \%$ \\
\hline 7 & 1044 & $2 \%$ & 26254 & $70 \%$ \\
\hline 8 & 890 & $2 \%$ & 27144 & $73 \%$ \\
\hline 9 & 822 & $2 \%$ & 27966 & $75 \%$ \\
\hline 10 & 622 & $1 \%$ & 28588 & $77 \%$ \\
\hline 11 & 548 & $1 \%$ & 29136 & $78 \%$ \\
\hline 12 & 458 & $1 \%$ & 29594 & $79 \%$ \\
\hline 13 & 493 & $1 \%$ & 30087 & $81 \%$ \\
\hline \hline 18 & 283 & $0,7 \%$ & 31776 & $85 \%$ \\
\hline \hline 27 & 123 & $0,3 \%$ & 33427 & $90 \%$ \\
\hline \hline 51 & 40 & $0,1 \%$ & 35264 & $95 \%$ \\
\hline \hline 1292 & 1 & $0,002 \%$ & 37108 & $100 \%$ \\
\hline
\end{tabular}

Fonte: Elaborada pelo autor.

Assim, foi possível observar que quanto menor o número de defeitos, maior a quantidade de códigos incorretos. Em outras palavras, os resultados sugerem que a maioria dos códigos incorretos possuem poucos defeitos. 


\section{Análise dos defeitos em comandos}

Na Figura 6 é apresentada a frequência absoluta dos defeitos em comandos. Defeitos em comandos de expressão (CD) são os mais comuns, totalizando 77266 defeitos. Outros defeitos frequentes estão associados a comandos de seleção (CS) (37066 defeitos) e comandos de desvio incondicional (CDI) (35885 defeitos).

$\mathrm{Na}$ Figura 7 é apresentada a frequência relativa dos defeitos em comandos. Os defeitos em comandos de laço (CL) são os mais comuns, uma vez que a porcentagem de defeitos nesse tipo de comando em relação ao total de comandos de laço é de $4.65 \%$. Outros defeitos comuns são relacionados a comandos de seleção (CS) (4.59\%) e comandos de desvio incondicional (CDI) $(4.15 \%)$.

Figura 6 - Defeitos em comandos: Frequência absoluta

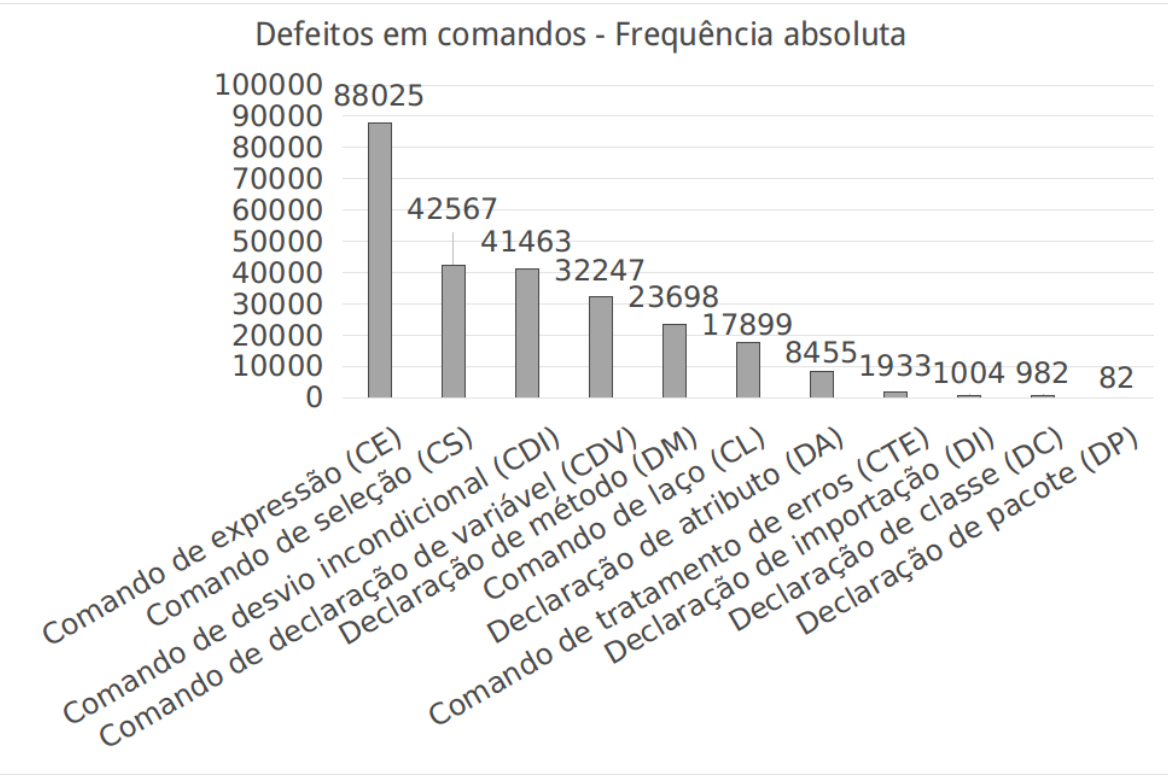

Fonte: Elaborada pelo autor.

Comparando as frequências absolutas e relativas, é possível destacar as diferenças com relação ao número de defeitos em comandos de expressão e comandos de laço. Comandos de expressão têm um número alto de defeitos associados, mas é menos notável quando se leva em conta o número alto de comandos de expressão nos códigos obtidos. Por outro lado, comandos de laço têm um número pouco notável de defeitos associados, mas este número é alto quando considerado o total de comandos de laço.

Assim, os resultados sugerem que: (i) defeitos em comandos de expressão são os mais comuns, uma vez que este é o tipo de comando mais frequente nos programas; (ii) defeitos em comandos de seleção e comandos de desvio incondicional também são comuns, independentemente da frequência desses tipos de comandos nos códigos; e (iii) defeitos em comandos de laço são comuns se levado em conta o total de comandos de laço. 
Figura 7 - Defeitos em comandos: Frequência relativa

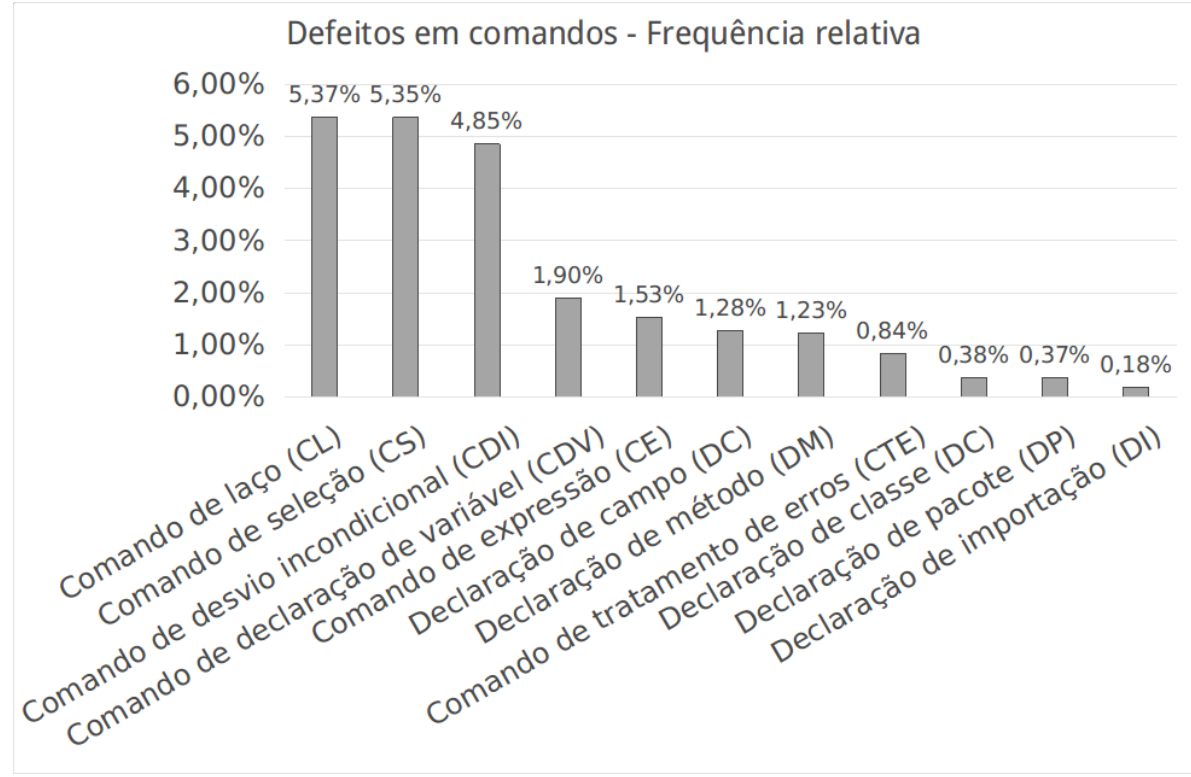

Fonte: Elaborada pelo autor.

Na Figura 8 são detalhados os resultados de acordo com as categorias e subcategorias definidas no esquema de classificação proposto. Para todos os tipos de comandos, inserção (I) de novos comandos são as correções mais comuns, ou seja, os defeitos estavam relacionados a comandos ausentes. No entanto, é possível observar que, com exceção dos defeitos em comandos de desvio incondicional (CDI), as categorias com o segundo maior número de defeitos estão relacionadas à alteração de expressões (A-E). No caso dos comandos de desvio incondicional (CDI), movimento (M) e remoção (R) de comandos possuem mais defeitos associados, também frequentes nos demais tipos de comandos.

Assim, os resultados sugerem que: (i) os defeitos mais frequentes estão relacionados às categorias de adição de comandos; (ii) defeitos relacionados às categorias de alteração de expressões estão entre os mais comuns; e (iii) defeitos relacionados às categorias de movimento e remoção de comandos também são significativos.

\section{Análise dos defeitos em expressões}

Na Figura 9 é ilustrada a frequência absoluta dos defeitos em expressões. Defeitos em expressões de atribuição (EAT) são as mais comuns, totalizando 20025 defeitos. Outros defeitos comuns estão relacionados à declaração de variáveis (DV) (14252 defeitos), invocação de métodos (IME) (12321 defeitos) e expressões relacionais (ERE) (11837 defeitos).

Por outro lado, na Figura 10 é ilustrada a frequência relativa dos defeitos em expressões. Defeitos em expressões lógicas (ELO) são os mais comuns, uma vez que a porcentagem 
Figura 8 - Defeitos em comandos: Categorias e subcategorias com maior número de defeitos associados

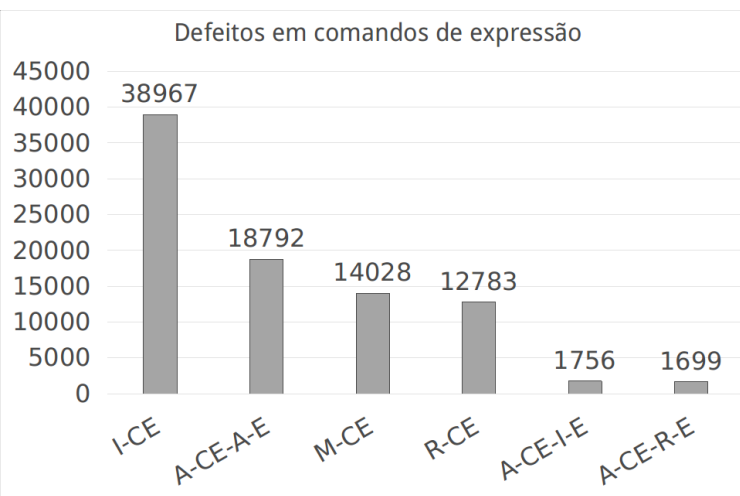

(a) Defeitos em comandos de expressão

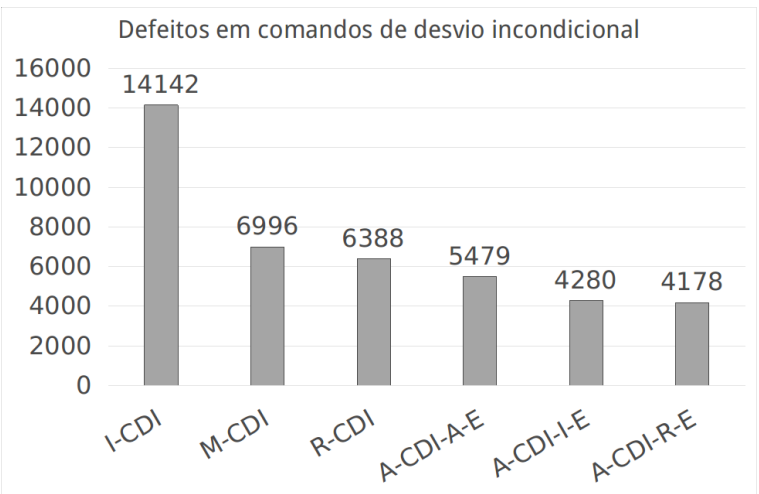

(c) Defeitos em comandos de desvio incondicional

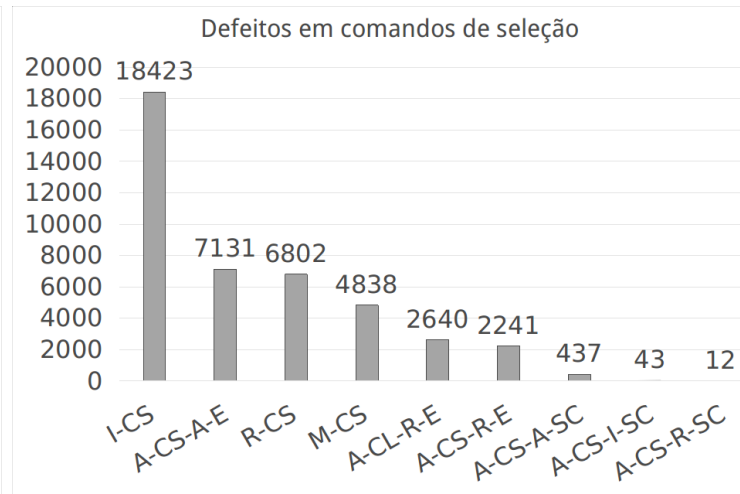

(b) Defeitos em comandos de seleção

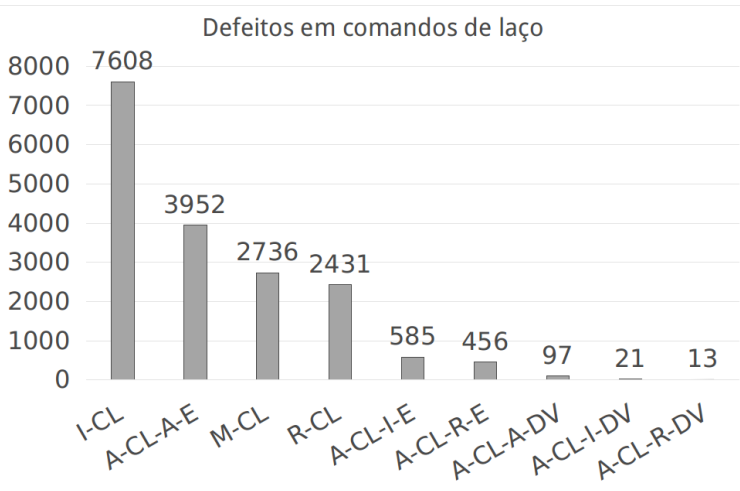

(d) Defeitos em comandos de laço

Fonte: Elaborada pelo autor.

de defeitos neste tipo de expressão em relação ao total de expressões lógicas é de $0.77 \%$. Outros defeitos comuns estão relacionadas a expressões relacionais (ERE) $(0.71 \%) \mathrm{e}$ expressões de atribuição (EAT) (0.63\%).

Comparando as frequências absolutas e relativas, é possível ressaltar diferenças entre as expressões relacionadas ao fluxo de dados (tais como expressões de atribuição, declaração de variáveis e invocação de métodos) e as expressões relacionadas ao fluxo de controle (tais como expressões relacionais e expressões lógicas). Expressões relacionadas ao fluxo de dados têm um maior número de defeitos associados, mas este número de defeitos é menos expressivo quando considerando a alta quantidade destes tipos de expressões nos códigos. Por outro lado, expressões relacionadas ao fluxo de controle têm um menor número de defeitos associados, mas este número de defeitos é expressivo quando considerando a menor quantidade destes tipos de expressões nos códigos.

Assim, os resultados sugerem que: (i) defeitos em expressões de fluxo de dados são os mais comuns, mas também são os tipos de expressões com mais ocorrências; (ii) defeitos em expressões de fluxo de controle são comuns se levado em conta o menor número de ocorrência destes tipos de expressões; (iii) defeitos em expressões de atribuição e expressões 
Figura 9 - Defeitos em expressões: Frequência absoluta

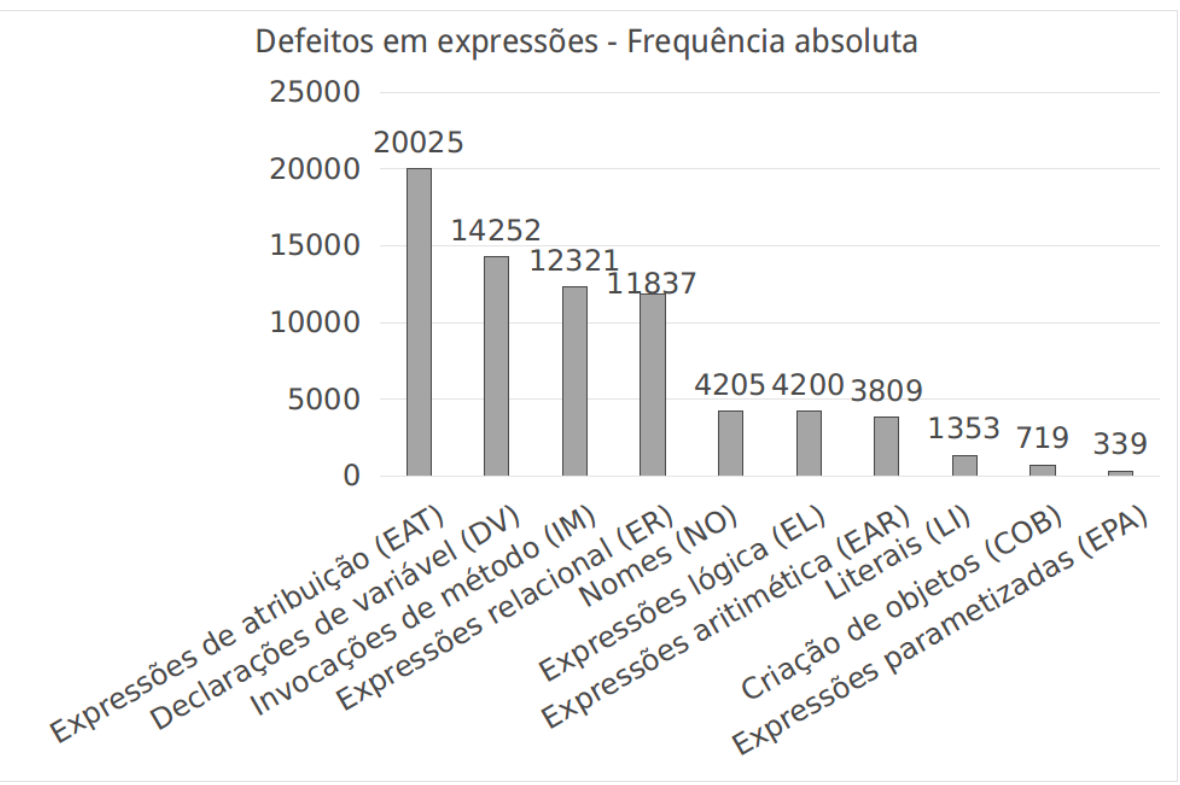

Fonte: Elaborada pelo autor.

Figura 10 - Defeitos em expressões: Frequência relativa

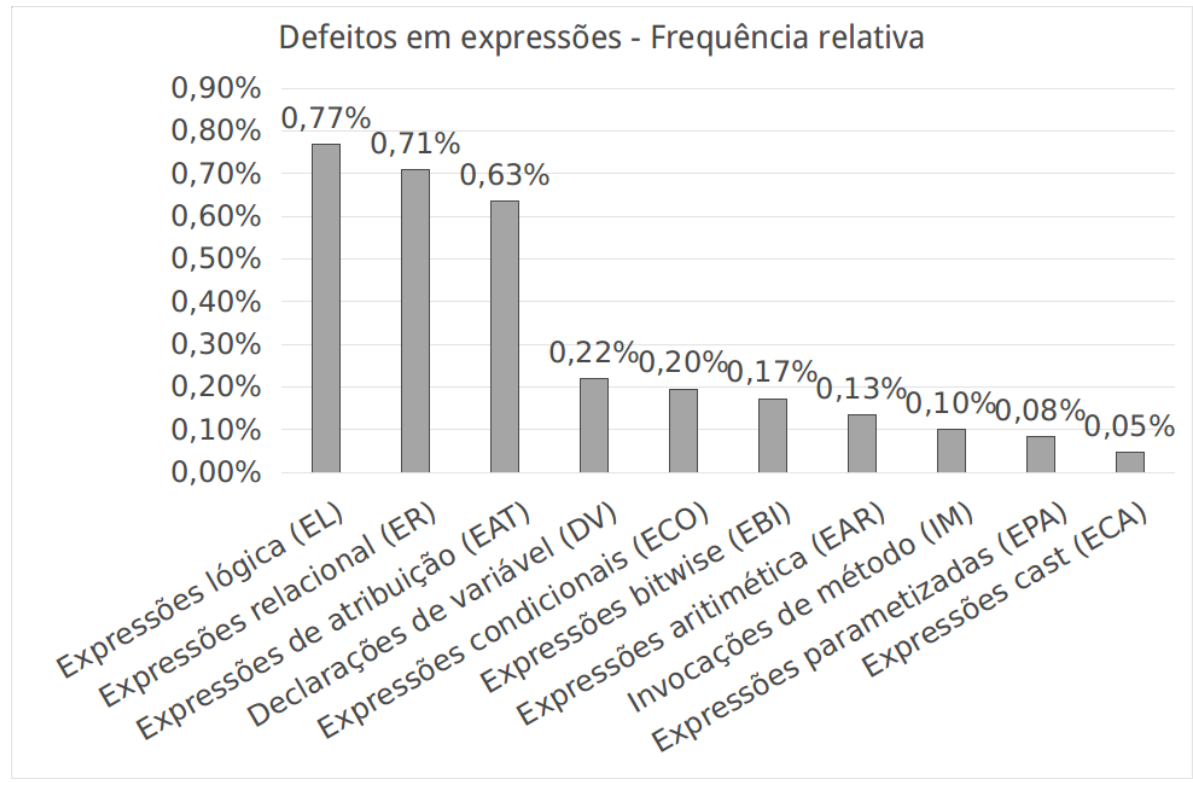

Fonte: Elaborada pelo autor.

relacionais estão entre os mais comuns, independentemente do tipo de frequência considerada (absoluta ou relativa).

Na Figura 11 são ilustrados os resultados de acordo com as categorias e subcategorias definidas no esquema de classificação. Em síntese, considerando as expressões de fluxo de dados, alteração de nomes (A-NO) e alteração de expressões aritméticas (A-EAR) são a primeira e a segunda subcategoria com mais defeitos associados, respectivamente. Conside- 
rando as expressões relacionais (ERE), alteração de operador ( $A-0$ ) é a categoria com mais defeitos associados. Considerando as expressões lógicas (ELO), alteração de sub-expressões relacionais (A-ERE) é a categoria com mais defeitos associados, reforçando o alto número de defeitos em expressões relacionais (ERE).

Figura 11 - Defeitos em expressões: Categorias e subcategorias com maior número de defeitos associados

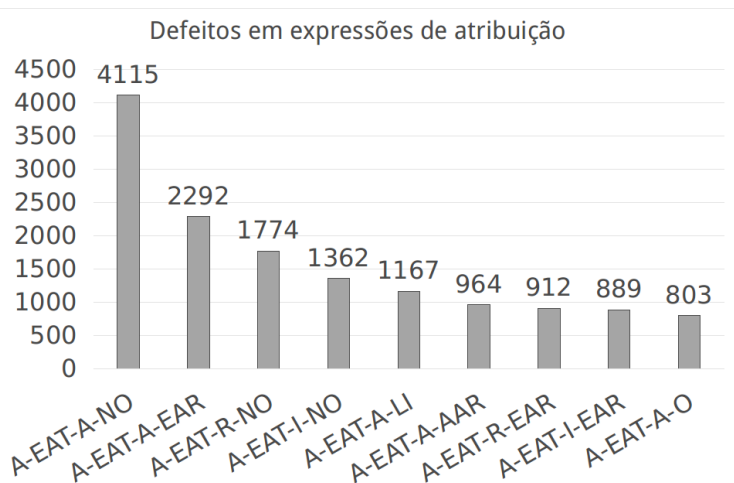

(a) Defeitos em expressões de atribuição

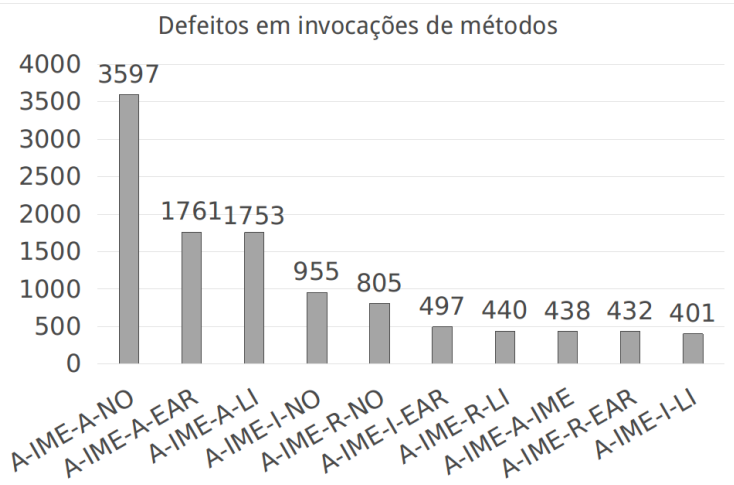

(c) Defeitos em invocação de métodos

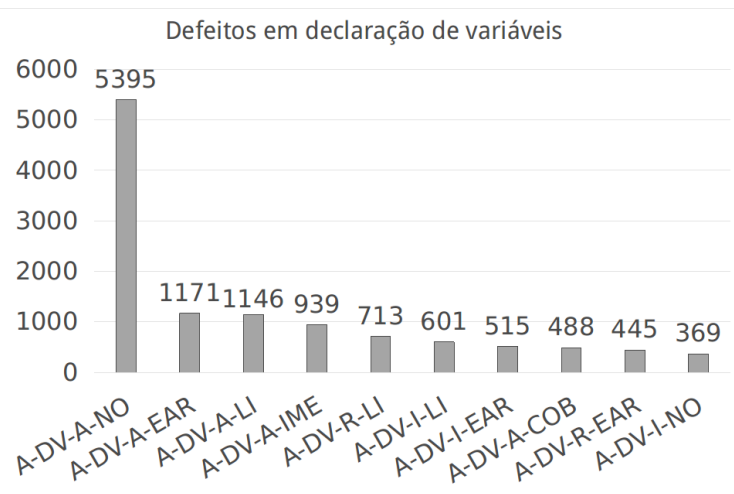

(b) Defeitos em declaração de variáveis

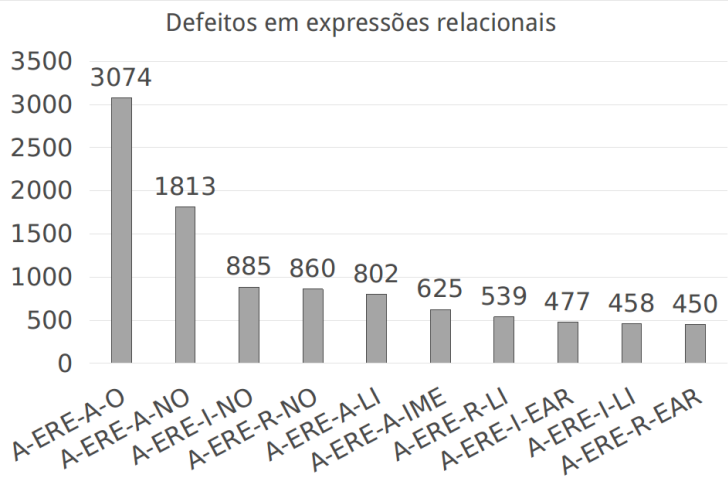

(d) Defeitos em expressões relacionais

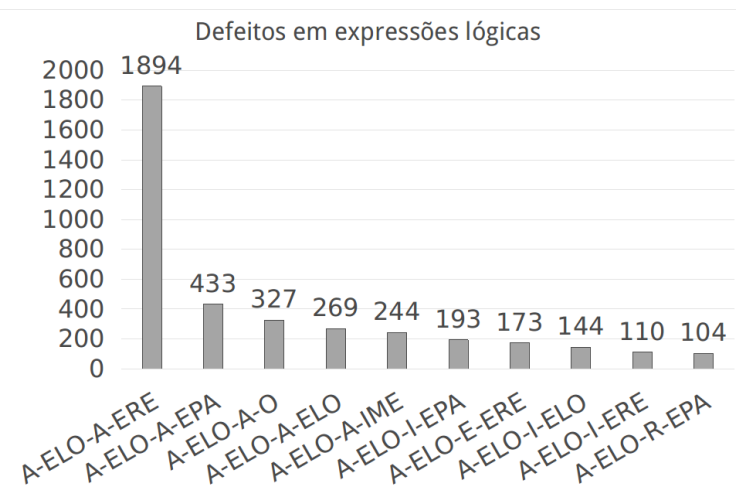

(e) Defeitos em expressões lógicas

Fonte: Elaborada pelo autor.

Assim, os resultados sugerem que: (i) os defeitos mais comuns em expressões de fluxo de dados são alteração de nomes e alteração de expressões aritméticas; (ii) os defeitos mais comuns relacionados a expressões de fluxo de controle são alteração de 
expressões relacionais, em especial, alteração de operadores.

\subsubsection{Discussão}

A Figura 12 sumariza os resultados e conclusões obtidos por meio deste estudo. Com base nos resultados obtidos e na observação dos códigos fontes incorretos foi possível observar que os tipos de defeitos e suas correções consistem em três direções. A primeira está relacionada com o alto número de defeitos cujas correções envolveram a inserção, movimento e remoção de comandos. Observando alguns exemplos, foi possível verificar que, em vários casos, os alunos praticamente reestruturam os seus códigos.

Figura 12 - Comparação entre os defeitos e as dificuldades em programação

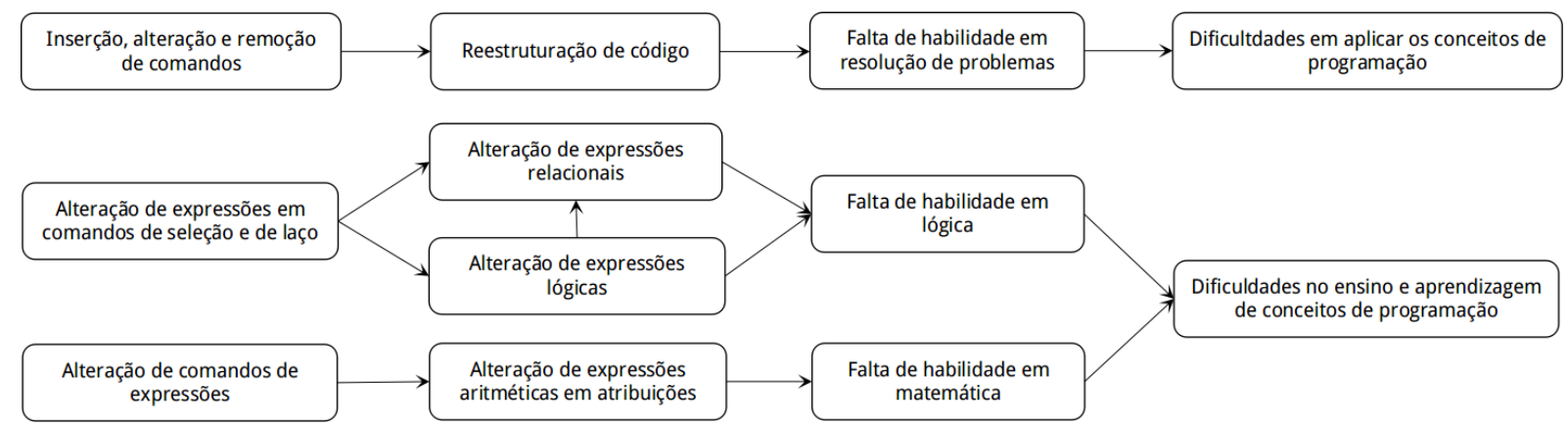

Fonte: Elaborada pelo autor.

A segunda direção está relacionada com um alto número de defeitos envolvendo a alteração de expressões em comandos de laço e comandos de seleção. De fato, ao realizar a análise de expressões, foi possível perceber também um alto número de defeitos envolvendo expressões relacionais, em especial, principalmente envolvendo operadores relacionais. Ressaltando ainda mais os defeitos em expressões relacionais, as correções mais aplicadas pelos alunos nas expressões lógicas também consistiam em alterar uma sub-expressão relacional.

Já a terceira direção está relacionada aos defeitos em comandos de expressões. Por meio da análise de expressões, observou-se um alto número de correções envolvendo a alteração de expressões aritméticas em expressões de atribuição.

Comparando os resultados deste estudo com as dificuldades em programação identificadas por meio do mapeamento sistemático (Seção 2.2.2), foi possível perceber que os defeitos que levaram a uma reestruturação do código estão relacionados com as dificuldades dos alunos no projeto de programas, ou seja, em aplicar os conceitos de programação aprendidos na construção de programas válidos. Dentre tais dificuldades, destaca-se a falta de habilidade dos alunos na resolução de problemas.

Por outro lado, tanto os defeitos em expressões relacionais como os defeitos em expressões aritméticas refletem a carência dos alunos no que se refere a conhecimentos de lógica e matemática, gerando dificuldades no ensino e aprendizagem dos conceitos de programação. 
No entanto, ressalta-se que todos os defeitos observados foram corrigidos pelos alunos depois que eles receberam um feedback sobre a correção dos seus programas. Isto mostra que um feedback mais rápido e adequado, como os fornecidos pelas ferramentas de avaliação para trabalhos de programação, ajudam os alunos a superarem as suas dificuldades na aprendizagem de conceitos de programação e na aplicação desses conceitos, motivando-os a melhorarem os seus programas.

\subsection{Considerações finais}

Nesta seção foram apresentados dois estudos relacionados a problemas e dificuldades no ensino e na aprendizagem de programação. Inicialmente, foi realizado um mapeamento sistemático de artigos presentes na literatura relacionados ao assunto. Como resultado, cinco categorias de dificuldades foram identificadas e estudadas. Em seguida, no segundo estudo, foram identificados os tipos de defeitos nos programas dos alunos frequentemente corrigidos por eles após receberem um feedback sobre a qualidade dos seus programas.

Comparando os resultados dos dois estudos foi possível perceber que um feedback mais rápido e adequado, como o fornecido pelas ferramentas de avaliação, ajudam os alunos a superarem as suas dificuldades na aprendizagem de conceitos de programação e na aplicação desses conceitos na construção de programas. Tais dificuldades, em geral, estão relacionadas à falta de habilidade dos alunos em lógica, matemática e resolução de problemas.

Assim, por meio destes estudos, foi possível verificar a importância da adoção e utilização de ferramentas de avaliação para trabalhos de programação nos cursos de programação, uma vez que o feedback fornecido por elas motiva os alunos a entenderem melhor os conceitos de programação e a desenvolverem suas habilidades no projeto de programas.

Nesse sentido, este trabalho visa facilitar o uso e adoção de ferramentas de avaliação, propondo uma arquitetura que permite a integração de diferentes ferramentas de avaliação em LMSs. De fato, pesquisas têm mostrado que a falta de integração de ferramentas nos LMSs de suas instituições é uma das principais dificuldades dos professores em adotá-las.

Como base para a proposição da arquitetura, ferramentas de avaliação e LMSs foram identificados e estudados. Tais ferramentas e LMSs são apresentados e discutidos no próximo capítulo. 
CAPÍTULO

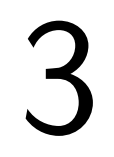

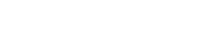

\section{FERRAMENTAS DE AVALIAÇÃO, SISTEMAS DE GERENCIAMENTO DE APRENDIZAGEM E ARQUITETURAS DE SOFTWARE}

\subsection{Considerações iniciais}

Conforme discutido nos capítulos anteriores, este trabalho tem como principal objetivos o desenvolvimento de uma arquitetura que permite a integração de ferramentas de avaliação para trabalhos de programação em LMSs. Para atingir tal objetivo, ferramentas de avaliação e LMSs foram identificados, analisados e são descritos neste capítulo.

Na Seção 3.2 são descritos o planejamento, condução e resultados de um mapeamento sistemático realizado a fim de identificar as principais características e funcionalidades das ferramentas de avaliação para trabalhos de programação. A ideia foi identificar as diferenças entre as ferramentas de avaliação as quais poderiam impactar sua integração em LMSs.

Em seguida, na Seção 3.3 é apresentada uma visão geral sobre LMSs, suas características e funcionalidades. De forma análoga às ferramentas de avaliação, procurou-se verificar as diferenças e similaridades entre os LMSs as quais deveriam ser consideradas ao integrar ferramentas de avaliação a eles. Além disso, são apresentados trabalhos relacionados que discutem a necessidade de integração entre ferramentas de apoio ao ensino e a aprendizagem de programação em LMSs e algumas propostas de soluções associadas.

Por fim, na Seção 3.4 alguns conceitos envolvendo arquiteturas de software são apresentados. Tais conceitos foram considerados durante a definição da arquitetura IMPACTLE, proposta neste trabalho. 


\subsection{Ferramentas de avaliação para trabalhos práticos de programação}

A fim de identificar como os LMSs poderiam acessar as funcionalidades de diferentes ferramentas de avaliação automática para trabalhos de programação, um mapeamento sistemático das ferramentas foi realizado. O objetivo foi identificar as principais similaridades e diferenças entre as funcionalidades das ferramentas de avaliação. Os resultados obtidos foram publicados em:

- Souza, D. M.; Felizardo, K. R.; Barbosa, E. F. A Systematic Literature Review of Assessment Tools For Programming Assignments. In Proceedings of the 29th IEEE Conference on Software Engineering Education and Training (CSEE\&T 2016). Dallas, TX, USA, pages 147-156, 2016.

O planejamento e a execução desse mapeamento sistemático é apresentado a seguir.

\subsubsection{Planejamento e execução do mapeamento sistemático}

O mapeamento sistemático conduzido neste trabalho teve como objetivo identificar: (i) as ferramentas de avaliação para trabalhos de programação; e (ii) as principais características e funcionalidades das ferramentas de avaliação para trabalhos de programação.

Para atender aos objetivos propostos, foram elaboradas uma questão primária e uma questão secundária:

- Questão Primária: Quais ferramentas de avaliação para trabalhos de programação têm sido desenvolvidas?

- Questão Secundária: Quais são as principais características e funcionalidades das ferramentas de avaliação para trabalhos de programação?

As questões elaboradas visaram atender aos seguintes itens de escopo e especificidade (PICO):

- População: Ferramentas de avaliação automática para trabalhos de programação.

- Intervenção: Características e funcionalidades das ferramentas de avaliação para trabalhos de programação.

- Comparação: Não se aplica a mapeamentos sistemáticos.

- Resultados: Principais similaridades e diferenças entre as ferramentas de avaliação para trabalhos de programação. 
Como fontes de pesquisa, foram consideradas as sete bases eletrônicas identificadas por (BRERETON et al., 2007) como as mais relevantes para a Engenharia de Software. São elas: ACM Digital Library, CiteSeerX, Compendex, Google Scholar, IEEE Xplore, ScienceDirect e Inspec.

As palavras-chave definidas para o mapeamento foram assessment, tool e students' programs, com os seguintes termos relacionados:

- assessment: evaluation, marking, grading, testing;

- tool: system, environment;

- students' programs: programming assignments.

Por meio das palavras-chave definidas, foi construída a seguinte string de busca:

(assessment OR evaluation OR marking OR grading OR testing) AND (tool OR environment OR system) AND (students' programs OR programming assignments)

Para a seleção dos artigos, os seguintes critérios de inclusão de artigos foram definidos para atender às questões de pesquisa:

- $C I 1=\mathrm{O}$ artigo apresenta uma ferramenta de avaliação para trabalhos de programação.

- $C I 2=\mathrm{O}$ artigo descreve uma característica ou funcionalidade de uma ferramenta de avaliação para trabalhos de programação.

De forma análoga, o seguinte critério de exclusão de artigos foi definido para atender às questões de pesquisa:

- $C E 1=\mathrm{O}$ artigo não menciona uma ferramenta de avaliação para trabalhos de programação.

Na Figura 13 é ilustrado o procedimento utilizado para a seleção dos artigos. Inicialmente, foi realizada a leitura dos títulos e dos resumos dos artigos recuperados. Constatando-se a relevância de um artigo, ele era pré-selecionado para ser lido na íntegra. Os demais foram classificados como excluídos.

Em seguida, foi realizada a leitura completa dos artigos pré-selecionados. Durante a leitura, os artigos foram classificados como incluídos ou excluídos, conforme os critérios de inclusão e exclusão definidos. Ocorrendo dúvida, o trabalho era colocado em espera, e sua inclusão ou exclusão era definida em reuniões com especialista.

Com relação à extração dos dados, um formulário foi elaborado para auxiliar a extração dos dados durante a leitura dos artigos. Na Figura 14 é ilustrado o procedimento utilizado para 
Capítulo 3. Ferramentas de avaliação, sistemas de gerenciamento de aprendizagem e arquiteturas de

Figura 13 - Ferramentas de avaliação: Procedimento de seleção dos artigos

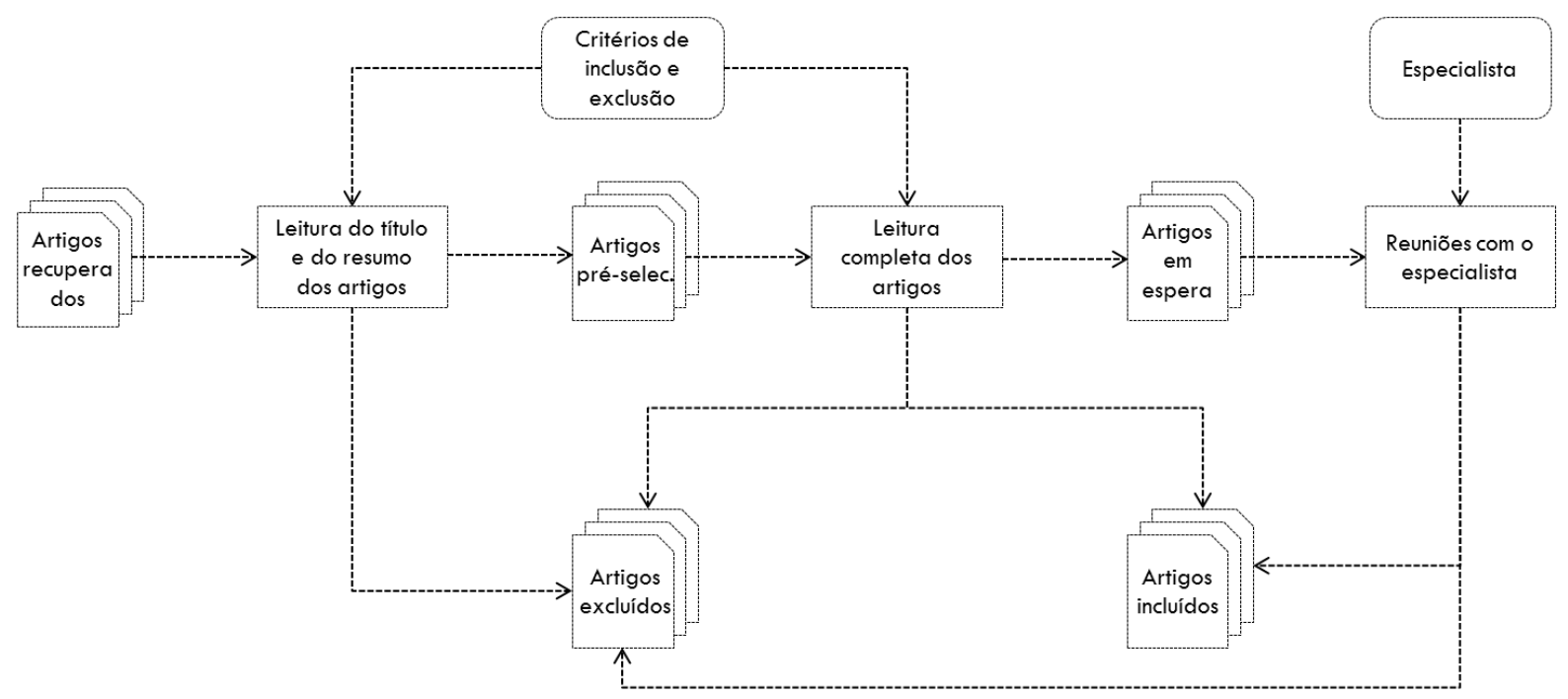

Fonte: Elaborada pelo autor.

a extração. Para cada artigo, uma instância do formulário de extração foi preenchida com os dados presentes no artigo. Em seguida, os dados extraídos foram agrupados por ferramenta de avaliação. Com base nesses dados, foram elaborados: (1) um mapa, relacionando as ferramentas com suas características e funcionalidades; e (2) um resumo sobre cada ferramenta, destacando as suas vantagens e limitações.

Figura 14 - Ferramentas de avaliação: Procedimento de extração dos dados

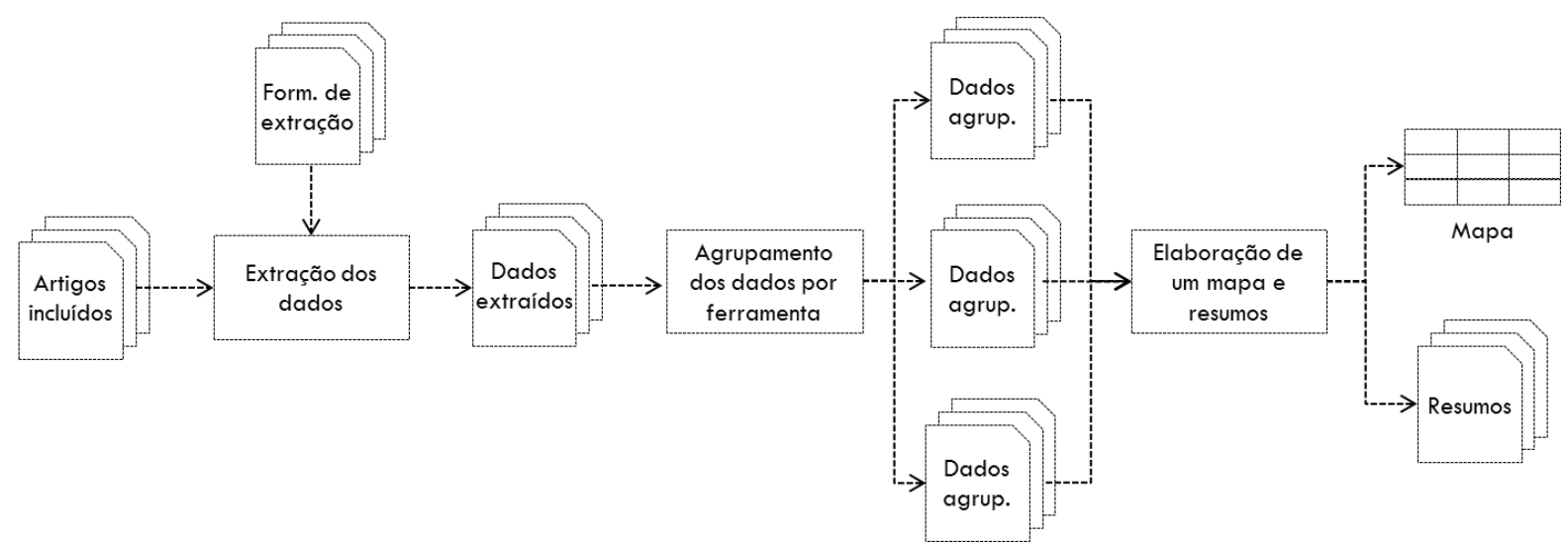

Fonte: Elaborada pelo autor.

O mapeamento sistemático foi conduzido com base no planejamento apresentado. Inicialmente, a string de busca foi adaptada segundo a notação de cada base eletrônica. Os campos de busca considerados foram o título e o resumo dos artigos. No entanto, para a base Google Scholar apenas o título foi considerado, uma vez que esta base não permite buscas por termos no resumo dos artigos. Além disso, a base eletrônica Inspec foi desconsiderada, uma vez que esteve indisponível durante a realização das buscas. 
Na Figura 15 são ilustrados os resultados obtidos em cada fase do mapeamento. Inicialmente, as strings de busca foram executadas nas bases eletrônicas, que retornaram um total de 587 resultados.

Figura 15 - Ferramentas de avaliação: Fases do mapeamento sistemático

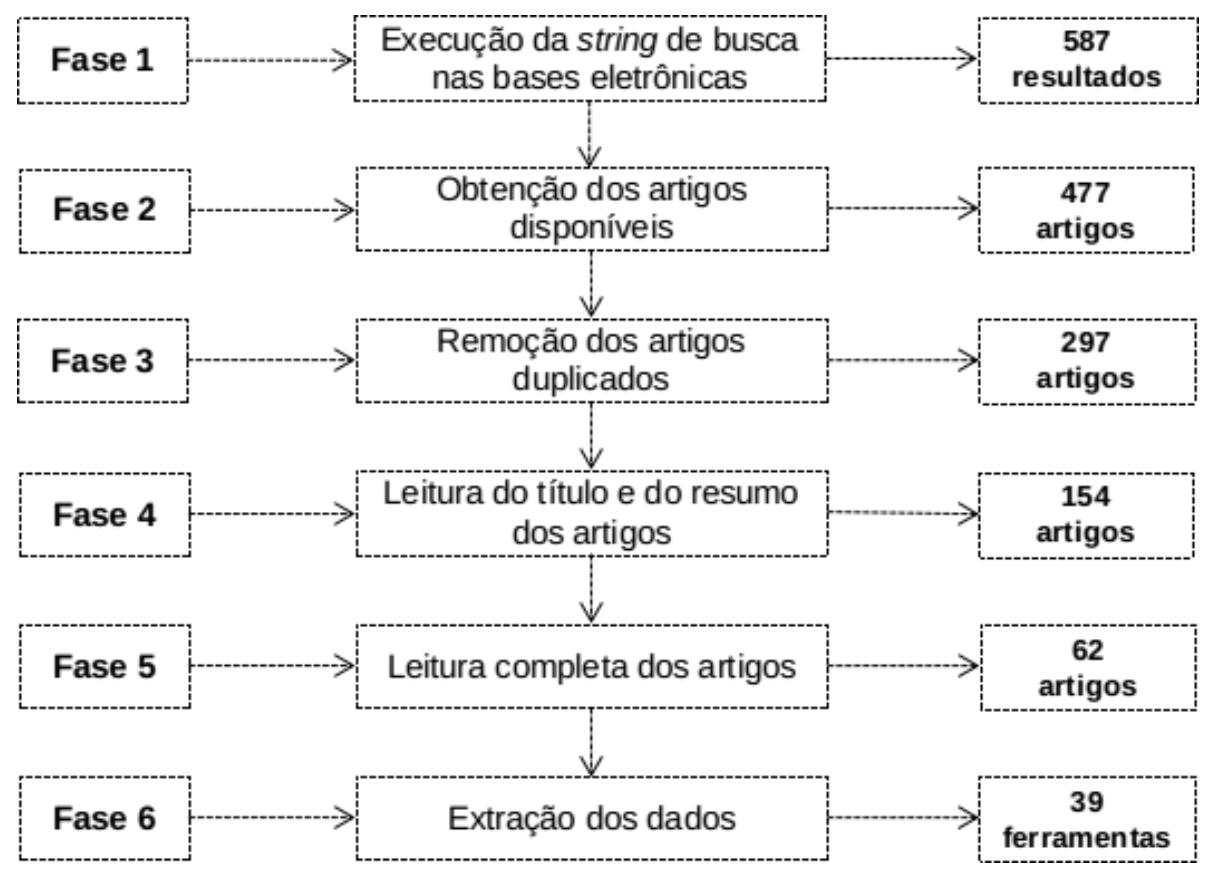

Fonte: Elaborada pelo autor.

A partir dos artigos retornados, notou-se que alguns resultados levavam a páginas ou trabalhos indisponíveis. Assim, dos 587 resultados retornados, 477 resultados consistiam em artigos disponíveis. Removendo os artigos duplicados, obteve-se um total de 297 artigos recuperados.

Durante o processo de seleção dos artigos, 154 artigos foram identificados como relevantes e pré-selecionados para serem lidos na íntegra. Após a leitura completa dos artigos pré-selecionados, 62 artigos foram incluídos nos resultados, com base nos critérios de inclusão e exclusão adotados. A lista de todos os artigos incluídos é apresentada nos quadros 14 e 15 . Realizando o processo de extração dos dados, 39 ferramentas de avaliação automática de trabalhos de programação foram identificadas.

No gráfico da Figura 16 é apresentado o número de artigos por ano de publicação. Observa-se que a quantidade de publicações aumenta a partir do final dos anos 90, tendo pelo menos uma publicação por ano a partir de 2000. Percebe-se também alguns picos de publicações em alguns anos específicos, como por exemplo, em 2008 (9 artigos), 2012 (7 artigos) e 2015 (7 artigos). Ressalta-se que os valores para 2016 e 2017 podem estar incompletos, uma vez que alguns artigos podem ainda não terem sidos disponibilizados ou publicados.

Com relação às bases eletrônicas, no gráfico da Figura 17 é apresentada a porcentagem de artigos incluídos retornados por cada base. A base que mais retornou artigos relevantes foi a Compendex (39 artigos), seguida da ACM Digital Library (25 artigos). 
Quadro 14 - Ferramentas de avaliação: Artigos incluídos no mapeamento sistemático

\begin{tabular}{|c|c|c|}
\hline Autores & Título & Ano \\
\hline Benson (1985) & Machine assisted marking of programming assignments & 1985 \\
\hline $\begin{array}{l}\text { Fleming, Redish e } \text { Smyth } \\
\text { (1988) }\end{array}$ & Comparison of manual and automated marking of student programs & 1988 \\
\hline Hasan (1988) & Assessment of student programming assignments in COBOL & 1988 \\
\hline Luck e Joy (1995) & $\begin{array}{l}\text { Automatic submission in an evolutionary approach to computer science te- } \\
\text { aching }\end{array}$ & 1995 \\
\hline Dawson-Howe (1996) & Automatic submission and administration of programming assignments & 1996 \\
\hline Joy e Luck (1996) & A User-Friendly On-Line Submission System & 1996 \\
\hline Joy e Luck (1998) & Effective electronic marking for on-line assessment & 1998 \\
\hline Leal e Silva (2003) & Automatic Grading of Programming Exercises & 1998 \\
\hline Leal, Moreira e Moreira (1998) & Automatic grading of programming exercises & 1998 \\
\hline Matt (1998) & Kassandra: The Automatic Grading System & 1998 \\
\hline Jackson (2000) & A semi-automated approach to online assessment & 2000 \\
\hline Huizinga (2001) & $\begin{array}{l}\text { Identifying topics for instructional improvement through on-line tracking of } \\
\text { programming assignments }\end{array}$ & 2001 \\
\hline Kurnia, Lim e Cheang (2001) & Online Judge & 2001 \\
\hline Goldwasser (2002) & A Gimmick to Integrate Software Testing Throughout the Curriculum & 2002 \\
\hline Morris (2002) & $\begin{array}{l}\text { Automatically grading Java programming assignments via reflection, inhe- } \\
\text { ritance, and regular expressions }\end{array}$ & 2002 \\
\hline Cheang et al. (2003) & $\begin{array}{l}\text { On automated grading of programming assignments in an academic institu- } \\
\text { tion }\end{array}$ & 2003 \\
\hline Edwards (2003) & Rethinking computer science education from a test-first perspective & 2003 \\
\hline Edwards (2003) & Teaching software testing: automatic grading meets test-first coding & 2003 \\
\hline Morris (2003) & $\begin{array}{l}\text { Automatic grading of student's programming assignments: An interactive } \\
\text { process and suite of programs }\end{array}$ & 2003 \\
\hline Blumenstein et al. (2004) & $\begin{array}{l}\text { GAME: A generic automated marking environment for programming asses- } \\
\text { sment }\end{array}$ & 2004 \\
\hline Blumenstein et al. (2004) & $\begin{array}{l}\text { An experimental analysis of (GAME): a generic automated marking envi- } \\
\text { ronment }\end{array}$ & 2004 \\
\hline De-Campos e Ferreira (2004) & BOCA: um sistema de apoio a competições de programação & 2004 \\
\hline Tremblay, Guerin e Pons (2005) & A generic and extensible tool for marking programming assignments & 2005 \\
\hline Spacco et al. (2006) & $\begin{array}{l}\text { The Marmoset project: an automated snapshot, submission, and testing sys- } \\
\text { tem }\end{array}$ & 2006 \\
\hline Edwards e nones (2007) & Experiences using test-driven development with an automated grader & 2007 \\
\hline $\begin{array}{l}\text { Spinellis, Zaharias e Vrecho- } \\
\text { poulos (2007) }\end{array}$ & $\begin{array}{l}\text { Coping with plagiarism and grading load: Randomized programming as- } \\
\text { signments and reflective grading, Computer Applications in Engineering } \\
\text { Education }\end{array}$ & 2007 \\
\hline Allevato et al. (2008) & $\begin{array}{l}\text { Mining Data from an Automated Grading and Testing System by Adding } \\
\text { Rich Reporting Capabilities }\end{array}$ & 2008 \\
\hline Auffarth et al. (2008) & $\begin{array}{l}\text { System for Automated Assistance in Correction of Programming Exercises } \\
\text { (SAC) }\end{array}$ & 2008 \\
\hline Barbosa et al. (2008) & Integrated teaching of programming foundations and software testing & 2008 \\
\hline Blumenstein et al. (2008) & $\begin{array}{l}\text { Performance analysis of GAME: A generic automated marking environ- } \\
\text { ment }\end{array}$ & 2008 \\
\hline Choy et al. (2008) & $\begin{array}{l}\text { Design and implementation of an automated system for assessment of com- } \\
\text { puter programming assignments }\end{array}$ & 2008 \\
\hline $\begin{array}{l}\begin{array}{l}\text { Edwards } \\
\text { (2008) }\end{array} \\
\text { e Perez-Quinones }\end{array}$ & Web-CAT: automatically grading programming assignments & 2008 \\
\hline
\end{tabular}

Fonte: Elaborada pelo autor. 
Quadro 15 - Ferramentas de avaliação: Artigos incluídos no mapeamento sistemático (continuação)

\begin{tabular}{|c|c|c|}
\hline Autores & Título & Ano \\
\hline $\begin{array}{l}\text { Gotel, Scharff e Wildenberg } \\
\text { (2008) }\end{array}$ & $\begin{array}{l}\text { Global perceptions on the use of WeBWorK as an online tutor for computer } \\
\text { science }\end{array}$ & 2008 \\
\hline $\begin{array}{l}\text { Gotel, Scharff e Wildenberg } \\
\text { (2008) }\end{array}$ & $\begin{array}{l}\text { Teaching software quality assurance by encouraging student contributions } \\
\text { to an open source web-based system for the assessment of programming } \\
\text { assignments }\end{array}$ & 2008 \\
\hline Tremblay et al. (2008) & Oto, a generic and extensible tool for marking programming assignments & 2008 \\
\hline Sant (2009) & "Mailing it in": email-centric automated assessment & 2009 \\
\hline Wang et al. (2009) & $\begin{array}{l}\text { AutoLEP: An automated learning and examination system for programming } \\
\text { and its application in programming course }\end{array}$ & 2009 \\
\hline Georgouli e Guerreiro (2010) & $\begin{array}{l}\text { Incorporating an automatic judge into blended learning programming acti- } \\
\text { vities }\end{array}$ & 2010 \\
\hline Law, Lee e Yu (2010) & $\begin{array}{l}\text { Learning motivation in e-learning facilitated computer programming cour- } \\
\text { ses }\end{array}$ & 2010 \\
\hline $\begin{array}{l}\text { Souza, Maldonado e Barbosa } \\
\text { (2011) }\end{array}$ & $\begin{array}{l}\text { ProgTest: An environment for the submission and evaluation of program- } \\
\text { ming assignments based on testing activities }\end{array}$ & 2011 \\
\hline Tremblay e Lessard (2011) & A marking language for the oto assignment marking tool & 2011 \\
\hline Wang et al. (2011) & $\begin{array}{l}\text { Ability-training-oriented automated assessment in introductory program- } \\
\text { ming course }\end{array}$ & 2011 \\
\hline Allevato (2012) & $\begin{array}{l}\text { From Intuition to Evidence: A Data-driven Approach to Transforming Cs } \\
\text { Education }\end{array}$ & 2012 \\
\hline Chou e Cheng (2012) & $\begin{array}{l}\text { Developing program grading suggestion mechanism by reusing teacher gra- } \\
\text { ding records }\end{array}$ & 2012 \\
\hline Kaushal e Singh (2012) & Automated evaluation of programming assignments & 2012 \\
\hline Ng, Lui e Wong (2012) & $\begin{array}{l}\text { Tree-based comparison for plagiarism detection and automatic marking of } \\
\text { programming assignments }\end{array}$ & 2012 \\
\hline Paralic e Martoncik (2012) & Support for management of programming assignments - Automated grading & 2012 \\
\hline Rajaguru et al. (2012) & E-assessment of programming assignments in web service & 2012 \\
\hline Yusof, Zin e Adnan (2012) & $\begin{array}{l}\text { Java Programming Assessment Tool for Assignment Module in Moodle E- } \\
\text { learning System }\end{array}$ & 2012 \\
\hline Holton e Wallace (2013) & $\begin{array}{l}\text { Investigating the Use of an Online Assignment Submission and Assessment } \\
\text { System in the CS Classroom }\end{array}$ & 2013 \\
\hline Buffardi e Edwards (2014) & A formative study of influences on student testing behaviors & 2014 \\
\hline Edwards (2014) & $\begin{array}{l}\text { Work-in-progress: Program grading and feedback generation with Web- } \\
\text { CAT }\end{array}$ & 2014 \\
\hline Fonte et al. (2014) & $\begin{array}{l}\text { Partial correctness and continuous integration in computer supported educa- } \\
\text { tion }\end{array}$ & 2014 \\
\hline Souza et al. (2014) & $\begin{array}{l}\text { Towards the use of an automatic assessment system in the teaching of soft- } \\
\text { ware testing }\end{array}$ & 2014 \\
\hline Akahane, Kitaya e Inoue (2015) & Design and evaluation of automated scoring Java programming assignments & 2015 \\
\hline Aziz et al. (2015) & Auto-grading for parallel programs & 2015 \\
\hline Buffardi e Edwards (2015) & Reconsidering Automated Feedback: A Test-Driven Approach & 2015 \\
\hline Pettit et al. (2015) & An empirical study of iterative improvement in programming assignments & 2015 \\
\hline Špaček, Sohlich e Dulík (2015) & Docker as Platform for Assignments Evaluation & 2015 \\
\hline Thiébaut (2015) & $\begin{array}{l}\text { Automatic evaluation of computer programs using Moodle's virtual pro- } \\
\text { gramming lab VPL plug-in }\end{array}$ & 2015 \\
\hline Zhang et al. (2016) & A system for analysis of code on cloud as an educational service to students & 2016 \\
\hline Staubitz et al. (2016) & $\begin{array}{l}\text { CodeOcean - A versatile platform for practical programming excercises in } \\
\text { online environments }\end{array}$ & 2017 \\
\hline
\end{tabular}

Fonte: Elaborada pelo autor. 
Capítulo 3. Ferramentas de avaliação, sistemas de gerenciamento de aprendizagem e arquiteturas de 58 software

Figura 16 - Ferramentas de avaliação: Número de artigos por ano

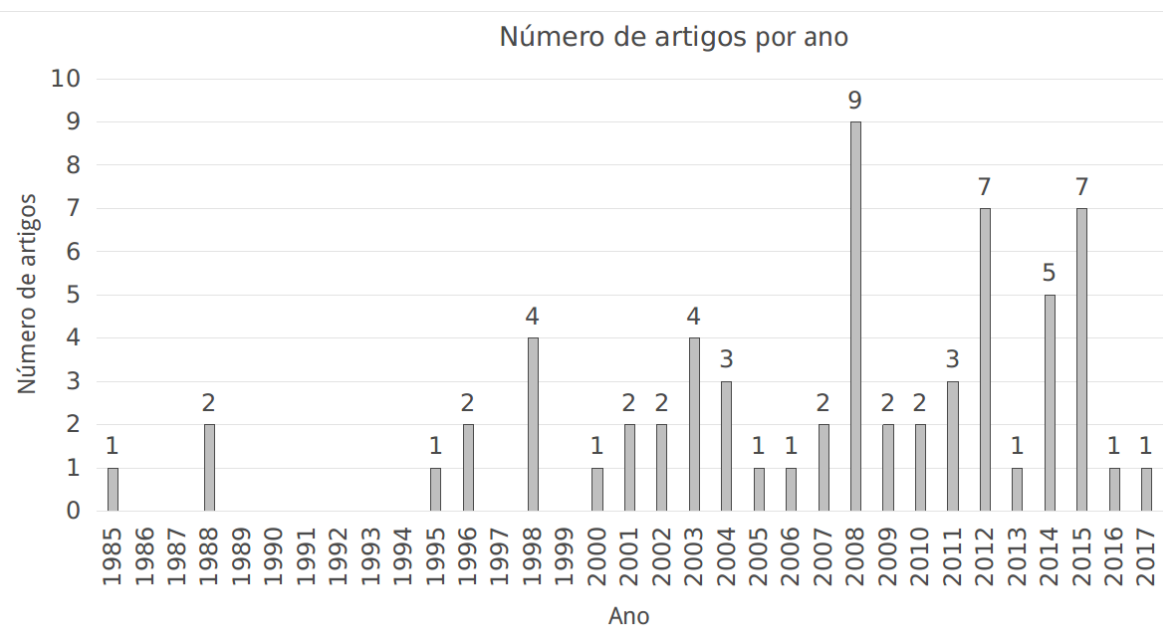

Fonte: Elaborada pelo autor.

Figura 17 - Ferramentas de avaliação: Número de artigos por base eletrônica

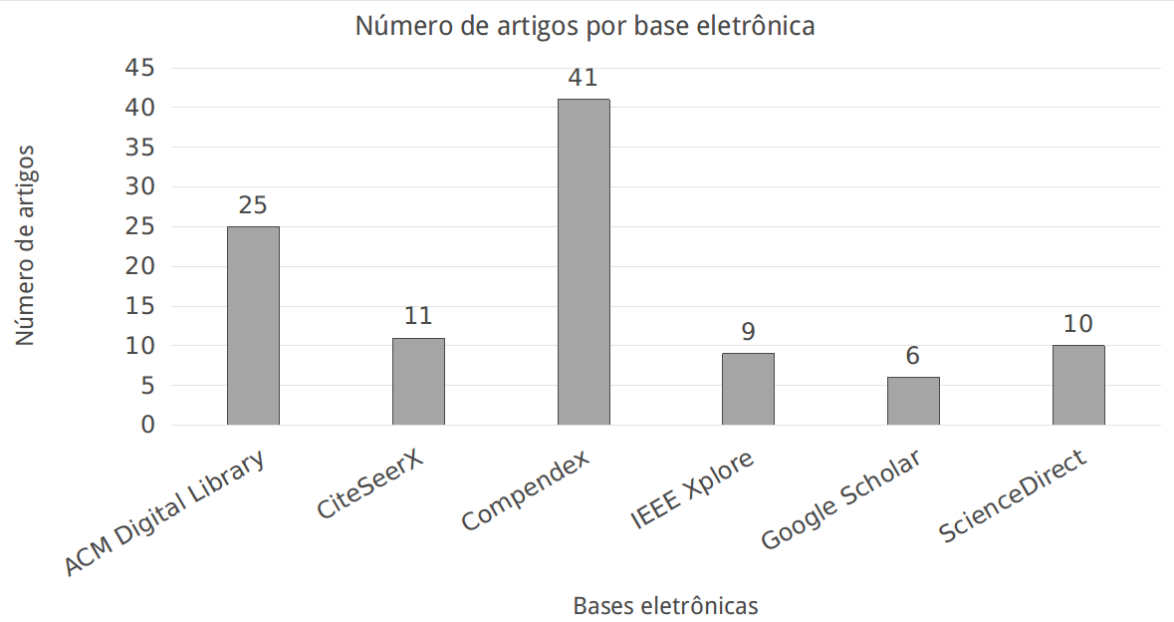

Fonte: Elaborada pelo autor.

Como resultado do mapeamento, as ferramentas de avaliação identificadas foram classificadas e as suas funcionalidades e características analisadas. Tais resultados são apresentados nas seções seguintes.

\subsubsection{Classificação das ferramentas de avaliação para trabalhos de programação}

Com base nos resultados do mapeamento sistemático, uma classificação das ferramentas de avaliação para trabalhos de programação foi proposta. Assim, as ferramentas foram classificadas de acordo com três características: (1) nível de automatização; (2) acionamento do processo de avaliação; e (3) ambiente de execução. No Quadro 16 é apresentada a lista de ferramentas 
identificadas e a classificação delas considerando cada uma dessas três características.

Quadro 16 - Ferramentas de avaliação para trabalhos de programação

\begin{tabular}{|c|c|c|c|}
\hline Ferramenta & Nível de automatização & Acionamento da avaliação & Ambiente de execução \\
\hline AEPA & Automática & Pelo instrutor & Remoto \\
\hline AKAHANE & Automática & Pelo aluno & Remoto \\
\hline APAC & Automática & Pelo aluno & Remoto \\
\hline ATHENE & Automática & Pelo aluno & Remoto \\
\hline AUTOGRADE & Automática & Pelo instrutor & Local \\
\hline AUTOLEP & Automática & Pelo aluno & Remoto \\
\hline AUTOMARK & Automática & Pelo aluno & Local \\
\hline BOCA & Automática & Pelo aluno & Remoto \\
\hline BOSS & Semiautomática & Híbrida & Local \\
\hline CODEOCEAN & Automática & Pelo aluno & Remoto \\
\hline GAME & Automática & Pelo instrutor & Local \\
\hline GLAB & Automática & Pelo aluno & Remoto \\
\hline HoGG & Automática & Pelo instrutor & Local \\
\hline JARPEB & Automática & Pelo aluno & Parcialmente remoto \\
\hline JASSESS & Manual & Pelo instrutor & Remoto \\
\hline KASSANDRA & Automática & Pelo aluno & Parcialmenre remoto \\
\hline MARMOSET & Automática & Pelo aluno & Remoto \\
\hline MOOSHAK & Semiautomática & Híbrida & Remoto \\
\hline OAMS & Automática & Pelo instrutor & Remoto \\
\hline ONLINE JUDGE & Automática & Pelo aluno & Remoto \\
\hline Ото & Automática & Híbrida & Local \\
\hline PASS & Automática & Híbrida & Remoto \\
\hline PROGRAMHELPER & Semiautomática & Híbrida & Remoto \\
\hline PROGTEST & Automática & Pelo aluno & Remoto \\
\hline QUIMERA & Automática & Híbrida & Remoto \\
\hline SAC & Semiautomática & Híbrida & Remoto \\
\hline TRILLIUM & Automática & Pelo aluno & Remoto \\
\hline VPL & Automática & Pelo aluno & Remoto \\
\hline WEB-CAT & Semiautomática & Híbrida & Remoto \\
\hline WEBWORK & Automática & Pelo aluno & Remoto \\
\hline Ferramenta de Benson (1985) & Semiautomática & Híbrida & Local \\
\hline Ferramenta de Dawson-Howe (1996) & Manual & Pelo aluno & Local \\
\hline Ferramenta de Hasan (1988) & Automática & Pelo aluno & Local \\
\hline Ferramenta de Huizinga (2001) & Automática & Pelo aluno & Local \\
\hline Ferramenta de Jackson (2000) & Semiautomática & Pelo instrutor & Local \\
\hline Ferramenta de Leal e Silva (2003) & Automática & Pelo aluno & Local \\
\hline Ferramenta de Sant (2009) & Automática & Pelo instrutor & Local \\
\hline Ferramenta de Zhang et al. (2016) & Automática & Pelo aluno & Remoto \\
\hline
\end{tabular}

Fonte: Elaborada pelo autor.

\subsubsection{Classificação por nível de automatização}

Com relação ao nível de automatização, três categorias foram identificadas: (a) ferramentas de verificação automática; (b) ferramentas de verificação manual; e (c) ferramentas de verificação semiautomática. Tais categorias são detalhadas a seguir:

\section{Ferramentas de verificação automática}

As ferramentas de verificação automática são aquelas que verificam automaticamente as características (correção, documentação do código, complexidade do algoritmo, entre outros.) das soluções desenvolvidas pelos alunos. Em geral, o professor deve prover um esquema de avaliação que pode incluir, por exemplo, um programa de referência, critérios de avaliação, dados 
Capítulo 3. Ferramentas de avaliação, sistemas de gerenciamento de aprendizagem e arquiteturas de 60 software

de teste, dentre outras propriedades. Uma vez acionado o processo de avaliação, a ferramenta verifica a solução do aluno e gera relatórios sobre sua qualidade.

A principal desvantagem desse tipo de ferramenta é que as soluções providas pelos alunos, em geral, devem seguir rigorosamente um determinado formato. Por exemplo, verificando a correção das soluções dos alunos por meio da saída textual dos programas, um espaço ou quebra de linha a mais ou a menos pode fazer com que a ferramenta de avaliação automática compute a saída como incorreta, mesmo que ela esteja semanticamente correta. Alternativas que desconsideram pequenas diferenças no formato de saída podem ser encontradas, mas a necessidade de seguir um formato é sempre presente nesse tipo de ferramenta.

Outra desvantagem é que elas não permitem uma avaliação mais subjetiva e detalhada de certas características das soluções dos alunos. Por exemplo, verificando a documentação dos códigos, as ferramentas de avaliação automática podem verificar, por exemplo, a quantidade de comentários nos códigos, mas não conseguem verificar o quão relevante é o conteúdo desses comentários.

Apesar dessas limitações, as ferramentas de avaliação automática permitem verificar as características das soluções dos alunos com muito menos tempo e esforço. O tempo e esforço excessivo é um dos principais problemas relacionados à avaliação de trabalhos de programação, principalmente em cursos com um número grande de alunos.

Ainda, a avaliação objetiva realizada pelas ferramentas de avaliação automática permite que os resultados da avaliação possam ser facilmente explicados e justificados. Cada ponto positivo ou negativo indicado pela ferramenta de avaliação automática está associado a um critério de avaliação bem definido e que é igual para todas as soluções desenvolvidas para aquele trabalho.

\section{Ferramentas de verificação manual}

Já as ferramentas de verificação manual são aquelas que proveem funcionalidades para auxiliar a avaliação das soluções desenvolvidas pelos alunos, mas a verificação propriamente dita é realizada manualmente pelo professor. Por exemplo, uma ferramenta de verificação manual pode automaticamente compilar e executar os programas dos alunos, mas é o professor quem vai manualmente julgar se as saídas produzidas pelos programas são corretas.

Em comparação com as ferramentas de verificação automática, o processo de avaliação apoiado por uma ferramenta de verificação manual demanda um tempo e esforço maior. Ainda, a avaliação não é sistemática como a apoiada pelas ferramentas de verificação automática, de forma que a qualidade dos resultados de cada avaliação depende do empenho e capacidade de julgamento do professor durante o processo avaliação.

No entanto, como a verificação das características dos programas é realizada manualmente, o rigor em seguir um determinado formato é menor. Ainda, a avaliação subjetiva apoiada 
pelas ferramentas de verificação manual permite que o professor realize verificações que são difíceis de serem automatizadas, como a relevância de um comentário no código ou o quão criativa foi a solução proposta pelo aluno. Esta maior liberdade e flexibilidade podem ajudar na criatividade e motivação dos alunos no desenvolvimento das soluções, trazendo benefícios ao processo de aprendizagem.

\section{Ferramentas de verificação semiautomática}

Por fim, as ferramentas de verificação semiautomática são aquelas que verificam automaticamente as características das soluções dos alunos, mas em alguns casos requerem que o professor realize uma verificação manual.

Assim, as ferramentas de verificação semiautomática herdam vantagens e desvantagens das ferramentas de verificação automática e de verificação manual, sendo um meio termo entre os dois outros tipos.

\subsubsection{Classificação por tipo de abordagem}

Com relação ao tipo de abordagem, três categorias foram identificadas: (a) abordagem centrada no professor; (b) abordagem centrada no aluno; e (c) abordagens híbridas.

\section{Ferramentas de abordagem centrada no professor}

As ferramentas com abordagem centrada no professor são aquelas em que o processo de avaliação é acionado pelo professor. Geralmente, a avaliação em ferramentas com este tipo de abordagem é realizada somente depois que todos os alunos entregaram as suas soluções. Os alunos não têm acesso aos resultados da avaliação (seja ela automática, manual ou semiautomática) enquanto o professor não os disponibilizar.

A principal desvantagem desse tipo de abordagem é que, para terem algum feedback sobre a qualidade das suas soluções, os alunos têm que esperar o professor realizar a avaliação e disponibilizar os resultados. Dentre as principais vantagens desse tipo de abordagem está a possibilidade de realizar verificações que envolvem todas as soluções desenvolvidas, como por exemplo, a detecção de plágio entre os alunos.

\section{Ferramentas de abordagem centrada no aluno}

Já as ferramentas com abordagem centrada no aluno são aquelas em que o processo de avaliação é acionado pelo aluno. Em geral, a avaliação em ferramentas com este tipo de abordagem é realizada individualmente para cada solução. A avaliação é iniciada assim que o aluno fornece a sua solução, considerando critérios e dados previamente fornecidos pelo professor, e os resultados são disponibilizados tanto para o professor como para o aluno. 
Capítulo 3. Ferramentas de avaliação, sistemas de gerenciamento de aprendizagem e arquiteturas de 62 software

A principal desvantagem desse tipo de abordagem é que, uma vez que os alunos começaram a submeter suas soluções à avaliação, os critérios e dados fornecidos pelo professor dificilmente poderão ser corrigidos ou alterados, pois alunos já estariam recebendo resultados com base nos critérios e dados definidos. Apesar de algumas ferramentas permitirem essas alterações, realizá-las poderia causar uma desconfiança por parte dos alunos com relação ao processo de avaliação, além de não ser possível garantir que todos os alunos receberão os resultados com base nos novos critérios e dados definidos.

No entanto, as ferramentas com abordagem centrada no aluno têm como vantagem a possibilidade dos alunos receberem um feedback imediato sobre as suas soluções, tendo a oportunidade de melhorá-las continuamente até o prazo final do trabalho. Tal vantagem se reflete no processo de aprendizagem, uma vez que estimula os alunos a aprender por meio dos seus próprios erros.

\section{Ferramentas de abordagem híbrida}

Por fim, as ferramentas com abordagem híbrida são aquelas que implementam estratégias que visam combinar as vantagens das abordagens centradas no professor e no aluno. Assim, três estratégias puderam ser identificadas:

- Validação preliminar: As ferramentas que implementam essa estratégia são similares àquelas que possuem uma abordagem centrada no professor. Porém, permitem que o aluno adicionalmente realize uma validação preliminar da solução. Em geral, a validação consiste na execução de um conjunto pequeno de testes contra o programa do aluno.

- Feedback parcial: As ferramentas que implementam essa estratégia permitem que algumas características (por exemplo, a correção dos programas) sejam avaliadas assim que o aluno fornece a sua solução, seguindo uma abordagem centrada no aluno, enquanto outras características (por exemplo, documentação e detecção de plágio) são avaliadas após o prazo final do trabalho, por meio de uma abordagem centrada no professor.

- Revisão do professor: As ferramentas que implementam essa estratégia são similares àquelas que possuem uma abordagem centrada no aluno. Porém, os alunos são notificados que os resultados da avaliação não são os finais. Os professores podem revisar os resultados, modificá-los e notificar os alunos sobre a finalização dos resultados.

\subsubsection{Classificação por ambiente de execução}

Com relação ao ambiente de execução, três categorias foram identificadas: (a) ferramentas com execução local; (b) ferramentas com execução remota; e (c) ferramentas com execução parcialmente remota. 


\section{Ferramentas com execução local}

As ferramentas com execução local são aquelas projetadas para serem executadas localmente na máquina do professor e/ou do aluno. Em alguns casos, possuem mecanismos para que os alunos entreguem as suas soluções por e-mail ao professor ou a um repositório remoto. Caso a avaliação seja centrada no aluno, os resultados da avaliação automática geralmente devem ser enviados junto com as soluções. De forma análoga, também podem fornecer mecanismos para o envio de feedback do professor aos alunos por e-mail ou por outro meio de comunicação eletrônico.

A principal desvantagem deste tipo de ferramenta é que diferentes configurações locais de máquina podem prejudicar a execução correta da avaliação. Ainda, a entrega das soluções dos alunos ao professor e a disponibilização de feedback do professor aos alunos também pode ser prejudicada. Por outro lado, tais ferramentas eliminam a necessidade de conexão para executar a avaliação e eliminam a necessidade de configurar e manter um servidor robusto capaz de executar uma grande quantidade de procedimentos ao mesmo tempo.

\section{Ferramentas com execução remota}

Já as ferramentas com execução remota são aquelas em que os procedimentos automatizados são realizados remotamente. Em geral, a ferramenta deve ser instalada em um servidor, ficando disponível tanto para professores e alunos por meio de uma página web.

A principal desvantagem deste tipo de ferramenta é a necessidade em manter um servidor robusto para gerenciar a execução de um vários procedimentos de avaliação de um grande número de alunos ao mesmo tempo. Além disso, existe uma dependência maior de conexão para realizar o processo de avaliação. Por outro lado, a execução remota garante que todos os trabalhos de programação serão executados considerando a mesma configuração. Ainda, por conter todas as informações sempre em um componente remoto, este tipo de ferramenta facilita a disponibilização dos resultados aos alunos e ao professor.

\section{Ferramentas com execução parcialmente remota}

Por fim, as ferramentas parcialmente remotas possuem um componente principal remoto, mas alguns procedimentos que exigem uma maior capacidade de processamento e memória (como por exemplo, a compilação, a execução e a verificação dos programas) são executados por um componente local da ferramenta, na maioria das vezes, nas máquinas dos alunos.

A ideia desse tipo de ferramenta é diminuir a necessidade de manter um servidor robusto, mas mantendo todas as informações em um componente remoto, combinando vantagens e desvantagens das ferramentas com execução local e com execução remota.

Além desses diferentes tipos de avaliação, outras funcionalidades e características das 
Capítulo 3. Ferramentas de avaliação, sistemas de gerenciamento de aprendizagem e arquiteturas de 64 software

ferramentas foram observadas e são descritas a seguir.

\subsubsection{Funcionalidades e características das ferramentas de avaliação}

Nesta seção é apresentada uma análise das principais características das ferramentas de avaliação identificadas durante a condução do mapeamento sistemático. Ênfase é dada às características consideradas importantes para desenvolvimento deste trabalho de doutorado. Tais características são: (1) as funcionalidades apoiadas; (2) as linguagens de programação apoiadas; e (3) as interfaces com o usuário e outros ambientes.

\section{Principais funcionalidades}

Uma das características analisadas nas ferramentas refere-se às funcionalidades disponíveis. Dentre elas, destacam-se: (1) verificação de trabalhos de programação; (2) submissão de trabalhos de programação; (3) disponibilização de relatório de problemas; (4) emissão de relatórios estatísticos; (5) pontuação dos trabalhos de programação; (6) armazenamento do histórico de submissões; (7) fornecimento de feedback imediado aos alunos. Essas funcionalidades são sintetizadas na Figura 18.

A principal funcionalidade que caracteriza uma ferramenta de avaliação automática de trabalhos de programação é a verificação automática de algum aspecto dos trabalhos dos alunos. Basicamente, os aspectos foram classificados em dois tipos: (i) aspectos dinâmicos; e (ii) aspectos estáticos.

Os aspectos dinâmicos são aqueles que para serem avaliados precisam que o programa seja executado. Em geral, a maioria das ferramentas executam o programa para avaliar a sua correção. No entanto, algumas ferramentas baseadas em teste também avaliam a adequação do conjunto de teste projetado pelo aluno para testar o seu programa. É comum também que as ferramentas realizem uma verificação inicial compilando e executando os programas para verificar a validade da solução, ou seja, se os arquivos e dados submetidos pelos alunos são adequados. Por fim, algumas ferramentas ainda avaliam o desempenho dos programas em termos de tempo e recursos de memória.

Os aspectos estáticos, por sua vez, são aqueles que podem ser verificados sem a execução do programa. Tais aspectos incluem: (1) a complexidade, que consiste em analisar o quão complexo é o algoritmo implementado pelo aluno; (2) a documentação, que consiste em analisar o nível de comentários no código do aluno; (3) os erros de codificação, que consiste em identificar defeitos no programa por meio da análise do seu código fonte; (4) estilo, que consiste em analisar a adoção adequada de determinadas boas práticas de programação, tais como indentação, modularização, etc; e (5) originalidade, que consiste em detectar a possibilidade de plágio entre os códigos dos alunos.

Dentre os diversos aspectos avaliados, atenção especial é dada à avaliação da correção 
Figura 18 - Principais funcionalidades identificadas em ferramentas de avaliação

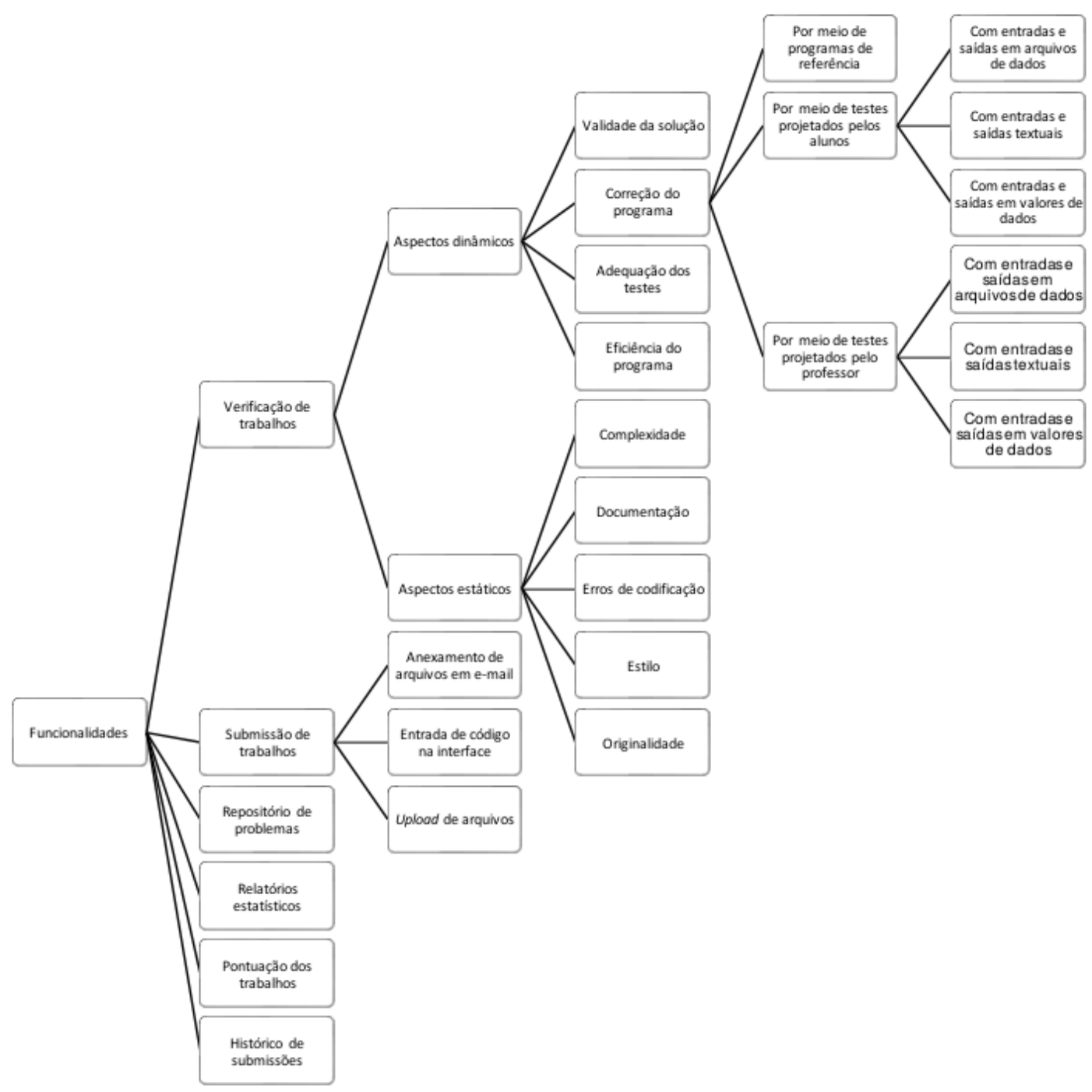

Fonte: Elaborada pelo autor.

dos programas, a qual, em geral, exige a submissão de artefatos adicionais para a sua verificação, tais como um conjunto de teste a ser executado contra os programas dos alunos.

Basicamente, para avaliar a correção dos programas, três estratégias podem ser adotadas: (1) comparar o programa do aluno com um programa de referência fornecido pelo professor; (2) executar o programa do aluno com casos de teste também fornecidos por ele; e (3) executar o programa do aluno com um conjunto de teste fornecido pelo professor.

Ainda, os casos de teste fornecidos pelos alunos e pelo professor podem ser de três tipos: (1) testes com entrada e saída em arquivos de dados, em que um arquivo de dados é fornecido como entrada para o programa que, por sua vez, deve gerar outro arquivo de dados como saída; (2) testes baseados em comparação textual, em que a correção é determinada por meio da análise da saída textual do programa; e (3) testes de unidade automatizados, em que os módulos do 
Capítulo 3. Ferramentas de avaliação, sistemas de gerenciamento de aprendizagem e arquiteturas de 66 software

programa são testados individualmente e a saída a ser validada consiste em valores de retorno e de variáveis.

Ressalta-se que, apesar de todas as ferramentas realizarem alguma verificação nos trabalhos dos alunos, nem todas pontuam os trabalhos com base nos resultados dessa verificação, ou seja, nem todas sugerem uma nota ou atribuem uma quantidade de pontos a eles. Em alguns casos, cabe ao professor analisar os resultados e atribuir ao trabalho a nota que considerar adequada.

Outra funcionalidade relevante diz respeito à submissão eletrônica dos trabalhos de programação. Foram identificados três meios de submissão: (1) envio de arquivos via e-mail, em que arquivos com o código do programa são enviados por meio de um mensagem de e-mail com um cabeçalho específico; (2) entrada de código na interface da ferramenta, em que o aluno desenvolve os seus programas diretamente na interface da ferramenta; e (3) upload de arquivos, em que os arquivos com o código fonte dos programas são carregados por meio da interface da ferramenta. Quando esta funcionalidade não é apoiada, a entrega/recebimento dos trabalhos deve ser realizada diretamente ao professor ou por meio de outros sistemas.

O feedback fornecido pelas ferramentas foi outra funcionalidade importante observada. Apesar de todas as ferramentas analisadas fornecerem algum tipo de feedback aos alunos, somente algumas delas fornecem feedback imediato. O feedback imediato é essencial para que os alunos entendam os erros cometidos, melhorem os seus trabalhos e, consequentemente, evoluam no processo de aprendizagem e construção do conhecimento.

Por fim, com relação às demais funcionalidades identificadas, destacam-se: (1) a disponibilização de um repositório de problemas com especificações de trabalhos pré-definidas, as quais o professor pode aplicar em suas disciplinas ao invés de definir suas próprias especificações de trabalhos; (2) a emissão de relatórios estatísticos, que forneçam ao professor informações sobre o desempenho dos alunos, ajudando-o a identificar possíveis falhas no processo de aprendizagem; e (3) o armazenamento do histórico de submissões, que permite ao professor avaliar a evolução dos alunos no desenvolvimento dos seus trabalhos, facilitando o melhor entendimento de suas dificuldades.

\section{Linguagens de programação}

Além das funcionalidades já discutidas, uma outra característica importante observada foi a linguagem de programação apoiada pelas ferramentas (Figura 19).

A linguagem mais apoiada foi JAVA, que tem sido bastante utilizada em disciplinas de programação. Em seguida, destacam-se as linguagens C, C++ e PASCAL, que também são comumente utilizadas em disciplinas introdutórias de programação. Ressalta-se, ainda, o apoio às linguagens lógicas PROLOG e HASKELL, permitindo que ferramentas de avaliação também sejam utilizadas em disciplinas de Inteligência Artificial. 
Figura 19 - Principais linguagens apoiadas pelas ferramentas de avaliação

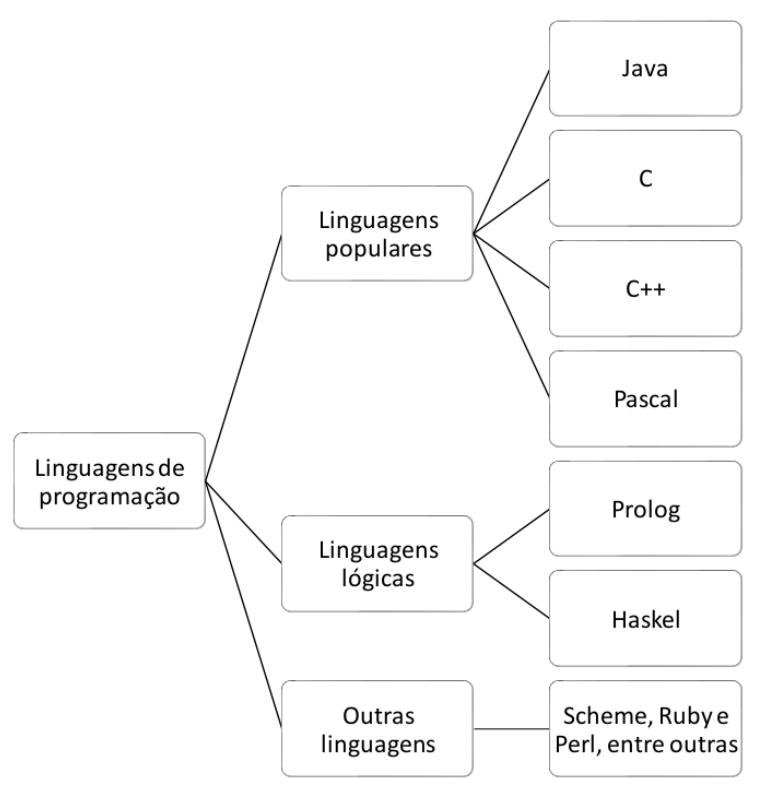

Fonte: Elaborada pelo autor.

\section{Interfaces com o usuário e com outros ambientes}

As interfaces das ferramentas com o usuário e com outros ambientes também consistem em uma característica importante observada (Figura 20). Com relação às interfaces com o usuário, as mais recentes, em geral, apresentam uma interface web com o usuário (WUI). Por outro lado, as mais antigas, apresentam interfaces em linha de comando (CLI). Além disso, algumas ferramentas também apresentam uma interface gráfica com o usuário (GUI).

Figura 20 - Interfaces entre as ferramentas de avaliação e outros ambientes

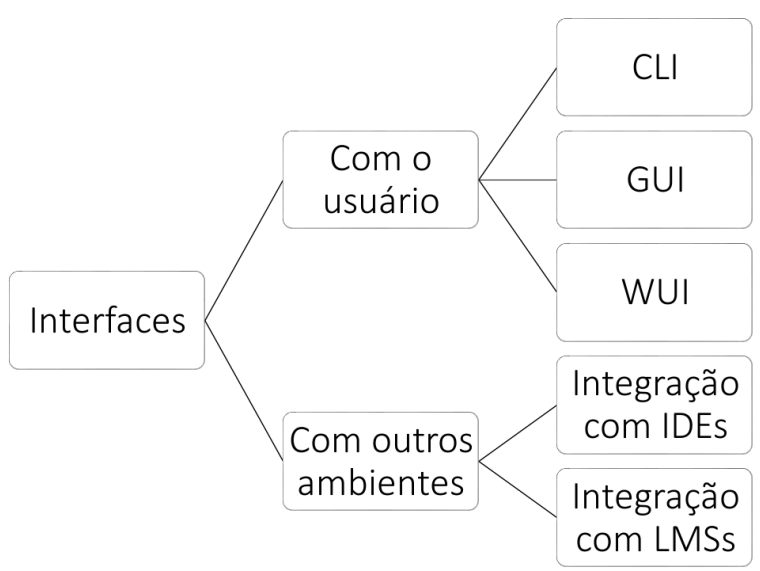

Fonte: Elaborada pelo autor.

Destacam-se, ainda, ferramentas desenvolvidas de forma integrada a outros ambientes. Assim, algumas ferramentas identificadas podem ser acessadas por meio de um ambiente de 
Capítulo 3. Ferramentas de avaliação, sistemas de gerenciamento de aprendizagem e arquiteturas de 68 software

desenvolvimento integrado (Integrated Development Environment - IDE) ou podem ser acessadas por meio de um LMS.

A integração de ferramentas de avaliação para trabalhos de programação é o principal objetivo deste trabalho. Neste sentido, a identificação e estudo dos LMSs também constitui uma atividade importante realizada, sendo descrita a seguir.

\subsection{Sistemas de gestão da aprendizagem}

Sistemas de gestão da aprendizagem (Learning Management Systems - LMSs) são aplicações baseadas na web que permitem planejar, implementar e avaliar a aprendizagem de várias formas, incluindo funcionalidades para criar e disponibilizar conteúdo, monitorar a participação nos cursos e avaliar o desempenho dos alunos (BAKER, 2015). Exemplos de LMSs incluem o Moodle (Moodle Community, 2016), o CHAMILO (The Chamilo Association, 2017) e o BLACKBOARD (Blackboard Inc., 2017), entre outros.

Há diferentes definições de LMS e não há uma visão muito clara sobre as diferenças entre os LMSs e outros sistemas educacionais. Neste trabalho de doutorado, são considerados LMSs quaisquer sistemas de apoio à aprendizagem baseados na web que: (1) forneçam apoio ao gerenciamento de cursos e alunos; (2) permitam a disponibilização de conteúdos; (3) possuam mecanismos de apoio à avaliação; e (4) disponibilizem ferramentas de colaboração e comunicação. Esta definição foi elaborada comparando diversos ambientes educacionais considerados como LMSs. Tais LMSs são sumarizados no Quadro 17. Exemplos desses ambientes e detalhes sobre as suas funcionalidades são apresentados a seguir.

\subsubsection{Funcionalidades dos LMSs}

Com base no estudo e utilização dos LMSs identificados, foi possível classificar as funcionalidades dos LMSs em quatro categorias: organização, conteúdo, atividades e comunicação.

As funcionalidades de organização estão relacionadas ao gerenciamento dos cursos e alunos. Quatro funcionalidades principais de organização foram identificadas: (i) definição de cursos; (ii) gerenciamento dos participantes; (iii) acompanhamento dos eventos; e (iv) acompanhamento do progresso dos alunos. Tais funcionalidades são descritas no Quadro 18.

As funcionalidades de conteúdo estão relacionadas ao gerenciamento dos materiais didáticos e outros recursos, os quais podem ser documentos de textos, slides de aula, links, vídeos, dentre outros. Três funcionalidades principais de conteúdo foram identificadas: (i) disponibilização de conteúdo; (ii) repositório de conteúdo; e (iii) produção de conteúdo. Tais funcionalidades são descritas no Quadro 19.

As funcionalidades de atividades estão relacionadas à realização de exercícios, testes, trabalhos práticos, dentre outras atividades. Três funcionalidades principais de atividades foram 
Quadro 17 - Visão geral dos principais LMSs identificados

\begin{tabular}{|c|c|}
\hline LMS & Descrição \\
\hline AMADEUS & $\begin{array}{l}\text { O AMADEUS implementa o conceito de blended-learning (aprendizagem híbrida), em que a } \\
\text { maior parte das atividades são realizadas a distância, que atividades presenciais também são } \\
\text { exigidas. Assim sendo, sua principal característica é a integração com diversas mídias, tais } \\
\text { como: jogos e simulações multiusuários. }\end{array}$ \\
\hline ATUTOR & $\begin{array}{l}\text { No ATUTOR, além de conduzir os seus cursos online, os educadores também podem montar, em- } \\
\text { pacotar e redistribuir conteúdos instrucionais, bem como importar conteúdos pré-empacotados. }\end{array}$ \\
\hline BLACKBOARD & $\begin{array}{l}\text { O BLACKBOARD é centrado no aluno, sendo projetado para facilitar o acesso a notas e trabalhos, } \\
\text { manter os alunos informados sobre datas e eventos, mantê-los em contato com a comunidade } \\
\text { acadêmica, dentre outros requisitos. Além disso, o LMS também permite facilitar algumas tare- } \\
\text { fas básicas de ensino, tais como a criação de trabalhos e a avaliação de aprendizes. }\end{array}$ \\
\hline CHAMILO & $\begin{array}{l}\text { No CHAMILO a ênfase é dada ao gerenciamento de conteúdo e ensino a distância. A ideia é } \\
\text { permitir que os professores desenvolvam seus cursos usando o paradigma de ensino que consi- } \\
\text { derarem mais adequado (construtivismo, behaviorismo, interacionismo, entre outros.) por meio } \\
\text { da combinação das diversas ferramentas disponibilizadas pelo LMS. }\end{array}$ \\
\hline CHAMILO LCMS & $\begin{array}{l}\text { No CHAMILO LCMS a ênfase é dada no compartilhamento de conteúdo. Cada usuário possui } \\
\text { um repositório central, no qual é possível armazenar diversos objetos de conteúdo. Os objetos } \\
\text { de conteúdo podem ser publicados por meio de diferentes aplicações: um curso, um fórum, um } \\
\text { portfólio, entre outros. Porém, somente uma cópia do objeto é mantida, a qual está armazenada } \\
\text { no repositório pessoal do usuário. }\end{array}$ \\
\hline CLAROLINE & $\begin{array}{l}\text { O conceito implementado pelo CLAROLINE baseia-se em um modelo educacional flexível, em } \\
\text { que a informação transforma-se em conhecimento por meio de atividades e produções realizadas } \\
\text { pelo aprendiz. }\end{array}$ \\
\hline DOKEOS & $\begin{array}{l}\text { No DOKEOS a ênfase é dada à criação e disponibilização de conteúdo. Por meio das ferramentas } \\
\text { disponibilizadas por ele, os professores podem criar conteúdos por meio da própria interface do } \\
\text { LMS. }\end{array}$ \\
\hline EFRONT & $\begin{array}{l}\text { No EFRONT a ênfase é dada ao ambiente corporativo, disponibilizando ferramentas que permi- } \\
\text { tem, por exemplo, representar a hierarquia organizacional da empresa, atribuir aulas e atividades } \\
\text { de acordo com o cargo do usuário na empresa, dentre outras funcionalidades. }\end{array}$ \\
\hline ILIAS & $\begin{array}{l}\text { O ILIAS é um LMS de múltiplos propósitos, podendo ser utilizado como um meio para a } \\
\text { condução de cursos, como uma ferramenta de autoria e também como uma plataforma para } \\
\text { comunicação e colaboração. }\end{array}$ \\
\hline JOOMLALMS & $\begin{array}{l}\text { O JOOMLALMS foi desenvolvido como um componente para o JOOMLA, um sistema de gestão } \\
\text { de conteúdo que facilita a construção e manutenção de websites e aplicações online. Neste } \\
\text { sentido, o LMS fornece ferramentas e funcionalidades que auxiliam a aprendizagem por meio } \\
\text { de websites criados para os cursos. }\end{array}$ \\
\hline MOODLE & $\begin{array}{l}\text { O projeto e desenvolvimento do MoODLE é guiado por uma abordagem construtivista social, } \\
\text { em que um determinado grupo de aprendizes deve construir o conhecimento de forma colabo- } \\
\text { rativa. A ideia é criar uma cultura em que os alunos se sintam motivados em compartilhar suas } \\
\text { experiências e artefatos que agreguem algum conhecimento. }\end{array}$ \\
\hline OLAT & $\begin{array}{l}\text { No OLAT ênfase é dada na disponibilização de funcionalidades que atendam as necessidades } \\
\text { de ensino e aprendizagem baseados na web. }\end{array}$ \\
\hline SAKAI CLE & $\begin{array}{l}\text { No SAKAI a ênfase é dada à colaboração e compartilhamento de conhecimento. Além de permi- } \\
\text { tir que alunos e professores compartilhem conteúdos educacionais e realizem atividades colabo- } \\
\text { rativamente, os pesquisadores também podem utilizar o SAKAI para colaborar e compartilhar } \\
\text { informações e ferramentas. }\end{array}$ \\
\hline SHAREPOINTLMS & $\begin{array}{l}\text { O SHAREPOINTLMS é baseado no MICROSOFT SHAREPOINT, uma plataforma que permite } \\
\text { armazenar, organizar, compartilhar e acessar informações por meio de diferentes dispositivos. } \\
\text { O LMS possui integração com o MICROSOFT OFFICE COMMUNICATION SERVER AND LYNC, } \\
\text { que combina em um único software mensagens instantâneas, vídeo conferência e telefonia VoIP. }\end{array}$ \\
\hline TIDIA-AE & $\begin{array}{l}\text { No TIDIA-AE a ênfase é dada ao gerenciamento de cursos e atividades de aprendizagem. A } \\
\text { ideia é fornecer um arcabouço de ferramentas que ajudam alunos, professores e pesquisado- } \\
\text { res em suas ações. Assim, os usuários podem criar um portal que reúna suas necessidades de } \\
\text { aprendizagem por meio de um conjunto de ferramentas. }\end{array}$ \\
\hline TELEDUC & $\begin{array}{l}\text { O TELEDUC foi desenvolvido de forma participativa, ou seja, todas as suas ferramentas foram } \\
\text { idealizadas, projetadas e depuradas segundo necessidades relatadas por seus usuários. Com isso, } \\
\text { ele apresenta algumas vantagens com relação à facilidade de uso, à flexibilidade e ao conjunto } \\
\text { de funcionalidades disponível. }\end{array}$ \\
\hline WEBAULA LMS & $\begin{array}{l}\text { No WEBAULA a ênfase é dada no fornecimento de interfaces mais intuitivas, na compatibili- } \\
\text { dade com diferentes navegadores e na integração com redes as sociais (tais como FACEBOOK, } \\
\text { TWEETER e LINKEDIN). }\end{array}$ \\
\hline
\end{tabular}

Fonte: Elaborada pelo autor. 
Quadro 18 - LMSs: Funcionalidades de organização

\begin{tabular}{|l|l|}
\hline Funcionalidades & Descrição \\
\hline \hline Definição de cursos & $\begin{array}{l}\text { Permite que os professores definam os cursos que serão apoiados pelo LMS. Em geral, para cada } \\
\text { curso, o LMS cria um página web, que funciona como um portal com ferramentas e recursos de } \\
\text { apoio ao desenvolvimento do curso. Em alguns LMSs, nesta página, o professor também pode } \\
\text { organizar a estrutura do curso. }\end{array}$ \\
\hline $\begin{array}{l}\text { Gerenciamento dos par- } \\
\text { ticipantes }\end{array}$ & $\begin{array}{l}\text { Permite que os professores adicionem e gerenciem os participantes dos cursos dos quais são } \\
\text { responsáveis. Os papéis que cada participante pode assumir depende do LMS em questão, mas } \\
\text { geralmente incluem alunos, assistentes/monitores e professores. }\end{array}$ \\
\hline $\begin{array}{l}\text { Acompanhamento dos } \\
\text { eventos }\end{array}$ & $\begin{array}{l}\text { Permite melhor acompanhar os eventos relacionados ao curso, tais como datas de provas, prazos } \\
\text { para entrega de atividades, dentre outros. Estão relacionadas a ferramentas como calendário, } \\
\text { atividades recentes e notificaçôes. }\end{array}$ \\
\hline $\begin{array}{l}\text { Acompanhamento do do } \\
\text { progresso dos alunos }\end{array}$ & $\begin{array}{l}\text { Permite que os professores e monitores registrem e acompanhem o progresso dos alunos e } \\
\text { que os alunos acompanhem o seu próprio progresso ao longo do curso. Estão relacionadas a } \\
\text { ferramentas como quadro de notas e relatórios de desempenho. }\end{array}$ \\
\hline
\end{tabular}

Fonte: Elaborada pelo autor.

Quadro 19 - LMSs: Funcionalidades de conteúdo

\begin{tabular}{|l|l|}
\hline Funcionalidades & Descrição \\
\hline \hline $\begin{array}{l}\text { Disponibilização de } \\
\text { conteúdo }\end{array}$ & $\begin{array}{l}\text { Presente em todos os LMSs identificados, permite que os responsáveis por um curso adicionem } \\
\text { conteúdos à página do curso, para que todos os participantes do curso possam acessá-los. }\end{array}$ \\
\hline $\begin{array}{l}\text { Repositório de con- } \\
\text { teúdo }\end{array}$ & $\begin{array}{l}\text { Alguns LMSs permitem que cada usuário possa manter um repositório pessoal de conteúdos, } \\
\text { podendo compartilhá-lo individualmente com outros usuários, com todos os participantes de } \\
\text { um curso ou com outras ferramentas do LMS. }\end{array}$ \\
\hline Produção de conteúdo & $\begin{array}{l}\text { Alguns LMSs também disponibilizam funcionalidades para produção de conteúdo, como edito- } \\
\text { res de texto e ferramentas para elaboração de slides de aula. }\end{array}$ \\
\hline
\end{tabular}

Fonte: Elaborada pelo autor.

identificadas: (i) definição de atividades; (ii) execução de atividades; e (iii) avaliação dos alunos na realização de atividades. Tais funcionalidades são descritas no Quadro 20.

Quadro 20 - LMSs: Funcionalidades de atividades

\begin{tabular}{|l|l|}
\hline Funcionalidades & Descrição \\
\hline \hline Definição de atividades & $\begin{array}{l}\text { Permite que os responsáveis pelo curso definam atividades a serem realizadas pelos alunos, } \\
\text { especificando o tipo de atividade, prazo máximo para o término e outras propriedades. Tais } \\
\text { propriedades variam de acordo com o tipo de atividade e o LMS em questão. }\end{array}$ \\
\hline Execução de atividades & $\begin{array}{l}\text { Apoiam a execução de atividades por parte dos alunos, sejam elas individuais ou em grupo. } \\
\text { Incluem ferramentas de submissão de arquivos, testes objetivos, editores de texto, dentre outros. }\end{array}$ \\
\hline $\begin{array}{l}\text { Avaliação dos alunos na } \\
\text { realização de atividades }\end{array}$ & $\begin{array}{l}\text { Permite que os responsáveis pelo curso avaliem o desempenho dos alunos na realização das } \\
\text { atividades e forneçam um feedback a eles. Podem incluir ferramentas que contabilizam as res- } \\
\text { postas corretas em questionários, permitem a atribuição de notas às atividades, permitem a } \\
\text { adição de comentários de feedback aos alunos, dentre outras. }\end{array}$ \\
\hline
\end{tabular}

Fonte: Elaborada pelo autor.

Por fim, as funcionalidades de comunicação estão relacionadas à interação entre os participantes de um curso. Três funcionalidades principais de comunicação foram identificadas: (i) avisos e comunicados; (ii) discussões abertas; (iii) conversas privadas. Tais funcionalidades são descritas no Quadro 21.

Apesar dessa importância das funcionalidade identificadas e categorizadas, o ensino de programação ainda é pouco apoiado por LMSs. Trabalhos de pesquisa que discutem esse problema são apresentados nas próximas seções. 
Quadro 21 - LMSs: Funcionalidades de comunicação

\begin{tabular}{|l|l|}
\hline Funcionalidades & Descrição \\
\hline Avisos e comunicados & $\begin{array}{l}\text { Permite que os responsáveis pelo curso emitam avisos e comunicados importantes relacionados } \\
\text { ao curso para todos os participantes. Incluem ferramentas de avisos e notificações. }\end{array}$ \\
\hline Discussões abertas & $\begin{array}{l}\text { Permite que os participantes do cursos compartilhem e discutam sobre dúvidas e outros assuntos } \\
\text { relacionados ao curso em um espaço em que todos possam participar. Incluem ferramentas de } \\
\text { fóruns e outras similares. }\end{array}$ \\
\hline Conversas privadas & $\begin{array}{l}\text { Permite que os alunos comuniquem-se particularmente com um professor/monitor, com outros } \\
\text { alunos ou grupos de trabalho. Incluem ferramentas de mensagens e bate-papo. }\end{array}$ \\
\hline
\end{tabular}

Fonte: Elaborada pelo autor.

\subsubsection{LMSs no ensino de programação}

Apesar das funcionalidades oferecidas pelos LMSs apoiarem o processo de aprendizagem em geral, a maioria desses sistemas não são, por padrão, desenvolvidos de maneira adequada para atender às demandas das disciplinas de computação (em especial, programação) (RÖSSLING et $a l ., 2010)$. Nesta direção, Rößling et al. (2008) propõem o aprimoramento dos LMSs, definindo o conceito de sistema de gestão da aprendizagem estendido para computação (Computing Augmented Learning Management System - CALMS). Um CALMS é um LMS que, além das suas funcionalidades de propósito geral, possui como componentes especializados no apoio ao ensino de computação. Basicamente, os tipos de sistemas que podem ser considerados como componentes de um CALMS consistem em:

- Ferramentas pedagógicas: Fornecem funcionalidades pedagógicas que vão além daquelas habitualmente apoiadas por um LMS típico. Incluem ferramentas colaborativas para apoiar o desenvolvimento de projetos em grupos, ferramentas de autoria para apoiar o desenvolvimento rápido e fácil de materiais didáticos e exercícios, dentre outras.

- Ferramentas de avaliação para trabalhos e exercícios de programação: Tais ferramentas, assim como os LMSs de propósito geral, permitem que os professores disponibilizem trabalhos e exercícios aos alunos e gerenciem o recebimento dos mesmos. No entanto, o apoio de tais ferramentas vai além do recebimento de trabalhos, podendo fornecer, dentre outras funcionalidades, subsídios para a avaliação automática. Em síntese, pelo menos dois tipos de sistemas podem ser identificados: (1) ferramentas de avaliação automática para trabalhos de programação, que apoiam a avaliação dos programas desenvolvidos pelos alunos; e (2) ferramentas que avaliam o conhecimento teórico dos alunos em tópicos específicos.

- Ferramentas de visualização de programas: Fornecem funcionalidades semelhantes às de uma ferramenta de depuração, mas com propósito de ilustrar a execução de programas, permitindo que os alunos entendam melhor o comportamento dos mesmos. Em geral, uma ferramenta de visualização de programa precisa traduzir, analisar e interpretar os comandos e as operações da linguagem de programação em questão, cobrindo aspectos 
Capítulo 3. Ferramentas de avaliação, sistemas de gerenciamento de aprendizagem e arquiteturas de

como declarações e pesquisa de variáveis, métodos de declaração e invocação, passagem de parâmetros, avaliação de expressões, e assim por diante.

- Ferramentas de visualização de algoritmos: Fornecem animações que ilustram os passos dos algoritmos sendo estudados, permitindo que os alunos tenham uma melhor compreensão dos mesmos. Ao contrário da visualização de programas, que ilustra os comandos e variáveis, na visualização de algoritmos são ilustradas as estruturas/objetos e como elas são modificadas durante a execução do algoritmo. Um exemplo seria uma animação que ilustra um vetor de números e simula as modificações nos valores do vetor durante a execução de um algoritmo de ordenação.

Em outro trabalho, Rößling et al. (2010) enumeraram alguns requisitos específicos da área de computação e necessidades especiais dos próprios professores em cursos de programação que, geralmente, não são implementados por padrão pelos LMSs. Tais requisitos e necessidades são (RÖSSLING et al., 2010):

- Habilidade de integrar visualizações e simulações dinâmicas de algoritmos e estruturas de dados.

- Apoio ao oferecimento de trabalhos extraclasse que solicitam aos alunos a submissão de código (opcionalmente com uma avaliação automática integrada).

- Apoio à disponibilização de exemplos de código, os quais os alunos possam facilmente copiar para suas áreas de trabalho e realizar experimentos.

- Apoio à distribuição dos alunos em grupos ou equipes para auxiliar, por exemplo, a realização de exercícios práticos de programação.

- Apoio a discussões focadas em materiais didáticos, sem a necessidade de referências extensas a textos base.

- Facilidade na utilização de código fonte em todas as entradas como, por exemplo, em fóruns ou blogs, com destaque sintático apropriado.

- Apoio a subáreas específicas da computação, tais como linguagens formais, modelagem e simulações.

Nesta mesma direção, Brusilovsky et al. (2014) realizaram uma pesquisa de opinião com professores em Ciência da Computação e identificaram que uma das principais dificuldades encontradas por eles em adotar ferramentas para o ensino de programação é a integração dessas ferramentas com os LMSs das instituições em que os professores atuam. Outros problemas apontados pelos professores e que também podem ser mitigados por meio da integração dessas ferramentas em LMSs são a dificuldade em encontrar ferramentas que estejam disponíveis 
para serem utilizadas e a dificuldade em customizar as ferramentas para se ajustarem às suas necessidades locais.

Brusilovsky et al. (2014) também investigaram os tipos de ferramentas para o ensino de programação que os professores gostariam que estivessem disponíveis nos LMSs para utilizarem em seus cursos. Os tipos de ferramentas mais mencionados foram: (i) ferramentas de visualização de programas e algoritmos; (ii) ferramentas de avaliação para trabalhos de programação; (iii) ferramentas de apoio à condução de exercícios simples de codificação; (iv) ferramentas de apoio à programação e avaliação em pares.

Por fim, Sirkiä e Haaranen (2015) descrevem os desafios encontrados em disponibilizar ferramentas para o ensino de programação em vários LMSs. Tais dificuldades são:

- Interoperabilidade: Na maioria das vezes, as universidades e demais instituições de ensino possuem suas próprias ferramentas, integradas aos seus LMSs. Os problemas surgem quando um professor de uma instituição se interessa em utilizar uma ferramenta de outra instituição e não há maneira alguma de utilizá-la em outros LMSs. A interoperabilidade tenta resolver estes problema, permitindo o compartilhamento de ferramentas. Isto geralmente é feito criando interfaces que fornecem acesso às funcionalidades das ferramentas a vários LMSs.

- Extensibilidade: Idealmente, seria importante que novas ferramentas pudessem ser criadas a partir das existentes, sem a necessidade de se preocupar com os LMSs que disponibilizam as funcionalidades destas ferramentas.

- Aprendizagem analítica: A realização de pesquisas sobre as atividades de aprendizagem on-line exigem registrar as ações dos alunos quando interagem com as ferramentas. Apesar da tarefa de registrar atividades parecer trivial no início, ela se torna cada vez mais complexa quando diferentes LMSs e ferramentas estão envolvidos.

- Escalabilidade: A escalabilidade nos LMSs também é uma preocupação importante. Refere-se à capacidade de lidar com uma grande quantidade de solicitações simultâneas.

- Descoberta: Apesar de existir em várias ferramentas disponíveis gratuitamente, ainda é uma tarefa difícil para a maioria dos professores descobrirem e explorarem as ferramentas que são relevantes.

Apesar dos desafios apresentados, algumas propostas visando a integração de ferramentas externas em LMSs podem ser encontradas, as principais são sintetizadas a seguir.

\subsubsection{Introdução de ferramentas externas em LMSs}

Nesta seção, são sintetizadas as principais propostas identificadas na literatura que visam a integração de ferramentas externas, em especial ferramentas para o ensino de programação, em 
LMSs.

\subsubsection{Arquitetura SOA de Amelung, Krieger e Rosner (2011)}

Dentre os trabalhos que visam a integração de ferramentas externas em LMSs, encontrase o trabalho de Amelung, Krieger e Rosner (2011), no qual foi desenvolvida uma arquitetura orientada a serviços (Service-Oriented Architecture - SOA) a fim de permitir que programas submetidos em LMSs possam ser automaticamente verificados por ferramentas externas. $\mathrm{Na}$ Figura 21 é ilustrada uma visão geral da arquitetura. As ferramentas externas são implementadas em serviços independentes, chamados backends. Cada backend implementa um método específico de verificação para programas em uma determinada linguagem. Por exemplo, o backend KEYWORDS executa os programas com um conjunto de valores de entrada e verifica se a saída contém um conjunto de palavras-chave esperadas.

Figura 21 - Arquitetura SOA de Amelung, Krieger e Rosner (2011)

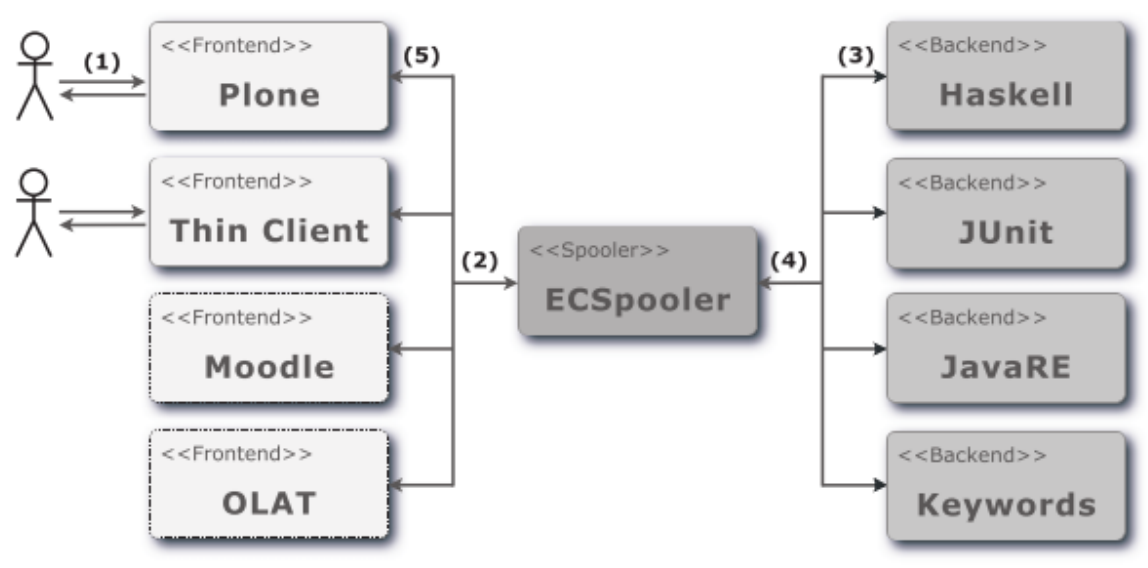

Fonte: Amelung, Krieger e Rosner (2011).

Por outro lado, os LMSs atuam como serviços consumidores, os quais são chamados de frontend. As principais funções do frontend são armazenar os trabalhos e submissões, gerenciar os prazos de submissão e disponibilizar os resultados aos alunos.

Para habilitar o acesso uniforme dos frontends aos backends e evitar muitas conexões ponto a ponto, foi introduzido um terceiro elemento, chamado spooler. Semelhante a um spooler de impressão, ele gerencia uma fila de verificações, oferecendo as seguintes funções: (1) adição de uma nova verificação a ser realizada por um backend; (2) obtenção dos resultados de uma verificação; (3) visualização de informações de status, tais como backends disponíveis, número de verificações na fila, entre outros.; (4) adição e remoção de backends; (5) obtenção das entradas requeridas para a verificação com um determinado backend; e (6) obtenção das opções disponíveis para um determinado verificador. 


\subsubsection{Sistema de gestão de aprendizagem $A+$}

Em outro trabalho, Karavirta, Ihantola e Koskinen (2013) desenvolveram um LMS orientado a serviços, projetado para que várias ferramentas de apoio à condução e avaliação de exercícios de programação possam ser integradas a ele. $\mathrm{Na}$ arquitetura do $\mathrm{A}+$, as ferramentas são disponibilizadas como serviços de exercícios, os quais podem prover ao LMS as seguintes funcionalidades:

- Descrição de exercícios: A descrição dos exercícios é armazenada nos serviços de exercícios e pode ser recuperada pelo A+ por meio de uma URL.

- Avaliação síncrona das soluções: Consiste em avaliações automáticas que podem ser processadas durante um requisição simples. Alguns exemplos de exercícios que podem ser avaliados de forma síncrona pelos serviços de exercícios do A+ incluem questionários de múltipla escolha ou exercícios de programação simples com um tempo de execução limitado.

- Avaliação assíncrona das soluções: consiste em avaliações automáticas que levam mais tempo para serem processadas. Ocorre em duas fases: (i) na fase 1, o aluno requisita um exercício do A+ e obtém um applet, que deve ser utilizado para completar o exercício; (ii) na fase 2, o aluno submete a sua solução por meio do applet, que realiza a avaliação e envia os resultados para o serviço de exercícios associados.

- Avaliação estática: consiste em avaliações manuais realizadas pelo professor. Também consiste em duas fases: (i) na fase 1, os alunos obtêm as instruções dos exercícios e submetem a sua solução ao A+; (ii) em um outro momento, na fase 2, o professor autoriza no A+o envio de submissões para um determinado serviço de exercícios e, por meio dele, obtém e avalia as soluções, sendo que os resultados são enviados posteriormente pelo serviço ao A+.

\subsubsection{Arquitetura GLUE!}

Uma outra iniciativa que visa a integração de múltiplas ferramentas externas em múltiplos LMSs é a arquitetura GLUE! (Group Learning Uniform Environment), proposta por Alario-Hoyos et al. (2013). A arquitetura GLUE! permite o acesso a diferentes ferramentas colaborativas, tais como GoogleDocs (Google, 2017), MEDIAWIKI (Wikimedia Foundation, 2017) e DoodLE (Doodle, 2017), por meio de diferentes LMSs.

Na Figura 22 é ilustrada uma visão geral da arquitetura. De forma semelhante à arquitetura proposta por Amelung, Krieger e Rosner (2011), a GLUE! consiste em uma arquitetura em três camadas formadas por serviços. Assim, LMSs e ferramentas tornam-se interoperáveis por meio de uma camada de software intermediária e um conjunto de adaptadores. As camadas à direita e à esquerda da GLUE! fazem uso do padrão adaptador para encapsular os LMSs e as 
Capítulo 3. Ferramentas de avaliação, sistemas de gerenciamento de aprendizagem e arquiteturas de 76 software

ferramentas. Os seus contratos específicos e heterogêneos são adaptados em dois contratos intermediários, genéricos e homogêneos: o contrato de integração GLUE! para LMSs e o contrato de integração GLUE! para ferramentas.

Figura 22 - Arquitetura GLUE!

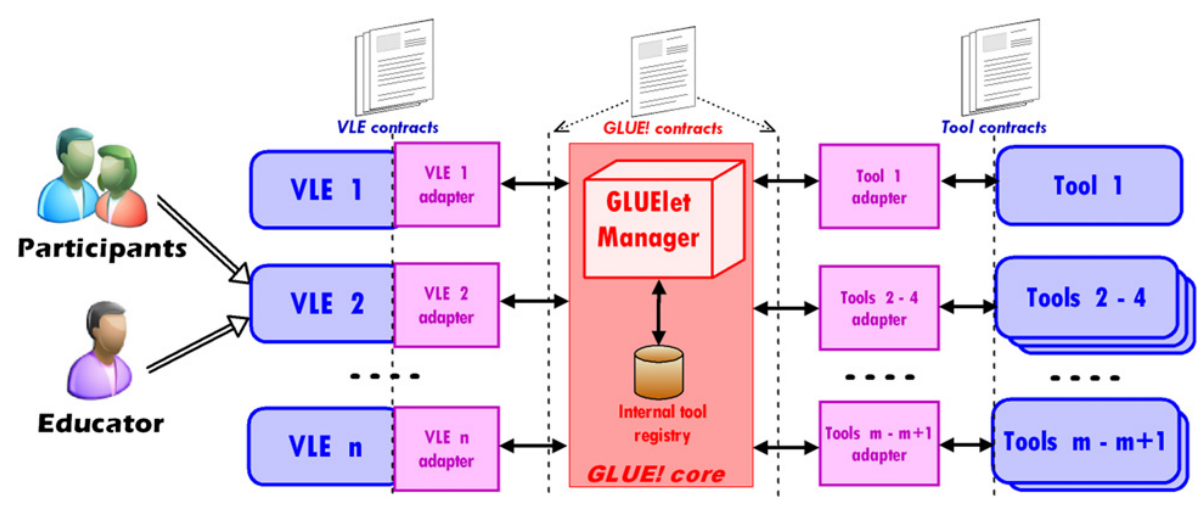

Fonte: Alario-Hoyos et al. (2013).

A arquitetura também possui uma camada intermediária de software, chamada GLUECORE, que realiza a integração dos contratos de integração GLUE!. A ideia da GLUECORE é dissociar os adaptadores de ferramentas e de LMSs, assumindo a maioria das funcionalidades de integração. Isto facilita a implementação independente dos adaptadores e reduz os esforços em seus desenvolvimentos.

A arquitetura GLUE! provê as funcionalidades para criar, configurar, receber, atualizar e deletar instâncias de ferramentas, gerenciando o ciclo de vida das ferramentas colaborativas. Este ciclo de vida pode ser combinado com as funcionalidades dos LMSs para o gerenciamento de grupos e atividades, a fim de associar cada instância de ferramenta com cada grupo que participa de uma dada atividade. Assim, os alunos que fazem parte de um mesmo grupo podem colaborar, compartilhando a mesma instância.

\subsubsection{Protótipo de arquitetura para integração de conteúdos de aprendizagem inteligentes}

Brusilovsky et al. (2014) também propuseram uma arquitetura em alto nível para integrar diferentes ferramentas externas (referenciadas pelos autores como conteúdos de aprendizagem inteligentes) em vários LMSs (os quais eles chamam de plataformas de entrega). Nesta arquitetura, as funcionalidades críticas necessárias para apoiar o uso de conteúdos de aprendizagem inteligentes foram decompostas em três camadas: (i) a camada de entrega, que é composta por vários LMSs e permite que os alunos acessem os conteúdos sendo disponibilizados; (ii) a camada de aplicação, que é composta por servidores de conteúdos, disponibilizando diferentes tipos de conteúdos (ferramentas); e (iii) a camada de dados, que hospedam todos os tipos de sistemas para armazenamento e registro da aprendizagem, coletando e armazenando as informações sobre as ações e progresso dos alunos. 
Os conteúdos de aprendizagem inteligentes devem ser hospedados em servidores de conteúdos independentes dos servidores que hospedam as plataformas de entrega. Cada servidor de conteúdo deve poder hospedar vários conteúdos e disponibilizar qualquer item requisitado pela plataforma de entrega. A separação entre os servidores de conteúdo e os servidores das plataformas de entrega deve ser baseada em uma interface de comunicação padronizada.

A arquitetura também provê o apoio à autoria. Dois tipos de autoria são previstas: (i) a autoria de conteúdo, permitindo que os professores estendam os conteúdos, adicionando novos componentes ou clonando e editando os itens existentes de um conteúdo; e (ii) a autoria de cursos, permitindo que os professores organizem os conteúdos que desejam utilizar em seus cursos, adequando o apoio às necessidades únicas de um curso.

Por fim, a arquitetura também visa facilitar a obtenção de dados sobre a utilização de conteúdos pelos alunos, propondo a adoção de sistemas independentes para o armazenamento e o registro da aprendizagem.

\subsubsection{Acos server}

Sirkiä e Haaranen (2015) desenvolveram um sistema que atua como um repositório de ferramentas externas (também referenciadas pelos autores como conteúdos de aprendizagem inteligentes), tornando-as mais fáceis de serem localizadas e disponibilizadas nos LMSs. Assim, a arquitetura do sistema ACOS consiste em um módulo servidor principal e três elementos: protocolos, tipos de conteúdos e pacotes de conteúdos.

Os desenvolvedores podem implementar novos protocolos, novos tipos de conteúdos e adicionar mais conteúdos aos tipos de conteúdos existentes. Estes elementos são separados em uma forma que, por exemplo, desenvolvedores criando novos conteúdos não precisam se preocupar com os protocolos.

Os professores veem o sistema ACOs como um repositório de exercícios, podendo navegar e testar os conteúdos (ferramentas) existentes. Uma vez que o professor decide utilizar um conteúdo, ele pode copiar o endereço URL do conteúdo e inseri-lo no LMS.

Por fim, os alunos podem visualizar as atividades selecionadas pelo professor, sem ter ciência da tecnologia por trás dos exercícios.

\subsubsection{Outras iniciativas}

Além dos trabalhos descritos anteriormente, foram identificadas outras iniciativas que visam a integração de ferramentas externas em LMSs, especialmente ferramentas de avaliação para trabalhos de programação. No trabalho de Georgouli e Guerreiro (2010), por exemplo, são descritos os esforços que os autores tiveram em integrar a ferramenta MooshAK (LEAL; SILVA, 2003) no ambiente CLAROLINE (Claroline Community, 2012). 
Capítulo 3. Ferramentas de avaliação, sistemas de gerenciamento de aprendizagem e arquiteturas de 78 software

Suleman (2008), por sua vez, descreve o desenvolvimento da ferramenta de avaliação Automatic MAKeR e a sua integração no LMS SAKAi (Sakai Project, 2012). Na proposta de Suleman (2008), a comunicação entre a AUTOMATIC MAKER e o S AKAI é realizada por meio de webservices.

Em outro estudo, Ozel e Kaya (2012) desenvolveram um website baseado no MoodLE, incluindo um compilador online para facilitar o processo de avaliação. De forma similar ao MOODLE, o professor pode visualizar as submissões realizadas pelos alunos para o trabalho em questão. No entanto, o website desenvolvido por Ozel e Kaya (2012) permite que o professor também visualize e compile o código fonte dos programas online.

\subsubsection{Limitações}

Apesar da existência de várias iniciativas visando a integração, várias limitação também podem ser identificadas. Tais limitações são sintetizadas no Quadro 22. Por exemplo, a maioria dos trabalhos identificados investiga a integração de uma ferramenta específica em um LMS específico. Assim, os problemas surgem quando o professor cuja instituição adota um determinado LMS deseja utilizar uma ferramenta que só está disponível para outro LMS. A solução implementada no LMS A+, por exemplo, permite que várias ferramentas de avaliação possam ser integradas a ele, mas não é aplicável aos demais LMSs existentes.

Também existem trabalhos que visam uma integração de diferentes ferramentas em muitos LMSs. No entanto, em geral, eles consistem em arquiteturas modelos mais abstratos e em alto nível, ou não exploram certas especificidades das ferramentas de avaliação para trabalhos de programação. O protótipo arquitetural proposto por Brusilovsky et al. (2014) é um exemplo de trabalho que propõe essa integração muitos para muitos, mas que consiste apenas em uma solução conceitual, em alto nível e não específica para ferramentas de avaliação. A arquitetura proposta por Amelung, Krieger e Rosner (2011) também carece de alguns detalhes e não propõe a integração com ferramentas de avaliação, mas sim com verificadores individuais. Um ferramenta de avaliação pode combinar diferentes tipos de verificadores e pontuar o trabalhos dos alunos com base em um esquema de avaliação que considera os diferentes tipos de verificação. Por fim, a arquitetura GLUE! fornece um projeto arquitetural mais detalhado, porém, para ferramentas colaborativas.

Considerando tais limitações, este trabalho de doutorado tem como principal objetivo o desenvolvimento de uma arquitetura que permite a integração de diferentes ferramentas de avaliação para trabalhos de programação em LMSs. Para isto, alguns conceitos relacionados à arquitetura de software foram considerados. Tais conceitos são apresentados a seguir. 
Quadro 22 - Integração de ferramentas em LMSs: Limitações dos trabalhos identificados

\begin{tabular}{|l|l|}
\hline Trabalhos relacionados & Limitações \\
\hline \hline $\begin{array}{l}\text { Arquitetura SOA de Amelung, Krieger } \\
\text { e Rosner (2011) }\end{array}$ & $\begin{array}{l}\text { Arquitetura relativamente em alto nível. Integra verificadores e não ferramentas } \\
\text { de avaliação. }\end{array}$ \\
\hline A+ & $\begin{array}{l}\text { Consiste apenas em um modelo conceitual em alto nível. Integração ocorre so- } \\
\text { mente com o LMS A+. Funcionalidades como definição de trabalhos e avalia- } \\
\text { ção manual pelo professor precisam ser acessadas diretamente na ferramenta de } \\
\text { avaliação. }\end{array}$ \\
\hline Arquitetura GLUE! & Integra ferramentas colaborativas e não ferramentas de avaliação. \\
\hline $\begin{array}{l}\text { Protótipo arquitetural de Brusilovsky et } \\
\text { al. }(2014)\end{array}$ & $\begin{array}{l}\text { Integra ferramentas externas em geral, não tratando certas especificidades das } \\
\text { ferramentas de avaliação. }\end{array}$ \\
\hline Acos Server & Arquitetura relativamente em alto nível. Não realiza, de fato, uma integração. \\
\hline Outros & Integram uma única ferramenta em um único LMS. \\
\hline
\end{tabular}

Fonte: Elaborada pelo autor.

\subsection{Arquitetura de software}

Uma arquitetura de software é uma estrutura (ou um conjunto de estruturas) de um sistema computacional (ou de um programa) que compreende elementos de software, as propriedades externamente visíveis destes elementos e os relacionamentos entre eles (BASS; CLEMENTS; KAZMAN, 2012).

Bass, Clements e Kazman (2012) enfatizam que uma arquitetura deve conter as seguintes informações:

- A natureza dos elementos: indicando o que a separação entre os elementos representa. Por exemplo, objetos diferentes, tarefas diferentes, funções diferentes, divisão de trabalho no projeto, conjunto de processos a serem executados em tempos de execução diferentes, entre outros.

- As responsabilidades dos elementos: indicando o que os elementos fazem e quais suas funções no sistema.

- A significância das conexões: indicando o que representam as conexões entre os elementos, quais são os mecanismos para a comunicação entre eles e quais informações fluem por meio destes mecanismos. Por exemplo, as conexões podem representar que um elemento se comunica com outro elemento, controla outro elemento, envia dados a outro elemento, usa outro elemento, invoca outro elemento, sincroniza com outro elemento, compartilha informações privadas com outro elemento ou alguma combinação destas e outras relações.

- A significância do layout: indicando o que representa a disposição dos elementos no layout da arquitetura.

Por fim, as propriedades externamente visíveis podem incluir características de desempenho, tolerância a falhas, recursos compartilhados, dentre outros (BASS; CLEMENTS; KAZMAN, 2012). 
Capítulo 3. Ferramentas de avaliação, sistemas de gerenciamento de aprendizagem e arquiteturas de 80 software

Três são as principais finalidades das arquiteturas de software (BASS; CLEMENTS; KAZMAN, 2012):

- Facilitar a comunicação: Uma arquitetura representa uma abstração comum de um sistema. Assim, todos os envolvidos podem utilizá-la como uma base para entendimento comum.

- Registrar decisões de projeto: Uma arquitetura de software manifesta as decisões de projeto a respeito de um sistema. Assim, a arquitetura permite racionalizar sobre o sistema e os recursos necessários para instanciá-lo.

- Modelo para construção de sistemas semelhantes: Uma arquitetura é um modelo relativamente pequeno que pode ser aplicado em vários sistemas. Assim, a arquitetura pode ser utilizada como uma forma de reúso em larga escala.

Além desses conceitos e definições, o termo arquitetura de software também emerge como uma disciplina que envolve o estudo de estruturas de sistemas computacionais (BOURQUE; FAIRLEY, 2014). Tal disciplina define vários conceitos úteis durante o projeto arquitetural de um sistema. Alguns desses conceitos são sintetizados nas seções seguintes.

\subsubsection{Visões arquiteturais}

Os sistemas de software atuais, em geral, são bastante complexos, de forma que é difícil descrever todas as características de sua arquitetura em uma única representação (ROZANSKI; WOODS, 2011). Dessa forma, as visões arquiteturais são diferentes representações das estruturas arquiteturais de um sistema, que permitem descrevê-las considerando diferentes pontos de vista (BASS; CLEMENTS; KAZMAN, 2012).

Existem vários trabalhos propondo diferentes modelos de visões arquiteturais. No entanto, Bass, Clements e Kazman (2012) sugerem que, em geral, cada uma das visões propostas por estes trabalhos pode ser associada a um dos três seguintes grupos:

- Estruturas de módulos: Definem como o sistema será estruturado por meio de um conjunto de unidades funcionais.

- Estruturas de componentes e conectores: Definem o comportamento dos elementos do sistema (componentes) em tempo de execução e as interações entre eles (conectores).

- Estruturas de alocação: Definem como o sistema irá se relacionar com os elementos do ambiente que não são software (CPUs, sistemas de arquivo, rede, equipes de desenvolvimento, entre outros.). 
Dentre os trabalhos envolvendo visões arquiteturais, Kruchten (1995) propõe o modelo "4+1", que segundo Bass, Clements e Kazman (2012) é a base do processo RUP (IBM staff, 2005). O modelo sugere a descrição arquitetural considerando cinco visões:

- Visão lógica: Está relacionada com os requisitos funcionais do sistema, ilustrando quais as funcionalidades que o sistema deve prover aos usuários (estrutura de módulos).

- Visão de processos: Está relacionada com os aspectos dinâmicos do sistema, ilustrando o comportamento do sistema em tempo de execução (estrutura de componentes e conectores).

- Visão de implementação: Está relacionada ao gerenciamento da aplicação, ilustrando como os módulos da aplicação são organizados (estrutura de alocação).

- Visão de implantação: Está relacionada aos componentes físicos que envolvem a aplicação, ilustrando as características dos componentes físicos necessários para executar a aplicação e as conexões entre eles (estrutura de alocação).

- Visão de casos de uso: Reúne os elementos das demais visões em um conjunto de casos de uso ou de cenários.

\subsubsection{Estilos arquiteturais}

Um estilo arquitetural, por sua vez, especifica quais os tipos de elementos e de relações uma arquitetura contempla, junto com um conjunto de restrições definindo como os elementos e relações podem ser utilizados (BASS; CLEMENTS; KAZMAN, 2012). Segundo Pressman e Maxim (2014), a maioria das arquiteturas desenvolvidas podem ser categorizadas em um dos seguintes estilos arquiteturais:

- Arquitetura centrada em dados: Um componente de armazenamento de dados reside no centro desta arquitetura e os demais componentes adicionam, atualizam, deletam ou realizam qualquer outra modificação nos dados armazenados neste componente.

- Arquitetura de fluxo de dados: Dados de entrada são transformados por meio de um série de componentes computacionais ou manipulativos, resultando em dados de saída.

- Arquitetura de chamada e retorno: São sub-categorizadas em dois sub-estilos:

- Arquitetura de programa principal/subprograma: As funcionalidades do sistema são decompostas em uma hierarquia de controle em que um programa "principal" invoca um número de programas componentes que, por sua vez, podem invocar outros programas componentes, e assim por diante.

- Arquitetura de chamada de procedimentos remotos: os componentes são distribuídos através de vários computadores na rede. 
Capítulo 3. Ferramentas de avaliação, sistemas de gerenciamento de aprendizagem e arquiteturas de 82 software

- Arquitetura orientada a objeto: Os componentes encapsulam dados e as operações que devem ser aplicadas para manipular esses dados. A comunicação e coordenação entre os componentes são realizadas por meio de envio de mensagens.

- Arquitetura em camadas: Um número de camadas é definido, realizando operações que se tornam progressivamente mais próximas do conjunto de instruções da máquina.

Dentre as arquiteturas de chamada de procedimentos remotos encontram-se as arquiteturas orientadas a serviços, as quais são sintetizadas a seguir.

\subsubsection{Arquitetura orientada a serviços}

Arquitetura orientada a serviços (Service-Oriented Architecture - SOA) é uma forma de desenvolver sistemas em que seus componentes são serviços autônomos (SOMMERVILLE, 2007), executando em computadores geograficamente distribuídos. Assim, SOA permite que sistemas de software possam ser construídos por meio da composição de vários serviços, sejam eles locais ou remotos, disponibilizados por diferentes provedores (SOMMERVILLE, 2007).

Utilizando protocolos padronizados e linguagens independentes, SOA também permite a integração de sistemas de software heterogêneos, provendo interoperabilidade entre eles (HEWITT, 2009). Outra vantagem de sistemas com SOA é a possibilidade de reúso no desenvolvimento de novas aplicações. Sistemas de software complexos podem ser desenvolvidos combinando serviços providos por outros sistemas (HEWITT, 2009).

Um tópico relevante relacionado à SOA é o desenvolvimento e disponibilização de webservices. Os webservices permitem que organizações disponibilizem por meio da web recursos computacionais ou informações que podem ser acessadas e utilizadas por outros sistemas (ERL, 2005). A comunicação com os webservices é estabelecida por meio de protocolos padronizados. Os principais padrões de SOA para web services são (SOMMERVILLE, 2007):

- SOAP (Simple Object Access Protocol): Padrão de troca de mensagens para a comunicação entre os serviços. Define os componentes essenciais e opcionais das mensagens.

- WSDL (Web Services Description Language): Padrão para definição da interface dos serviços. Define as operações disponibilizadas pelos serviços, incluindo nome das operações, parâmetros e seus tipos.

- UDDI (Universal Description, Discovery and Integration): Padrão para utilizado para descobrir a existência de um serviço. Define os provedores de serviços, os serviços providos, a localização da descrição do serviço, dentre outras informações.

- WS-BPEL (Web Services Business Process Execution Language): Padrão para uma linguagem de workflow. Define programas de processo que envolvem vários serviços diferentes. 


\subsubsection{Avaliação de arquiteturas de software}

Várias ferramentas e técnicas podem ajudar na análise e avaliação da qualidade de arquiteturas de software. Em geral, as técnicas podem ser classificadas em três categorias (BOURQUE; FAIRLEY, 2014):

- Revisões de projeto de software: técnicas informais e formalizadas para determinar a qualidade dos artefatos, como por exemplo, revisões arquiteturais, técnicas baseadas em cenários e rastreamento de requisitos.

- Análises estáticas: técnicas formais e semiformais para analisar arquiteturas sem a execução dos sistemas construídos a partir delas. Análises formais, por exemplo, utilizam modelos matemáticos que permitem predizer o comportamento do software.

- Simulação e prototipação: técnicas dinâmicas que permitem avaliar arquiteturas simulando cenários de execução com os sistemas construídos a partir delas ou com protótipos dos mesmos.

Em geral, as avaliações de arquiteturas de software visam verificar se uma arquitetura provê ao sistema (ou sistemas) que é construído a partir dela, atributos de qualidade desejados (BASS; CLEMENTS; KAZMAN, 2012). Tais atributos de qualidade podem ser discerníveis em tempo de execução (por exemplo, desempenho, segurança, disponibilidade, funcionalidade, usabilidade), ou não discerníveis em tempo de execução (por exemplo, modificabilidade, portabilidade, reusabilidade, testabilidade) (BOURQUE; FAIRLEY, 2014). Bass, Clements e Kazman (2012) também ressaltam que alguns atributos de qualidade relacionados ao ambiente de negócios (tempo para comercialização, relação custo/benefício, entre outros.) podem ser afetados pela arquitetura.

No entanto, existem atributos de qualidade que estão intrinsecamente relacionados à arquitetura. São eles (BASS; CLEMENTS; KAZMAN, 2012):

- Integridade conceitual: Garante que os conceitos e partes centrais do sistema trabalham harmonicamente, de forma coesa, como um todo. Os componentes ou módulos se integram e trabalham bem conjuntamente.

- Correção e completude: Garante que todos os requisitos do sistema e todas as restrições de recursos de tempo de execução possam ser satisfeitos.

- Capacidade de construção: Garante que o sistema possa ser construído por uma equipe disponível em um tempo satisfatório e possa estar aberto a determinadas mudanças durante o desenvolvimento.

Os conceitos de arquitetura descritos nesta seção foram considerandos durante o desenvolvimento da IMPACTLE, que é descrita no Capítulo 4. 
Capítulo 3. Ferramentas de avaliação, sistemas de gerenciamento de aprendizagem e arquiteturas de 84 software

\subsection{Considerações finais}

O principal objetivo deste trabalho é o desenvolvimento de uma arquitetura que permita a integração de diferentes ferramentas de avaliação para trabalhos de programação em LMSs. Assim, neste capítulo foram sintetizados os principais resultados de pesquisas realizadas a respeito desses sistemas.

Com relação às ferramentas de avaliação, um mapeamento sistemático foi realizado visando identificar as funcionalidades, características e tipos de avaliação que as ferramentas apoiam. A ideia foi verificar quais aspectos das ferramentas de avaliação impactam a sua integração com os LMSs e devem ser tratados pela solução proposta por este trabalho.

Por outro lado, um conjunto de LMSs e suas principais funcionalidades também foram analisados. O objetivo foi verificar que as funcionalidades das ferramentas de avaliação podem ser inseridas nos LMSs.

Ainda, trabalhos que discutem a falta de apoio em LMSs para o ensino de computação foram identificados e estudados. Algumas propostas que visam mitigar esse problema e suas limitações também foram descritas.

Com base nos levantamentos e estudos descritos neste capítulo, a arquitetura IMPACTLE foi desenvolvida visando mitigar as limitações encontradas nos trabalhos relacionados. A arquitetura é detalhada no próximo capítulo. 


\subsection{Considerações iniciais}

No Capítulo 3 foi discutida a importância da integração de diferentes ferramentas de avaliação em LMSs. Brusilovsky et al. (2014), por exemplo, apontam que a adaptação e integração de ferramentas em LMSs é uma das maiores dificuldades que os professores encontram em adotar e utilizar uma ferramenta de avaliação, uma vez que nem sempre o professor encontra a ferramenta desejada disponível no LMS adotado por ele ou pela sua instituição. Além disso, as ferramentas de avaliação para trabalhos de programação consistem em um dos tipos de ferramentas identificadas por Brusilovsky et al. (2014) como mais procuradas pelos professores. Algumas soluções visando aumentar a interoperabilidade entre LMSs e ferramentas externas vêm sendo propostas. No entanto, em geral, elas consistem apenas em modelos conceituais abstratos, não propõem uma integração com vários LMSs ou não tratam certas dificuldades específicas encontradas quando integrando ferramentas de avaliação.

Neste capítulo é apresentada e detalhada a arquitetura IMPACTLE, que consiste em uma solução para integrar diferentes ferramentas de avaliação para trabalhos de programação em vários LMSs. Na Seção 4.2 são apresentados os requisitos a partir dos quais a arquitetura foi projetada. Tais requisitos foram levantados com base na análise do problema discutido nos trabalhos relacionados. Por meio dos requisitos e da análise das ferramentas de avaliação, algumas decisões de projeto foram tomadas. Tais decisões são detalhadas na Seção 4.3. Na Seção 4.4 a arquitetura e seus componentes são descritos. Em seguida, a arquitetura foi formalizada seguindo o modelo arquitetural "4+1" proposto por Kruchten (1995) e a notação UML. Esta formalização é sintetizada na Seção 4.5. Por fim, a fim de validar a arquitetura, protótipos arquiteturais foram desenvolvidos para cada componente. O desenvolvimento destes protótipos é descrito na Seção 4.6. 


\subsection{Requisitos da arquitetura}

A fim de garantir que a arquitetura IMPACTLE consista em uma solução adequada, alguns requisitos foram levantados a partir da análise dos trabalhos relacionados (RÖSSLING et al., 2010; KARAVIRTA; IHANTOLA; KOSKINEN, 2013; BRUSILOVSKY et al., 2014; SIRKIÄ; HAARANEN, 2015). Assim, os principais requisitos que a arquitetura IMPACTLE deve satisfazer são:

- REQ1: A arquitetura deve fornecer uma estrutura que permite a integração de diferentes ferramentas de avaliação em vários LMSs. Independentemente do LMS adotado pelo professor ou pela instituição, alunos e professores devem ser capazes de acessar as funcionalidades das diferentes ferramentas de avaliação para trabalhos de programação ainda que interfaces, tipos de avaliação e outras características sejam distintas.

- REQ2: Ao integrar uma ferramenta de avaliação à estrutura da IMPACTLE, todos os LMSs previamente integrados devem ser capazes de acessar as funcionalidades da ferramenta. A ideia é reduzir o esforço na integração de ferramentas de avaliação em LMSs. Ao integrar uma ferramenta de avaliação em vários LMSs individualmente, o esforço cresce de acordo com o número de LMSs considerados. Por meio da arquitetura, o esforço é constante, consistindo em uma única integração à estrutura definida pela arquitetura.

- REQ3: Ao integrar um LMS à estrutura da IMPACTLE, este deve ter acesso a todas as ferramentas de avaliação previamente integradas. De forma análoga ao requisito REQ2, A ideia é reduzir o esforço na inclusão de ferramentas de avaliação em LMSs. Por meio da arquitetura, o esforço é constante, consistindo na construção de uma única extensão que acessa as funcionalidades das ferramentas de avaliação por meio da estrutura definida pela arquitetura.

- REQ4: Uma ferramenta de avaliação para trabalhos de programação não deve precisar de alterações para ser integrada. A necessidade de modificar uma ferramenta de avaliação pode tornar a sua integração inviável. Dificuldades podem surgir desde a indisponibilidade do código fonte da ferramenta de avaliação até a necessidade de manter duas versões da ferramenta de avaliação (uma versão principal e uma versão modificada).

- REQ5: As funcionalidades das ferramentas de avaliação para trabalhos de programação devem estar em consonância com as demais ferramentas que compõem o LMS. A ideia é que o tempo e esforço despendido pelos alunos e professores a fim de aprender a utilizar uma nova ferramenta de avaliação seja reduzido, uma vez que as suas funcionalidades estarão em consonância com o ambiente do LMS em que eles já estão habituados.

- REQ6: A estrutura da IMPACTLE deve permitir que as abordagens de avaliação propostas pelas ferramentas de avaliação sejam mantidas. Por exemplo, algumas ferramentas 
possuem características que apoiam a realização de maratonas de programação, outras a condução de exames com questões práticas de programação, outras a condução de atividades de teste em conjunto com programação, e assim por diante. A ideia é que estas características sejam mantidas utilizando tais ferramentas de avaliação são utilizadas por meio de um LMS.

- REQ7: Uma funcionalidade só deve ser disponibilizada aos alunos e professores nos LMSs quando a ferramenta de avaliação sendo considerada possuir essa funcionalidade. Tal requisito é necessário, uma vez que certas funcionalidades não estão presentes em todas as ferramentas. Assim, a arquitetura deve ser capaz de tratar essas diferenças em termos de funcionalidades para serem disponibilizadas de forma adequada aos alunos e professores nos LMSs.

A partir dos requisitos levantados, algumas decisões de projeto foram estabelecidas. Tais decisões são descritas a seguir.

\subsection{Decisões de projeto}

Nesta seção são discutidas algumas questões iniciais identificadas durante a proposição da arquitetura, as possíveis soluções e as decisões tomadas, visando atender os requisitos descritos na Seção 4.2.

\subsubsection{Funcionalidades redundantes entre os LMSs e as ferramentas de avaliação}

Uma das questões de projeto tratadas diz respeito às funcionalidades redundantes entre os LMSs e as ferramentas de avaliação. Basicamente, foi possível observar que algumas funcionalidades dos LMSs também poderiam ser encontradas em algumas ferramentas de avaliação. Entre tais funcionalidades destacam-se:

- Gerenciamento de cursos e alunos: Permite que os professores gerenciem informações sobre os cursos que estão ministrando e sobre os alunos que estão matriculados nestes cursos. Semelhantemente, os alunos podem visualizar as informações dos cursos que estão matriculados e editar as suas informações pessoais.

- Gerenciamento de atividades: Permite que os professores definam atividades (como trabalhos de programação) para os alunos matriculados em seus cursos, enquanto os alunos podem visualizar as informações das atividades definidas para os cursos em que estão matriculados. 
- Submissão eletrônica: Apoia a entrega das soluções dos alunos, podendo o professor configurar vários parâmetros, tais como o prazo máximo para a entrega e número máximo de submissões, entre outros.

- Repositório de arquivos: Permite armazenar os arquivos associados à definição das atividades e os arquivos submetidos pelos alunos como soluções para as atividades atribuídas a eles.

Para as quatro funcionalidades identificadas, as seguintes decisões de projeto eram possíveis:

- Utilizar somente os mecanismos fornecidos pelas ferramentas de avaliação: Esta decisão não foi adotada na arquitetura IMPACTLE. O principal problema é o fato de que estas funcionalidades não estão presentes em todas as ferramentas de avaliação. Se esta decisão fosse adotada, seria necessário adicionar às ferramentas de avaliação as funcionalidades faltantes, aumentando o esforço em integrar uma ferramenta de avaliação.

\section{- Utilizar ambos os mecanismos fornecidos pelos LMSs e pelas ferramentas de ava-} liação: Esta decisão também não foi adotada na arquitetura IMPACTLE. O principal problema é a necessidade de manter cópias dos dados e arquivos tanto nos LMSs como nas ferramentas de avaliação, favorecendo a presença de ambiguidades e inconsistência entre os dados. Por exemplo, quando um aluno submeter um código fonte para um trabalho de programação, este ficaria armazenado tanto no LMS como na ferramenta de avaliação. Ao matricular um aluno em um curso, essa informação deveria ser registrada tanto no LMS como na ferramenta de avaliação. Outra desvantagem é a necessidade de um maior tráfego de dados entre estes dois tipos de sistemas (LMS e ferramenta de avaliação), prejudicando características como desempenho e segurança.

- Utilizar somente os mecanismos fornecidos pelos LMSs: Esta foi a decisão adotada para a arquitetura IMPACTLE. A ideia é explorar as funcionalidades que cada tipo de sistema (LMS e ferramenta de avaliação) melhor oferece. De fato, todos os LMSs estudados oferecem estas funcionalidades e, em geral, fornecem um apoio adequado; por outro lado, nem todas as ferramentas de avaliação oferecem essas funcionalidades ou as oferecem de forma limitada.

Assim, na arquitetura IMPACTLE são atribuídas aos LMSs todas as funcionalidades de gerenciamento e submissão, enquanto às ferramentas de avaliação são atribuídas as funcionalidades relacionadas à verificação, pontuação e feedback sobre as soluções dos alunos para os trabalhos de programação. 


\subsubsection{Diferentes contextos de atividades de programação}

Na maioria das ferramentas de avaliação estudadas, um trabalho de programação consiste em um problema (questão) em que o aluno deve projetar um programa ou fragmento de código para resolvê-lo. No entanto, foi possível identificar que em algumas ferramentas um trabalho de programação pode ser composto por vários problemas (questões) de programação. Assim, o aluno somente completa o trabalho após fornecer sua solução (programa ou fragmento de código, dentre outros itens que podem ser requeridos) para cada uma das questões do trabalho.

Nesse sentido, a arquitetura IMPACTLE foi projetada considerando a segunda abordagem descrita, ou seja, que um trabalho de programação pode ser composto por várias questões de programação. Tal decisão foi tomada visando fornecer um melhor apoio aos contextos em que as ferramentas que também seguem essa abordagem apoiam. Tais contextos incluem a condução de exames (provas) com questões práticas de programação, maratonas de programação, trabalhos práticos em que os alunos devem fornecer uma solução considerando duas ou mais linguagens de programação (por exemplo, em uma disciplina de orientação a objetos, os alunos podem ser requeridos a apresentar para cada problema um código em Java e outro em C++), dentre outros.

Outra motivação para adotar esta abordagem é a possibilidade de utilizar mais de uma ferramenta de avaliação. Por exemplo, as ferramentas ProgTest e WEB-CAT consideram, durante a avaliação, os testes projetados pelos alunos para testarem seus programas. No entanto, a WEB-CAT possui a vantagem de avaliar a legibilidade e estilo do código dos alunos, enquanto a ProgTest possui como vantagem uma melhor avaliação dos testes dos alunos por meio de ferramentas e critérios de teste. Assim, em um trabalho de programação, o professor poderia criar duas questões: uma em que os alunos deveriam fornecer soluções em que seus programas tivessem uma boa legibilidade, correção e estilo (avaliados por meio da WEB-CAT) e outra em que os alunos deveriam melhorar os seus programas e testes segundo as técnicas e critérios de teste apoiados pela ProgTest.

Por fim, ressalta-se que os contextos em que um trabalho de programação consiste em um único problema (questão) podem ser apoiados associando apenas uma questão para cada trabalho de programação.

\subsubsection{Diferentes dados e artefatos de entrada}

Em geral, as diferentes ferramentas de avaliação exigem diferentes dados e artefatos de entrada. Por exemplo, a submissão de uma solução em uma ferramenta de avaliação pode consistir no envio de um arquivo com o código fonte, enquanto em outra pode consistir na inserção de um fragmento textual do código diretamente na interface da ferramenta. Algumas ferramentas exigem somente o código do programa, enquanto outras podem requerer artefatos como arquivo com a documentação do programa, arquivos com testes de unidade, dentre outras possibilidades. A definição de um trabalho de programação é outro exemplo em que os dados 
requeridos pelas ferramentas diferem, podendo incluir um programa de referência, dados de entrada para a execução dos programas do aluno, critérios de avaliação, dentre outros.

Assim, outra questão levantada foi a forma como essas diferenças poderiam ser tratadas para que os usuários (professores e alunos) pudessem, por meio do LMS, verificar e fornecer os dados e artefatos de entrada necessários para cada ferramenta de avaliação sendo considerada. Duas alternativas foram consideradas:

- Utilizar a interface das ferramentas embutidas nos LMSs: Esta alternativa consiste em criar mecanismos para que os LMSs apresentem, de forma embutida em sua interface, as interfaces das ferramentas de avaliação para que os usuários realizem as interações de entrada de dados e artefatos conforme implementadas pela ferramenta de avaliação.

- Utilizar a interface dos LMSs: Esta alternativa consiste em criar mecanismos para que os LMSs recuperem das ferramentas de avaliação informações sobre os dados e artefatos requeridos, apresentando dinamicamente uma interface para que os usuários realizem as interações de entrada de dados e artefatos conforme implementadas pelos LMSs.

Nesse sentido, a segunda alternativa foi considerada, em que a interface dos LMSs é considerada. A principal vantagem que motivou essa decisão foi a garantia de que as ferramentas de avaliação sendo integradas estarão em consonância com as demais ferramentas disponíveis nos LMSs. A utilização da interface das ferramentas de avaliação embutidas nos LMSs estão mais suscetíveis à presença de problemas de usabilidade, indo contra um dos propósitos desse trabalho, que visa diminuir o tempo e esforço dos alunos e professores lidando e aprendendo a usar as ferramentas.

Uma vez que tais decisões foram tomadas, o próximo passo foi a proposição da arquitetura IMPACTLE. A descrição da arquitetura é apresentada a seguir.

\subsection{Descrição da arquitetura}

A arquitetura IMPACTLE consiste em uma solução para que professores e alunos possam acessar as funcionalidades de diferentes ferramentas de avaliação para trabalhos de programação por meio de vários LMSs. Uma visão geral da arquitetura proposta e seus componentes principais são descritos a seguir.

\subsubsection{Visão geral}

Na Figura 23 é ilustrada uma visão geral da arquitetura IMPACTLE. Semelhantemente aos trabalhos de Amelung, Krieger e Rosner (2011) e Alario-Hoyos et al. (2013), os componentes da arquitetura IMPACTLE seguem uma distribuição em três camadas. A camada à esquerda consiste em vários LMSs, por meio dos quais os alunos e professores conduzem as atividades de 
ensino e aprendizagem. Já a camada à direita consiste em diferentes ferramentas de avaliação para trabalhos de programação, que fornecem funcionalidades de apoio às atividades práticas de programação. Por sua vez, no centro encontra-se o middleware, que realiza a comunicação entre os vários LMSs e as diferentes e ferramentas de avaliação.

Figura 23 - Arquitetura IMPACTLE: Visão geral

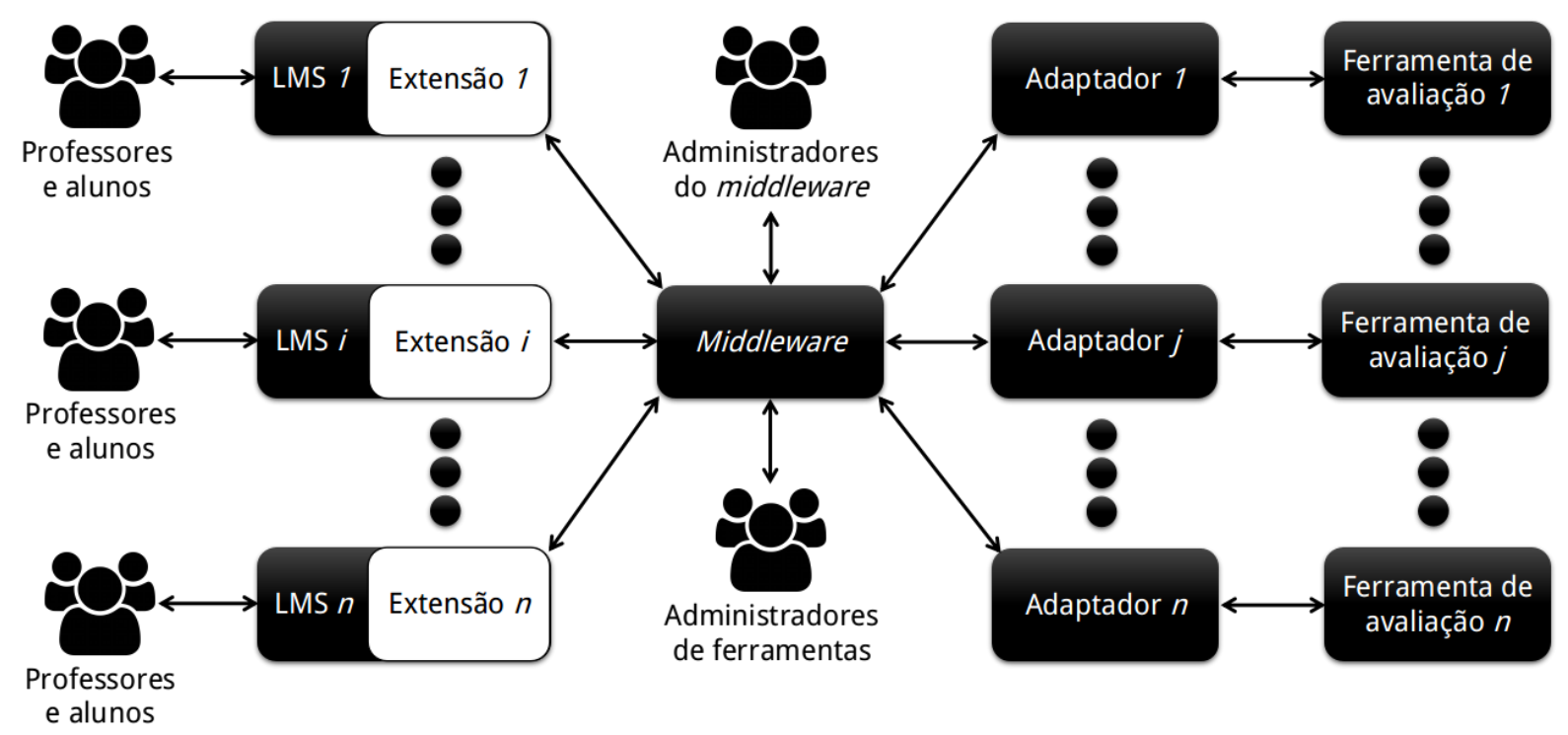

Fonte: Elaborada pelo autor.

A comunicação entre o middleware e as ferramentas de avaliação ocorre por meio de adaptadores. Os adaptadores são responsáveis em adaptar as interfaces heterogêneas das ferramentas de avaliação à uma interface padrão de comunicação. Assim, o middleware pode trocar informações e artefatos com as diferentes ferramentas de avaliação, sem a necessidade de lidar com as diferenças entre as interfaces dessas ferramentas. Em geral, um adaptador tem duas interfaces, uma para se comunicar com o middleware e outra para se comunicar com a ferramenta de avaliação. Cada ferramenta de avaliação deve conter um adaptador associado. No entanto, o adaptador de uma ferramenta pode ser reutilizado para a construção de um adaptador para outra ferramenta de avaliação.

Já a comunicação entre o middleware e os LMSs ocorre por meio de extensões dos LMSs. Os LMSs consistem em um ambiente com várias ferramentas integradas a ele (por exemplo, ferramentas de notificação, fórum, calendário, disponibilização de conteúdo, entre outras). Por este motivo, é comum que os LMSs, por padrão, já possuam mecanismos que os estendem com a adição de novas funcionalidades. De fato, mais de 70\% dos LMSs identificados possuem mecanismos que permitem a sua extensão. Assim, a arquitetura IMPACTLE considera os mecanismos já existentes nos LMSs. A ideia é que as funcionalidades das ferramentas estejam disponíveis aos alunos em concordância com as demais ferramentas que compõem o LMS. Em síntese, as extensões devem ser responsáveis por fornecer a interação com o usuário (professores e alunos) na definição, submissão e avaliação dos trabalhos práticos de programação, bem como 
se comunicar com o middleware para receber dados relacionados às ferramentas disponíveis (por exemplo, quais informações o professor deve fornecer para definir um trabalho de programação), enviar dados e arquivos para serem processados por elas (por exemplo, programas a serem verificados) e obter o resultado desses processamentos (por exemplo, o resultado das avaliações).

Por sua vez, o middleware é responsável por gerenciar a comunicação entre os LMSs e as diferentes ferramentas de avaliação. O middleware deve ser capaz de: (i) receber requisições de vários LMSs; (ii) encaminhar uma requisição para a ferramenta adequada; (iii) receber resultados de requisições processadas pelas ferramentas de avaliação; e (iv) retornar os resultados de uma requisição para o LMS que a gerou. Para isto, o middleware deve manter um registro das ferramentas de avaliação disponíveis, com informações de como acessá-las e quais funcionalidades elas disponibilizam.

Por fim, a arquitetura IMPACTLE define quatro tipos de atores: professor, aluno, administrador do middleware e administrador de ferramentas de avaliação. Os professores e alunos são os usuários dos LMSs, que por meio destes podem acessar as funcionalidades das ferramentas de avaliação. Basicamente, os professores podem acessar as funcionalidades das ferramentas para definir trabalhos práticos de programação, avaliar as soluções dos alunos e visualizar os resultados, enquanto os alunos podem submeter soluções aos trabalhos definidos pelos professores e visualizar os resultados das avaliações.

Já os administradores são usuários do middleware. Um administrador de ferramentas de avaliação consiste em um mantenedor de uma ou mais ferramentas de avaliação que deseja disponibilizá-las para serem utilizadas por meio de LMSs, sejam da sua própria instituição bem como de outras instituições. Assim, um administrador de ferramentas de avaliação pode registrar ou editar o registro de suas ferramentas no middleware, especificando o endereço em que elas estão disponibilizadas e as funcionalidades que elas fornecem. Por sua vez, o administrador do middleware é o responsável em manter o funcionamento do middleware. Em síntese, eles podem gerenciar os administradores de ferramentas e todos os registros de ferramentas.

A seguir, são detalhados os componentes que compõe cada uma das três camadas da arquitetura IMPACTLE.

\subsubsection{Componentes da arquitetura}

Nesta seção são descritos cada um dos componentes da arquitetura IMPACTLE, detalhando as suas funcionalidades, estrutura e comportamento.

\subsubsection{LMSs e extensões}

Os LMSs e extensões compõem a camada à esquerda da arquitetura IMPACTLE. Por meio deles os professores e alunos acessam as funcionalidades das ferramentas de avaliação, realizando atividades como a definição de questões de programação, submissão de soluções para 
as questões e a avaliação das soluções submetidas. As funcionalidades disponibilizadas pelos LMSs por meio das extensões são apresentadas a seguir.

\section{Funcionalidades oferecidas pelas extensões dos LMSs}

No Quadro 23 são sumarizadas as funcionalidades oferecidas pelas extensões. Como discutido na Seção 4.4.1, as extensões são os componentes da arquitetura responsáveis por definir a interação dos usuários (professores e alunos) com o LMS durante a definição de atividades de programação, submissão de soluções e avaliação das soluções. Outra função da extensão é realizar a comunicação entre o LMS e o middleware, obtendo informações sobre as ferramentas de avaliação disponíveis e sobre os dados e arquivos requeridos por elas, bem como enviando estes dados e arquivos para serem processados pelas ferramentas de avaliação. Por ser o componente que define a interação dos usuários, a extensão deve abranger todas às funcionalidades relacionadas as atividades de programação. A ideia é que tais funcionalidades estejam em consonância com as demais ferramentas do LMS.

Quadro 23 - Arquitetura IMPACTLE: Funcionalidades das extensões

\begin{tabular}{|c|c|}
\hline Funcionalidades & Descrição \\
\hline $\begin{array}{l}\text { Gerenciamento de atividades de progra- } \\
\text { mação }\end{array}$ & $\begin{array}{l}\text { Permite que os professores definam e disponibilizem aos alunos atividades de } \\
\text { programação, adicionando a elas questões de programação em que as soluções } \\
\text { dos alunos serão avaliadas com o apoio de uma ferramenta de avaliação. Infor- } \\
\text { mações sobre as ferramentas disponíveis e os dados e arquivos que as ferramen- } \\
\text { tas requerem do professor são obtidos por meio do middleware. }\end{array}$ \\
\hline Gerenciamento de submissões & $\begin{array}{l}\text { Permite que os alunos submetam suas soluções às questões de programação e o } \\
\text { controle das submissões por parte do professor. As informações sobre os dados } \\
\text { e arquivos que os alunos devem submeter como soluções são obtidos por meio } \\
\text { do middleware. }\end{array}$ \\
\hline $\begin{array}{l}\text { Acionamento de verificações automáti- } \\
\text { cas pelo aluno }\end{array}$ & $\begin{array}{l}\text { Quando apoiada pela ferramenta de avaliação associada à uma questão, permite } \\
\text { que o aluno acione a verificação automática para a solução que submeteu à ques- } \\
\text { tão. O acionamento pode ocorrer também automaticamente após a submissão. A } \\
\text { extensão requisita a verificação e obtém os resultados por meio do middleware. }\end{array}$ \\
\hline $\begin{array}{l}\text { Acionamento de verificações automáti- } \\
\text { cas pelo professor }\end{array}$ & $\begin{array}{l}\text { Quando apoiada pela ferramenta de avaliação associada à uma questão, permite } \\
\text { que o professor acione a verificação automática das soluções submetidas pelos } \\
\text { alunos à questão. A extensão requisita a verificação e obtém os resultados por } \\
\text { meio do middleware. }\end{array}$ \\
\hline $\begin{array}{l}\text { Apoio a verificações manuais pelo pro- } \\
\text { fessor }\end{array}$ & $\begin{array}{l}\text { Quando apoiada pela ferramenta de avaliação associada à uma questão, permite } \\
\text { que o professor manualmente verifique individualmente as soluções submetidas } \\
\text { pelos alunos à questão. A especificação de quais informações o professor deve } \\
\text { fornecer durante a sua verificação manual são obtidas por meio do middleware. }\end{array}$ \\
\hline $\begin{array}{l}\text { Visualização dos resultados das verifica- } \\
\text { ções e da avaliação como um todo }\end{array}$ & $\begin{array}{l}\text { Permite que tanto os professores como os alunos visualizem os resultados das } \\
\text { verificações e dos resultados finais das avaliações envolvendo todas as verifi- } \\
\text { cações e pontuações realizadas. Em adição, permite que o professor controle a } \\
\text { visualização das verificações realizadas por ele. Os resultados são obtidos por } \\
\text { meio do middleware após serem processadas pelas ferramentas de avaliação. }\end{array}$ \\
\hline
\end{tabular}

Fonte: Elaborada pelo autor.

\section{Extensões e demais recursos dos LMSs}

Na Figura 24 são ilustrados os recursos dos LMSs utilizados para implementar as funcionalidades descritas anteriormente. O principal recurso, como já discutido, é uma extensão que provê a interação com o usuário e a comunicação com o middleware. Os recursos que compõem 
a extensão e a forma como a extensão estará inserida no LMS dependem das especificidades de cada LMS e são decisões a serem tomadas pelo desenvolvedor que estiver estendendo um LMS. No entanto, a arquitetura IMPACTLE prevê que a extensão deve ter acesso a dois recursos que estão presentes em todos os LMSs identificados e analisados: o banco de dados e o repositório de arquivos do LMS. Por meio do banco de dados do LMS, a extensão pode manter os dados relacionados às atividades de programação, submissões e resultados de avaliações. Semelhantemente, por meio do repositório de arquivos, a extensão pode armazenar os arquivos associados às definições de trabalhos, submissões de soluções e relatórios com os resultados das avaliações.

Figura 24 - Arquitetura IMPACTLE: Extensão e demais recursos de um LMS

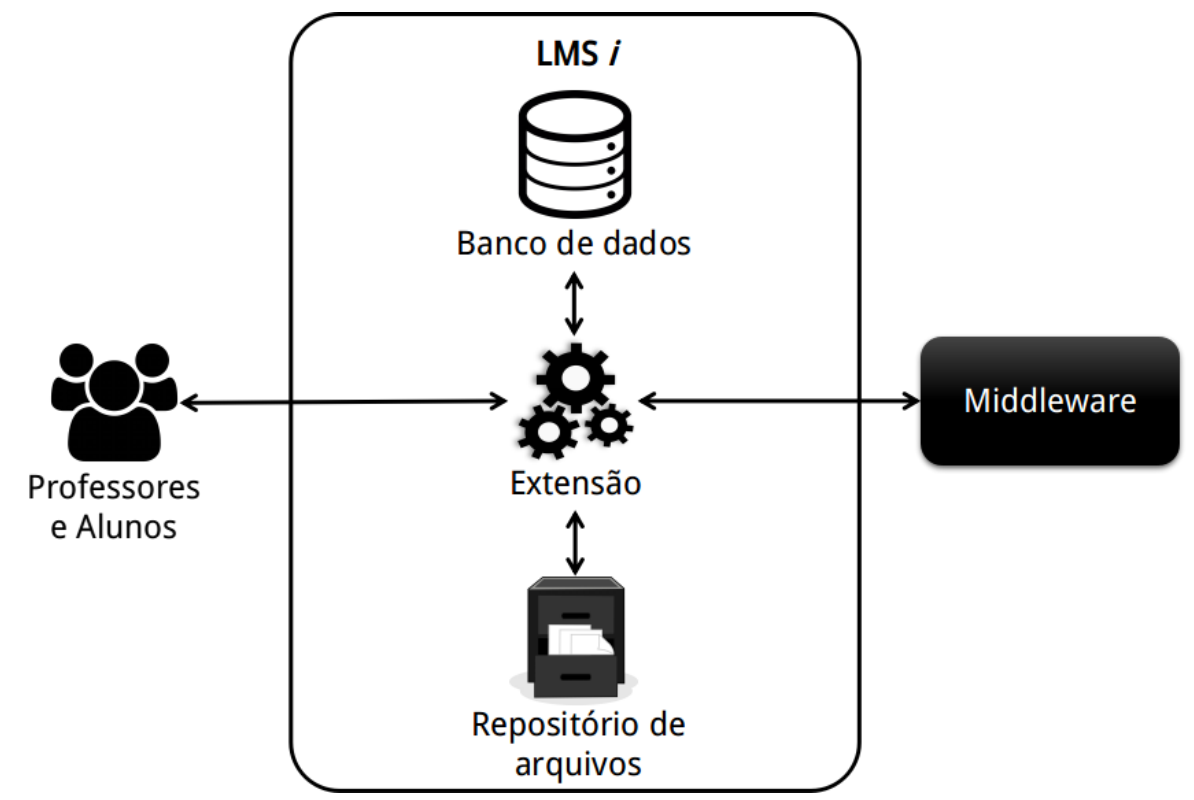

Fonte: Elaborada pelo autor.

\section{Comportamento das extensões}

Por fim, a Figura 25 ilustra os comportamentos típicos de uma extensão. Basicamente, quatro tipos de comportamentos foram previstos:

- Manipulação de dados: Este comportamento está relacionado com operações que não envolvem a comunicação com o middleware. Em geral, consiste em salvar e em recuperar dados e arquivos armazenados no LMS, como por exemplo, quando um aluno seleciona a opção para visualizar os dados de uma questão de programação. Em síntese, a extensão comporta-se da seguinte forma: (1) o usuário seleciona a opção disponibilizada pela extensão (como por exemplo, por um botão de submissão em um formulário); (2) a extensão salva ou recupera dados no banco de dados; (3) a extensão salva ou recupera arquivos do repositório; e (4) a extensão exibe o resultado da operação ao usuário (como por exemplo, exibindo os dados de uma questão de programação ou notificando sobre o sucesso na submissão de um formulário). 
- Envio de requisições com baixa taxa de processamento: Este comportamento está relacionado com operações que envolvem a comunicação com o middleware, aguardando a resposta do middleware para enviar um retorno ao usuário. Envolvem operações como a requisição de informações como a lista de ferramentas disponibilizadas pelo middleware ou as especificações que definem os dados que devem ser fornecidos pelo aluno para submeter uma solução. Em linhas gerais, a extensão comporta-se da seguinte forma: (1) o usuário seleciona a operação da extensão por meio da interface do LMS; (2) a extensão requisita os dados e arquivos necessários ao middleware (como por exemplo, a lista de ferramentas disponíveis); (3) a extensão recebe os dados e arquivos enviados pelo middleware; e (4) a extensão exibe os dados ao usuário.

- Envio de requisições com alta taxa de processamento: Este comportamento está relacionado com operações que envolvem a comunicação com o middleware, mas que os resultados são recuperados posteriormente. Envolvem operações como o envio de soluções para serem verificadas por meio de uma ferramenta de avaliação. A extensão comporta-se da seguinte forma: (1) o usuário seleciona a operação da extensão por meio da interface do LMS; (2) a extensão recupera os dados que serão enviados do banco de dados; (3) a extensão obtém do repositório uma cópia dos arquivos que serão enviados; (4) a extensão envia a requisição ao middleware; (5) a extensão recebe do middleware um identificador da requisição para que os resultados sejam obtidos posteriormente; (6) a extensão salva os dados da requisição no banco de dados; e (7) a extensão notifica o usuário sobre o andamento da operação.

- Obtenção dos resultados de requisições: Este comportamento complementa o anterior, envolvendo a comunicação com o middleware para obter os resultados das requisições com alta taxa de processamento. Envolvem operações como a obtenção dos resultados de uma verificação realizada por uma ferramenta de avaliação. Basicamente, a extensão comporta-se da seguinte forma: (1) a extensão recupera do banco de dados os dados de uma requisição; (2) a extensão solicita ao middleware os resultados da requisição; (3) a extensão recebe do middleware os resultados da requisição; (4) a extensão atualiza os dados da requisição no banco de dados; (5) a extensão salva os resultados no repositório de arquivos; e (6) a extensão notifica o usuário sobre o término da operação.

\subsubsection{Adaptadores}

Enquanto a camada à esquerda da arquitetura é composta pelos LMSs e suas extensões, a camada à direita é composta pelas ferramentas de avaliação e seus adaptadores. Os adaptadores são responsáveis em adaptar as interfaces heterogêneas das diferentes ferramentas de avaliação para trabalhos de programação em uma interface padrão. Isso permite a comunicação entre o middleware e as ferramentas de avaliação. As funcionalidades, estrutura e comportamento dos adaptadores são detalhados a seguir. 
Figura 25 - Arquitetura IMPACTLE: Comportamento das extensões

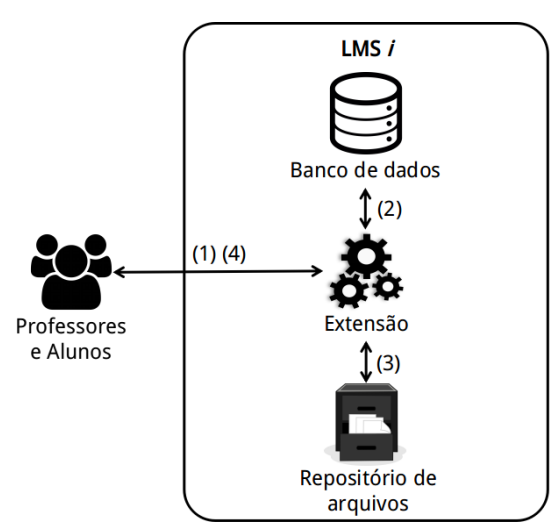

(a) Manipulação de dados

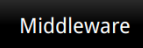

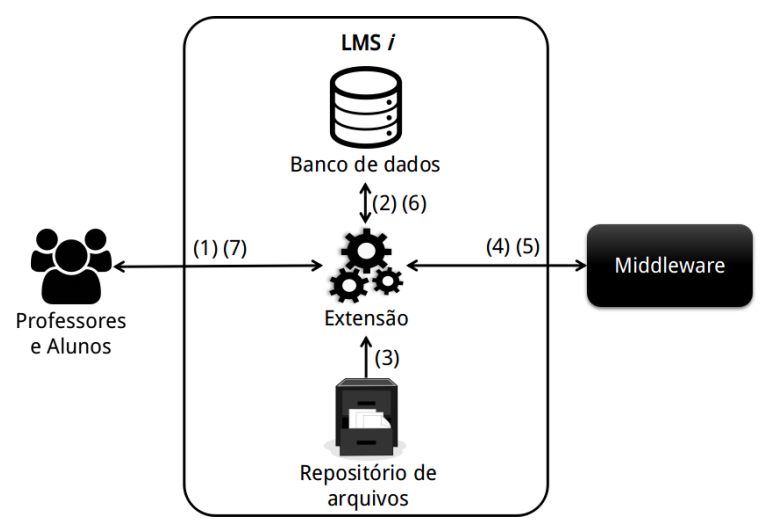

(c) Envio de requisições com alta taxa de processamento

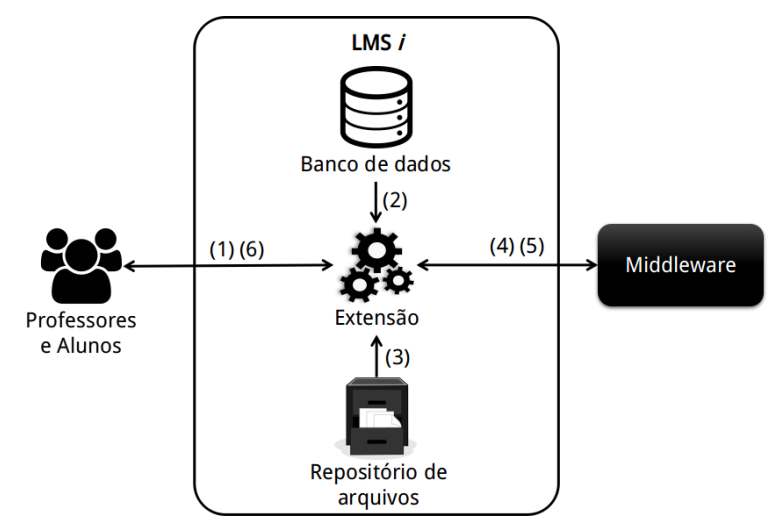

(b) Envio de requisições com baixa taxa de processamento

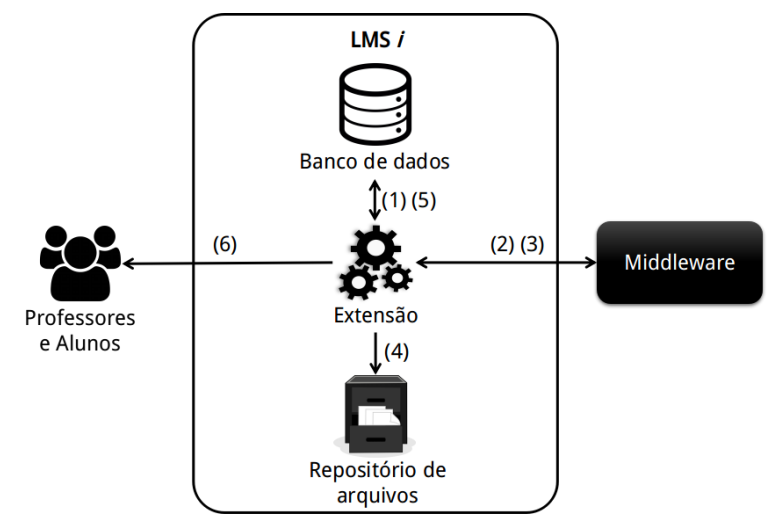

(d) Obtenção dos resultados de requisições

Fonte: Elaborada pelo autor.

\section{Funcionalidades dos adaptadores}

As funcionalidades de um adaptador refletem as funcionalidades da ferramenta de avaliação que ele adapta. Com base no estudo das funcionalidades das ferramentas de avaliação (Seção 3.2) foi levantado um conjunto de funcionalidades que os adaptadores podem disponibilizar a fim de abranger as funcionalidades de todas as ferramentas identificadas e analisadas.

No Quadro 24 são sumarizadas as funcionalidades que um adaptador pode disponibilizar. No entanto, nem todas devem estar presentes em um adaptador. As funcionalidades devem ser disponibilizadas pelo adaptador de acordo com a ferramenta de avaliação sendo adaptada. Por exemplo, a funcionalidade de realizar uma verificação automática pelo professor somente será disponibilizada se a ferramenta de avaliação sendo integrada realiza verificações automáticas e se na abordagem dessa ferramenta de avaliação estas verificações são acionadas pelo professor. Ressalta-se que, dentre as três funcionalidades de verificação previstas, um adaptador deve disponibilizar pelo menos uma delas.

Outro fator importante com relação às funcionalidades de verificação é a sua complemen- 
Quadro 24 - Arquitetura IMPACTLE: Funcionalidades dos adaptadores

\begin{tabular}{|l|l|}
\hline Funcionalidade & Descrição \\
\hline Verificação automática pelo aluno & $\begin{array}{l}\text { Verifica a solução de um aluno para uma questão de programação, considerando } \\
\text { os mecanismos da ferramenta de avaliação que devem ser acionados pelos alu- } \\
\text { nos. }\end{array}$ \\
\hline Verificação automática pelo professor & $\begin{array}{l}\text { Verifica um conjunto de soluções desenvolvidas para uma questão de progra- } \\
\text { mação, considerando os mecanismos da ferramenta de avaliação que devem ser } \\
\text { acionados pelos professores. }\end{array}$ \\
\hline Verificação manual pelo professor & $\begin{array}{l}\text { Apoia e processa os resultados de uma verificação manual realizada pelo pro- } \\
\text { fessor, como por exemplo, gerando um relatório final da avaliação combinando } \\
\text { os dados das verificações automáticas e da verificação manual, calculando a } \\
\text { pontuação final do aluno, entre outros. }\end{array}$ \\
\hline Repositório de questões & $\begin{array}{l}\text { Disponibiliza questões de programação para serem utilizadas com a ferramenta } \\
\text { de avaliação. Esta funcionalidade permite facilitar o trabalho do professor, que } \\
\text { pode utilizar as questões já prontas ao invés de definir as suas próprias questões. }\end{array}$ \\
\hline Eeração de dados de teste & $\begin{array}{l}\text { Gera dados de teste para serem utilizados na verificação dos programas. Os } \\
\text { dados de teste são associados às questões de programação e podem ser gerados, } \\
\text { por exemplo, por meio de um programa de referência fornecido pelo professor. }\end{array}$ \\
\hline Especificações de dados e arquivos & $\begin{array}{l}\text { Fornece especificações dos dados e arquivos requeridos para realizar as demais } \\
\text { funcionalidades. Por exemplo, especificações de quais dados e arquivos o pro- } \\
\text { fessor deve fornecer para que a ferramenta realize uma verificação automática, } \\
\text { quais dados e arquivos os alunos devem submeter como uma solução, dentre } \\
\text { outros. }\end{array}$ \\
\hline
\end{tabular}

Fonte: Elaborada pelo autor.

tariedade. Em ferramentas em que mais de um desses três tipos de verificação estão presentes, o resultado final da avaliação é fornecido com base nos resultados das três verificações, em alguns casos, fornecendo até mesmo uma pontuação final para a solução sendo avaliada. De forma análoga, a verificação manual pelo professor muitas vezes deve ser realizada considerando os relatórios das verificações automáticas. Assim, o resultado final da avaliação sempre deve ser fornecido como resultado da última verificação a ser realizada.

Os recursos que precisam estar presentes nos adaptadores para que estas funcionalidades sejam disponibilizadas são detalhados a seguir.

\section{Estrutura dos adaptadores}

Na Figura 26 são ilustrados os recursos que podem compor um adaptador e o fluxo de dados entre eles. Em síntese, os recursos são:

- Serviço adaptador: Consiste em um serviço web que implementa as interfaces para as funcionalidades do adaptador. Tem por objetivo receber as requisições enviadas pelo middleware.

- Artefatos: Os artefatos consistem em formulários XHTML que especificam quais dados e arquivos os professores e alunos devem fornecer durante a definição de questões, submissão de soluções e avaliação de soluções com a ferramenta de avaliação para qual o adaptador foi construído. O Quadro 25 sumariza os artefatos que um adaptador pode conter. Artefatos como o formulário de definição de questão devem estar presentes em todos os adaptadores, enquanto formulários como o de avaliação manual pelo professor 
devem estar presentes somente quando a ferramenta de avaliação sendo integrada possui a funcionalidade associada.

- Fila de requisições: Mecanismo proposto para tratar as requisições que exigem maior capacidade de processamento ou volume de dados, como a verificação automática de programas com as ferramentas de avaliação. Processando uma requisição de cada vez é possível evitar que a máquina em que a ferramenta de avaliação estiver hospedada exceda a sua capacidade de processamento por causa do número de requisições em processamento.

- Banco de dados: Necessário, por exemplo, para armazenar os dados de uma requisição na fila de requisições ou os dados das questões disponíveis no repositório de questões da ferramenta de avaliação.

- Repositório de arquivos: Necessário, por exemplo, para armazenar os resultados das avaliações realizadas pela ferramenta de avaliação, que serão posteriormente enviados ao middleware.

Figura 26 - Arquitetura IMPACTLE: Estrutura do adaptadores

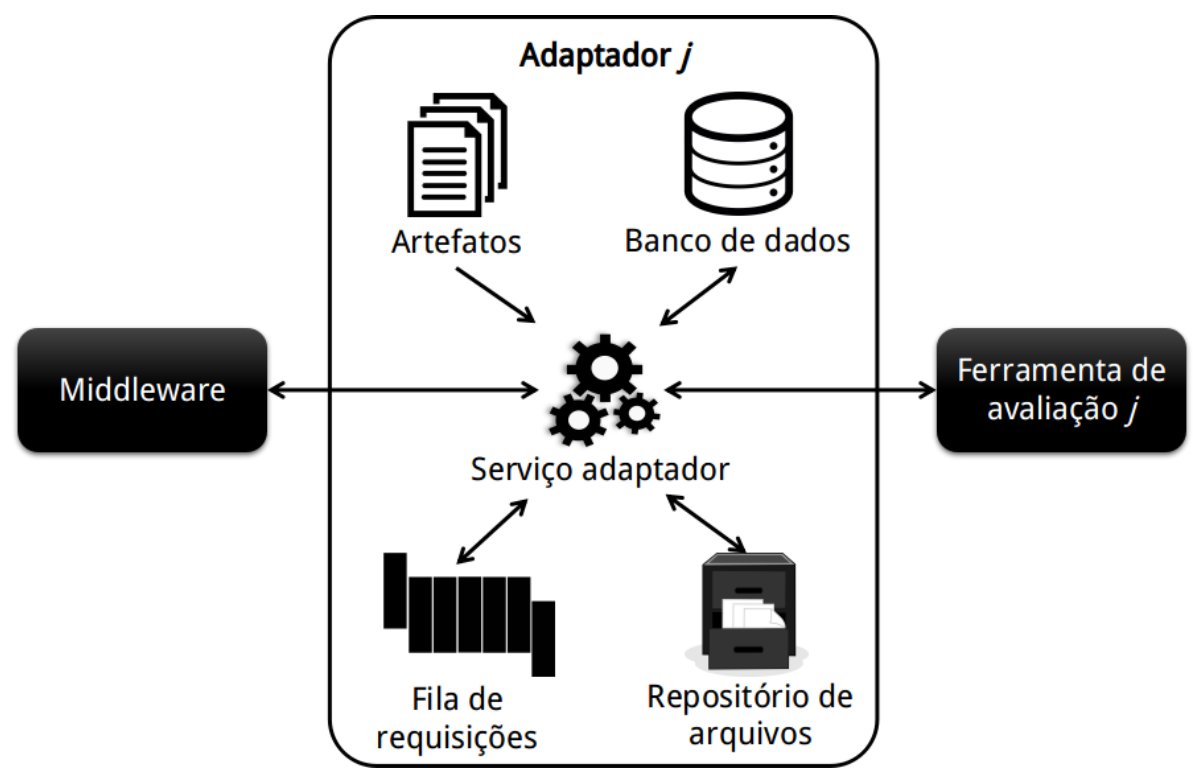

Fonte: Elaborada pelo autor.

Na implementação de um adaptador, algumas decisões de projeto são livres e dependem das especificidades de cada ferramenta de avaliação sendo integrada. Neste sentido, outros componentes podem ser adicionados ao adaptador, conforme as decisões de projeto do desenvolvedor que estiver integrando uma determinada ferramentas de avaliação. Ainda, os componentes fila de requisições, banco de dados e repositório de arquivos não são obrigatórios. Um exemplo em que tais componentes não são necessários é o caso em que a ferramenta de avaliação associada ao adaptador já os implementam. Neste caso, o serviço adaptador pode utilizar e se comunicar diretamente com os componentes da ferramenta de avaliação. 
Quadro 25 - Arquitetura IMPACTLE: Artefatos dos adaptadores

\begin{tabular}{|l|l|}
\hline Artefatos & Descrição \\
\hline Formulário de questão & $\begin{array}{l}\text { Especifica os dados e arquivos que um professor deve fornecer para definir uma } \\
\text { questão para ser avaliada com a ferramenta de avaliação. Exemplos de dados } \\
\text { e arquivos incluem um programa de referência implementando uma solução } \\
\text { correta para a solução, critérios de avaliação, testes de unidade para serem exe- } \\
\text { cutados contra os programas dos alunos, dentre outros. }\end{array}$ \\
\hline Formulário de submissão & $\begin{array}{l}\text { Especifica os dados e arquivos que um aluno deve fornecer como uma solução } \\
\text { para ser avaliada pela ferramenta de avaliação. Exemplos de dados e arquivos } \\
\text { incluem um fragmento de código fonte, um arquivo de código fonte, arquivos } \\
\text { de texto com documentação, testes de unidade projetados pelo aluno para testar } \\
\text { o seu programa, dentre outros. }\end{array}$ \\
\hline Formulário de geração de dados de teste & $\begin{array}{l}\text { Especifica os dados e arquivos que um professor deve fornecer para gerar dados } \\
\text { de teste com a ferramenta de avaliação. Exemplos de dados e arquivos incluem } \\
\text { dados de entrada e programas de referência. }\end{array}$ \\
\hline $\begin{array}{l}\text { Formulário de verificação manual pelo } \\
\text { professor }\end{array}$ & $\begin{array}{l}\text { Especifica os dados e arquivos que um professor deve fornecer como resultado } \\
\text { de uma verificação manual. Exemplos de dados e arquivos incluem comentá- } \\
\text { rios textuais sobre a solução, pontos atingidos para um determinado critério de } \\
\text { avaliação, dentre outros. }\end{array}$ \\
\hline
\end{tabular}

Fonte: Elaborada pelo autor.

Considerando os recursos descritos nesta seção, os comportamentos típicos a serem realizados pelos adaptadores são detalhados a seguir.

\section{Comportamento dos adaptadores}

Na Figura 27 são ilustrados os comportamentos típicos de um adaptador. Basicamente, quatro comportamentos são previstos:

- Fornecimento de artefatos: Este comportamento é realizado quando o adaptador recebe do middleware a requisição de um cópia dos artefatos armazenados no adaptador (como por exemplo, o formulário de questão ou de submissão). Em síntese, o adaptador: (1) recebe a requisição enviada pelo middleware; (2) obtém uma cópia do artefato; (3) envia a cópia do artefato ao middleware.

- Fornecimento de dados: Este comportamento é realizado quando o adaptador recebe do middleware a requisição de dados armazenados no banco de dados do adaptador (como por exemplo, dados sobre as questões disponibilizadas no repositório de questões da ferramenta de avaliação). Basicamente, assim como no fornecimento de artefatos, o adaptador: (1) recebe a requisição enviada pelo middleware; (2) recupera os dados do banco de dados; e (3) envia os dados ao middleware.

- Recebimento de requisições com alta taxa de desempenho: Este comportamento é realizado quando o middleware envia dados e arquivos para serem processados pela ferramentas de avaliação (como por exemplo, soluções dos alunos para um trabalho de programação que deverão ser verificadas pelas ferramentas de avaliação). Em síntese, o adaptador: (1) recebe os dados e arquivos enviados pelo middleware; (2) salva os dados 
da requisição no banco de dados; (3) armazena os arquivos associados à requisição no repositório de arquivos; e (4) adiciona a requisição na fila de requisições.

- Processamento de requisições com alta taxa de desempenho: Este comportamento é realizado quando o adaptador, em conjunto com a ferramenta de avaliação associada, processa uma requisição enviada pelo middleware (como por exemplo, a realização da avaliação de uma solução). Em síntese, o adaptador: (1) obtém a requisição da fila de requisições; (2) recupera os dados da requisição da fila de requisições; (3) carrega os arquivos associados à requisição do repositório de arquivos; (4) aciona a operação a ser realizada pela ferramenta de avaliação, provendo os dados e arquivos necessários; (5) recebe os resultados fornecidos pela ferramenta de avaliação; (6) atualiza os dados da requisição no banco de dados; e (7) armazena relatórios com os resultados no repositório de arquivos.

- Fornecimento de resultados: Este comportamento é realizado quando o adaptador recebe do middleware a requisição dos resultados de um processamento de dados e arquivos (como por exemplo, os resultados de uma avaliação). Em síntese, o adaptador: (1) recebe a requisição enviada pelo middleware; (2) obtém os relatórios com os resultados do repositório de arquivos; e (3) envia os relatórios ao middleware.

Por fim, ressalta-se que a forma como um adaptador e uma ferramenta de avaliação se comunicam depende da especificidade de cada ferramenta de avaliação, sendo esta uma decisão de projeto que deve ser tomada pelo desenvolvedor que estiver integrando a ferramenta à estrutura definida pela arquitetura.

\subsubsection{O Middleware}

O middleware é o componente central da arquitetura IMPACTLE. A principal finalidade do middleware é permitir a interoperabilidade entre os vários LMSs e as diferentes ferramentas de avaliação. Assim, o middleware é capaz de receber requisições de várias extensões de LMSs e, quando necessário, direcioná-las para o adaptador da ferramenta de avaliação selecionada para processar a requisição. As funcionalidades, estrutura e comportamentos do middleware são descritos a seguir.

\section{Funcionalidades do middleware}

No Quadro 26 são sintetizadas as funcionalidades do middleware. A principal funcionalidade do middleware é encaminhar as requisições dos LMSs aos adaptadores das ferramentas de avaliação. O middleware é capaz de receber requisições de vários LMSs e encaminhar cada uma delas para o adaptador da ferramenta de avaliação para o qual a requisição foi destinada. 
Figura 27 - Arquitetura IMPACTLE: Comportamento dos adaptadores

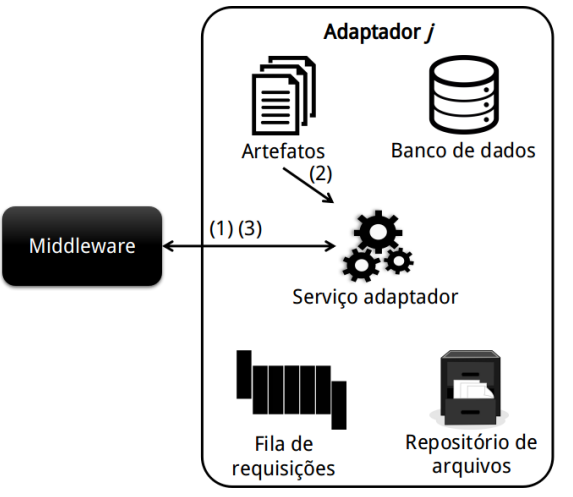

(a) Fornecimento de artefatos

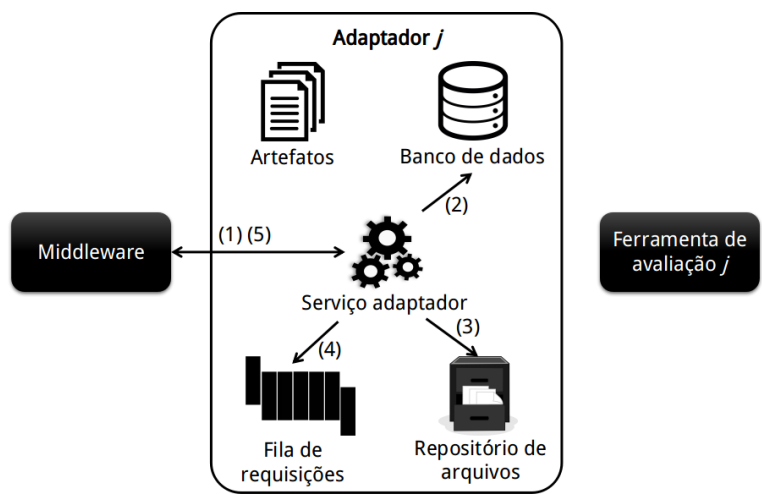

(c) Recebimento de requisições com alta taxa de processamento

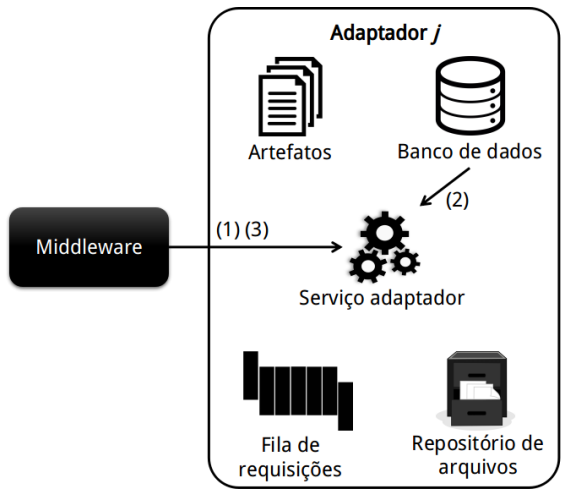

Ferramenta de

(b) Fornecimento de dados

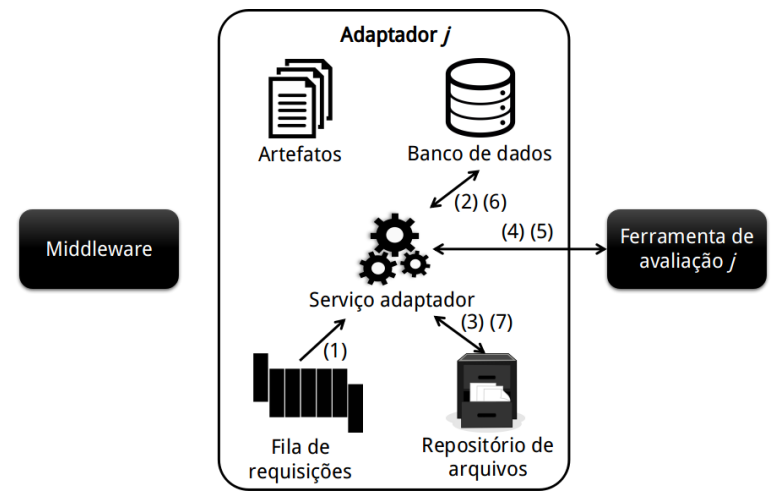

(d) Processamento de requisições com alta taxa de desempenho

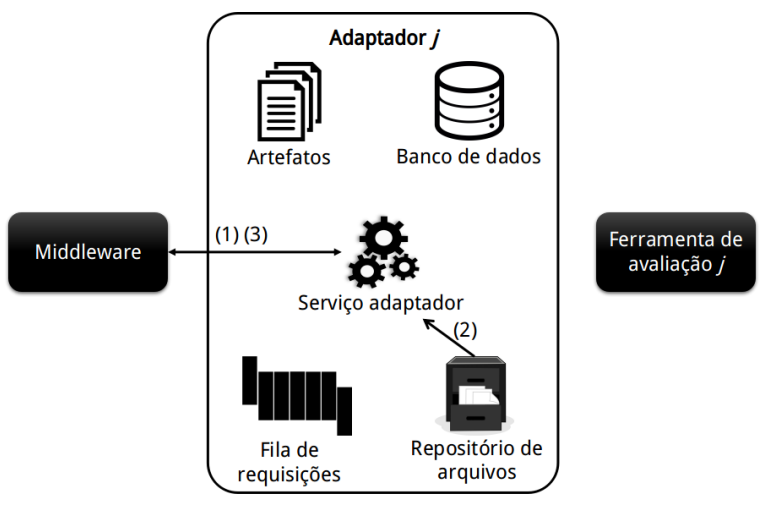

(e) Fornecimento de resultados

Fonte: Elaborada pelo autor.

Quadro 26 - Arquitetura IMPACTLE: Funcionalidades do middleware

\begin{tabular}{|l|l|}
\hline Funcionalidades & Descrição \\
\hline Encaminhamento de requisições & $\begin{array}{l}\text { Recebe e encaminha requisições dos LMSs para os adaptadores das ferramentas } \\
\text { de avaliação. }\end{array}$ \\
\hline Registro das ferramentas de avaliação & $\begin{array}{l}\text { Permite controlar a disponibilização de ferramentas de avaliação por meio do } \\
\text { middleware. }\end{array}$ \\
\hline
\end{tabular}

Fonte: Elaborada pelo autor. 
Para encaminhar tais requisições, o middleware também possui um registro de ferramentas de avaliação. Assim, os administradores de ferramentas de avaliação (desenvolvedores ou pesquisadores que desejam integrar as suas ferramentas de avaliação em LMSs) podem disponibilizar as suas ferramentas de avaliação adicionando um registro delas no middleware. Uma vez registradas, elas tornam-se visíveis para que suas funcionalidades possam ser acessadas por meio dos LMSs. As informações requeridas para o registro incluem dados como o nome da ferramenta de avaliação, as funcionalidades apoiadas por ela e o endereço web do adaptador (para onde o middleware encaminhará as requisições). Adicionalmente, um administrador do middleware pode controlar o acesso ao registro de ferramentas de avaliação e controlar todos os dados relacionados aos registros de ferramenta e administradores de ferramentas.

Ainda, por meio do registro, as extensões dos LMSs podem obter as informações sobre as ferramentas de avaliação disponíveis e permitir que elas sejam selecionadas para serem utilizadas em uma atividade de programação.

Os recursos necessários no middleware para que estas funcionalidades sejam implementadas são descritos a seguir.

\section{Estrutura do middleware}

Na Figura 28 são ilustrados os recursos que compõem o middleware e o fluxo de dados entre eles. Em síntese, os recursos são:

- Serviço de execução: Principal recurso do middleware. Consiste em um serviço web que implementa as interfaces pelas quais as extensões dos LMSs enviarão suas requisições. Também, implementa os mecanismos necessários para, quando necessário, encaminhar estas requisições aos adaptadores das ferramentas.

- Serviço de administração: Consiste em serviço web que implementa as interfaces por meio das quais os administradores (do middleware e de ferramentas de avaliação) poderão gerenciar os registros de ferramentas de avaliação.

- Fila de requisições: Mecanismo proposto para tratar as requisições que exigem maior capacidade de processamento ou volume de dados, como a verificação automática de programas com as ferramentas de avaliação. Processando uma requisição de cada vez é possível evitar que a capacidade de processamento exceda por causa do número de requisições em processamento.

- Banco de dados: Necessário, por exemplo, para armazenar os dados de uma requisição na fila de requisições ou os dados dos registros de ferramentas de avaliação.

- Repositório de arquivos: Necessário, por exemplo, para armazenar os arquivos associados às requisições, como por exemplo, os programas dos alunos que serão enviados para 
verificação em uma ferramenta de avaliação.

Figura 28 - Arquitetura IMPACTLE: Estrutura do middleware

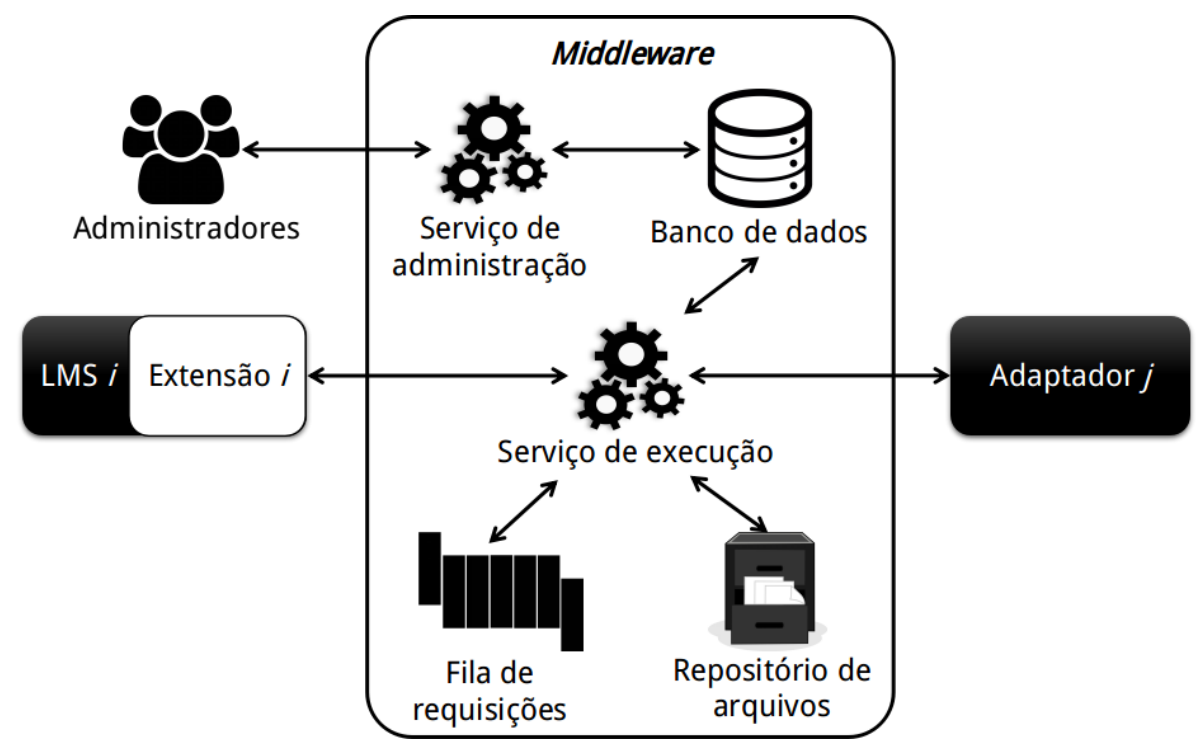

Fonte: Elaborada pelo autor.

Considerando os recursos descritos, o comportamento do middleware é detalhado a seguir.

\section{Comportamento do middleware}

Na Figura 29 são ilustrados os comportamentos típicos do middleware. Sete comportamentos foram previstos:

- Fornecimento de dados e artefatos de um adaptador: Este comportamento é realizado quando uma extensão solicita dados ou artefatos que estão armazenados em um adaptador de uma ferramenta de avaliação (como por exemplo, o formulário de questão para uma ferramenta de avaliação ou dados sobre as questões disponibilizadas pelo repositório de questões de uma ferramenta de avaliação). Em linhas gerais, o middleware comporta-se da seguinte forma: (1) o serviço de execução recebe a requisição da extensão; (2) recupera do banco de dados o endereço do adaptador da ferramenta de avaliação associada à requisição; (3) encaminha a requisição para o adaptador; (4) recebe os dados ou artefatos retornados pelo adaptador; e (5) envia os dados ou artefatos para a extensão.

- Fornecimento de informações sobre as ferramentas de avaliação: Este comportamento é realizado quando uma extensão solicita ao middleware informações sobre as ferramentas de avaliação (por exemplo, a lista de todas as ferramentas de avaliação disponíveis). Em síntese, o middleware comporta-se da seguinte forma: (1) o serviço de execução recebe a 
requisição da extensão; (2) recupera do banco de dados os dados requisitados; (3) retorna os dados para a extensão.

- Recebimento de requisições com alta taxa de processamento: Este comportamento é realizado quando uma extensão solicita ao middleware o processamento de dados e arquivos por meio de uma ferramenta de avaliação (por exemplo, a verificação de soluções submetidas pelos alunos para uma questão de programação). O middleware comporta-se da seguinte forma: (1) o serviço de execução recebe a requisição da extensão. (2) salva os dados da requisição no banco de dados; (3) armazena os arquivos associados à requisição no repositório de arquivos; (4) adiciona a requisição na fila de requisições em espera; e (5) retorna à extensão um identificador da requisição para que os resultados possam ser obtidos posteriormente.

- Processamento de requisições em espera: Este comportamento é realizado quando o serviço de execução seleciona uma requisição em espera na fila de requisições. Basicamente, o middleware comporta-se da seguinte forma: (1) o serviço de execução remove a requisição da fila de requisições; (2) recupera os dados da requisição do banco de dados; (3) carrega os arquivos associados a requisição do repositório de arquivos; (4) recupera do banco de dados o endereço do adaptador da ferramenta de avaliação associada à requisição; (5) encaminha a requisição com os dados e arquivos ao adaptador; (6) altera no banco de dados o estado da requisição para "em processamento"; e (7) retorna a requisição na fila de requisições.

- Obtenção dos resultados de uma requisição em processamento: Este comportamento é realizado quando o serviço de execução seleciona uma requisição em processamento na fila de requisições. Em síntese, o middleware comporta-se da seguinte forma: (1) o serviço de execução remove a requisição da fila de requisição; (2) recupera do banco de dados os dados da requisição e o endereço do adaptador da ferramenta de avaliação associada à requisição; (3) requisita do adaptador os resultados do processamento da requisição; (4) recebe os resultados da requisição retornados pelo adaptador; (5) atualiza no banco de dados o estado da requisição para "concluído"; e (6) armazena os relatórios resultantes do processamento da requisição no repositório de arquivos de saída.

- Fornecimento de resultados de uma requisição: Este comportamento é realizado quando uma extensão de um LMS solicita ao middleware os resultados de uma requisição (por exemplo, os resultados de uma avaliação). O middleware comporta-se da seguinte forma: (1) o serviço de execução recebe a requisição da extensão; (2) carrega do repositório de arquivos os relatórios com os resultados do processamento da requisição; (3) remove os dados da requisição do banco de dados; e (4) retorna os relatórios para a extensão.

- Operações de administração: Este comportamento é realizado quando um administrador solicita a adição, visualização, edição e remoção de dados no middleware (por exemplo, o 
registro de uma ferramenta de avaliação). Em linhas gerais, o middleware comporta-se da seguinte forma: (1) o serviço de administração recebe a requisição do usuário; (2) atualiza (a) ou recupera (b) os dados do banco de dados; e (3) notifica o usuário sobre a conclusão da operação ou exibe os dados recuperados.

Os componentes, funcionalidades, recursos e comportamentos descritos nesta seção foram modelados como visões arquiteturais. Assim, as visões arquiteturais modeladas para a arquitetura IMPACTLE são apresentadas a seguir.

\subsection{Visões da arquitetura}

A arquitetura IMPACTLE foi formalizada considerando o modelo de visão arquitetural “4+1”, proposto por Kruchten (1995). O modelo sugere a descrição arquitetural considerando cinco visões: casos de uso, lógica, processos, implementação e física. As cinco visões arquiteturais modeladas para a arquitetura IMPACTLE são apresentadas e detalhadas a seguir.

\subsubsection{Visão de casos de uso}

A visão de casos de uso é o componente central do modelo de visão "4+1" e tem por objetivo reunir todos os elementos das demais visões em um conjunto de casos de uso ou de cenários.

$\mathrm{Na}$ arquitetura IMPACTLE, a visão de casos de uso foi composta por meio da elaboração de dois conjuntos de casos de uso. O primeiro representa os cenários relacionados ao professor, envolvendo principalmente a definição de trabalhos de programação e avaliações centradas no professor. O segundo representa os cenários relacionados aos alunos, envolvendo principalmente a submissão de soluções e avaliações centradas no aluno.

Os casos de uso foram levantados por meio do estudo das ferramentas de avaliação para trabalhos de programação identificadas por meio do mapeamento sistemático, conforme discutido na Seção 3.2. Para cada ferramenta identificada, foram elaborados casos de uso representando seus cenários de uso. Em seguida, os casos de uso de todas as ferramentas foram agrupados, unificando aqueles que eram semelhantes. Apesar de algumas ferramentas definirem outros papéis, como o de assistente ou monitor, em geral, os usuários que assumem estes papéis realizam as mesmas atividades associadas ao professor.

Os casos de uso representando os cenários para professor e aluno, respectivamente, são apresentados nas próximas seções.

\subsubsection{Casos de uso do professor}

No diagrama da Figura 30 são ilustrados os casos de uso para o professor. Os cenários de uso relacionados aos professores incluem a criação, edição, remoção e visualização de definições 
Figura 29 - Arquitetura IMPACTLE: Comportamento do middleware

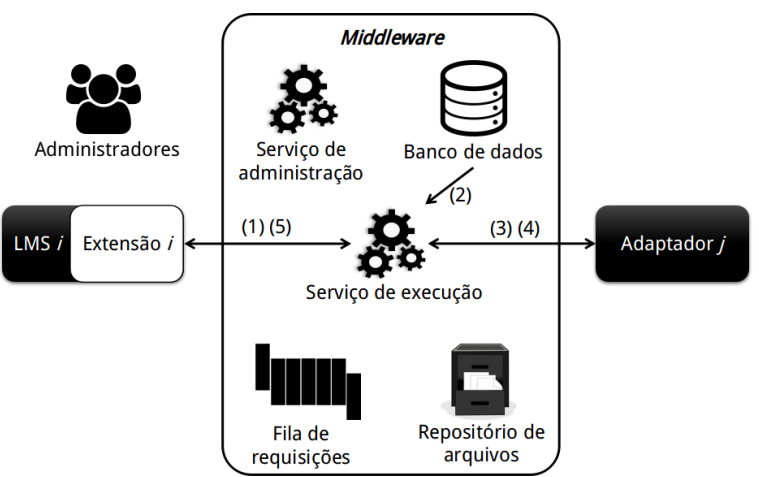

(a) Fornecimento de informações sobre as ferramentas de avaliação

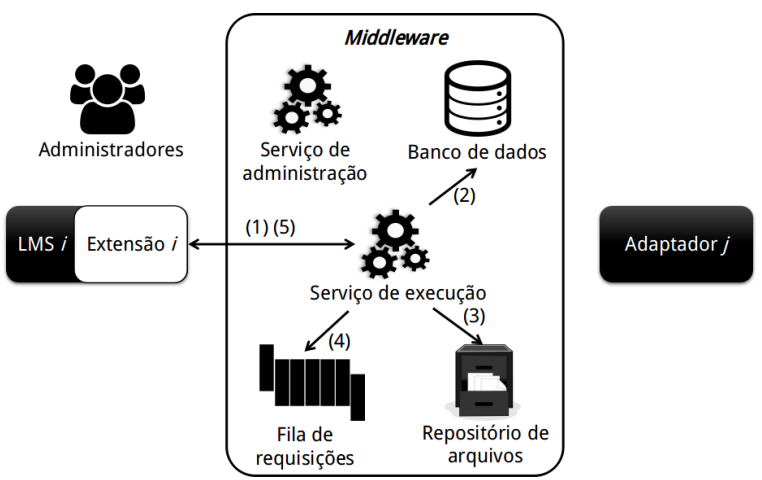

(c) Recebimento de requisições com alta taxa de processamento

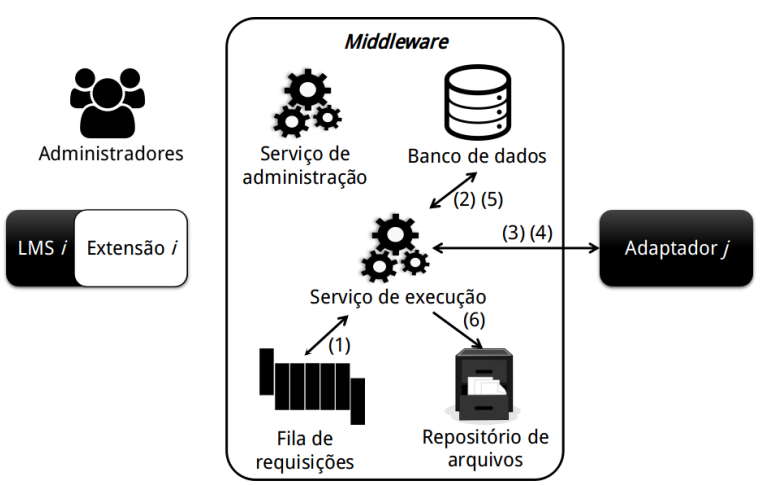

(e) Obtenção dos resultados de requisições em andamento

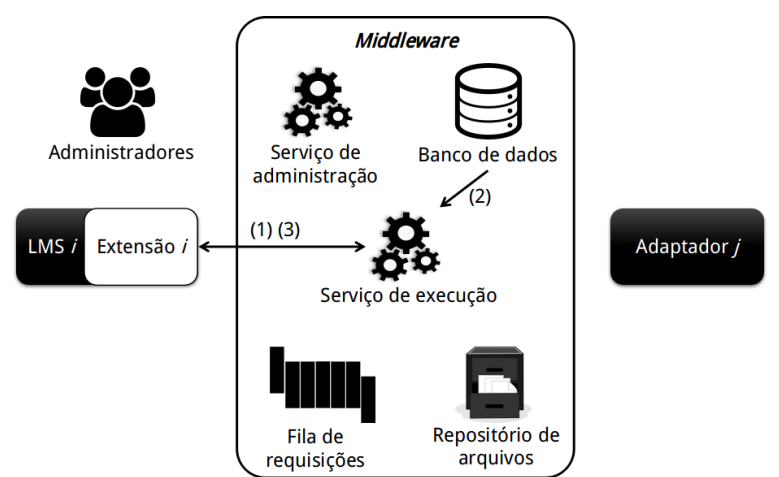

(b) Fornecimento de dados e artefatos de um adaptador

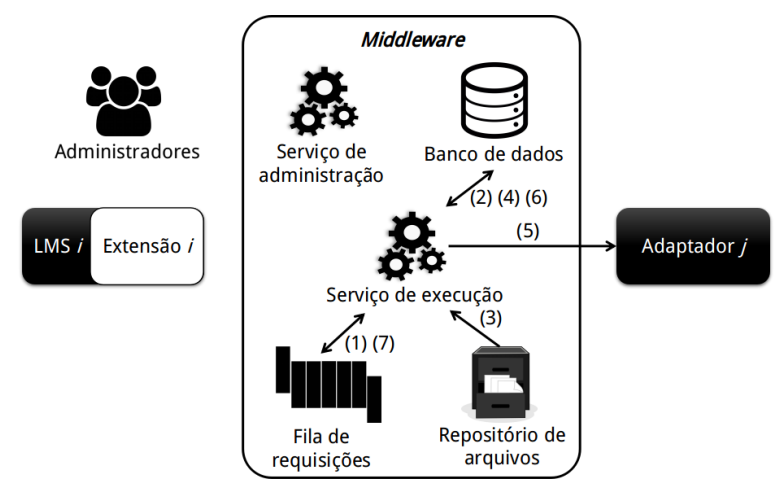

(d) Processamento de requisições em espera

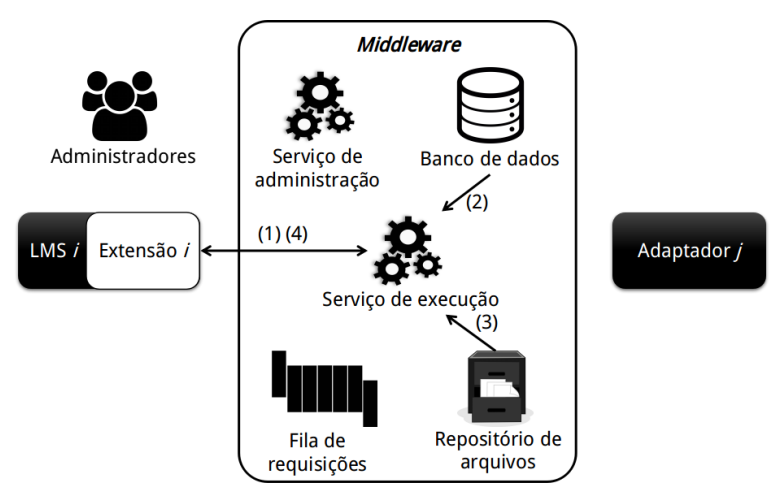

(f) Fornecimento de resultados de requisições

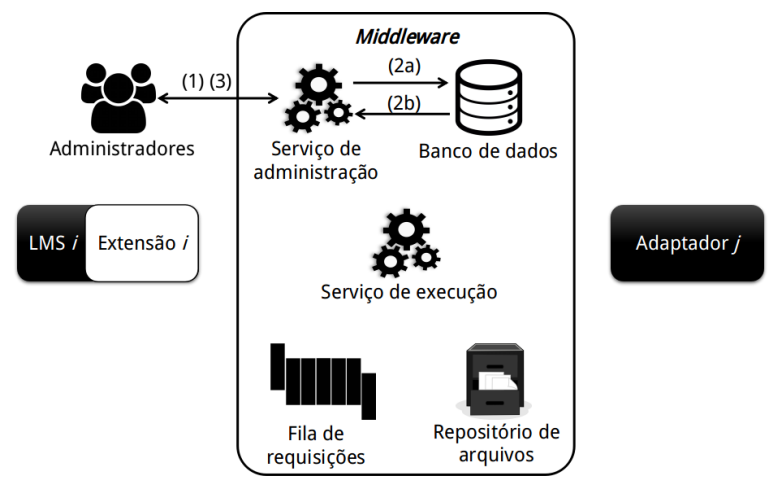

(g) Operações administrativas

Fonte: Elaborada pelo autor. 
de trabalhos de programação, sendo possível aos professores controlarem se estarão visíveis ou não aos alunos e a permissão ou não de submissão de soluções para os trabalhos. Tal controle pode também estar associado às datas de início e término dos trabalhos. Para cada trabalho, os professores podem adicionar, editar, remover e visualizar questões de programação. Se disponível, na adição ou edição de uma questão, o professor também pode selecionar uma questão de uma base de problemas, ao invés de definir a sua própria. Além disso, dependendo da ferramenta de avaliação considerada, é possível gerar e editar dados de teste que serão utilizados para verificar a correção dos programas dos alunos.

Figura 30 - Arquitetura IMPACTLE: Visão de casos de uso (Professor)

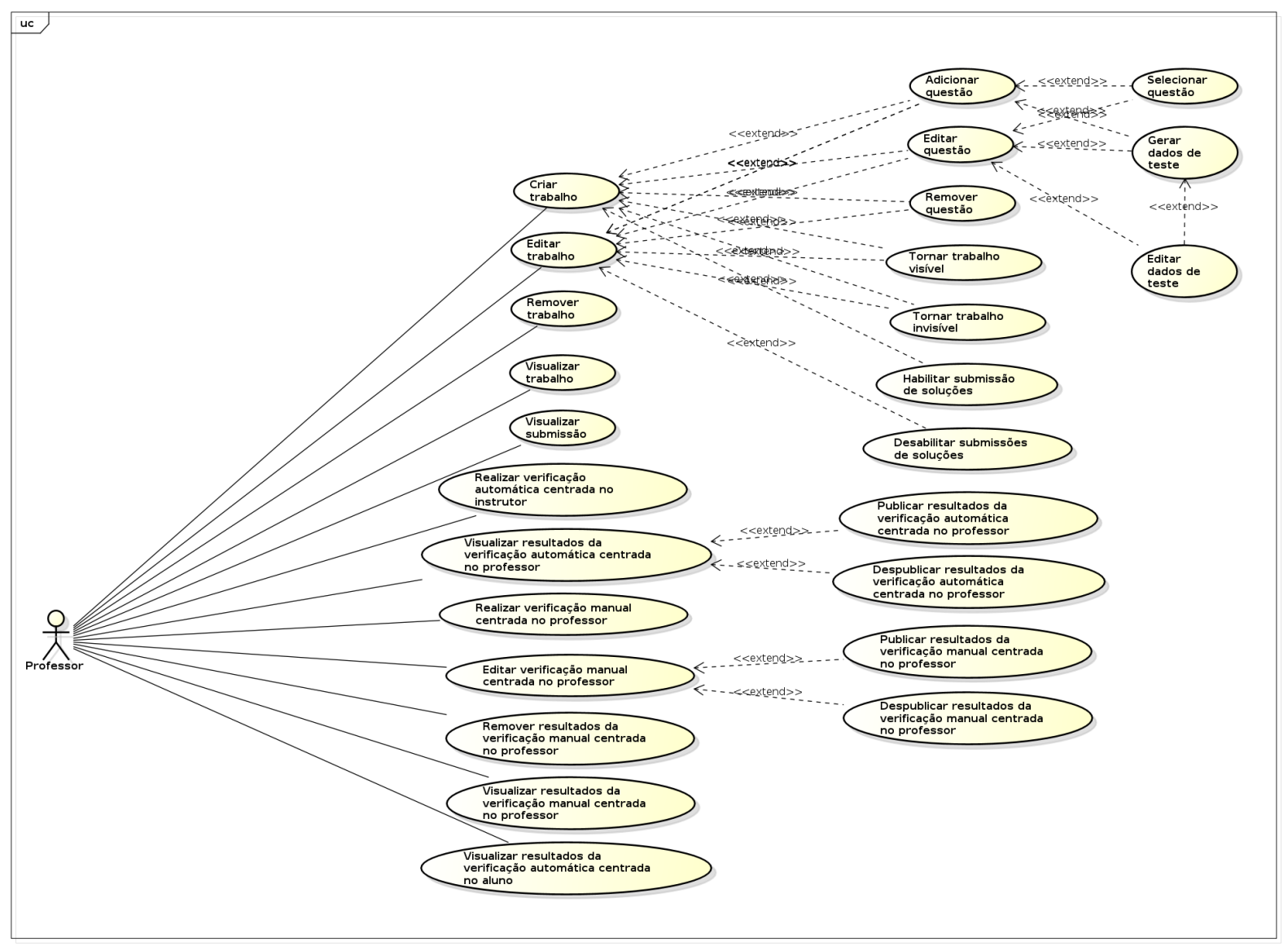

Fonte: Elaborada pelo autor.

Além da definição de trabalhos, também estão associados ao professor casos de uso relacionados à avaliação automática e manual de trabalhos de programação. Na avaliação automática, o professor pode executar a avaliação e visualizar os resultados, bem como controlar a visualização dos resultados pelos alunos. Na avaliação manual, o professor pode pontuar a solução dos alunos (acrescentando também outras informações de feedback) e controlar a visualização das pontuações e demais informações pelos alunos. Outra funcionalidade é a visualização dos resultados da avaliação automática centrada no aluno. No Quadro 27 são sumarizados todos os casos de uso do professor. 
Quadro 27 - Arquitetura IMPACTLE: Casos de uso (Professor)

\begin{tabular}{|c|c|}
\hline Caso de uso & Descrição \\
\hline Criar trabalho & $\begin{array}{l}\text { O professor define um novo trabalho de programação à ser atribuído aos } \\
\text { alunos. }\end{array}$ \\
\hline Editar trabalho & $\begin{array}{l}\text { O professor modifica a definição de um trabalho de programação previa- } \\
\text { mente criado por ele. }\end{array}$ \\
\hline Remover trabalho & $\begin{array}{l}\text { O professor exclui a definição de um trabalho programação previamente } \\
\text { criado por ele. }\end{array}$ \\
\hline Visualizar trabalho & $\begin{array}{l}\text { O professor visualiza a definição de um trabalho de programação previa- } \\
\text { mente criado por ele. }\end{array}$ \\
\hline Adicionar questão & $\begin{array}{l}\text { O professor adiciona uma questão à uma definição de trabalho de programa- } \\
\text { ção. }\end{array}$ \\
\hline Editar questão & $\begin{array}{l}\text { O professor modifica uma questão previamente adicionada à um trabalho } \\
\text { de programação. }\end{array}$ \\
\hline Remover questão & $\begin{array}{l}\text { O professor exclui uma questão previamente adicionada à um trabalho de } \\
\text { programação. }\end{array}$ \\
\hline Tornar trabalho visível & $\begin{array}{l}\text { O professor torna visível aos alunos um trabalho de programação definido } \\
\text { por ele. }\end{array}$ \\
\hline Tornar trabalho invisível & $\begin{array}{l}\text { O professor torna invisível aos alunos um trabalho de programação definido } \\
\text { por ele. }\end{array}$ \\
\hline Visualizar submissão & $\begin{array}{l}\text { O professor visualiza os dados da submissão de uma solução, realizada por } \\
\text { um aluno, à uma questão de um trabalho de programação previamente defi- } \\
\text { nido pelo professor em questão. }\end{array}$ \\
\hline Habilitar submissão de soluções & $\begin{array}{l}\text { O professor habilita a submissão de soluções pelos alunos às questões de } \\
\text { um trabalho de programação. }\end{array}$ \\
\hline Desabilitar submissão de soluções & $\begin{array}{l}\text { O professor desabilita a submissão de soluções pelos alunos às questões de } \\
\text { um trabalho de programação. }\end{array}$ \\
\hline Selecionar questão & $\begin{array}{l}\text { O professor seleciona uma questão da base de questões de uma ferramenta } \\
\text { para ser adicionada à um trabalho de programação. }\end{array}$ \\
\hline Gerar dados de teste & $\begin{array}{l}\text { O professor gera dados de teste para serem utilizados na verificação dos } \\
\text { programas submetidos pelos alunos. }\end{array}$ \\
\hline Editar dados de teste & $\begin{array}{l}\text { O professor modifica os dados de teste gerados para serem utilizados na } \\
\text { verificação dos programas submetidos pelos alunos. }\end{array}$ \\
\hline $\begin{array}{l}\text { Realizar verificação automática centrada no } \\
\text { professor }\end{array}$ & $\begin{array}{l}\text { O professor aciona a verificação automática das soluções submetidas pelos } \\
\text { alunos às questões de um trabalho. }\end{array}$ \\
\hline $\begin{array}{l}\text { Visualizar resultados da verificação automá- } \\
\text { tica centrada no professor }\end{array}$ & $\begin{array}{l}\text { O professor visualiza os resultados de uma verificação automática previa- } \\
\text { mente acionada por ele. }\end{array}$ \\
\hline $\begin{array}{l}\text { Publicar resultados da verificação automá- } \\
\text { tica centrada no professor }\end{array}$ & $\begin{array}{l}\text { O professor torna disponível aos alunos os resultados de uma verificação } \\
\text { automática acionada por ele. }\end{array}$ \\
\hline $\begin{array}{l}\text { Despublicar resultados da verificação auto- } \\
\text { mática centrada no professor }\end{array}$ & $\begin{array}{l}\text { O professor torna indisponível aos alunos os resultados de uma verificação } \\
\text { automática acionada por ele. }\end{array}$ \\
\hline $\begin{array}{l}\text { Realizar verificação manual centrada no } \\
\text { professor }\end{array}$ & $\begin{array}{l}\text { O professor realiza a verificação manual de uma solução submetida por um } \\
\text { aluno à uma questão de um trabalho, atribuindo pontuações, anotações e/ou } \\
\text { comentários. }\end{array}$ \\
\hline $\begin{array}{l}\text { Editar verificação manual centrada no pro- } \\
\text { fessor }\end{array}$ & $\begin{array}{l}\text { O professor modifica as pontuações, anotações e/ou comentários associados } \\
\text { à uma verificação manual previamente realizada por ele. }\end{array}$ \\
\hline $\begin{array}{l}\text { Publicar verificação manual centrada no } \\
\text { professor }\end{array}$ & $\begin{array}{l}\text { O professor torna disponível aos alunos as pontuações, anotações e/ou co- } \\
\text { mentários associados às verificações manuais realizadas por ele nas solu- } \\
\text { ções submetidas pelos alunos às questões de um trabalho. }\end{array}$ \\
\hline $\begin{array}{l}\text { Despublicar verificação manual centrada no } \\
\text { professor }\end{array}$ & $\begin{array}{l}\text { O professor torna indisponível aos alunos as pontuações, anotações e/ou } \\
\text { comentários associados às verificações manuais realizadas por ele nas solu- } \\
\text { ções submetidas pelos alunos às questões de um trabalho. }\end{array}$ \\
\hline $\begin{array}{l}\text { Visualizar verificação manual centrada no } \\
\text { professor }\end{array}$ & $\begin{array}{l}\text { O professor visualiza as pontuações, anotações e/ou comentários associados } \\
\text { à uma verificação manual previamente realizada por ele. }\end{array}$ \\
\hline $\begin{array}{l}\text { Remover verificação manual centrada no } \\
\text { professor }\end{array}$ & $\begin{array}{l}\text { O professor exclui as pontuações, anotações e/ou comentários associados à } \\
\text { uma verificação manual previamente realizada por ele. }\end{array}$ \\
\hline $\begin{array}{l}\text { Visualizar resultados da verificação automá- } \\
\text { tica centrada no aluno }\end{array}$ & $\begin{array}{l}\text { O professor visualiza os resultados de uma verificação automática acionada } \\
\text { por um aluno, sendo que a solução foi submetida pelo aluno à uma questão } \\
\text { de um trabalho definido pelo professor em questão. }\end{array}$ \\
\hline
\end{tabular}

Fonte: Elaborada pelo autor. 


\subsubsection{Casos de uso do aluno}

No diagrama da Figura 31 são ilustrados os casos de uso para o aluno. Os cenários de uso relacionados aos alunos incluem a visualização de trabalhos, submissão de soluções e funcionalidades relacionados à avaliação automática e manual de trabalhos. Assim, os alunos podem executar uma avaliação automática das suas soluções e visualizar os resultados, bem como visualizar os resultados das avaliações centradas no professor. No Quadro 28 são sumarizados os casos de uso do aluno.

Figura 31 - Arquitetura IMPACTLE: Visão de casos de uso (Aluno)

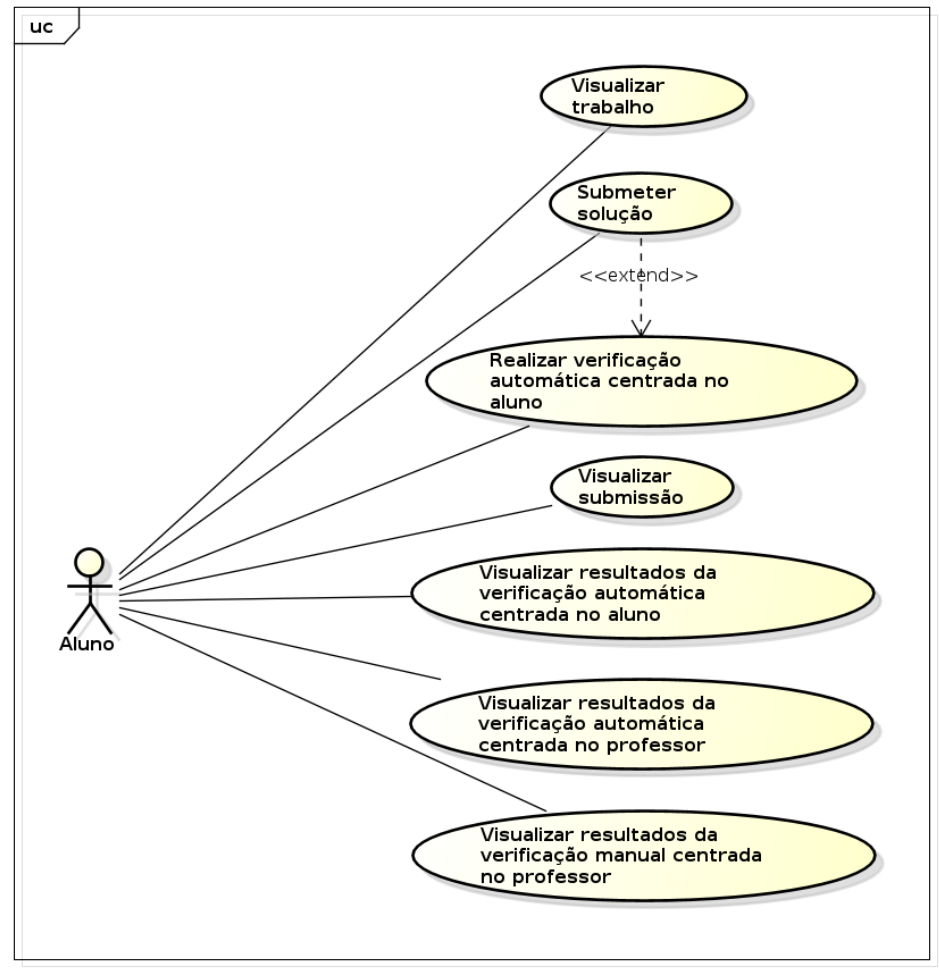

Fonte: Elaborada pelo autor.

\subsubsection{Visão lógica}

A visão lógica está relacionada com os requisitos funcionais do sistema, ilustrando quais as funcionalidades que o sistema deve fornecer aos usuários.

$\mathrm{Na}$ arquitetura IMPACTLE, a visão lógica (Figura 46) envolve quatro tipos de subsistemas: (1) os LMSs, nos quais os alunos e professores realizam as atividades de ensino e aprendizagem; (2) o middleware, responsável pela comunicação entre os diferentes LMSs e as diferentes ferramentas de avaliação; (3) os adaptadores, que proveem uma interface de comunicação padrão entre o middleware e as ferramentas de avaliação; e (4) as ferramentas de avaliação para trabalhos práticos de programação, que proveem as funcionalidades relacio- 
Quadro 28 - Arquitetura IMPACTLE: Casos de uso (Aluno)

\begin{tabular}{|l|l|}
\hline Caso de uso & Descrição \\
\hline \hline Visualizar trabalho & $\begin{array}{l}\text { O aluno visualiza os dados de um trabalho de programação definido para } \\
\text { um curso em que o aluno está matriculado. }\end{array}$ \\
\hline Submeter solução & $\begin{array}{l}\text { O aluno submete uma solução à uma questão de um trabalho de programa- } \\
\text { ção. }\end{array}$ \\
\hline Visualizar submissão & O aluno visualiza os dados de uma submissão realizada por ele. \\
\hline $\begin{array}{l}\text { Realizar verificação automática centrada no } \\
\text { aluno }\end{array}$ & O aluno aciona a verificação automática de uma solução submetida por ele. \\
\hline $\begin{array}{l}\text { Verificar resultados da verificação automá- } \\
\text { tica centrada no aluno }\end{array}$ & $\begin{array}{l}\text { O aluno visualiza os resultados de uma verificação automática acionada por } \\
\text { ele. }\end{array}$ \\
\hline $\begin{array}{l}\text { Verificar resultados da verificação automá- } \\
\text { tica centrada no professor }\end{array}$ & $\begin{array}{l}\text { O aluno visualiza os resultados associados a solução dele, gerados por meio } \\
\text { de uma verificação automática acionada pelo professor sobre as soluções } \\
\text { submetidas à uma questão. }\end{array}$ \\
\hline $\begin{array}{l}\text { Verificar resultados da verificação manual } \\
\text { centrada no professor }\end{array}$ & $\begin{array}{l}\text { O aluno visualiza as pontuações, anotações e/ou comentários resultantes de } \\
\text { uma verificação manual realizada pelo professor em uma solução submetida } \\
\text { pelo aluno. }\end{array}$ \\
\hline
\end{tabular}

Fonte: Elaborada pelo autor.

nadas à avaliação dos trabalhos. No Quadro 37 são sumarizados os quatro tipos de subsistemas que a arquitetura IMPACTLE envolve.

Quadro 29 - Arquitetura IMPACTLE: Subsistemas

\begin{tabular}{|l|l|}
\hline Subsistema & Descrição \\
\hline \hline LMS & $\begin{array}{l}\text { Sistemas de gestão de aprendizagem, com funcionalidades que apoiam o processo de apren- } \\
\text { dizagem em geral. Exemplos são o Blackboard (Blackboard Inc., 2017), o Chamilo (The } \\
\text { Chamilo Association, 2017) e o Moodle (Moodle Community, 2016), entre outros. }\end{array}$ \\
\hline Middleware & $\begin{array}{l}\text { Sistema central responsável em gerenciar a comunicação e a troca de dados entre os LMSs } \\
\text { e as ferramentas de avaliação. }\end{array}$ \\
\hline Adaptador & $\begin{array}{l}\text { Adapta uma ferramenta de avaliação, provendo uma interface padrão para acesso às funcio- } \\
\text { nalidades da ferramenta. }\end{array}$ \\
\hline Ferramenta de avaliação & $\begin{array}{l}\text { Ferramenta de avaliação para trabalho de programação. Exemplos são a ferramenta } \\
\text { BOCA (DE-CAMPOS; FERREIRA, 2004), a ProgTest (SOUZA et al., 2014) e a Web- } \\
\text { CAT (EDWARDS, 2014), entre outras. }\end{array}$ \\
\hline
\end{tabular}

Fonte: Elaborada pelo autor.

No Quadro 30 são sumarizados os componentes necessários nos LMSs. Basicamente, os LMSs devem conter uma extensão que implemente um conjunto de operações definidas pela arquitetura. A extensão deve ser capaz de acessar o serviço de execução, componente lógico do subsistema middleware.

Quadro 30 - Arquitetura IMPACTLE: Visão lógica (Componentes dos LMSs)

\begin{tabular}{|l|l|}
\hline Componente & Descrição \\
\hline Extensão & $\begin{array}{l}\text { Estende um LMS, incluindo as funcionalidades de definição, submissão e avaliação de trabalhos de } \\
\text { programação. De acordo com as especificidades de cada LMS, pode ser um serviço web, um plugin } \\
\text { para o LMS, uma nova aplicação ou até mesmo um conjunto de funcionalidades adicionadas à uma } \\
\text { nova versão do LMS. }\end{array}$ \\
\hline
\end{tabular}

Fonte: Elaborada pelo autor.

No Quadro 31 são sintetizados os componentes do middleware. Em síntese, o middleware é composto pelo serviço de administração e o serviço de execução, bem 
Figura 32 - Arquitetura IMPACTLE: Visão lógica

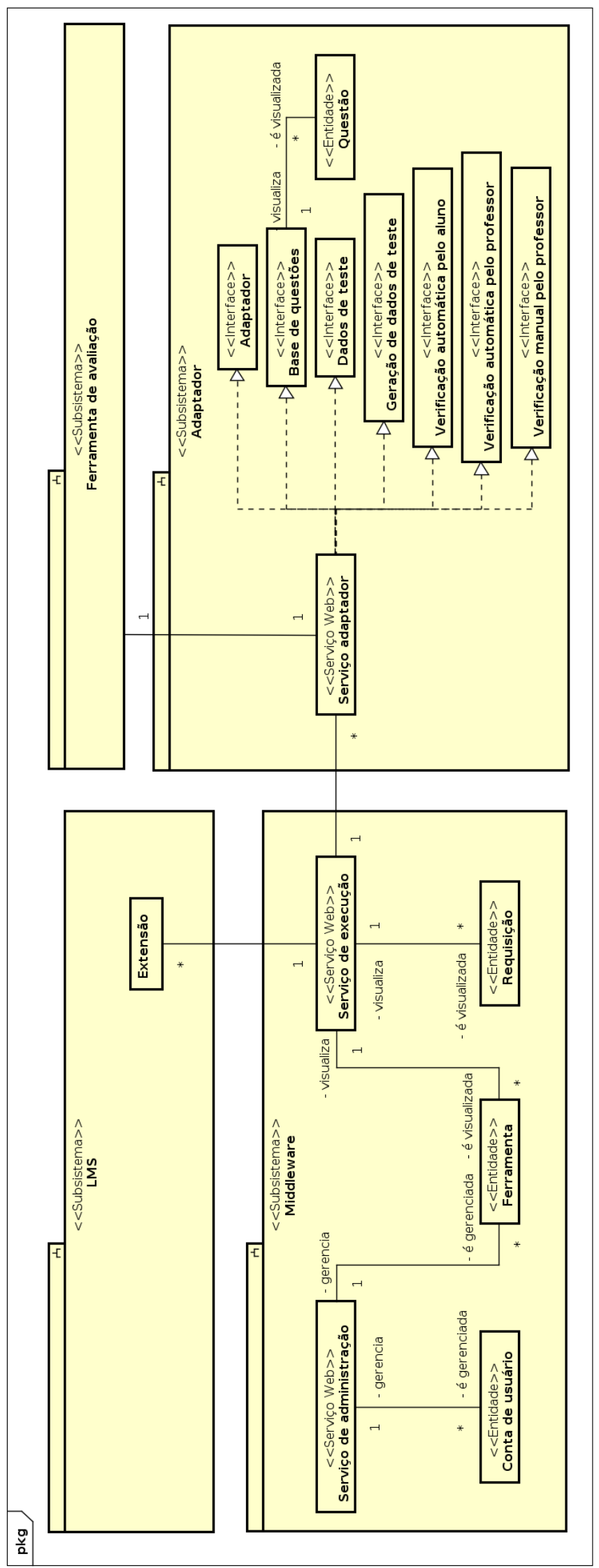

Fonte: Elaborada pelo autor. 
como as entidades conta de usuário, ferramenta e requisição, que definem os dados que os serviços manipulam.

Quadro 31 - Arquitetura IMPACTLE: Visão lógica (Componentes do middleware)

\begin{tabular}{|l|l|}
\hline Componente & Descrição \\
\hline Serviço de administração & $\begin{array}{l}\text { Serviço web pelo qual administradores podem realizar a manutenção do middleware. Em es- } \\
\text { pecial, permite que mantenedores de ferramentas registrem as suas ferramentas e respectivos } \\
\text { adaptadores para serem disponibilizados aos LMSs. }\end{array}$ \\
\hline Serviço de execução & $\begin{array}{l}\text { Serviço web responsável por receber e processar as requisições provindas dos LMSs e } \\
\text { encaminhando-as, quando necessário, para o adaptador de uma ferramenta de avaliação. }\end{array}$ \\
\hline Conta de usuário & Entidade para manipulação e persistência dos dados dos administradores. \\
\hline Ferramenta & $\begin{array}{l}\text { Entidade para manipulação e persistência dos dados das ferramentas e respectivos adaptadores } \\
\text { registrados no middleware. }\end{array}$ \\
\hline Requisição & $\begin{array}{l}\text { Entidade para manipulação e persistência dos dados das requisiçães recebidas pelo serviço de } \\
\text { execução. }\end{array}$ \\
\hline
\end{tabular}

Fonte: Elaborada pelo autor.

O serviço de administração tem por finalidade o gerenciamento do registro dos adaptadores no middleware, enquanto o serviço de execução tem por finalidade receber e responder as requisições das extensões dos LMSs, em alguns casos, encaminhando-as para o componente serviço adaptador do adaptador da ferramenta de avaliação em questão e recuperando os resultados retornados por ele.

O middleware deve conter apenas uma única instância do serviço de administração, que gerencia várias instâncias de contas de usuário e ferramentas. De forma análoga, o middleware deve conter também somente uma instância do serviço de execução, que pode acessar as várias instâncias de registros de ferramentas e gerencia várias instâncias de requisições.

Por sua vez, no Quadro 32 são sumarizados os componentes lógicos dos adaptadores. Assim, o serviço adaptador de um adaptador deve implementar as interfaces definidas de acordo com as funcionalidades da ferramenta de avaliação que ele adapta. Todos os serviços de adaptador devem implementar a interface adaptador e pelo menos uma das interfaces verificação automática pelo professor, verificação manual pelo professor e verificação automática pelo aluno.

Em especial, quando um adaptador implementa a interface base de questões, que permite a utilização de uma base de problemas mantida pela ferramenta de avaliação adaptada, o adaptador também deve manter um registro das questões disponíveis na ferramenta.

$\mathrm{O}$ adaptador deve se comunicar com a ferramenta de avaliação durante a execução das operações. Similarmente às extensões e os LMSs, a forma em que o adaptador e a ferramenta de avaliação se comunicam é uma decisão de projeto a ser tomada de acordo com a especificidade de cada ferramenta de avaliação considerada.

Por fim, é importante observar que a arquitetura IMPACTLE não define mudanças na estrutura das ferramentas de avaliação. A ideia é que qualquer ferramenta de avaliação para trabalhos práticos de programação possa ser integrada ao sistema sem ser modificada, consi- 
Quadro 32 - Arquitetura IMPACTLE: Visão lógica (Componentes do adaptador)

\begin{tabular}{|l|l|}
\hline Componente & Descrição \\
\hline \hline Serviço adaptador & $\begin{array}{l}\text { Serviço web responsável em receber requisições do middleware, processá-las, e retor- } \\
\text { nar os resultados, utilizando as ferramentas de avaliação associadas quando necessário. }\end{array}$ \\
\hline Adaptador & $\begin{array}{l}\text { Interface que define os métodos essenciais que devem ser implementados pelo serviço } \\
\text { adaptador. }\end{array}$ \\
\hline Base de questões & $\begin{array}{l}\text { Interface que define os métodos a serem implementados pelo serviço adaptador, quando } \\
\text { a ferramenta de avaliação associada possui uma base de questões. }\end{array}$ \\
\hline Geração de dados de teste & $\begin{array}{l}\text { Interface que define os métodos a serem implementados pelo serviço adaptador, quando } \\
\text { a ferramenta de avaliação associada permite a geração de dados de teste para serem } \\
\text { utilizados na verificação das soluçôes a serem submetidas pelos alunos. }\end{array}$ \\
\hline $\begin{array}{l}\text { Verificação automática pelo } \\
\text { professor }\end{array}$ & $\begin{array}{l}\text { Interface que define os métodos a serem implementados pelo serviço adaptador, quando } \\
\text { a ferramenta de avaliação associada permite que o professor acione uma verificação } \\
\text { automática das soluções submetidas pelos alunos. }\end{array}$ \\
\hline $\begin{array}{l}\text { Verificação manual pelo profes- } \\
\text { sor }\end{array}$ & $\begin{array}{l}\text { Interface que define os métodos a serem implementados pelo serviço adaptador, quando } \\
\text { a ferramenta de avaliação associada permite que o professor realize uma verificação } \\
\text { manual das soluções submetidas pelos alunos. }\end{array}$ \\
\hline $\begin{array}{l}\text { Verificação automática pelo } \\
\text { aluno }\end{array}$ & $\begin{array}{l}\text { Interface que define os métodos a serem implementados pelo serviço adaptador, quando } \\
\text { a ferramenta de avaliação associada permite que o aluno acione uma verificação auto- } \\
\text { mática de uma solução submetida por ele. }\end{array}$ \\
\hline Questão & $\begin{array}{l}\text { Entidade para manipulação e persistência dos dados das questões disponibilizadas na } \\
\text { base de questões da ferramenta associada. }\end{array}$ \\
\hline
\end{tabular}

Fonte: Elaborada pelo autor.

derando apenas a presença de um adaptador que possibilite a comunicação entre o middleware e a ferramenta de avaliação por meio de uma interface padrão.

Mais detalhes sobre cada um dos componentes da visão lógica da arquitetura IMPACTLE podem ser encontradas no Apêndice A.1.

\subsubsection{Visão de processos}

A visão de processos está relacionada com os aspectos dinâmicos do sistema, ilustrando seu comportamento em tempo de execução. No Quadro 33 os principais processos definidos para a arquitetura IMPACTLE são sintetizados.

Para ilustrar, na Figura 33 é apresentado o comportamento da arquitetura durante a submissão de uma solução desenvolvida por um aluno para uma questão. Em síntese, o LMS obtém e exibe ao aluno um formulário de submissão, para que o aluno informe os dados da submissão. $\mathrm{O}$ formulário é mantido pelo adaptador da ferramenta associada à questão e é obtido pelo LMS por meio do middleware. Em geral, os dados da submissão consistem em um arquivo com o código fonte do programa desenvolvido pelo aluno, mas pode incluir arquivos de teste desenvolvidos pelos alunos, arquivos de documentação, resultados de uma verificação offline, dentre outros.

Assim, o comportamento da arquitetura durante a submissão de uma solução é o seguinte:

1. O aluno seleciona a opção de submeter uma solução para uma questão, disponibilizada pela extensão do LMS. 
Quadro 33 - Arquitetura IMPACTLE: Visão de processos (Principais processos)

\begin{tabular}{|c|c|}
\hline Processos & Descrição \\
\hline $\begin{array}{l}\text { Definição de um traba- } \\
\text { lho prático }\end{array}$ & $\begin{array}{l}\text { Quando o professor seleciona a opção para criar um trabalho de programação, o LMS, por meio } \\
\text { do middleware, obtém a lista de ferramentas disponíveis. Repetitivamente, o professor pode } \\
\text { adicionar questões ao trabalho, informando a ferramenta que deverá avaliar as soluções enviadas } \\
\text { à cada questão. Cada vez que o professor seleciona a opção para adicionar uma questão, o LMS, } \\
\text { por meio do middleware, obtém do adaptador da ferramenta o formulário de questões. Tal } \\
\text { formulário especifica os dados e arquivos que a ferramenta necessita do professor para avaliar as } \\
\text { soluções. Após preencher o formulário, o professor pode salvar os dados e arquivos associados } \\
\text { à questão, que são armazenados no LMS. Encerrada a adição de questões, o professor pode salvar } \\
\text { os dados do trabalho, que também são armazenado no LMS. }\end{array}$ \\
\hline $\begin{array}{l}\text { Seleção de questão de } \\
\text { uma base de questões }\end{array}$ & $\begin{array}{l}\text { Quando o professor seleciona a opção para adicionar uma questão de uma determinada ferra- } \\
\text { menta, o LMS, por meio do middleware, obtém do adaptador da ferramenta a lista de questões } \\
\text { da base da ferramenta. Em seguida, o professor pode selecionar uma questão da lista. O LMS, } \\
\text { novamente por meio do middleware, obtém do adaptador os dados da questão, que podem ser } \\
\text { visualizados, editados e salvos como uma questão para o trabalho. }\end{array}$ \\
\hline $\begin{array}{l}\text { Geração de dados de } \\
\text { teste para uma questão }\end{array}$ & $\begin{array}{l}\text { Inicialmente, a extensão obtém e exibe ao professor um formulário para a adição dos dados } \\
\text { de entrada. O formulário é mantido pelo adaptador da ferramenta associada à questão e é obtido } \\
\text { pelo ambiente por meio do middleware. Quando o professor salva os dados de entrada, a } \\
\text { extensão requisita ao middleware o processamento dos dados preenchidos pelo professor, } \\
\text { enviando todos os dados e arquivos associados, bem como informando a ferramenta que deverá } \\
\text { ser utilizada para a geração. O middleware, por sua vez, adiciona a requisição em um fila } \\
\text { de processamento e retorna à extensão um identificador, para que a extensão recupere os } \\
\text { resultados posteriormente. }\end{array}$ \\
\hline $\begin{array}{l}\text { Submissão de uma solu- } \\
\text { ção }\end{array}$ & $\begin{array}{l}\text { O LMS obtém e exibe ao aluno um formulário de submissão, para que o aluno informe os } \\
\text { dados da submissão. O formulário é mantido pelo adaptador da ferramenta associada à questão } \\
\text { e é obtido pelo LMS por meio do middleware. Em geral, os dados da submissão consistem em } \\
\text { um arquivo com o código fonte do programa desenvolvido pelo aluno, mas pode incluir arquivos } \\
\text { de teste desenvolvidos pelos alunos, arquivos de documentação, resultados de uma verificação } \\
\text { offline, dentre outros. }\end{array}$ \\
\hline $\begin{array}{l}\text { Avaliação automática } \\
\text { centrada no professor }\end{array}$ & $\begin{array}{l}\text { A extensão requisita ao middleware a realização da avaliação, enviando todos os dados e } \\
\text { arquivos necessários, bem como informando a ferramenta que deverá ser utilizada para a avalia- } \\
\text { ção. O middleware, por sua vez, adiciona a requisição em um fila de processamento e retorna } \\
\text { à extensão um identificador, para que a extensão recupere os resultados posteriormente. }\end{array}$ \\
\hline $\begin{array}{l}\text { Avaliação manual cen- } \\
\text { trada no professor }\end{array}$ & $\begin{array}{l}\text { Inicialmente, a extensão obtém e exibe ao professor um formulário para a avaliação manual. } \\
\text { O formulário é mantido pelo adaptador da ferramenta associada à questão e é obtido pelo ambi- } \\
\text { ente por meio do middleware. De forma análoga à avaliação automática, quando o professor } \\
\text { salva os resultados da avaliação, a extensão requisita ao middleware o processamento dos } \\
\text { dados preenchidos pelo professor, enviando todos os dados e arquivos associados, bem como } \\
\text { informando a ferramenta que deverá ser utilizada para a avaliação. O middleware, por sua vez, } \\
\text { adiciona a requisição em um fila de processamento e retorna à extensão um identificador, para } \\
\text { que a extensão recupere os resultados posteriormente. }\end{array}$ \\
\hline $\begin{array}{l}\text { Avaliação automática } \\
\text { centrada no aluno }\end{array}$ & $\begin{array}{l}\text { De forma análoga à avaliação automática centrada no professor, a extensão requisita ao } \\
\text { middleware a realização da avaliação, enviando todos os dados e arquivos necessários, bem } \\
\text { como informando a ferramenta que deverá ser utilizada para a avaliação. O middleware, por } \\
\text { sua vez, adiciona a requisição em um fila de processamento e retorna à extensão um identifi- } \\
\text { cador, para que a extensão recupere os resultados posteriormente. }\end{array}$ \\
\hline $\begin{array}{l}\text { Processamento de uma } \\
\text { requisição em espera }\end{array}$ & $\begin{array}{l}\text { O middleware remove a requisição da fila de processamento, carrega os dados da requisição, } \\
\text { verifica qual ferramenta está associada à requisição e aciona a avaliação por meio do adap- } \\
\text { tador da ferramenta. O adaptador da ferramenta retorna um identificador externo para que o } \\
\text { middleware possa recuperar os resultados posteriormente. Por fim, o middleware atualiza os } \\
\text { dados da requisição e a adiciona novamente na fila de processamento. }\end{array}$ \\
\hline $\begin{array}{l}\text { Obtenção dos resulta- } \\
\text { dos de uma requisição } \\
\text { em processamento }\end{array}$ & $\begin{array}{l}\text { De forma análoga ao processamento de uma requisição em espera, o middleware remove a } \\
\text { requisição da fila de processamento, carrega os dados da requisição, verifica qual ferramenta } \\
\text { está associada à requisição e recupera os resultados da avaliação por meio do adaptador da } \\
\text { ferramenta. O middleware salva os resultados, atualiza os dados da requisição e a adiciona } \\
\text { novamente na fila de processamento. }\end{array}$ \\
\hline $\begin{array}{l}\text { Obtenção dos resulta- } \\
\text { dos de uma requisição } \\
\text { pronta }\end{array}$ & A extensão obtém os resultados do serviço de execução e os armazenam no LMS. \\
\hline
\end{tabular}

Fonte: Elaborada pelo autor. 
Figura 33 - Arquitetura IMPACTLE: Visão de processos (Submissão de uma solução)

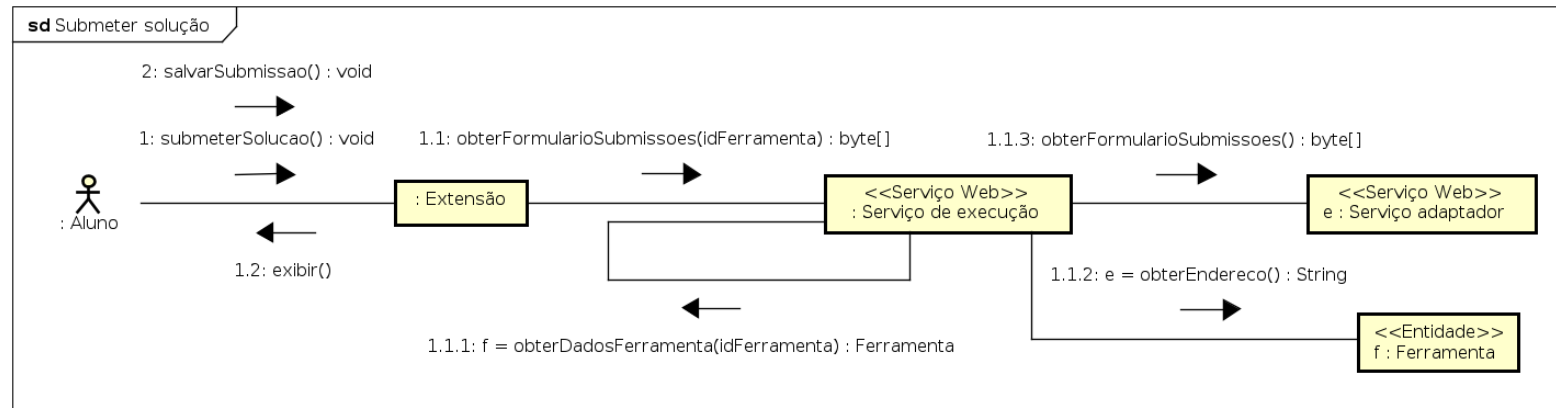

Fonte: Elaborada pelo autor.

a) A extensão requisita ao serviço de execução do middleware o formulário de submissão, enviando o "id" da ferramenta de avaliação.

i. O serviço de execução instancia o registro da ferramenta de avaliação.

ii. O serviço de execução obtém o endereço web do serviço adaptador da ferramenta.

iii. O serviço de execução encaminha a requisição do formulário ao serviço adaptador da ferramenta, retornando o resultado da requisição à extensão.

b) A extensão exibe o formulário ao aluno.

2. O aluno preenche o formulário e salva a submissão por meio da extensão.

Detalhes sobre os demais processos podem ser encontradas no Apêndice A.2.

\subsubsection{Visão de implementação}

A visão de implementação está relacionada ao gerenciamento da aplicação, ilustrando como os módulos da aplicação são organizados.

Na Figura 34 é ilustrada a visão de implementação da arquitetura IMPACTLE. Em síntese, a visão é composta pelas unidades de implementação do sistema e as interfaces entre eles. Como é possível observar, dois tipos de unidades são definidas: essenciais e adicionais. As unidades essenciais, como o próprio nome diz, são fundamentais para o funcionamento do sistema e devem ser instanciadas. Por outro lado, a instanciação ou não das unidades adicionais varia de acordo com a especificidade das unidades essenciais instanciadas. Por exemplo, se uma unidade essencial ferramenta de avaliação for instanciada como uma ferramenta de avaliação que necessita de um banco de dados para persistência dos dados (por exemplo, PROGTEST, WEB-CAT e BOCA), então uma unidade adicional banco de dados da ferramenta de avaliação também deverá ser instanciada. No Quadro 34 são sumarizadas as unidades de implementação da arquitetura IMPACTLE. 
Figura 34 - Arquitetura IMPACTLE: Visão de implementação

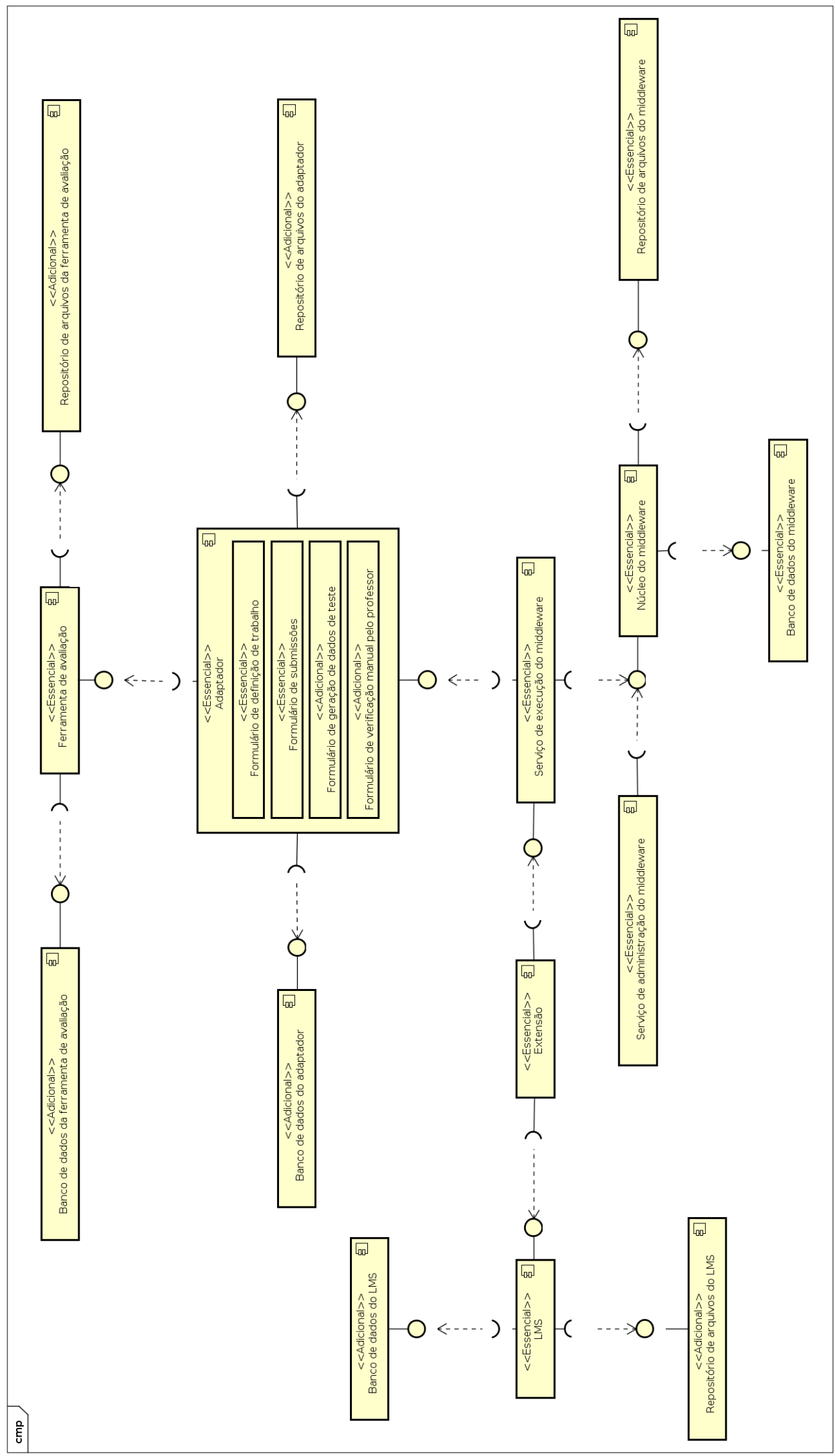

Fonte: Elaborada pelo autor. 
Quadro 34 - Arquitetura IMPACTLE: Visão de implementação (Unidades de implementação)

\begin{tabular}{|c|c|}
\hline Unidades & Descrição \\
\hline LMS & $\begin{array}{l}\text { Um LMS pelo qual os usuários terão acesso às funcionalidades das ferramentas de } \\
\text { avaliação. }\end{array}$ \\
\hline Banco de dados do LMS & $\begin{array}{l}\text { A maioria dos LMSs requerem um banco de dados para armazenar os dados dos usuá- } \\
\text { rios, cursos, atividades, entre outros. }\end{array}$ \\
\hline $\begin{array}{l}\text { Repositório de arquivos do } \\
\text { LMS }\end{array}$ & $\begin{array}{l}\text { A maioria dos LMSs requerem um repositório de arquivos para armazenar materiais de } \\
\text { conteúdo, submissões de alunos à atividades, entre outros. }\end{array}$ \\
\hline Extensão & $\begin{array}{l}\text { Unidade de um LMS responsável em estender as suas funcionalidades, adicionando } \\
\text { acesso às funcionalidades das ferramentas de avaliação. }\end{array}$ \\
\hline $\begin{array}{l}\text { Serviço de execução do mid- } \\
\text { dleware }\end{array}$ & $\begin{array}{l}\text { Implementa o serviço de execução do middleware, responsável em receber e proces- } \\
\text { sar as requisições provindas dos LMSs, quando necessário encaminhando-as para um } \\
\text { adaptador de ferramenta. }\end{array}$ \\
\hline $\begin{array}{l}\text { Serviço de administração do } \\
\text { middleware }\end{array}$ & $\begin{array}{l}\text { Implementa o serviço de administração do middleware, por onde administradores po- } \\
\text { dem manter os registros de ferramentas a serem disponibilizadas aos LMSs. }\end{array}$ \\
\hline Núcleo do middleware & $\begin{array}{l}\text { Implementa os mecanismos de manipulação e persistência dos dados que serão utiliza- } \\
\text { dos pelo serviço de execução e pelo serviço de administração. }\end{array}$ \\
\hline Banco de dados do middleware & $\begin{array}{l}\text { Banco de dados para armazenar os dados persistentes a serem manipulados pelo mid- } \\
\text { dleware (contas de usuário, registros de ferramenta e requisições). }\end{array}$ \\
\hline $\begin{array}{l}\text { Repositório de arquivos do mid- } \\
\text { dleware }\end{array}$ & $\begin{array}{l}\text { Repositório de arquivos para armazenar os arquivos a serem manipulados pelo mid- } \\
\text { dleware (como pro exemplo, os programas submetidos pelos alunos, que serão encami- } \\
\text { nhados à uma ferramenta de avaliação) }\end{array}$ \\
\hline Adaptador & $\begin{array}{l}\text { Implementa um serviço }\{\text { web }\} \text { que provê uma comunicação padrão entre o middleware } \\
\text { e uma ferramenta de avaliação. }\end{array}$ \\
\hline Banco de dados do adaptador & $\begin{array}{l}\text { Um banco de dados para o adaptador pode ser necessário para armazenar dados persis- } \\
\text { tentes. }\end{array}$ \\
\hline $\begin{array}{l}\text { Repositório de arquivos do } \\
\text { adaptador }\end{array}$ & $\begin{array}{l}\text { Um repositório de arquivos pode ser necessário para armazenar os arquivos enviados } \\
\text { pelo middleware. }\end{array}$ \\
\hline Ferramenta de avaliação & Uma ferramenta de avaliação para trabalhos de programação. \\
\hline $\begin{array}{l}\text { Banco de dados da ferramenta } \\
\text { de avaliação }\end{array}$ & $\begin{array}{l}\text { A maioria das ferramentas de avaliação requerem um banco de dados para armazenar } \\
\text { os dados relacionados ao processo de avaliação. }\end{array}$ \\
\hline $\begin{array}{l}\text { Repositório de arquivos da fer- } \\
\text { ramenta de avaliação }\end{array}$ & $\begin{array}{l}\text { A maioria das ferramentas de avaliação requerem um repositório de arquivos para ar- } \\
\text { mazenar as soluções submetidas pelos alunos e os relatórios resultantes do processo de } \\
\text { avaliação. }\end{array}$ \\
\hline
\end{tabular}

Fonte: Elaborada pelo autor.

Em especial, as unidades do tipo adaptador devem possuir alguns artefatos associados, que por sua vez, são requisitados pelo LMS em situações específicas. No Quadro 35 são sumarizados os artefatos que dever ser disponibilizados pelos adaptadores.

Quadro 35 - Arquitetura IMPACTLE: Visão de implementação (Artefatos)

\begin{tabular}{|l|l|}
\hline Artefatos & Descrição \\
\hline \hline $\begin{array}{l}\text { Formulário de definição de tra- } \\
\text { balho }\end{array}$ & $\begin{array}{l}\text { Este artefato deve estar presente em todos os adaptadores. Ele define quais informações } \\
\text { e arquivos o professor deverá fornecer durante a definição de um trabalho de progra- } \\
\text { mação para considerar a ferramenta associada ao adaptador na avaliação das soluções } \\
\text { submetidas pelos alunos. }\end{array}$ \\
\hline Formulário de submissões & $\begin{array}{l}\text { Este artefato deve estar presente em todos os adaptadores. Ele define quais informações } \\
\text { e arquivos os alunos deverão fornecer durante a submissão para que suas soluções seja } \\
\text { avaliadas pela ferramenta associada ao adaptador. }\end{array}$ \\
\hline $\begin{array}{l}\text { Formulário de geração de dados } \\
\text { de teste }\end{array}$ & $\begin{array}{l}\text { Este artefato deve estar presente nos adaptadores das ferramentas que geram casos de } \\
\text { teste para serem utilizados na avaliação dos programas dos alunos. Ele define quais } \\
\text { informações são necessárias para que a ferramenta associada ao adaptador gere os casos } \\
\text { de teste. }\end{array}$ \\
\hline $\begin{array}{l}\text { Formulário de verificação ma- } \\
\text { nual pelo professor }\end{array}$ & $\begin{array}{l}\text { Este artefato deve estar presente nos adaptadores das ferramentas que fornecem apoio } \\
\text { à avaliação manual pelo professor. Ele define quais informações sobre a qualidade das } \\
\text { soluções dos alunos os professores devem fornecer. }\end{array}$ \\
\hline
\end{tabular}

Fonte: Elaborada pelo autor. 


\subsubsection{Visão física}

A visão física está relacionada aos componentes físicos que envolvem a aplicação, ilustrando as características dos componentes físicos necessários para executar a aplicação e as conexões entre eles.

Na Figura 35 é ilustrada a visão física da arquitetura IMPACTLE. Como é possível observar, as visões de implementação e a visão física são relacionadas entre si. No entanto, a visão física tem por objetivo ilustrar como os componentes do sistema se relacionam com os dispositivos físicos associados ao sistema. No Quadro 36 são sumarizados os dispositivos físicos previstos.

Quadro 36 - Arquitetura IMPACTLE: Visão física (Dispositivos)

\begin{tabular}{|l|l|}
\hline Dispositivos & Descrição \\
\hline \hline Servidor de LMS & Mantém um LMS em execução, recebendo requisições dos professores e alunos. \\
\hline Servidor do middleware & $\begin{array}{l}\text { Mantém os componentes do middleware em execução, recebendo requisições dos servi- } \\
\text { dores de LMSs e encaminhando requisições aos servidores de ferramenta de avaliação. }\end{array}$ \\
\hline $\begin{array}{l}\text { Servidor de ferramenta de avali- } \\
\text { ação }\end{array}$ & $\begin{array}{l}\text { Mantém uma ferramenta de avaliação e o seu adaptador em execução, recebendo requi- } \\
\text { sições do servidor de middleware. }\end{array}$ \\
\hline
\end{tabular}

Fonte: Elaborada pelo autor.

Ao instanciar a arquitetura IMPACTLE, sugere-se a presença de três tipos de dispositivos físicos: (i) servidores mantendo LMSs; (ii) um servidor para manter o middleware; e (iii) servidores mantendo adaptadores de ferramentas e as respectivas ferramentas associadas. Os servidores de LMS devem ter acesso ao servidor do middleware que, por sua vez, deve ter acesso aos servidores de ferramenta registrados no middleware.

Ressalta-se que visão física da arquitetura IMPACTLE representa uma sugestão mínima para a alocação dos componentes. A ideia é que ao instanciar os componentes, eles devem ser suficientemente independentes para que a distribuição apresentada na visão seja possível, garantindo que cada professor ou instituição possa manter o seu LMS em um servidor próprio e que cada fornecedor de ferramenta possa manter o seu próprio servidor. No entanto, nada impede que instâncias de todos os componentes possam ser alocadas em um mesmo servidor ou que cada instância esteja alocada em um servidor dedicado ou que qualquer outra distribuição seja realizada.

\subsection{Protótipos arquiteturais}

Um protótipo arquitetural consiste em um conjunto de executáveis desenvolvidos para investigar as qualidades arquiteturais de um sistema em desenvolvimento (BARDRAM; CHRISTENSEN; HANSEN, 2004). A prototipação pode ser utilizada também para avaliar a viabilidade de implementação de uma arquitetura ou modelo (BARDRAM et al., 2005). 
Figura 35 - Arquitetura IMPACTLE: Visão física

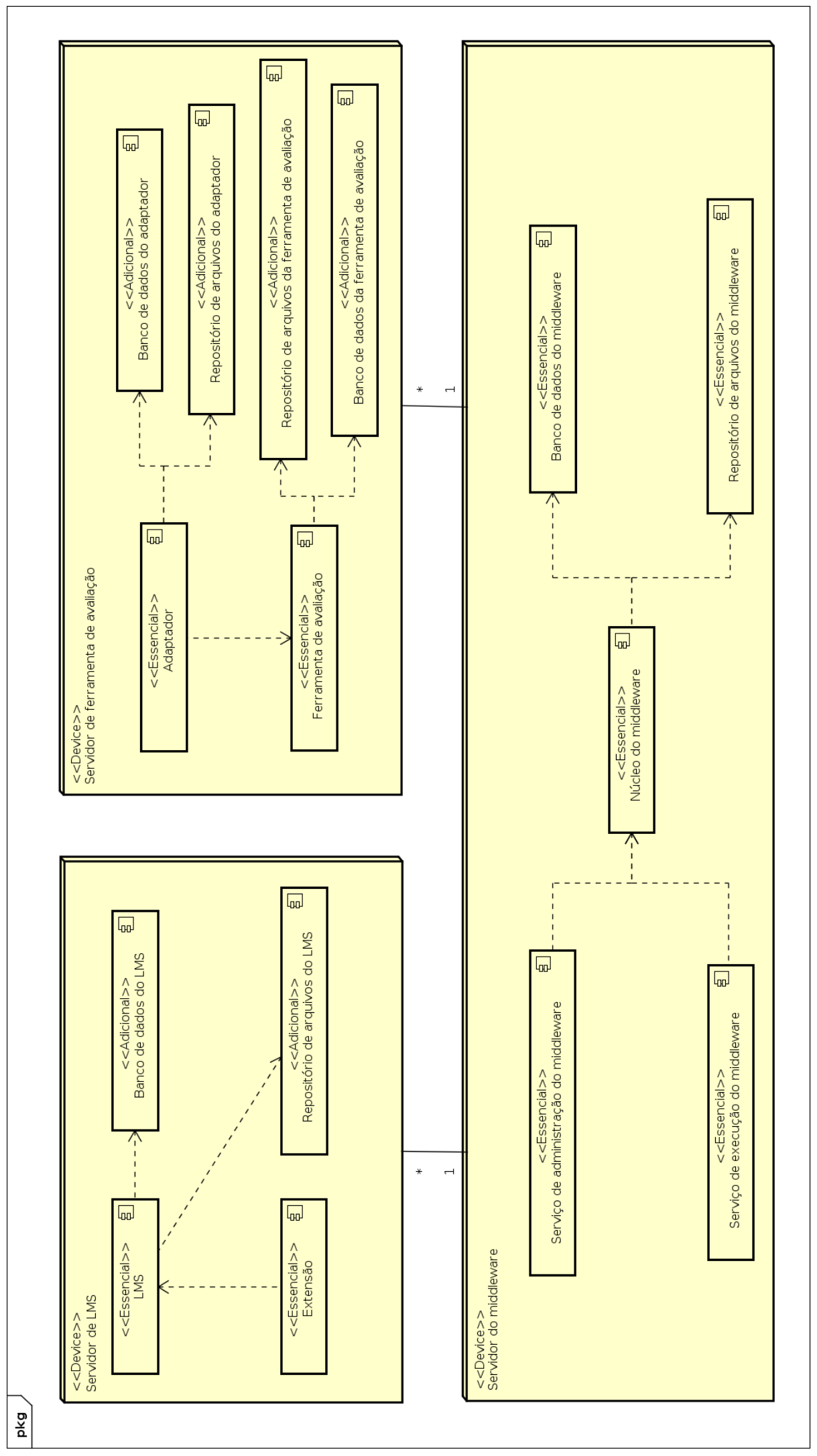

Fonte: Elaborada pelo autor. 
Nessa perspectiva, a IMPACTLE foi instanciada a fim de se verificar a sua capacidade de construção e, além disso, verificar aspectos relacionados à sua integridade conceitual, completude e correção. Foram desenvolvidos protótipos para cada componente definido na arquitetura. Detalhes sobre cada um dos protótipos são discutidos a seguir.

\subsubsection{O middleware}

Conforme discutido anteriormente, o middleware é o componente principal da arquitetura, realizando a comunicação entre as extensões dos LMSs e os adaptadores de ferramentas. A instância do middleware foi desenvolvida como um conjunto de serviços web em Java e a persistência dos dados é realizada por meio do sistema gerenciamento de banco de dados MYSQL (Oracle Corporation, 2017).

A instância implementa todas as estruturas e operações definidas para o middleware na arquitetura. Basicamente, ela consiste em dois serviços web: o serviço de execução e o serviço de administração. O primeiro é responsável em receber e responder as requisições dos LMSs, bem como em enviar e receber requisições às ferramentas de avaliação. Já o segundo serviço tem por objetivo permitir o registro de ferramentas no middleware, para que estas possam ser utilizadas pelos LMSs.

Na Figura 36a é ilustrado o retorno do serviço de execução quando os dados de uma ferramentas de avaliação são solicitados. Os serviços retornam os resultados no formato XML, podendo ser processados pelas extensões dos LMSs e exibidos aos usuários. Ainda, em complemento ao serviço de administração, foi desenvolvida uma interface para facilitar o registro de ferramentas. Esta interface é ilustrada na Figura 36b.

\subsubsection{Adaptadores para ferramentas de avaliação}

Os adaptadores de ferramentas são responsáveis em adaptar a interface com o usuário das ferramentas de avaliação em uma interface de comunicação padrão. Assim, o middleware pode se comunicar com diferentes ferramentas de avaliação, uma vez que todas elas possuirão a mesma interface de comunicação.

Como descrito na Seção 4.4.2, um adaptador consiste em um serviço web (serviço adaptador) que implementa um conjunto de operações. As operações a serem implementadas variam de acordo com as funcionalidades que a ferramenta associada ao adaptador, disponibiliza.

Inicialmente, uma instância do serviço adaptador foi desenvolvida. Esta instância implementa todas as operações definidas para os adaptadores de ferramentas. Esta instância inicial teve por objetivo verificar o funcionamento do middleware, simulando o comportamento de um adaptador de ferramenta, mas fornecendo ao middleware sempre o mesmo valor padrão para cada tipo de requisição. Além disso a instância também atua como um framework para a instanciação de adaptadores para as ferramentas de avaliação. Assim, com base nesta instância 
Figura 36 - Protótipo arquitetural do middleware

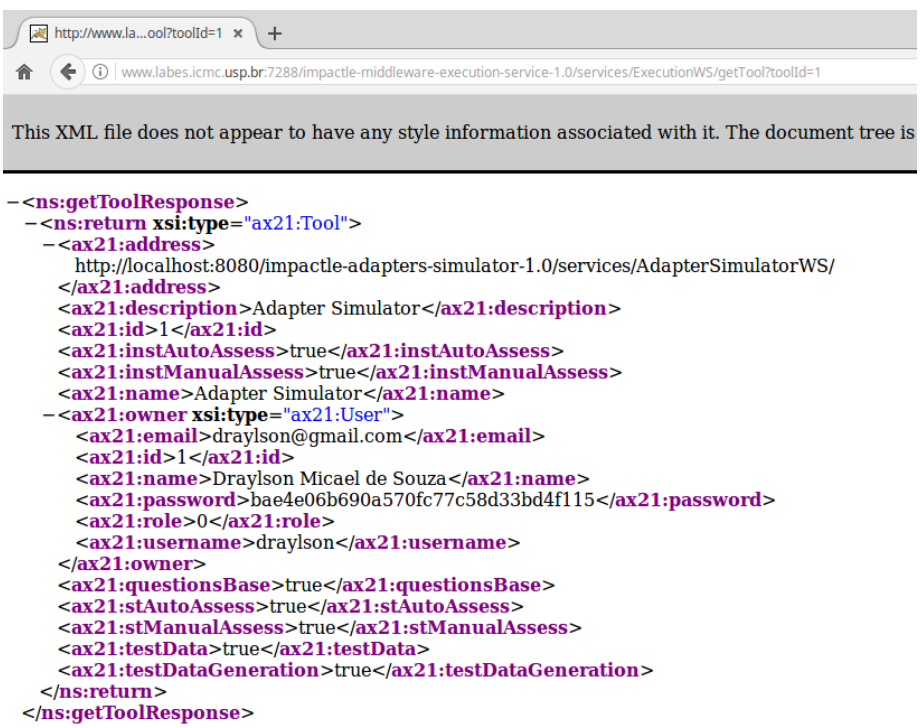

(a) Retorno do serviço adaptador

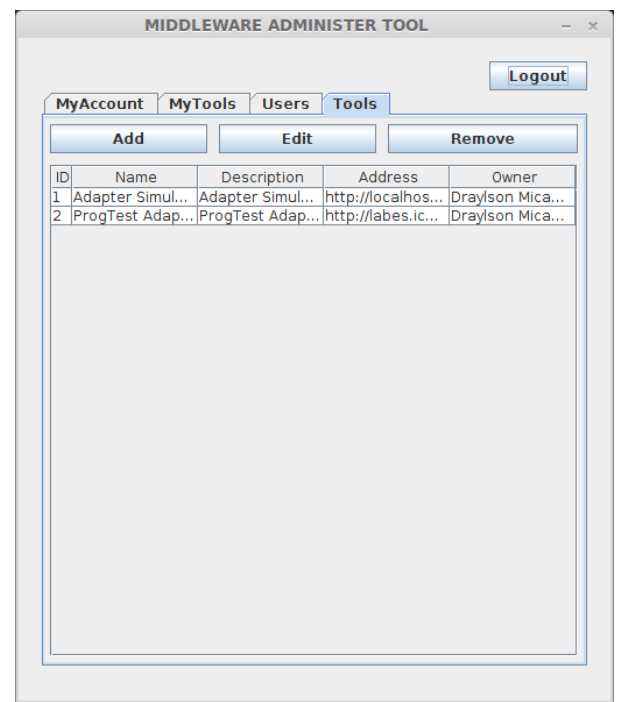

(b) Interface para o registro de ferramentas

Fonte: Elaborada pelo autor.

inicial desenvolvida, foram criadas instâncias de adaptadores para as ferramentas PROGTEST, WEB-CAT e BOCA.

A escolha das ferramentas de avaliação visou: (i) explorar a diversidade de contextos de atividades de programação que as ferramentas apoiam (tais como, ensino integrado de programação e teste, maratonas de programação, entre outros); (ii) explorar a diversidade de funcionalidades e tipos de verificação (tais como, repositório de questões, verificação estática do código, entre outros); (iii) considerar as ferramentas de avaliação que estavam disponíveis para serem utilizadas; e (iv) considerar as ferramentas mais utilizadas ou que se pretende incentivar o uso.

A forma como os adaptadores comunicam-se com cada ferramenta varia de acordo com a especificidade de cada ferramenta. A ProgTest, por exemplo, foi desenvolvida seguindo uma arquitetura em três camadas: (i) uma camada de modelo, que implementa as regras de negócio; (ii) uma camada de visão, que implementa a interface com o usuário; e (iii) uma camada de controle, que realiza a intermediação entre a camada de visão e a camada de modelo. $\mathrm{O}$ adaptador para a PROGTEST explora esta característica utilizando os métodos da camada de controle para acionar as funcionalidades da ferramenta. Esta instância foi desenvolvida no contexto de um trabalho de iniciação científica (Processo FAPESP n ${ }^{o}$ 2014/18913-5), vinculado ao presente projeto de doutorado.

Já, na WEB-CAT, todo o processo de avaliação é realizado por meio de plugins em Perl. Os plugins, de forma independente, atuam: (i) recebendo como entrada um arquivo de configuração e os arquivos fornecidos pelo professor e alunos; (ii) realizando o processo de 
avaliação por meio de verificadores integrados; (iii) gerando relatórios como página web; e (iv) salvando os resultados no próprio arquivo de configuração dado na entrada. $\mathrm{O}$ adaptador para a WEB-CAT utiliza os plugins para realizar o processo de avaliação. $\mathrm{O}$ adaptador prepara os arquivos de entrada, aciona a execução do plugin adequado e obtém os resultados e relatórios.

Por fim, a avaliação automática no BOCA é realizada por meio de um script chamado AUTOJUDGE. O adaptador para o BOCA realiza o processo de avaliação acionando um adaptação do AUTOJUDGE. O script salva os dados no BOCA, executa o processo de avaliação e provê um resultado para cada submissão.

\subsubsection{A extensão para o Moodle}

Assim como os adaptadores e o middleware, uma instância de extensão de LMS também foi desenvolvida. O LMS considerado foi o MOODLE, uma vez que ele é o mais utilizado atualmente ${ }^{1}$, possui um código fonte aberto, é bem documentado e pode ser facilmente encontrado na web.

O ambiente MoOdLE possui diversas características que o tornam extensível. Basicamente, ele é composto por vários módulos e cada módulo adiciona um recurso ou ferramenta, tais como calendário, notificações, fórum, anúncio, entre outros. Além disso, o MoodLE possui um conjunto de APIs que facilitam a criação de novos módulos que, por sua vez, podem ser instalados por meio da interface web do ambiente.

Assim, a extensão criada para o MoODLE foi instanciada na forma de um módulo para o ambiente, utilizando as APIs disponibilizadas pelo MoODLE. De modo geral, o módulo consiste em um conjunto de páginas e bibliotecas em linguagem PHP. Elas controlam todo o processo de definição de um trabalho de programação, submissão de soluções e avaliação das soluções. Para isso, elas conectam-se com o serviço de execução do middleware para enviar e receber informações, arquivos e resultados de avaliações.

Na Figura 37a é ilustrada a página da extensão desenvolvida para o MoOdLE. Nesta página, os professores podem criar questões de programação para serem avaliadas com o apoio de diferentes ferramentas de avaliação. Na Figura 37b é ilustrado o formulário para definição de uma questão por meio da WEB-CAT. Os campos do formulário correspondem aos dados e arquivos que a ferramenta de avaliação requer durante a definição de uma questão. A especificações de quais dados e arquivos eram necessários foram enviados pelo adaptador da ferramenta de avaliação e são fornecidas pelos professores por meio da interface do LMS.

\subsubsection{A extensão para o BlueJ}

Apesar da arquitetura IMPACTLE ter sido projetada para disponibilizar as funcionalidades de diferentes ferramentas de avaliação em LMSs, ela também pode ser utilizada para integrar

\footnotetext{
1 https://www.learndash.com/20-most-popular-learning-management-systems-infographic/
} 
Figura 37 - Extensão para o MoODLE

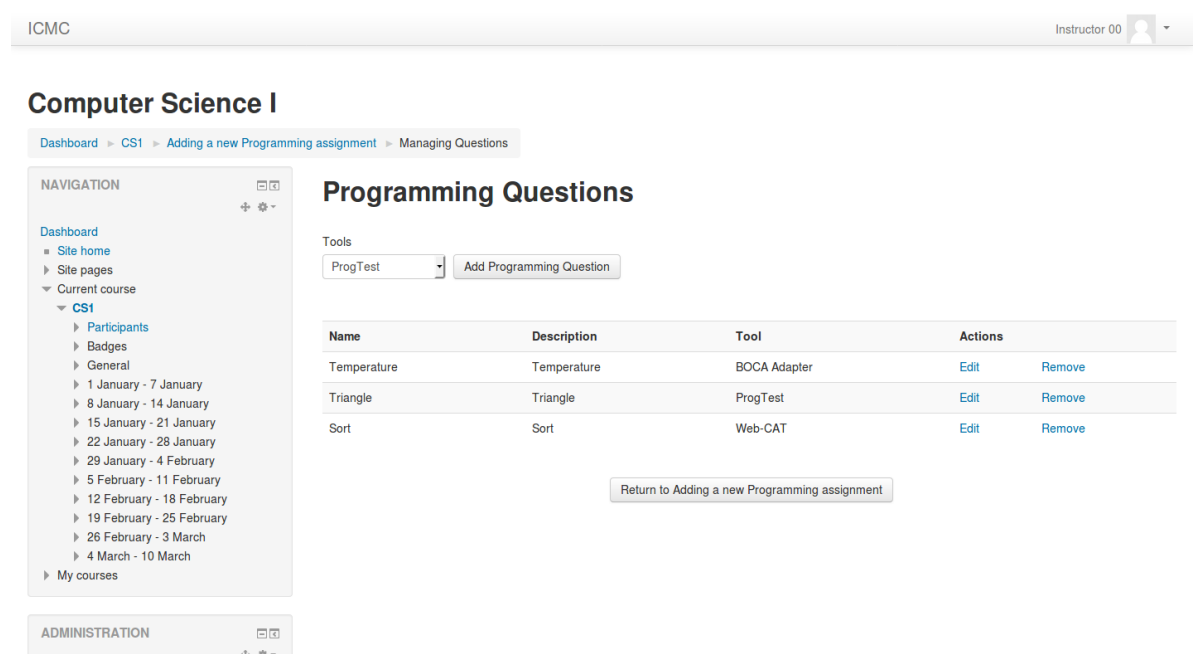

(a) Página para definição de questões

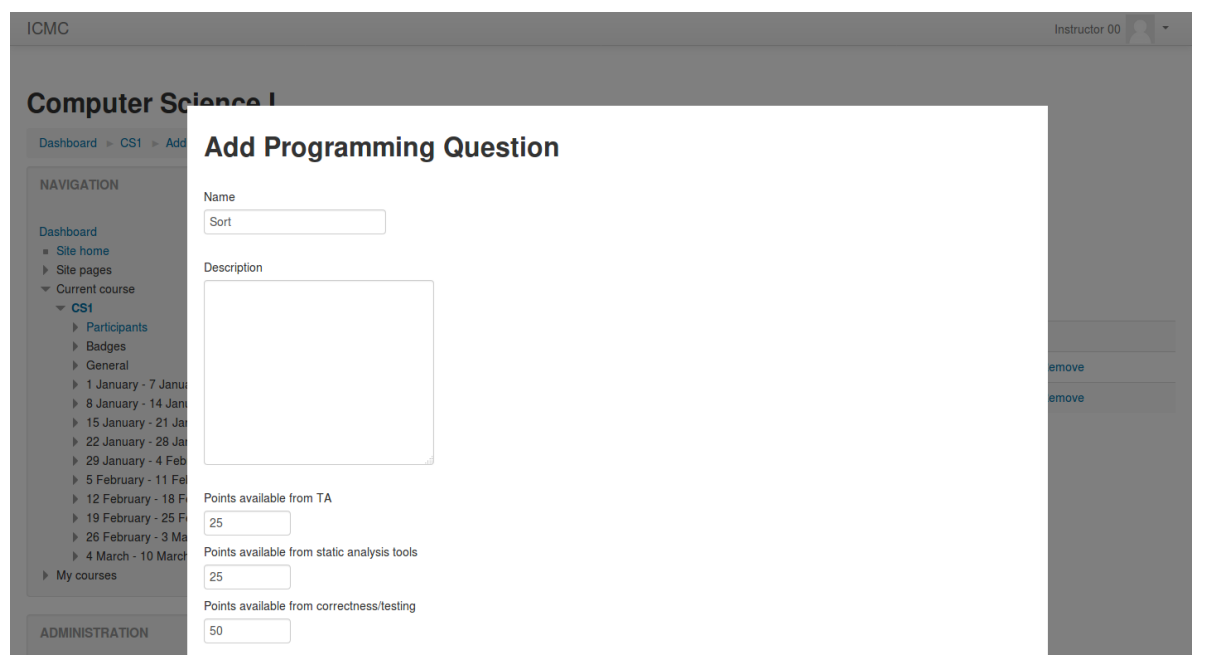

(b) Definição de uma questão

Fonte: Elaborada pelo autor.

as ferramentas de avaliação em outros tipos de ambientes de aprendizagem. A fim de verificar e validar esta possibilidade, uma extensão foi instanciada para o ambiente de programação BLUEJ (KÖLLING et al., 2003). O BLUEJ foi escolhido por ser voltado para iniciantes em programação e ter um grande número de usuários ao redor do mundo ${ }^{2}$.

O BLUEJ é um ambiente de desenvolvimento que enfatiza o ensino e a aprendizagem de conceitos de orientação a objetos por meio da linguagem de programação JAVA. O ambiente inclui um mecanismo que permite adicionar extensões às suas funcionalidades base. Por padrão, as distribuições do BLUEJ incluem a extensão SUBMITTER, que apoia a submissão online de projetos BLUEJ para avaliação ou assistência. Assim, a extensão para o BLUEJ foi instanciada utilizando o SUBMITTER.

2 https://bluej.org/ 
A extensão SUBMITTER funciona da seguinte forma. Para submeter um projeto por meio da extensão, um arquivo de definição deve ser criado e colocado no diretório do projeto, no diretório de instalação ou no diretório de configuração do BLUEJ. O arquivo de definição inclui um conjunto de configurações de submissões. Cada configuração de submissão contém um nome, os arquivos e informações que devem ser enviadas e o "mecanismo de transporte": cópia de arquivos, transferência de arquivos (FTP), e-mail ou enviando eles a um script web. Assim, por meio da interface gráfica do BLUEJ, os usuários podem selecionar uma das configurações disponibilizadas, realizar submissões e visualizar os resultados.

Dessa forma, a instanciação de uma extensão para o BLUEJ consistiu no desenvolvimento de scripts para: (i) intermediar as submissões do SUBMITTER para a instância do middleware; e (ii) retornar os resultados do middleware ao SUBMITTER. Além disso, foi criado um arquivo de definição, especificando as configurações de submissão para o script desenvolvido.

Nas figuras 38a e 38b são ilustradas a interface para submissão de uma solução e o resultado de uma submissão realizada por meio da extensão do BLUEJ e avaliada pela ferramenta BOCA.

Figura 38 - Extensão para o BLUEJ

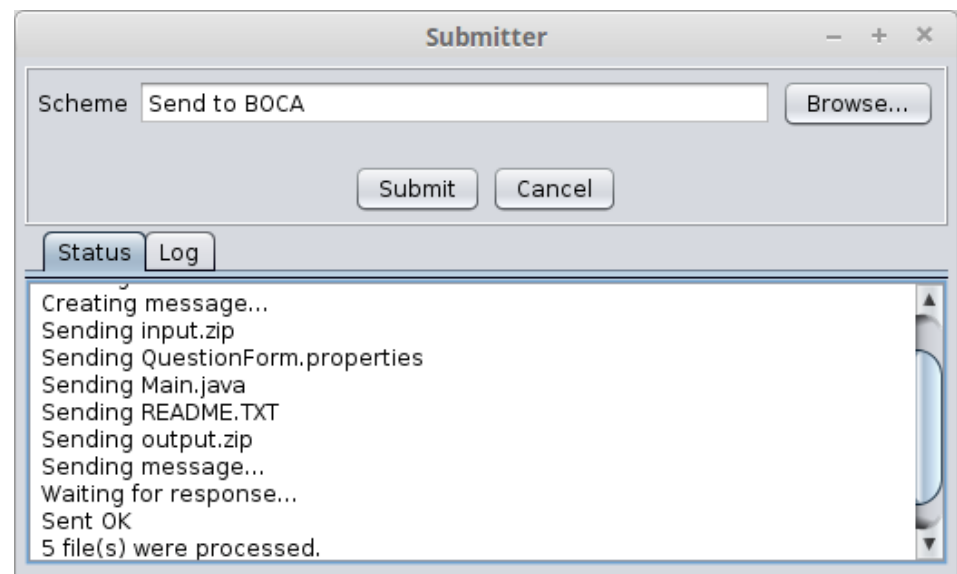

(a) Submissão de uma solução

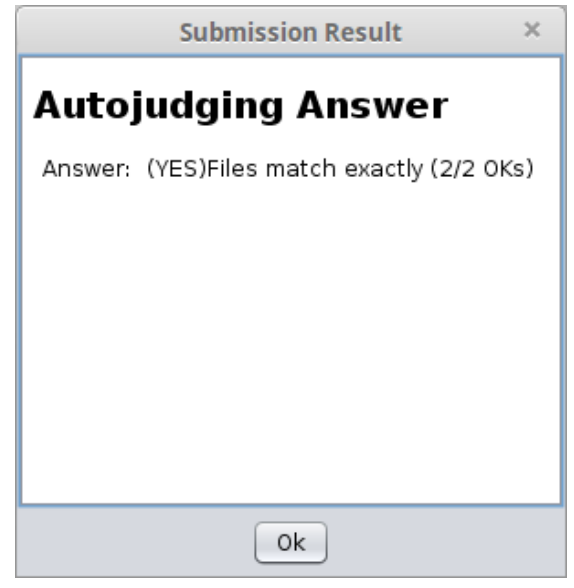

(b) Resultado de uma submissão

Fonte: Elaborada pelo autor.

As extensões e os demais protótipos desenvolvidos foram utilizados em alguns experimentos conduzidos. Tais experimentos são discutidos no Capítulo 5.

\subsection{Considerações finais}

Neste capítulo foi apresentada e detalhada a arquitetura IMPACTLE, que visa a integração de diferentes ferramentas de avaliação para trabalhos de programação em diferentes LMSs. Inicialmente, por meio da análise do problema e trabalhos relacionados, foram levantados os requisitos que arquitetura deve satisfazer. Considerando os requisitos e a análise de várias 
ferramentas de avaliação, algumas decisões de projeto iniciais foram tomadas. Guiados por estas decisões, a arquitetura IMPACTLE foi proposta e formalizada por meio do modelo de visão "4+1". Para avaliar a integridade conceitual, capacidade de construção, completude e correção da arquitetura, protótipos arquiteturais foram desenvolvidos por meio da instanciação da arquitetura.

A arquitetura IMPACTLE insere-se como uma solução para que as funcionalidades de diferentes ferramentas de avaliação para trabalhos de programação possam ser acessadas por meio de LMSs. De fato, estudos têm apontado que uma das principais dificuldades dos professores na adoção e uso de ferramentas para o ensino de programação é a falta de integração dessas ferramentas com os LMSs adotados pelas suas instituições. As ferramentas de avaliação são consideradas como um dos tipos de ferramentas mais procurados pelos professores. Apesar de algumas propostas de integração de ferramentas em LMSs ter sido identificadas, em geral, elas consistem apenas em modelos conceituais abstratos, não realizando uma integração com vários LMSs ou não tratando problemas específicos relacionados à integração de ferramentas de avaliação. Nesse sentido, um artigo descrevendo a arquitetura IMPACTLE e seus benefícios encontra-se em elaboração para ser submetido à uma revista de relevância na área:

- Souza, D. M; Kölling, M.; Barbosa, E. F. IMPACTLE architecture: Integration of assessment tools for programming assignments in LMSs. Computers and education., p. 1-15, 2017.

Uma das motivações para a integração de ferramentas em LMSs é evitar que os professores e alunos dispendam tempo e esforço lidando e aprendendo a utilizar diferentes ferramentas, ao invés disso, possam se concentrar mais em atividades pedagógicas. Assim, a fim de verificar tais benefícios, experimentos foram realizados utilizando os protótipos arquiteturais desenvolvidos. Os métodos e resultados desses experimentos são detalhados no próximo capítulo. 



\section{5}

\section{ASPECTOS DE USO E VALIDAÇÃO DA ARQUITETURA IMPACTLE}

\subsection{Considerações iniciais}

No Capítulo 4 foi descrita a arquitetura IMPACTLE, que permite o acesso às funcionalidades das ferramentas de avaliação para trabalhos de programação por meio de LMSs. A fim de verificar a viabilidade de uso da IMPACTLE, protótipos foram desenvolvidos a partir da instanciação dos componentes da arquitetura.

Dentre as motivações para integrar ferramentas de avaliação em LMSs, destaca-se a necessidade de diminuir o tempo e esforço empenhado pelos alunos e professores em entender, configurar e utilizar as ferramentas de avaliação. A ideia é que por meio de um LMS, as funcionalidades das ferramentas já estariam em conformidade com a interface de um ambiente com o qual os alunos e professores estão habituados a utilizar.

Assim, neste capítulo são descritos dois experimentos realizados a fim de avaliar os benefícios em utilizar as funcionalidades das ferramentas de avaliação para trabalhos de programação por meio de LMSs. Para isso, os protótipos construídos a partir da arquitetura IMPACTLE foram considerados.

Na Seção 5.2 são descritos os métodos e resultados do Experimento 1. Este experimento visou explorar a diversidade de funcionalidades entre as ferramentas de avaliação, considerando três diferentes ferramentas de avaliação (BOCA, PROGTEST e WEB-CAT) e dois tipos de usuários (professor/monitor e aluno).

Por sua vez, na Seção 5.3 são descritos os métodos e resultados do Experimento 2, que consistiu em avaliar a utilização de ferramentas de avaliação por meio de LMS em um cenário real de ensino e aprendizagem de programação. No experimento, alunos de uma disciplina de programação desenvolveram programas para um conjunto de exercícios propostos. 


\subsection{Experimento 1: Definição, submissão e avaliação de trabalhos}

A fim de validar tanto os protótipos desenvolvidos a partir da arquitetura IMPACTLE como a abordagem de utilizar ferramentas de avaliação integradas aos LMSs, foi realizado um experimento envolvendo a utilização dos protótipos na definição, submissão e avaliação de trabalhos de programação.

\subsubsection{Visão geral}

O Experimento 1 foi conduzido a fim de avaliar os benefícios de utilizar as ferramentas de avaliação para trabalhos de programação por meio de um LMS. O foco deste experimento foi a utilização de diferentes ferramentas de avaliação (BOCA, PROGTEST, WEB-CAT), explorando tanto as funcionalidades disponibilizadas para os alunos como as funcionalidades disponibilizadas para os professores.

A escolha das ferramentas BOCA, ProgTest e Web-CAT visou a utilização dos protótipos desenvolvidos com base na arquitetura IMPACTLE. Os protótipos foram desenvolvidos procurando: (i) explorar a diversidade de contextos de atividades de programação que as ferramentas apoiam (tais como, ensino integrado de programação e teste, maratonas de programação, entre outros); (ii) explorar a diversidade de funcionalidades e tipos de verificação (tais como, repositório de questões, verificação estática do código, entre outros); (iii) considerar as ferramentas de avaliação que estavam disponíveis para serem utilizadas; e (iv) considerar as ferramentas mais utilizadas ou que se pretende incentivar o uso.

Em síntese, alunos de pós-graduação utilizaram as ferramentas de avaliação, atuando como professores e como alunos, realizando algumas atividades propostas (como, por exemplo, a definição de um trabalho de programação ou a submissão de um programa em uma das ferramentas de avaliação). Os participantes foram divididos em dois grupos, sendo que os participantes de um grupo realizaram as atividades diretamente pela interface das ferramentas de avaliação, enquanto os participantes do outro grupo realizaram as atividades por meio do LMS MOODLE.

Assim como as ferramentas de avaliação, o MOODLE foi escolhido visando utilizar a extensão desenvolvida para ele com base na arquitetura IMPACTLE. Além disso, o MOODLE foi considerado por ser o mais utilizado atualmente e por ser o LMS em que os participantes do experimento estavam habituados a utilizar.

Para a análise dos resultados do experimento, foram consideradas as diferenças de valores obtidas pelos dois grupos de participantes considerando as seguintes variáveis:

- Eficiência: Definida como o uso ótimo dos recursos organizacionais para produzir pro- 
dutos ou serviços Maximiano (2011). No contexto deste experimento, como recurso foi considerado o tempo e como produtos/serviços foi considerada a realização das atividades. Em outras palavras, no que se refere à eficiência, mede-se o tempo que os participantes consumiram para realizar as atividades propostas. A ideia é que realizando mais atividades em menos tempo, os professores poderão dedicar-se mais nas demais atividades de ensino, enquanto os alunos poderão avançar mais rapidamente no processo de aprendizagem, podendo apresentar um melhor desenvolvimento das suas habilidades de programação.

- Eficácia: Definida como o alcance de metas e objetivos da organização Maximiano (2011). No contexto deste experimento, a meta é a conclusão das atividades propostas. Em outras palavras, no que se refere à eficácia, mede-se a quantidade de atividades concluídas pelo participante. Uma atividade somente é contabilizada como concluída se o participante a realizou de forma completa e adequada.

- Efetividade: Definida como o alcance de eficiência e eficácia ao mesmo tempo Cury (2005). Assim, neste experimento considera-se efetividade a combinação dos resultados para eficiência e eficácia.

Os métodos definidos durante o planejamento do experimento são melhor detalhados a seguir.

\subsubsection{Métodos}

O experimento foi planejado seguindo os procedimentos definidos por Wohlin et al. (2012). Detalhes sobre o escopo e planejamento do experimento são apresentados a seguir:

\section{Definição dos objetivos}

O experimento definido nesta seção deve avaliar como os meios de acesso às funcionalidades das ferramentas de avaliação para trabalhos de programação influenciam na eficiência, eficácia e efetividade para a realização de atividades nestas ferramentas. Desse modo, a meta do experimento é a seguinte:

Analisar os meios de acesso às funcionalidades das ferramentas de avaliação para trabalhos de programação

para o propósito de avaliar

com respeito à eficiência, eficácia, efetividade

do ponto de vista do pesquisador

no contexto de alunos de mestrado e doutorado em Ciência da Computação utilizando ferramentas de avaliação para trabalhos de programação 


\section{Formulação das hipóteses}

Neste experimento pretende-se investigar se a utilização de ferramentas de avaliação para trabalhos de programação por meio de um LMS é mais eficiente, eficaz e efetiva na realização de atividades como definição, submissão e avaliação de trabalhos práticos de programação. Assim, as hipóteses formuladas para este experimento foram as seguintes:

- Eficiência:

- Hipótese nula $\left(\mathbf{H}_{0}\right)$ : Não há diferença em eficiência utilizando as ferramentas por meio de um LMS e diretamente por meio de sua interface.

- Hipótese alternativa $\left(\mathbf{H}_{1}\right)$ : A eficiência utilizando as ferramentas de avaliação é maior por meio de um LMS do que diretamente por meio de sua interface.

- Hipótese alternativa $\left(\mathbf{H}_{2}\right)$ : A eficiência utilizando as ferramentas de avaliação é menor por meio de um LMS do que diretamente por meio de sua interface.

- Eficácia:

- Hipótese nula $\left(\mathbf{H}_{0}\right)$ : Não há diferença em eficácia utilizando as ferramentas por meio de um LMS e diretamente por meio de sua interface.

- Hipótese alternativa $\left(\mathbf{H}_{1}\right)$ : A eficácia utilizando as ferramentas de avaliação é maior por meio de um LMS do que diretamente por meio de sua interface.

- Hipótese alternativa $\left(\mathbf{H}_{2}\right)$ : A eficácia utilizando as ferramentas de avaliação é menor por meio de um LMS do que diretamente por meio de sua interface.

- Efetividade:

- Hipótese nula $\left(\mathbf{H}_{0}\right)$ : Não há diferença em efetividade utilizando as ferramentas por meio de um LMS e diretamente por meio de sua interface.

- Hipótese alternativa $\left(\mathbf{H}_{1}\right)$ : A efetividade utilizando as ferramentas de avaliação é maior por meio de um LMS do que diretamente por meio de sua interface.

- Hipótese alternativa $\left(\mathbf{H}_{2}\right)$ : A efetividade utilizando as ferramentas de avaliação é menor por meio de um LMS do que diretamente por meio de sua interface.

\section{Variáveis de entrada}

As variáveis de entrada representam as influências que podem afetar os resultados do experimento (WOHLIN et al., 2012). As influências que não são de interesse (parâmetros) devem ser configuradas em um valor constante ao longo do experimento. Já as influências de interesse que são manipuladas durante o experimento (fatores) devem ser configuradas atribuindo a elas 
determinados valores (tratamentos) durante a execução. Neste experimento as seguintes variáveis de entrada foram consideradas:

- Ferramentas de avaliação para trabalhos de programação (parâmetro): Consistem nas ferramentas de avaliação que serão utilizadas pelos participantes durante a condução do experimento. Foram selecionadas as ferramentas PROGTEST, WEB-CAT e BOCA, visando utilizar os protótipos resultantes da instanciação da arquitetura IMPACTLE (Seção 4.6).

- Atividades (parâmetro): Consistem nas atividades a serem realizadas pelos participantes durante a condução deste experimento. Foram definidas as seguintes atividades relacionadas à definição de trabalhos de programação (considerando a perspectiva de professores):

- Atividade 1: Consiste em definir um trabalho de programação na ferramenta PROGTEST.

- Atividade 2: Consiste em definir um trabalho de programação na ferramenta WEBCAT.

- Atividade 3: Consiste em definir um trabalho de programação na ferramenta BOCA.

Também foram definidas as seguintes atividades relacionadas à submissão e avaliação de soluções (considerando a perspectiva de alunos):

- Atividade 4: Consiste em submeter uma solução para um trabalho de programação para ser automaticamente avaliada pela ferramenta PROGTEST.

- Atividade 5: Consiste em submeter uma solução para um trabalho de programação para ser automaticamente avaliada pela ferramenta WEB-CAT.

- Atividade 6: Consiste em submeter uma solução para um trabalho de programação para ser automaticamente avaliada pela ferramenta BOCA.

Por fim, uma atividade relacionada à avaliação pelo professor também foi considerada:

- Atividade 7: Consiste em manualmente avaliar uma solução para um trabalho de programação, considerando a ferramenta BOCA.

- Meios de acesso às funcionalidades das ferramentas de avaliação para trabalhos de programação (fator): Consiste em como os participantes acessam as funcionalidades das ferramentas. Recebe dois tratamentos:

- Tratamento A: $\mathrm{O}$ acesso às funcionalidades das ferramentas ocorre diretamente por meio de sua interface.

- Tratamento B: O acesso às funcionalidades das ferramentas ocorre por meio da interface de um LMS. 
- LMS (fator): Consiste no LMS utilizado para acessar às funcionalidades das ferramentas. Recebe dois tratamentos:

- Tratamento A: Nenhum LMS é utilizado, uma vez que o acesso às funcionalidades das ferramentas é realizado diretamente por meio de sua interface.

- Tratamento B: Utilização do LMS MoOdLE, visando utilizar os protótipos resultantes da instanciação da arquitetura IMPACTLE.

\section{Variáveis de saída}

As variáveis de saída (de resposta) acomodam os valores dos resultados do experimento (WOHLIN et al., 2012). Essas variáveis representam os efeitos dos diferentes tratamentos nos fatores (variáveis de entrada). Neste experimento as seguintes variáveis de saída foram consideradas:

- Eficiência: O cálculo da eficiência foi realizado pela fórmula:

$$
\text { Eficiência }=\left(t_{M A X}-t\right) / t_{M A X}
$$

onde $t_{M A X}$ foi o tempo máximo de 10 minutos estipulado para a realização de cada atividade e $t$ o tempo despendido pelo participante na condução da atividade. Caso o participante tenha despendido mais de 10 minutos na realização de uma tarefa, o tempo máximo de 10 minutos foi atribuído à $t$. Assim, um participante que tenha despendido 10 minutos ou mais na realização de uma atividade recebe um valor de eficiência " 0,0 ", ou seja, $0 \%$ de eficiência naquela atividade. Já um participante que tenha realizado uma atividade, por exemplo, em 5 minutos, recebe um valor de eficiência “ 0,5 ", ou seja, 50\% de eficiência naquela atividade.

- Eficácia: O cálculo da eficácia foi realizado pela fórmula:

$$
\text { Eficácia }=n / n_{\text {TOTAL }}
$$

onde $n$ é o número de atividades concluídas pelo participante e $n_{\text {TOTAL }}$ é o total de atividades propostas. Assim, um participante que não tenha realizado nenhuma tarefa recebe um valor de eficácia " 0,0 ”, ou seja, $0 \%$ de eficácia. Já um participante que tenha concluído todas as atividades recebe um valor de eficácia “1,0”, ou seja, 100\% de eficácia.

- Efetividade: Por fim, o cálculo da efetividade foi realizado pela fórmula:

$$
\text { Efetividade }=\text { Eficiência } * \text { Eficácia }
$$


Adicionalmente, uma avaliação qualitativa também foi realizada, visando observar a percepção dos participantes durante a condução das atividades. Os dados para esta avaliação foram coletados solicitando que os participantes preenchessem um formulário no final de cada atividade. O formulário foi elaborado com base no NASA Task Load Index - NASA TLX) (CAO et al., 2009). De modo geral, o questionário pede que os participantes informem em uma escala de 0 a 10 a percepção deles com relação aos seguintes atributos:

- Demanda mental: Refere-se ao quão mentalmente exigente foi a atividade.

- Demanda física: Refere-se ao quão fisicamente exigente foi a atividade.

- Demanda temporal: Refere-se ao quão apressado foi o ritmo da atividade.

- Desempenho: Refere-se ao quão bem-sucedido o participante foi em realizar a atividade.

- Esforço: Refere-se ao quão empenhado o participante teve que trabalhar para atingir o nível de desempenho obtido na atividade.

- Frustração: Refere-se ao quão inseguro, desencorajado, irritado, estressado, aborrecido o participante ficou durante a realização da atividade.

\section{Seleção dos participantes}

Foram selecionados como participantes alunos de mestrado e doutorado em Ciência da Computação. No total, 16 alunos participaram do experimentos, sendo todos eles voluntários. A escolha de alunos de mestrado e doutorado deve-se ao fato destes participantes já terem experiência utilizando LMSs: (i) como alunos, para submeter trabalhos (nas disciplinas de pós-graduação ou mesmo durante graduação); e (ii) como assistentes/professores, na definição e avaliação de trabalhos (atuando como monitores, estagiários em programas de aperfeiçoamento do ensino ou até mesmo como professores em outras instituições). Além disso, a escolha de alunos de Ciência da Computação deve-se ao fato de já terem experiência com programação.

\section{Projeto experimental}

Os participantes selecionados foram divididos em dois grupos: Grupo A e Grupo B. A divisão dos participantes foi realizada de acordo com a ordem para aceitação para participação no experimento. Por exemplo, o primeiro participante a aceitar participar do experimento foi alocado ao Grupo A, o segundo foi alocado ao Grupo B, o terceiro ao Grupo A, e assim por diante.

Tanto os participantes do Grupo A quanto os participantes do Grupo B foram instruídos a realizarem as mesmas atividades, considerando as mesmas ferramentas de avaliação para 
trabalhos de programação. Ressalta-se que a ordem das atividades também foi mantida igual para os participantes de ambos os grupos.

Por outro lado, tratamentos diferentes foram dados aos participantes do Grupo A e do Grupo B com relação ao meio de acesso às ferramentas e à utilização de um LMS. Os participantes do Grupo A realizaram as atividades acessando as ferramentas diretamente por meio de suas interfaces (Tratamento A), enquanto os participantes do Grupo B realizaram as mesmas atividades acessando as ferramentas por meio do LMS MoodLE (Tratamento B). Para isso, os protótipos instanciados da arquitetura IMPACTLE foram considerados.

\subsubsection{Resultados}

\section{Eficiência}

No gráfico da Figura 39 são comparados os principais resultados obtidos com respeito à eficiência. Em síntese, os valores de eficiência do Grupo B são superiores aos valores de eficiência do Grupo A em todas as atividades. No entanto, ressalta-se uma maior diferença nos valores das Atividade 2 (19\% e 65\%) e Atividade 5 (64\% e 83\%), ambas relacionadas à ferramenta WEB-CAT, bem como nos valores da Atividade 7, que consistiu em avaliar manualmente um programa na ferramenta BOCA (62\% e 73\%). Estas diferenças estão maiormente relacionadas a aspectos de usabilidade das ferramentas, que são discutidos na Seção 5.2.4.

Figura 39 - Experimento 1: Eficiência

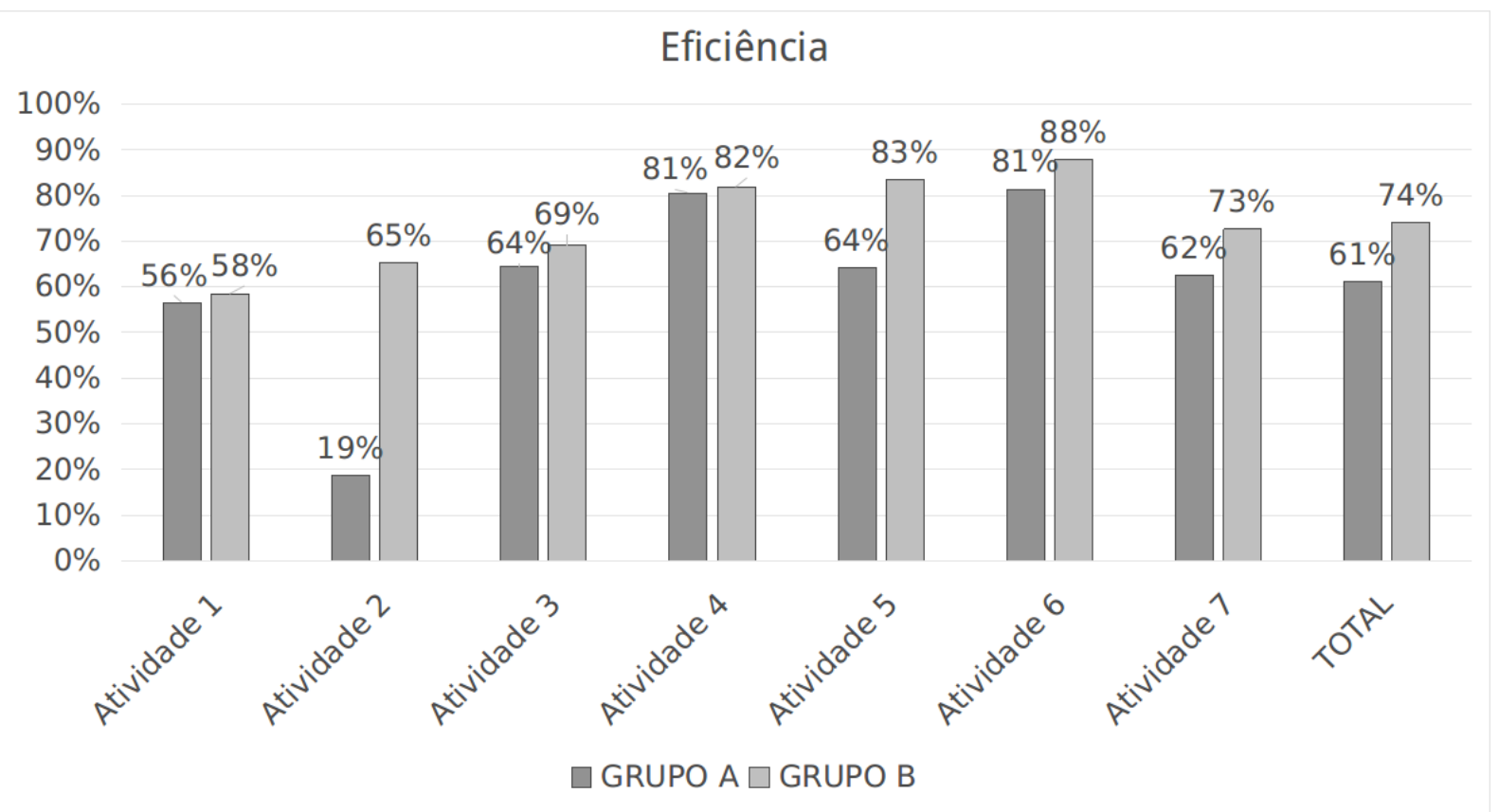

Fonte: Elaborada pelo autor.

Na Tabela 2 são apresentados detalhes sobre a eficiência dos participantes do Grupo 
A. O Participante 3A, por exemplo, foi o que obteve os melhores resultados, atingindo um total de $72 \%$ de eficiência, apesar de ter obtido apenas 36\% de eficiência na Atividade 2. Já o Participante $2 \mathrm{~A}$ foi o que obteve o menor valor, atingindo um total de $50 \%$ de eficiência, com menores valores na Atividade $1(14 \%)$ e na Atividade $2(0 \%)$, que consistiram em definir um trabalho de programação na PROGTEST e WEB-CAT, respectivamente.

Tabela 2 - Experimento 1: Resultados de eficiência do Grupo A

\begin{tabular}{|c|c|c|c|c|c|c|c|c|}
\hline GRUPO A & Atividade 1 & $\mid$ Atividade $2 \mid$ & | Atividade 3 & tividad & ivi & Ativida & vi & ГОТ \\
\hline Participante $1 \mathrm{~A}$ & $70 \%$ & $54 \%$ & $88 \%$ & $65 \%$ & $0 \%$ & $83 \%$ & $74 \%$ & $62 \%$ \\
\hline Participante $2 \mathrm{~A}$ & $14 \%$ & $0 \%$ & $71 \%$ & $75 \%$ & $77 \%$ & $66 \%$ & $50 \%$ & $50 \%$ \\
\hline Participante $3 \mathrm{~A}$ & $67 \%$ & $36 \%$ & $87 \%$ & $83 \%$ & $87 \%$ & $66 \%$ & $75 \%$ & $72 \%$ \\
\hline Participante $4 \mathrm{~A}$ & $50 \%$ & $20 \%$ & $0 \%$ & $90 \%$ & $90 \%$ & $90 \%$ & $40 \%$ & $54 \%$ \\
\hline Participante $5 \mathrm{~A}$ & $66 \%$ & $0 \%$ & $66 \%$ & $87 \%$ & $86 \%$ & $82 \%$ & $53 \%$ & $63 \%$ \\
\hline Participante 6A & $58 \%$ & $0 \%$ & $73 \%$ & $66 \%$ & $0 \%$ & $81 \%$ & $85 \%$ & $52 \%$ \\
\hline Participante 7A & $96 \%$ & $8 \%$ & $71 \%$ & $88 \%$ & $85 \%$ & $86 \%$ & $65 \%$ & $71 \%$ \\
\hline Participante $8 \mathrm{~A}$ & $31 \%$ & $32 \%$ & $59 \%$ & $89 \%$ & $89 \%$ & $97 \%$ & $57 \%$ & $65 \%$ \\
\hline MÉDIA & $56 \%$ & $19 \%$ & $64 \%$ & $81 \%$ & $64 \%$ & $81 \%$ & $62 \%$ & $61 \%$ \\
\hline DESVIO & $25 \%$ & $20 \%$ & $28 \%$ & $10 \%$ & $40 \%$ & $11 \%$ & $15 \%$ & $8 \%$ \\
\hline
\end{tabular}

Fonte: Elaborada pelo autor.

Já na Tabela 3 são apresentados detalhes sobre a eficiência dos participantes do Grupo B. O Participante 3B, por exemplo, foi o que obteve os melhores resultados, atingindo um total de $85 \%$ de eficiência, tendo como menor valor de eficiência $76 \%$ na Atividade 1. Já o Participante 2B foi o que obteve o menor valor, atingindo um total de $60 \%$ de eficiência, tendo o menor valor de eficiência na Atividade 7 (37\%), que consiste em avaliar um programa manualmente por meio da ferramenta BOCA.

Tabela 3 - Experimento 1: Resultados de eficiência para o Grupo B

\begin{tabular}{|c|c|c|c|c|c|c|c|c|}
\hline GRUPO B & vidade & idade 2 & Atividade 3 & $3 \mid$ Atividade 4 & Atividade 5 & $5 \mid$ Atividade 6 & tividade 7 & TOTAL \\
\hline Participante 1B & $60 \%$ & $74 \%$ & $73 \%$ & $79 \%$ & $82 \%$ & $80 \%$ & $73 \%$ & $74 \%$ \\
\hline Participante 2B & $47 \%$ & $50 \%$ & $52 \%$ & $73 \%$ & $79 \%$ & $82 \%$ & $37 \%$ & $60 \%$ \\
\hline Participante 3B & $76 \%$ & $80 \%$ & $80 \%$ & $90 \%$ & $90 \%$ & $90 \%$ & $90 \%$ & $85 \%$ \\
\hline Participante 4B & $73 \%$ & $77 \%$ & $65 \%$ & $71 \%$ & $71 \%$ & $95 \%$ & $90 \%$ & $77 \%$ \\
\hline Participante 5B & $50 \%$ & $50 \%$ & $60 \%$ & $93 \%$ & $93 \%$ & $95 \%$ & $82 \%$ & $75 \%$ \\
\hline Participante 6B & $49 \%$ & $59 \%$ & $70 \%$ & $90 \%$ & $91 \%$ & $91 \%$ & $56 \%$ & $72 \%$ \\
\hline Participante 7B & $43 \%$ & $50 \%$ & $80 \%$ & $68 \%$ & $70 \%$ & $80 \%$ & $80 \%$ & $67 \%$ \\
\hline Participante 8B & $69 \%$ & $82 \%$ & $73 \%$ & $90 \%$ & $92 \%$ & $90 \%$ & $72 \%$ & $81 \%$ \\
\hline MÉDIA & $58 \%$ & $65 \%$ & $69 \%$ & $82 \%$ & $83 \%$ & $88 \%$ & $73 \%$ & $74 \%$ \\
\hline DESVIO & $13 \%$ & $14 \%$ & $10 \%$ & $10 \%$ & $9 \%$ & $6 \%$ & $18 \%$ & $8 \%$ \\
\hline
\end{tabular}

Fonte: Elaborada pelo autor.

Com base nos resultados obtidos, foi aceita a hipótese alternativa $H_{1}$ para eficiência: 
$H_{1}=$ A eficiência utilizando as ferramentas de avaliação é maior por meio de um LMS do que diretamente por meio de sua interface.

\section{Eficácia}

No gráfico da Figura 40 são comparados os principais resultados para eficácia. De modo geral, os valores de eficácia do Grupo B são superiores ou iguais aos valores de eficácia do Grupo A em todas as atividades. Em especial, ressalta-se que os menores valores de eficácia para o Grupo A foram os da Atividade 2 (38\%), da Atividade 5 (38\%) e da Atividade 7 (38\%). Estas são as mesmas atividades que apresentarem menores valores de eficiência. Foi possível observar que os valores baixos para estas atividades estão maiormente relacionados a aspectos de usabilidade das ferramentas, que são discutidos na Seção 5.2.4.

Figura 40 - Experimento 1: Eficácia

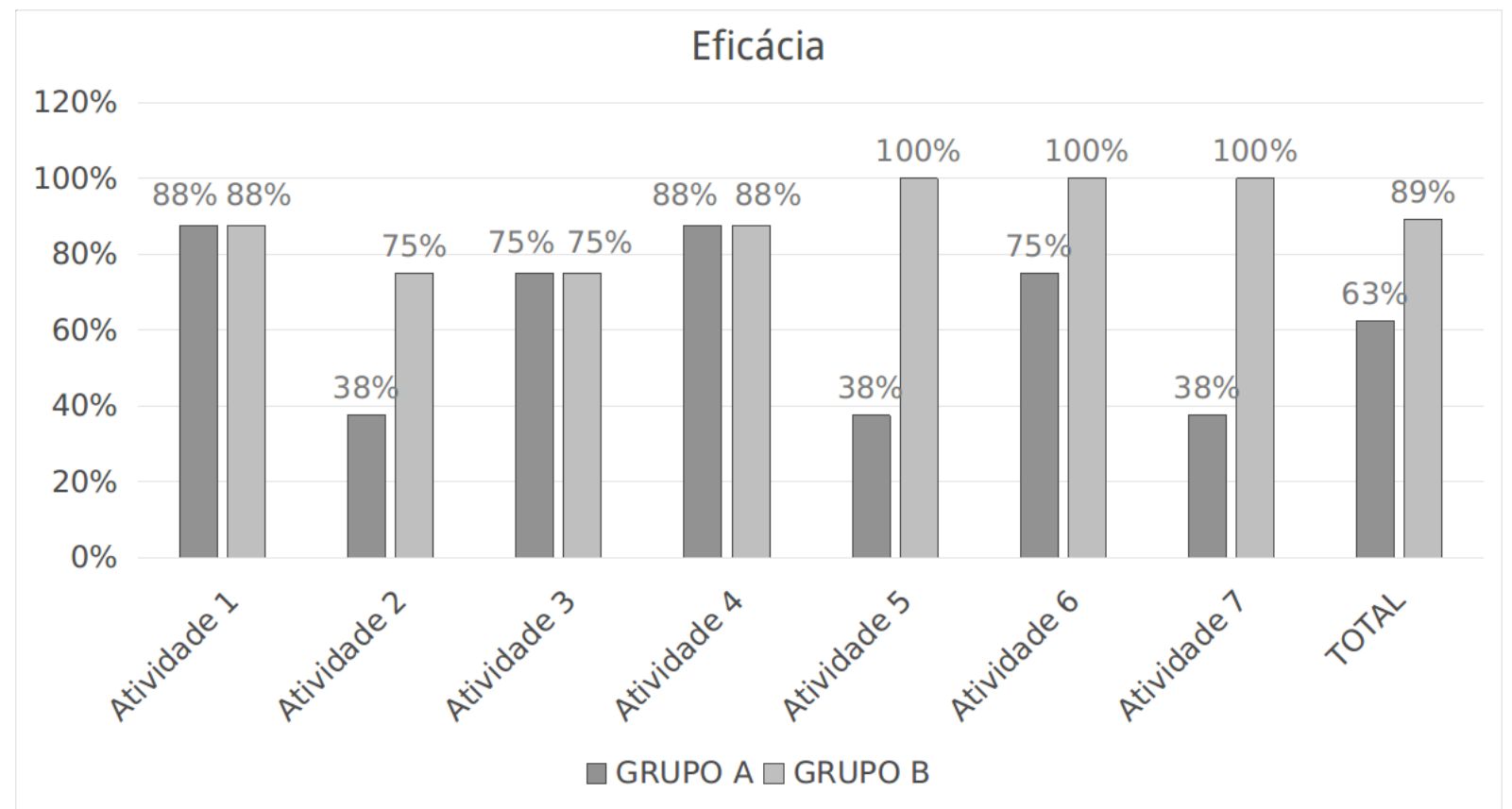

Fonte: Elaborada pelo autor.

Na Tabela 4 são apresentados mais detalhes sobre a eficácia dos participantes do Grupo A. O Participante 4A, por exemplo, foi o que obteve o melhor resultado, atingindo um total de $100 \%$ de eficácia, uma vez que completou adequadamente todas as atividades. Já o Participante 3A e o Participante 7A foram os que obtiveram os menores valores, atingindo um total de $14 \%$ de eficácia, ambos completando apenas uma atividade adequadamente.

Já na Tabela 5 são apresentados detalhes sobre a eficácia dos participantes do Grupo B. Em geral, cinco participantes atingiram um total 100\% de eficácia, completando todas as atividades adequadamente. O Participante $1 \mathrm{~B}$ foi o que obteve o menor valor, atingindo um 
Tabela 4 - Experimento 1: Resultados de eficácia para o Grupo A

\begin{tabular}{|c|c|c|c|c|c|c|c|c|}
\hline GRUPO A & Atividade 1 & Atividade 2 & Atividade 3 & Atividade 4 & Atividade 5 & Atividade 6 & | Atividade $7 \mid$ & TOTAL \\
\hline Participante 1A & 1 & 0 & 1 & 1 & 0 & 1 & 0 & $57 \%$ \\
\hline Participante 2A & 1 & 1 & 1 & 1 & 1 & 1 & 0 & $86 \%$ \\
\hline Participante $3 \mathrm{~A}$ & 0 & 0 & 0 & 1 & 0 & 0 & 0 & $14 \%$ \\
\hline Participante 4A & 1 & 1 & 1 & 1 & 1 & 1 & 1 & $100 \%$ \\
\hline Participante $5 \mathrm{~A}$ & 1 & 0 & 1 & 1 & 1 & 1 & 1 & $86 \%$ \\
\hline Participante 6A & 1 & 0 & 1 & 1 & 0 & 1 & 1 & $71 \%$ \\
\hline Participante 7A & 1 & 0 & 0 & 0 & 0 & 0 & 0 & $14 \%$ \\
\hline Participante 8A & 1 & 1 & 1 & 1 & 0 & 1 & 0 & $71 \%$ \\
\hline MÉDIA & $88 \%$ & $38 \%$ & $75 \%$ & $88 \%$ & $38 \%$ & $75 \%$ & $38 \%$ & $63 \%$ \\
\hline DESVIO PADRÃO & $35 \%$ & $52 \%$ & $46 \%$ & $35 \%$ & $52 \%$ & $46 \%$ & $52 \%$ & $32 \%$ \\
\hline
\end{tabular}

Fonte: Elaborada pelo autor.

total de 57\% de eficácia, não completando adequadamente a Atividade 1, a Atividade 2 e a Atividade 3 , que consistem em definir trabalhos de programação considerando as ferramentas ProgTest, Web-CAT e BOCA, respectivamente.

Tabela 5 - Experimento 1: Resultados de eficácia para o Grupo B

\begin{tabular}{|c|c|c|c|c|c|c|c|c|}
\hline GRUPO B & Atividade 1 & vidade 2 & Atividade 3 & Atividade 4 & tividade 5 & Atividade 6 & | Atividade $7 \mid$ & TOTAL \\
\hline Participante 1B & 0 & 0 & 0 & 1 & 1 & 1 & 1 & $57 \%$ \\
\hline Participante 2B & 1 & 1 & 1 & 1 & 1 & 1 & 1 & $100 \%$ \\
\hline Participante 3B & 1 & 1 & 1 & 1 & 1 & 1 & 1 & $100 \%$ \\
\hline Participante 4B & 1 & 1 & 1 & 0 & 1 & 1 & 1 & $86 \%$ \\
\hline Participante 5B & 1 & 0 & 0 & 1 & 1 & 1 & 1 & $71 \%$ \\
\hline Participante 6B & 1 & 1 & 1 & 1 & 1 & 1 & 1 & $100 \%$ \\
\hline Participante 7B & 1 & 1 & 1 & 1 & 1 & 1 & 1 & $100 \%$ \\
\hline Participante 8B & 1 & 1 & 1 & 1 & 1 & 1 & 1 & $100 \%$ \\
\hline MÉDIA & $88 \%$ & $75 \%$ & $75 \%$ & $88 \%$ & $100 \%$ & $100 \%$ & $100 \%$ & $89 \%$ \\
\hline DESVIO PADRÃO & $35 \%$ & $46 \%$ & $46 \%$ & $35 \%$ & $0 \%$ & $0 \%$ & $0 \%$ & $17 \%$ \\
\hline
\end{tabular}

Fonte: Elaborada pelo autor.

Com base nos resultados obtidos, foi aceita a hipótese alternativa $H_{1}$ para eficácia:

$H_{1}=$ A eficácia utilizando as ferramentas de avaliação é maior por meio de um LMS do que diretamente por meio de sua interface.

\section{Efetividade}

No gráfico da Figura 41 são comparados os principais resultados para efetividade. Em síntese, os valores de efetividade do Grupo B são superiores aos valores de efetividade do Grupo 
A em todas as atividades. No entanto, ressalta-se uma maior diferença nos valores das Atividade $2(6 \%$ e $50 \%)$ e Atividade 5 (32\% e 83\%), ambas relacionadas à ferramenta WEB-CAT, bem como nos valores da Atividade 7 (22\% e 73\%), que consistiu em avaliar manualmente um programa na ferramenta BOCA.

Figura 41 - Experimento 1: Efetividade

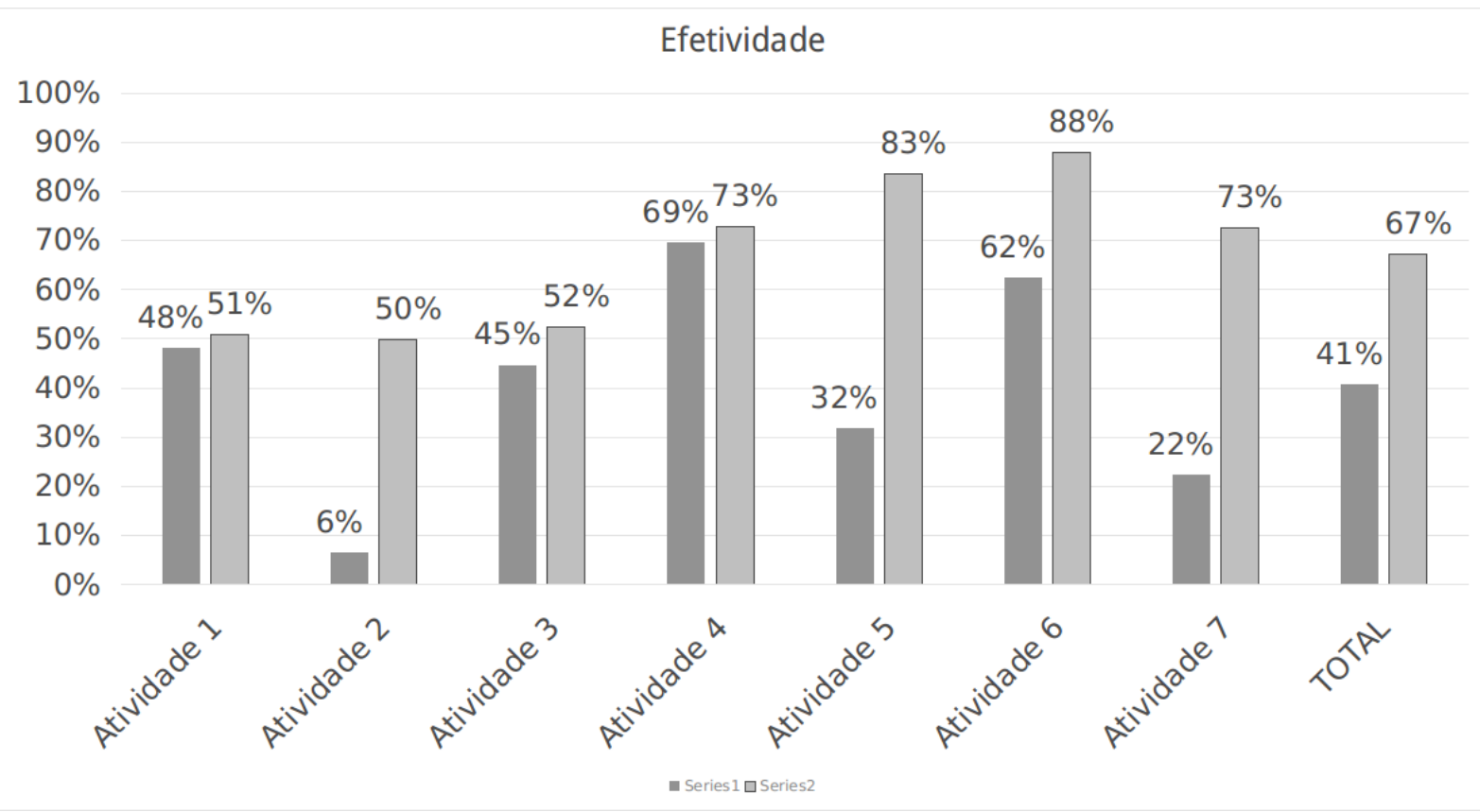

Fonte: Elaborada pelo autor.

Na Tabela 6 são apresentados detalhes sobre a efetividade dos participantes do Grupo A. O Participante 5A, por exemplo, foi o que obteve o melhor resultado, atingindo um total de $63 \%$ de efetividade, apesar de ter atingido um valor de $0 \%$ de efetividade na Atividade 2 , que consistiu em definir um trabalho de programação na ferramenta WEB-CAT. Já o Participante $3 \mathrm{~A}$ foi o que obteve o menor valor, atingindo um total de $12 \%$ de efetividade, uma vez que a única atividade em que obteve um valor superior a $0 \%$ de efetividade foi na Atividade 4 (83\% ), que consistiu em submeter um programa para ser automaticamente avaliado na ferramenta ProgTest.

Já na Tabela 7 são apresentado mais detalhes sobre a efetividade dos participantes do Grupo B. O Participante 3B, por exemplo, foi o que obteve o melhor resultado para efetividade, atingindo um total de $85 \%$ de efetividade, tendo como menor valor de efetividade $76 \%$ na Atividade 1. Já o Participante 1B foi o que obteve o menor valor para efetividade, atingindo um total de $45 \%$ de efetividade, obtendo $0 \%$ de efetividade na Atividade 1, na Atividade 2 e na Atividade 3, que consistem em definir trabalhos de programação considerando as ferramentas PROGTEST, WEB-CAT e BOCA, respectivamente.

Com base nos resultados obtidos, foi aceita a hipótese alternativa $H_{1}$ para efetividade: 
Tabela 6 - Experimento 1: Resultados de efetividade para o Grupo A

\begin{tabular}{c|c|c|c|c|c|c|c|c|c|c}
\hline GRUPO A & Atividade 1 & \multicolumn{7}{|c|}{ Atividade 2 } & \multicolumn{3}{|c|}{ Atividade 3 } & \multicolumn{3}{|c}{ Atividade 4tividade 5 } & Atividade & Atividade & TOTAL \\
\hline \hline Participante 1A & $70 \%$ & $0 \%$ & $88 \%$ & $65 \%$ & $0 \%$ & $83 \%$ & $0 \%$ & $44 \%$ \\
\hline Participante 2A & $14 \%$ & $0 \%$ & $71 \%$ & $75 \%$ & $77 \%$ & $66 \%$ & $0 \%$ & $43 \%$ \\
\hline Participante 3A & $0 \%$ & $0 \%$ & $0 \%$ & $83 \%$ & $0 \%$ & $0 \%$ & $0 \%$ & $12 \%$ \\
\hline Participante 4A & $50 \%$ & $20 \%$ & $0 \%$ & $90 \%$ & $90 \%$ & $90 \%$ & $40 \%$ & $54 \%$ \\
\hline Participante 5A & $66 \%$ & $0 \%$ & $66 \%$ & $87 \%$ & $86 \%$ & $82 \%$ & $53 \%$ & $63 \%$ \\
\hline Participante 6A & $58 \%$ & $0 \%$ & $73 \%$ & $66 \%$ & $0 \%$ & $81 \%$ & $85 \%$ & $52 \%$ \\
\hline Participante 7A & $96 \%$ & $0 \%$ & $0 \%$ & $0 \%$ & $0 \%$ & $0 \%$ & $0 \%$ & $14 \%$ \\
\hline Participante 8A & $31 \%$ & $32 \%$ & $59 \%$ & $89 \%$ & $0 \%$ & $97 \%$ & $0 \%$ & $44 \%$ \\
\hline MÉDIA & $48 \%$ & $6 \%$ & $45 \%$ & $69 \%$ & $32 \%$ & $62 \%$ & $22 \%$ & $41 \%$ \\
\hline DESVIO & $32 \%$ & $12 \%$ & $38 \%$ & $30 \%$ & $44 \%$ & $39 \%$ & $33 \%$ & $18 \%$ \\
\hline
\end{tabular}

Fonte: Elaborada pelo autor.

Tabela 7 - Experimento 1: Resultados de efetividade para o Grupo B

\begin{tabular}{|c|c|c|c|c|c|c|c|c|}
\hline GRUPO B & Atividade & Atividade & Atividade & | Atividade 4 & Atividade & Atividade 6 & 6| Atividade 7 & TOT \\
\hline Participante 1B & $0 \%$ & $0 \%$ & $0 \%$ & $79 \%$ & $82 \%$ & $80 \%$ & $73 \%$ & $45 \%$ \\
\hline Participante $2 \mathrm{~B}$ & $47 \%$ & $50 \%$ & $52 \%$ & $73 \%$ & $79 \%$ & $82 \%$ & $37 \%$ & $60 \%$ \\
\hline Participante $3 \mathrm{~B}$ & $76 \%$ & $80 \%$ & $80 \%$ & $90 \%$ & $90 \%$ & $90 \%$ & $90 \%$ & $85 \%$ \\
\hline Participante 4B & $73 \%$ & $77 \%$ & $65 \%$ & $0 \%$ & $71 \%$ & $95 \%$ & $90 \%$ & $67 \%$ \\
\hline Participante 5B & $50 \%$ & $0 \%$ & $0 \%$ & $93 \%$ & $93 \%$ & $95 \%$ & $82 \%$ & $59 \%$ \\
\hline Participante $6 \mathrm{~B}$ & $49 \%$ & $59 \%$ & $70 \%$ & $90 \%$ & $91 \%$ & $91 \%$ & $56 \%$ & $72 \%$ \\
\hline Participante 7B & $43 \%$ & $50 \%$ & $80 \%$ & $68 \%$ & $70 \%$ & $80 \%$ & $80 \%$ & $67 \%$ \\
\hline Participante $8 \mathrm{~B}$ & $69 \%$ & $82 \%$ & $73 \%$ & $90 \%$ & $92 \%$ & $90 \%$ & $72 \%$ & $81 \%$ \\
\hline MÉDIA & $51 \%$ & $50 \%$ & $52 \%$ & $73 \%$ & $83 \%$ & $88 \%$ & $73 \%$ & $67 \%$ \\
\hline DESVIO & $24 \%$ & $33 \%$ & $34 \%$ & $31 \%$ & $9 \%$ & $6 \%$ & $18 \%$ & $13 \%$ \\
\hline
\end{tabular}

Fonte: Elaborada pelo autor.

$H_{1}=$ A efetividade utilizando as ferramentas de avaliação é maior por meio de um LMS do que diretamente por meio de sua interface.

\section{Percepção dos participantes}

Por fim, no gráfico da Figura 42 é apresentada a percepção dos participantes dos Grupo A e Grupo B com relação a demanda mental, demanda física, demanda temporal, desempenho, esforço e frustração durante a realização das atividades.

De modo geral, no Grupo B houve mais participantes que atribuíram níveis baixos de demanda mental, demanda física, demanda temporal, esforço e frustração, bem como níveis altos de desempenho durante a realização das atividades. Por exemplo, 58\% dos participantes do Grupo A responderam que foram necessários níveis baixos de demanda mental para realizar 
as atividades, enquanto $78 \%$ dos participantes do Grupo B responderam o mesmo. De forma análoga, $84 \%$ dos participantes de Grupo A responderam que tiveram um desempenho alto na realização das atividades, enquanto $94 \%$ dos participantes do Grupo B responderam o mesmo.

Figura 42 - Experimento 1: Resultados da percepção dos participantes

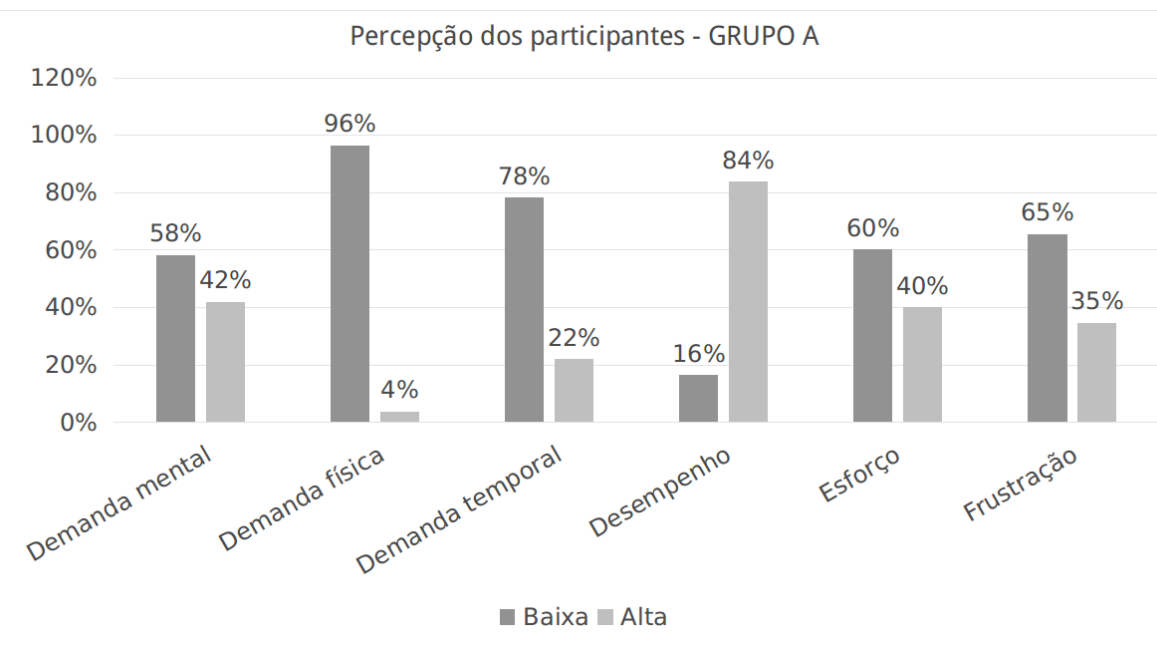

(a) Grupo A

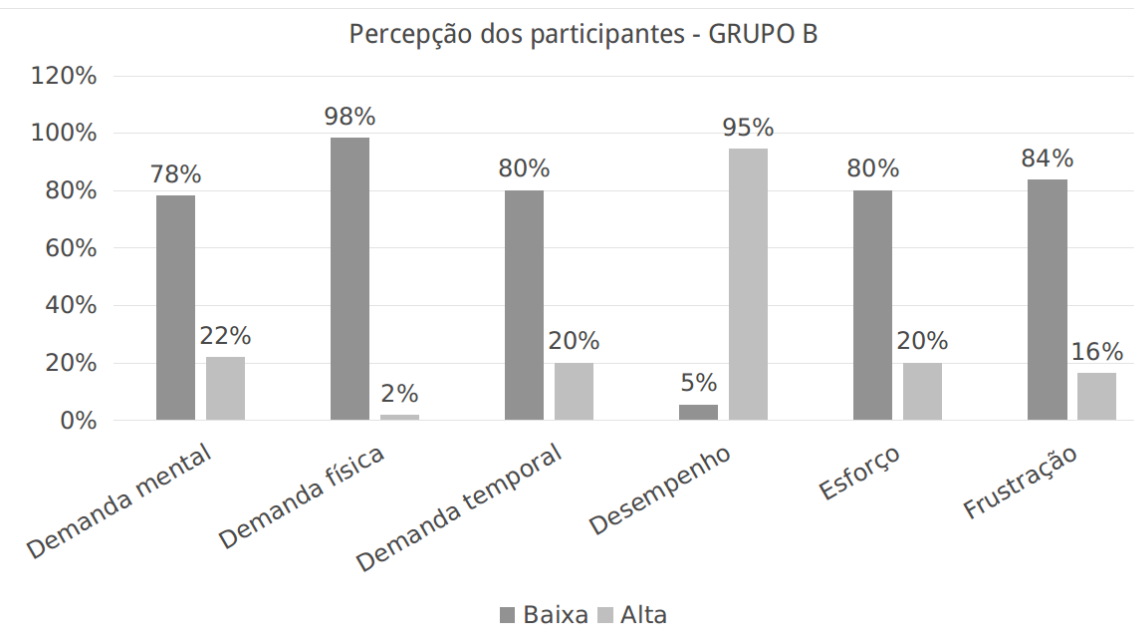

(b) Grupo B

Fonte: Elaborada pelo autor.

Com base nos resultados obtidos, é possível concluir que a percepção dos participantes utilizando as ferramentas de avaliação foi melhor por meio de um LMS do que diretamente por meio de sua interface.

\subsubsection{Discussões}

Um aspecto interessante observado a partir da condução do Experimento 1 refere-se à influência das ferramentas na eficiência, eficácia e efetividade dos participantes durante a realização das atividades. 
Como exemplo, considere os valores obtidos para as atividades realizadas com a ferramenta WEB-CAT pelo GRUPO A, que realizou tais atividades por meio da própria interface da ferramenta. Foi possível observar valores de eficiência, eficácia e efetividade significantemente mais baixos para a Atividade 2 e para a Atividade 5 , relacionadas à definição de um trabalho de programação na WEB-CAT e à submissão de um programa para ser avaliado pela WEB-CAT, comparando com as atividades similares nos ambientes PROGTEST e BOCA. De fato, a definição de um trabalho na WEB-CAT exige vários passos para ser realizada e vários parâmetros precisam ser configurados. Ainda, muitas vezes é difícil identificar em que local da interface da ferramenta é possível configurar um determinado parâmetro.

Esta dificuldade nas atividades relacionadas à ferramenta WEB-CAT não foi percebida nos resultados para o GRUPO B, em que todas as atividades foram realizadas por meio da interface do LMS MoOdLE e da extensão desenvolvida para ele. Neste sentido, foi possível perceber que a integração das ferramentas em LMSs pode mitigar os problemas relacionados à usabilidade. De fato, ao concentrar esforço em melhorias na usabilidade do LMS adotado pela instituição, haverá, por consequência, uma melhor usabilidade na utilização de todas as ferramentas a ele integradas.

Por fim, foi possível observar que houve um crescimento nos valores de eficiência entre a Atividade 1, a Atividade 2 e a Atividade 3 (relacionadas à definição de trabalhos de programação como professores), bem como entre a Atividade 4, a Atividade 5 e a Atividade 6 (relacionadas à submissão de soluções às ferramentas como alunos). Este crescimento pode ser resultado da aprendizagem dos participantes em como utilizar o LMS e sua extensão. Tal resultado sugere que, conforme os participante foram se familiarizando com as novas funcionalidades adicionadas pela extensão, sua eficiência foi melhorando, independentemente do fato de estarem trabalhando com outras ferramentas. Isto ressalta que a utilização de ferramentas por meio do LMS em que os alunos e professores já estão habituados pode diminuir o tempo e esforço gastos aprendendo a utilizar uma nova ferramenta.

Ressalta-se, no entanto, que estes resultados são preliminares e experimentos sistemáticos devem ser planejados e conduzidos em trabalhos futuros. Tais experimentos deverão envolver um número maior de participantes, bem como considerar outros contextos, outras atividades, outras ferramentas de avaliação e outros LMSs.

\subsection{Experimento 2: Desenvolvimento e correção de pro- gramas}

O Experimento 2 complementa o Experimento 1, considerando um contexto real de ensino e aprendizagem. Enquanto no Experimento 1 ênfase foi dada à capacidade dos participantes em utilizar as ferramentas de avaliação, no Experimento 2, foi dada ênfase à capacidade dos participantes em desenvolver e corrigir os seus programas com o auxílio das 
ferramentas de avaliação.

\subsubsection{Visão geral}

Assim como o Experimento 1, o Experimento 2 também foi conduzido a fim de avaliar os benefícios de utilizar as ferramentas de avaliação para trabalhos de programação por meio de um LMS. No entanto, o foco do Experimento 2 foi a utilização de uma ferramenta de avaliação em um cenário real de ensino e aprendizagem de programação. Assim, neste experimento foram selecionados como participantes os alunos de graduação de uma disciplina de programação do ICMC-USP.

Em síntese, foi solicitado aos alunos desenvolverem programas para um conjunto de exercícios de programação. Os alunos deveriam submeter seus programas para correção por meio de uma ferramenta de avaliação, recebendo feedback sobre a qualidade dos mesmos. Assim como no Experimento 1, os participantes foram divididos em dois grupos, sendo que os participantes de um grupo realizaram as submissões e visualizaram o feedback fornecido pela ferramenta de avaliação diretamente pela sua interface, enquanto os participantes do Grupo A realizaram as atividades por meio de um LMS.

Para a análise dos resultados do experimento, foram consideradas as diferenças de valores obtidas pelos dois grupos de participantes para eficiência, eficácia e efetividade. No entanto, em contraste com o Experimento 1, no Experimento 2 foram consideradas como uma atividade o desenvolvimento de um programa, sendo que esta atividade somente era tida como concluída quando o programa submetido pelo aluno era avaliado como $100 \%$ correto pela ferramenta de avaliação. Assim, no Experimento 2 foi considerado: (i) como eficiência, o tempo gasto pelos alunos para desenvolverem e corrigirem os seus programas com o auxílio da ferramenta de avaliação; e (ii) como efetividade, o número de programas avaliados como corretos pela ferramenta de avaliação.

Os métodos definidos durante o planejamento do experimento são melhor detalhados a seguir.

\subsubsection{Métodos}

Este experimento também foi planejado seguindo os procedimentos definidos por Wohlin et al. (2012). Detalhes sobre o escopo e o planejamento é descrito a seguir.

\section{Definição do objetivo}

A meta do Experimento 2 segue a mesma definição do Experimento 1, apenas considerando um contexto diferente: 
Analisar os meios de acesso às funcionalidades das ferramentas de avaliação para trabalhos de programação

para o propósito de avaliar

com respeito à eficiência, eficácia, efetividade

do ponto de vista do pesquisador

no contexto de alunos do primeiro ano de cursos de computação realizando exercícios de programação

\section{Formulação das hipóteses}

A ideia deste experimento foi verificar se a realização de exercícios de programação é mais eficiente, eficaz e efetiva utilizando ferramentas de avaliação para trabalhos de programação por meio de um LMS. Assim, as hipóteses formuladas para este experimento também são as mesmas definidas para o Experimento 1, diferindo apenas nas variáveis consideradas para avaliar as hipóteses. Tais variáveis são detalhadas a seguir.

\section{Variáveis de entrada}

Neste experimento as seguintes variáveis de entrada foram consideradas:

- Ferramenta de avaliação para trabalho de programação (parâmetro): Consiste na ferramenta de avaliação utilizada pelos participantes durante a condução do experimento. No contexto deste experimento, foi selecionada a ferramenta BOCA. A escolha da ferramenta BOCA visou motivar os alunos, uma vez que a ferramenta apoia a condução de atividades de programação no contexto de maratonas de programação.

- LMS (parâmetro): Consiste no LMS utilizado para disponibilizar os exercícios de programação e os mecanismos para submissão e avaliação. No contexto desse experimento, foi selecionado o LMS MOODLE, visando utilizar os protótipos resultantes da instanciação da arquitetura IMPACTLE (Seção 4.6).

- Experiência dos participantes (parâmetro): Refere-se ao nível de aptidão dos participantes em programação, ou seja, o quão habilidosos eles são em programação. Esta variável foi controlada considerando as notas dos alunos no decorrer da disciplina de programação.

- Exercícios de programação (parâmetro): Consistem nos exercícios a serem realizados pelos participantes durante a condução do experimento. Foram definidos os seguintes exercícios: 
- Exercício 1: Escrever um programa que converta uma temperatura em graus Fahrenheit para graus Celsius (explora majoritariamente expressões aritméticas e variáveis).

- Exercício 2: Escrever um programa que receba os valores dos lados de um triângulo e informe o tipo do triângulo (explora, em especial, expressões lógicas e comandos de seleção).

- Exercício 3: Escrever um programa que ordene uma sequência de valores (explora majoritariamente arrays e laços de execução).

- Meios de acesso às funcionalidades das ferramentas de avaliação para trabalhos de programação (fator): Consiste em como os participantes acessam as funcionalidades das ferramentas. Recebe dois tratamentos:

- Tratamento A: $\mathrm{O}$ acesso às funcionalidades das ferramentas ocorre diretamente por meio de sua interface.

- Tratamento B: O acesso às funcionalidades das ferramentas ocorre por meio da interface do LMS.

\section{Variáveis de saída}

De forma análoga ao Experimento 1, neste experimento as seguintes variáveis de saída foram consideradas:

- Eficiência: Refere-se ao tempo gasto pelos participantes para realizar os exercícios propostos. O cálculo da eficiência foi realizado pela seguinte fórmula:

$$
\text { Eficiência }=\left(t_{M A X}-t\right) / t_{M A X}
$$

onde $t_{M A X}$ foi o tempo máximo de 90 minutos estipulado para a realização dos três exercícios e $t$ o tempo despendido pelo participante na condução dos três exercícios. Assim, um participante que tenha despendido 90 minutos na realização dos exercícios recebe um valor de eficiência " 0,0 ", ou seja, $0 \%$ de eficiência. Já um participante que tenha realizado os três exercícios em 45 minutos, por exemplo, recebe um valor de eficiência "0,5”, ou seja, $50 \%$ de eficiência.

- Eficácia: Refere-se à quantidade de exercícios submetidos pelos participantes e avaliados como $100 \%$ corretos pela ferramenta BOCA. O cálculo da eficácia foi realizado pela seguinte fórmula:

$$
\text { Eficácia }=n / n_{\text {TOTAL }}
$$

onde $n$ é o número de exercícios concluídos pelo participante e $n_{T O T A L}$ é o total de exercícios propostos. Assim, um participante que não tenha concluído nenhum exercício 
recebe um valor de eficácia " 0,0 ,, ou seja, $0 \%$ de eficácia. Já um participante que tenha concluído todos os exercícios recebe um valor de eficácia “1,0”, ou seja, 100\% de eficácia.

- Efetividade: Refere-se à combinação dos resultados para eficiência e eficácia. O cálculo da efetividade foi realizado pela fórmula:

$$
\text { Efetividade }=\text { Eficiência } * \text { Eficácia }
$$

\section{Avaliação qualitativa}

Assim como no Experimento 1, em complemento à avaliação quantitativa realizada por meio da medição da eficiência, eficácia e efetividade, uma avaliação qualitativa também foi realizada, visando observar a percepção dos participantes durante a condução das atividades. Os dados para essa avaliação foram coletados solicitando que os participantes preenchessem um formulário após realizar todos os exercícios. De forma análoga ao Experimento 1, o formulário foi elaborado com base no NASA Task Load Index - NASA TLX) (CAO et al., 2009). Em síntese, o questionário pede que os participantes informem em uma escala de 0 a 10 sua percepção deles com relação à demanda mental, demanda física, demanda temporal, desempenho, esforço e frustração.

\section{Seleção dos participantes}

Foram selecionados como participantes alunos do primeiro ano do curso de Bacharelado em Sistemas de Informação do ICMC/USP, ingressantes em 2016. Os alunos estavam cursando a disciplina de Introdução à Ciência da Computação II (ICC2), que visa o ensino e a aprendizagem de conceitos de programação. No total, 16 alunos se voluntariaram a participar do experimento. Observa-se, no entanto, que o desempenho dos alunos nos exercícios propostos estavam sendo contabilizados como uma das notas na disciplina.

\section{Projeto experimental}

Os participantes foram divididos em dois grupos, balanceando suas experiências, de acordo com suas notas prévias obtidas na disciplina de ICC2. Os alunos de cada grupo receberam instruções sobre os exercícios de programação a serem realizados e sobre o LMS e as ferramentas de avaliação a serem utilizadas. A descrição dos exercícios, materiais adicionais e links para a entrega dos exercícios, foram disponibilizados para os dois grupos por meio do LMS MOODLE. 
Os alunos realizaram os exercícios de programação definidos e submeteram os seus programas à ferramenta BOCA. No entanto, para os participantes do Grupo A foi fornecido um link para entrega dos exercícios redirecionando-os para a interface da ferramenta BOCA, enquanto que para os participantes do GRUPO B foi fornecido um link para a entrega dos exercícios por meio do próprio LMS MOODLE, integrado aos protótipos da arquitetura IMPACTLE.

Por meio do feedback da ferramenta BOCA, os alunos tiveram a oportunidade de corrigir os seus programas e os submeteram novamente até tempo máximo permitido, de 90 minutos. Após finalizar os exercícios ou o tempo máximo definido para a realização dos exercícios ser atingido, os alunos preencheram um questionário de avaliação subjetiva.

\subsubsection{Resultados}

No gráfico da Figura 43 são comparados os principais resultados entre os dois grupos. Em síntese, os valores de eficiência, eficácia e efetividade do Grupo B foram superiores aos valores do Grupo A. No entanto, ressalta-se uma maior diferença nos valores de eficiência (44\% e $67 \%$ ), sendo o tempo o fator que mais influenciou a efetividade dos alunos.

Figura 43 - Experimento 2: Resultados

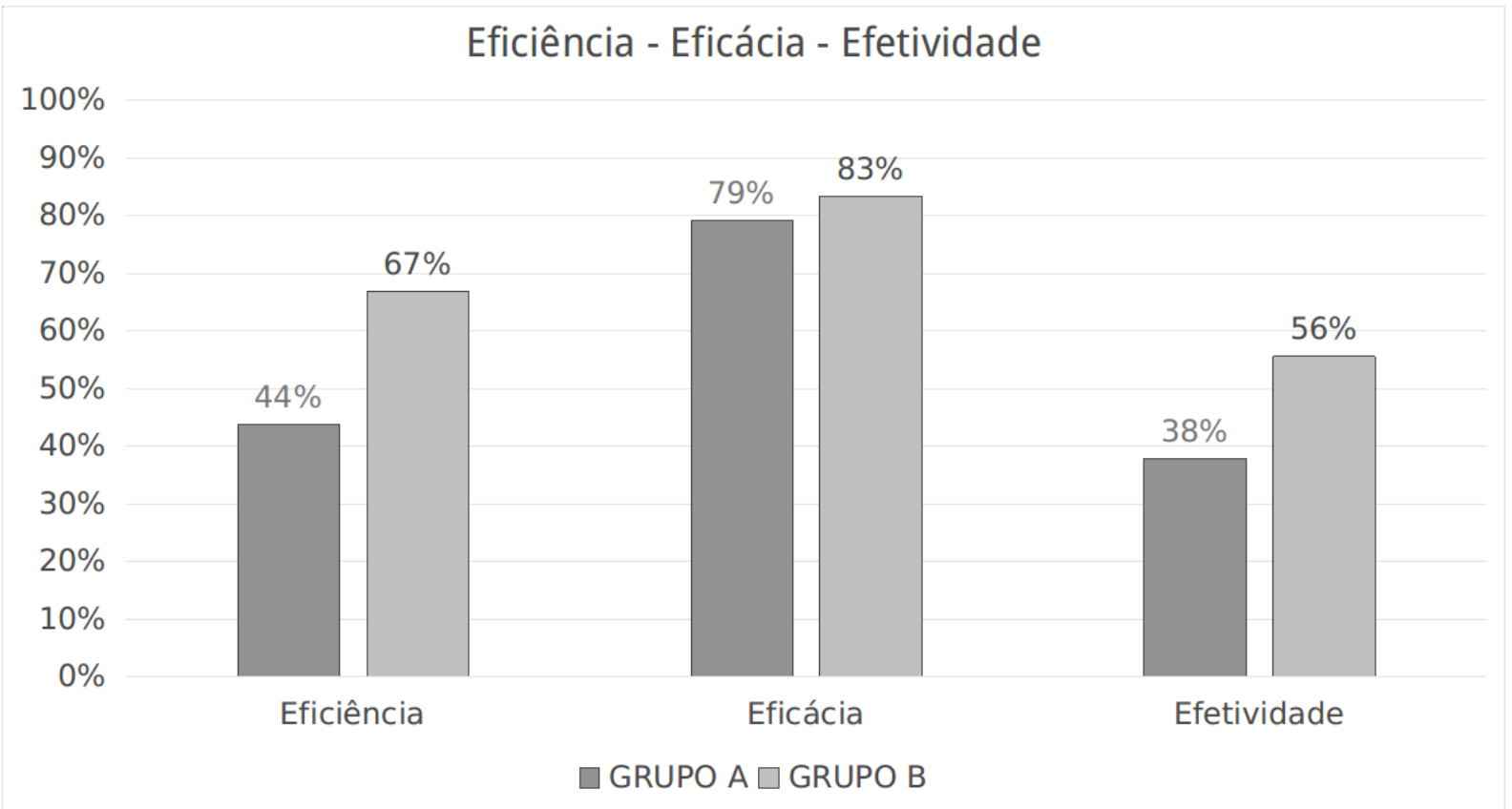

Fonte: Elaborada pelo autor.

Na Tabela 8 são apresentados detalhes sobre a eficiência, eficácia e efetividade dos participantes do Grupo A. O Participante 3A, por exemplo, foi o que obteve o melhor resultado, atingindo um total de $77 \%$ de efetividade, sendo que obteve $100 \%$ de correção (eficácia) na ferramenta BOCA para todos os seus programas, restando ainda $77 \%$ do tempo disponível (eficiência) para que ele completasse os exercícios. Já o Participante 8A foi o que obteve o menor valor para efetividade, atingindo um total de $0 \%$ de efetividade, uma vez que utilizou todo 
o tempo disponível ( $0 \%$ de eficiência) e, mesmo assim, nenhum de seus programas teve algum nível de correção ( $0 \%$ de eficácia).

Tabela 8 - Experimento 2: Resultados para o Grupo A

\begin{tabular}{|c|c|c|c|}
\hline GRUPO A & Eficiência & Eficácia & Efetividade \\
\hline Participante $1 \mathrm{~A}$ & $66 \%$ & $100 \%$ & $66 \%$ \\
\hline Participante $2 \mathrm{~A}$ & $65 \%$ & $67 \%$ & $43 \%$ \\
\hline Participante $3 \mathrm{~A}$ & $77 \%$ & $100 \%$ & $77 \%$ \\
\hline Participante 4A & $44 \%$ & $100 \%$ & $44 \%$ \\
\hline Participante 5A & $78 \%$ & $67 \%$ & $52 \%$ \\
\hline Participante $6 \mathrm{~A}$ & $17 \%$ & $100 \%$ & $17 \%$ \\
\hline Participante 7A & $3 \%$ & $100 \%$ & $3 \%$ \\
\hline Participante 8A & $0 \%$ & $0 \%$ & $0 \%$ \\
\hline MÉDIA & $44 \%$ & $79 \%$ & $38 \%$ \\
\hline DESVIO & $33 \%$ & $35 \%$ & $28 \%$ \\
\hline
\end{tabular}

Fonte: Elaborada pelo autor.

Já na Tabela 9 são apresentados detalhes sobre a efetividade dos participantes do Grupo B. O Participante 4B, por exemplo, foi o que obteve o melhor resultado, atingindo um total de $81 \%$ de efetividade, sendo que obteve $100 \%$ de correção (eficácia) na ferramenta BOCA para todos os seus programas, restando ainda $81 \%$ do tempo disponível (eficiência) para que ele completasse os exercícios. Já o Participante 2B foi o que obteve o menor valor para efetividade, atingindo um total de $0 \%$ de efetividade. efetividade. De fato, apesar de ter atingido $69 \%$ de eficiência, este participante não conseguiu que nenhum de seus de seus programas tivesse algum nível de correção ( $0 \%$ de eficácia).

Tabela 9 - Experimento 2: Resultados para o Grupo B

\begin{tabular}{|c|c|c|c|}
\hline GRUPO B & Eficiência & Eficácia & Efetividade \\
\hline Participante 1B & $68 \%$ & $100 \%$ & $68 \%$ \\
\hline Participante 2B & $69 \%$ & $0 \%$ & $0 \%$ \\
\hline Participante 3B & $63 \%$ & $100 \%$ & $63 \%$ \\
\hline Participante 4B & $81 \%$ & $100 \%$ & $81 \%$ \\
\hline Participante 5B & $54 \%$ & $100 \%$ & $54 \%$ \\
\hline Participante 6B & $62 \%$ & $67 \%$ & $42 \%$ \\
\hline Participante 7B & $72 \%$ & $100 \%$ & $72 \%$ \\
\hline Participante 8B & $66 \%$ & $100 \%$ & $66 \%$ \\
\hline MÉDIA & $67 \%$ & $83 \%$ & $56 \%$ \\
\hline DESVIO & $8 \%$ & $36 \%$ & $25 \%$ \\
\hline
\end{tabular}

Fonte: Elaborada pelo autor.

Com base nos resultados obtidos, foi aceita a hipótese alternativa $H_{1}$ para eficiência, eficácia e efetividade: 
$H_{1}=$ A eficiência utilizando as ferramentas de avaliação é maior por meio de um LMS do que diretamente por meio de sua interface.

$H_{1}=$ A eficácia utilizando as ferramentas de avaliação é maior por meio de um LMS do que diretamente por meio de sua interface.

$H_{1}=$ A efetividade utilizando as ferramentas de avaliação é maior por meio de um LMS do que diretamente por meio de sua interface.

Por fim, no gráfico da Figura 44 é apresentada a percepção dos participantes dos Grupo A e Grupo B com relação à demanda mental, demanda física, demanda temporal, desempenho, esforço e frustração durante a realização dos exercícios.

Em ambos os grupos, o mesmo número de participantes (75\%) atribuíram níveis altos para desempenho e o mesmo número de participantes (63\%) atribuíram níveis baixos para frustração. No entanto, no Grupo B houveram mais participantes do que no Grupo A que atribuíram níveis baixos de demanda mental, demanda física, demanda temporal, desempenho, esforço e frustração, bem como níveis altos de desempenho durante a realização das atividades. Por exemplo, 50\% dos participantes do Grupo A responderam que foram necessários níveis baixos de demanda mental para realizar as atividades, enquanto $63 \%$ dos participantes do Grupo B responderam o mesmo. De forma análoga, 25\% dos participantes de Grupo A responderam que tiveram um desempenho alto na realização das atividades, enquanto $63 \%$ dos participantes do Grupo B responderam o mesmo.

Por fim, nos gráficos da Figura 45 é sintetizada a opinião dos participantes sobre a utilização da ferramenta BOCA diretamente por meio da sua interface ou por meio do LMS Moodle. Apesar de 75\% dos alunos do Grupo B ter respondido que seria melhor se tivessem submetido os seus programas diretamente na interface do BOCA, todos os alunos do Grupo A concordaram que seria melhor se tivessem submetido seus trabalhos por meio do LMS MOODLE.

Com base nos resultados obtidos, é possível concluir que a percepção dos participantes realizando exercícios de programação foi melhor utilizando uma ferramenta de avaliação por meio de um LMS do que diretamente por meio de sua interface.

\subsubsection{Discussões}

Um aspecto interessante observado durante a condução e a análise dos resultados do Experimento 2 foi que as diferenças entre os valores obtidos pelo GRUPO A e os valores obtidos pelo GRUPO B são maiores em eficiência do que em eficácia. Uma vez que a efetividade foi considerada como a combinação entre a eficiência e eficácia, a eficiência dos alunos foi a que mais influenciou a sua efetividade. 
Figura 44 - Experimento 2: Percepção dos participantes

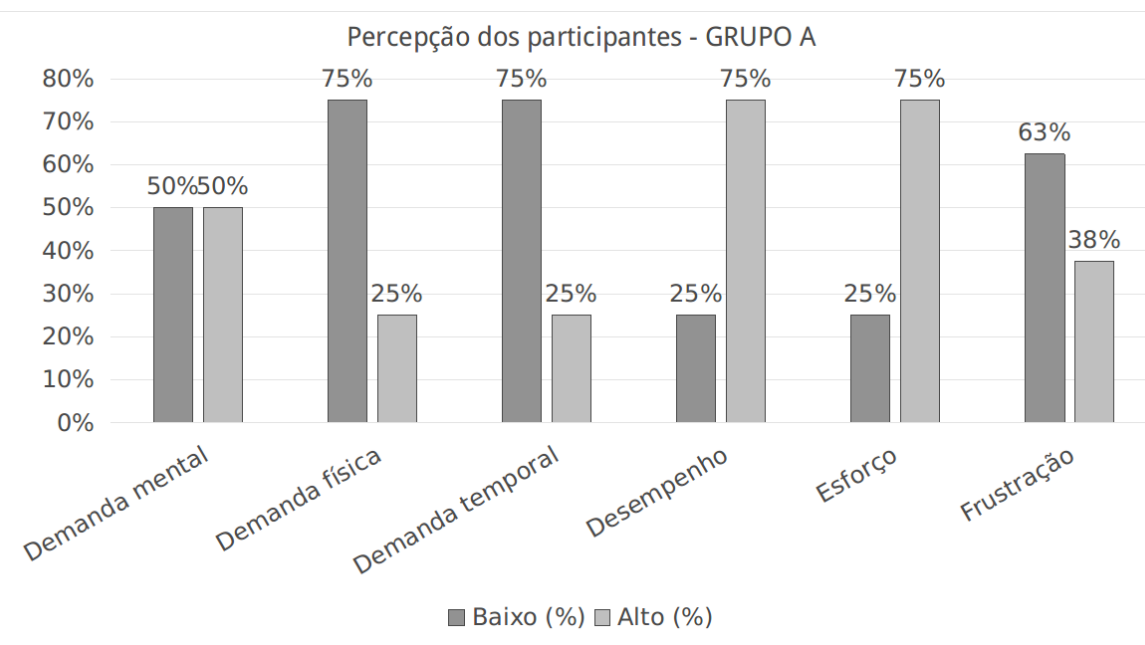

(a) Grupo A

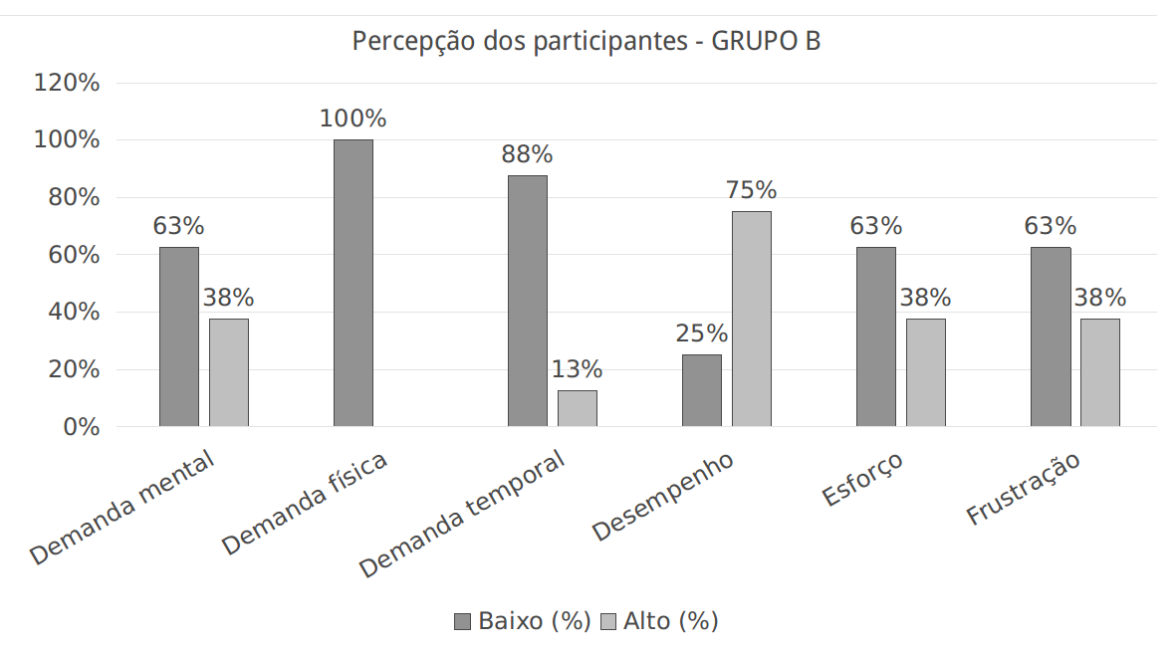

(b) Grupo B

Fonte: Elaborada pelo autor.

Ressalta-se também que a eficácia no Experimento 2 está relacionada a capacidade dos alunos em desenvolverem programas corretos como soluções para os exercícios propostos, enquanto no Experimento 1 a eficácia está relacionada a capacidade dos participantes em utilizar de forma adequada as funcionalidades das ferramentas de avaliação. No entanto, em ambos os casos, a eficiência foi a que mais influenciou os resultados de efetividade nos dois experimentos.

Apesar das diferenças nos valores de eficiência, a percepção dos alunos entre os dois grupos foi similar com relação ao desempenho e frustração. Ainda, embora todos os alunos do GRUPO A tenham concordado que teria sido melhor realizar as submissões por meio do MOODLE, vários alunos do GRUPO B acharam que teria sido melhor para eles realizar as submissões diretamente no BOCA. Acredita-se que estas percepções possam ter sido influenciadas pelo fato de os alunos de um grupo saberem o que os alunos do outro grupo estavam fazendo. 
Figura 45 - Experimento 2: Opinião dos participantes sobre a abordagem

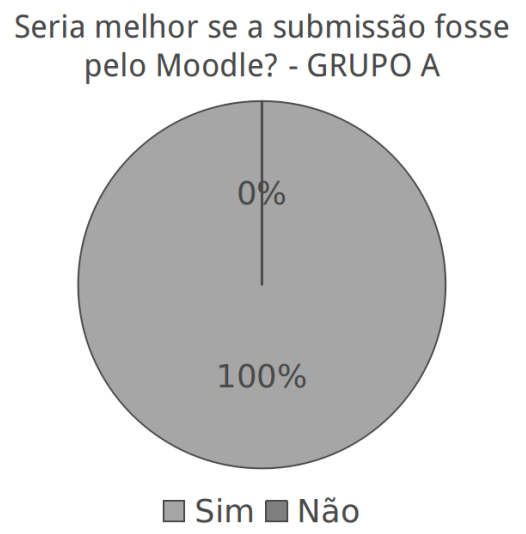

(a) Grupo A

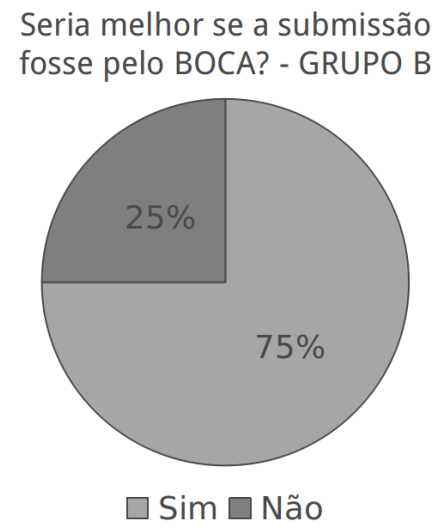

(b) Grupo B

Fonte: Elaborada pelo autor.

Ressalta-se, no entanto, que estes resultados são preliminares e experimentos sistemáticos devem ser planejados e conduzidos em trabalhos futuros. Tais experimentos deverão envolver um número maior de participantes, bem como considerar outras disciplinas de programação, outras instituições e outros contextos de atividades de programação (como por exemplo, maratonas de programação, exames práticos de programação, entre outros).

\subsection{Considerações finais}

Neste capítulo foram discutidos os métodos e resultados de dois experimentos conduzidos a fim de verificar os benefícios em utilizar as ferramentas de avaliação para trabalhos de programação LMSs. Por meio dos experimentos foi possível obter indicativos de que: (i) os alunos e professores utilizam as ferramentas de avaliação de forma mais eficiente, eficaz e efetiva por meio de um LMS; e (ii) os alunos desenvolvem e corrigem os seus programas de forma mais eficiente, eficaz e efetiva quando recebem um feedback da ferramenta de avaliação por meio de um LMS.

No entanto, ressalta-se que os resultados obtidos pelos experimentos são preliminares e experimentos sistemáticos envolvendo um número maior de participantes e outros contextos devem ser planejados e conduzidos. Outras limitações e trabalhos futuros, bem como as principais contribuições deste trabalho, são discutidas no próximo capítulo. 


\section{CONCLUSÃO}

\subsection{Caracterização da pesquisa realizada}

Um dos principais tópicos abordados em disciplinas introdutórias de computação é a programação (WATSON; LI, 2014). Apesar de sua importância, pesquisas têm identificado vários problemas no ensino e na aprendizagem de programação (BOSSE; GEROSA, 2017). Tais problemas, em geral, resultam em altas taxas de desistência e reprovação (WATSON; LI, 2014).

A avaliação dos programas desenvolvidos pelos alunos é um instrumento importante para identificar e tratar suas dificuldades com respeito à programação (KURVINEN et al., 2016). Visando melhorar o processo de avaliação, é possível encontrar várias propostas de ferramentas que fornecem um feedback mais adequado aos alunos sobre a qualidade dos seus programas $(\mathrm{CH}-$ RISTIAN; TRIVEDI, 2016; SOUZA; FELIZARDO; BARBOSA, 2016) e automatizam as tarefas repetitivas dos professores.

Por outro lado, ferramentas de avaliação, em geral, acabam sendo mais um recurso com o qual o professor precisa se preocupar em como configurar, manter e ensinar os alunos a utilizar, investindo tempo e esforço que poderiam ser utilizados em outras atividades pedagógicas relevantes (RÖSSLING et al., 2010; KARAVIRTA; IHANTOLA; KOSKINEN, 2013). Além disso, também é comum que os alunos gastem um tempo e esforço excessivo aprendendo a utilizar uma determinada ferramenta de avaliação ao invés de se dedicarem no entendimento e construção de seus programas (RÖSSLING et al., 2010; SIRKIÄ; HAARANEN, 2015).

Uma das propostas que procura mitigar estes problemas consiste na integração de ferramentas de avaliação para trabalhos de programação em LMSs (KARAVIRTA; IHANTOLA; KOSKINEN, 2013). A ideia é que, por meio de um LMS, as funcionalidades das ferramentas estão integradas ao ambiente o qual tanto alunos como professores já estão habituados a utilizar. Com isso, é possível diminuir o tempo e esforço despendido no entendimento de uma nova ferramenta (RÖSSLING et al., 2010; BRUSILOVSKY et al., 2014). 
Dentro deste contexto, um dos principais objetivos deste trabalho de doutorado foi a proposição da arquitetura IMPACTLE (Integration Modules for Programming Assignment Checking Tools and Learning Environments) como uma solução para integrar diferentes ferramentas de avaliação para trabalhos de programação em diferentes LMSs. Basicamente, além dos LMSs e das ferramentas de avaliação, a arquitetura IMPACTLE define três componentes:

1. Extensões dos LMSs: Estendem as funcionalidades dos LMSs para apoiar a avaliação de trabalhos de programação por meio da estrutura da IMPACTLE. As extensões implementam a interação com os usuários (professores e alunos), bem como utilizam os recursos dos LMSs para gerenciar as submissões e armazenar os dados e arquivos associados aos trabalhos de programação.

2. Adaptadores: Adaptam as interfaces heterogêneas das ferramentas de avaliação em uma interface padrão, permitindo que ferramentas de avaliação com diferentes funcionalidades e características possam ser acessadas em uma maneira uniforme.

3. Middleware: Realiza a comunicação entre as extensões dos LMSs e os adaptadores de ferramentas, sendo capaz de receber requisições de todos os LMSs associados à estrutura da IMPACTLE e encaminhá-las ao adaptador da ferramenta que deverá processar a requisição. Para isto, o middleware também contém um registro das ferramentas disponíveis.

A fim de validar a arquitetura IMPACTLE protótipos de seus componentes foram instanciados, em especial, integrando as ferramentas BOCA, PROGTEST e WEB-CAT no LMS Moodle. Ainda, com o propósito de verificar a possibilidade de integração com outros tipos de ambientes de aprendizagem, uma extensão para o ambiente de desenvolvimento BLUEJ também foi desenvolvida.

Por fim, os protótipos foram utilizados na condução de dois experimentos envolvendo a utilização das ferramentas de avaliação por meio de um LMS. Por meio dos experimentos, foi possível obter indicativos de que os alunos e professores são mais eficientes, eficazes e efetivos, quando utilizando as ferramentas de avaliação por meio de um LMS.

As principais contribuições deste trabalho são descritas a seguir.

\subsection{Contribuições}

Este trabalho de doutorado teve por objetivo desenvolver uma solução para que as funcionalidades das ferramentas de avaliação para trabalhos de programação pudessem ser acessadas por meio de diferentes LMSs. Assim, as principais contribuições deste trabalho foram:

- Identificação dos benefícios da adoção de ferramentas de avaliação para mitigar as dificuldades dos alunos em programação: Esta contribuição consistiu na identificação 
dos tipos de defeitos que são frequentemente cometidos pelos alunos, porém identificados e corrigidos por eles mesmos ao receberem feedback adequado sobre a correção de seus programas. Esta situação ocorre, em geral, quando se utiliza ferramentas de avaliação para trabalhos de programação. Comparando os defeitos com as dificuldades no ensino e na aprendizagem em programação discutidas na literatura, foi possível perceber que o feedback fornecido pelas ferramentas de avaliação pode contribuir para mitigar as dificuldades dos alunos na aprendizagem e aplicação de conceitos de programação.

\section{- Identificação de como as funcionalidades das ferramentas de avaliação podem ser} incorporadas aos LMSs: Esta contribuição consistiu no estudo e análise das funcionalidades e características dos LMSs e das ferramentas de avaliação para trabalhos de programação. A ideia foi identificar como que as diferentes funcionalidades e capacidades das ferramentas de avaliação podem ser inseridas nos LMSs para melhor apoiar o processo de ensino e aprendizagem em programação.

- Desenvolvimento de uma arquitetura que permita o acesso às funcionalidades das ferramentas de avaliação por meio LMSs: Esta contribuição consistiu no desenvolvimento da arquitetura IMPACTLE, que permite a integração de diferentes ferramentas de avaliação para trabalhos de programação em diferentes LMSs. A ideia é que os professores tenham uma ampla variedade de ferramentas de avaliação disponíveis nos LMSs adotados por ele ou pela sua instituição. Além disso, a arquitetura permite diminuir o esforço na integração de ferramentas de avaliação em LMSs, servindo como apoio para desenvolvedores e pesquisadores na integração de novas ferramentas e LMSs. Por fim, problemas de usabilidade podem ser mais facilmente tratados. Uma vez que as funcionalidades das ferramentas de avaliação são acessadas por meio da interface do LMS, ao melhorar a usabilidade deste, a utilização de todas as ferramentas associadas acaba sendo beneficiada também.

- Desenvolvimento de protótipos funcionais que instanciam a arquitetura proposta: Esta contribuição consistiu no desenvolvimento de protótipos funcionais que implementam a solução proposta pela arquitetura IMPACTLE. A construção dos protótipos permitiu verificar a viabilidade de uso da arquitetura. Em síntese, por meio dos protótipos, as funcionalidades das ferramentas de avaliação BOCA, PROGTEST e WEB-CAT puderam ser acessadas por meio do LMS MOODLE. Ainda, uma extensão foi criada para o ambiente de desenvolvimento BLUEJ, permitindo que programas desenvolvidos no BLUEJ também possam ser analisados pelas ferramentas de avaliação. Tal extensão permitiu verificar a viabilidade de adoção da solução proposta pela arquitetura IMPACTLE para integrar ferramentas de avaliação em outros tipos de ambientes de aprendizagem, além de LMSs.

- Estudo sobre a efetividade do uso de ferramentas de avaliação para trabalhos de programação por meio de LMSs: Esta contribuição consistiu na obtenção de indicati- 
vos de que a utilização de ferramentas de avaliação por meio de um LMS faz com que os professores e alunos dispendam menos tempo e esforço lidando com as ferramentas e, consequentemente, seja possível realizar as tarefas associadas de modo mais efetivo. Em um experimento com alunos de pós-graduação, verificou-se que os participantes, ao acessarem as funcionalidades das ferramentas de avaliação por meio de um LMS, conseguem completar, em menor tempo, um número maior de tarefas. Em outro experimento, dessa vez com alunos de graduação, percebeu-se que, dentre os alunos que realizaram as atividades como apoio de um LMS, um número maior de alunos conseguiu desenvolver, em menor tempo, um número maior de programas corretos.

\subsection{Limitações}

As principais limitações relacionadas a este trabalho de doutorado são sintetizadas a seguir:

- Necessidade de investigar diferentes aspectos da arquitetura IMPACTLE: Durante o projeto e validação da arquitetura IMPACTLE, ênfase foi dada às funcionalidades que arquitetura IMPACTLE deve satisfazer. No entanto, outros aspectos devem ser investigados com mais profundidade, tais como desempenho, segurança, tolerância a falhas, manutenibilidade, dentre outros.

- Necessidade de planejar e conduzir experimentos sistemáticos: Consiste na necessidade de planejar e conduzir experimentos sistemáticos a fim de validar a arquitetura proposta e obter evidências sobre os benefícios em utilizar as ferramentas de avaliação para trabalhos de programação em LMSs. Experimentos envolvendo um número maior de participantes, outros contextos de ensino e aprendizagem e outras instituições são exemplos de validações importantes para aumentar a confiabilidade dos resultados obtidos.

- Necessidade de estabelecer estratégias pedagógicas: Para que as funcionalidades fornecidas pelas ferramentas de avaliação proporcionem benefícios significativos elas devem ser adequadamente inseridas no processo de ensino e aprendizagem de conceitos de programação. Assim, é importante que se estabeleçam estratégias pedagógicas capazes de fornecer diretrizes sobre como as ferramentas de avaliação, integradas aos LMSs, podem ser utilizadas para melhor apoiar alunos e professores no ensino e na aprendizagem de programação.

\subsection{Trabalhos futuros}

Com base nas limitações identificadas, é possível identificar diferentes perspectivas para a continuidade deste trabalho bem como futuras direções de pesquisa. As principais são 
sumarizadas a seguir:

- Evolução da arquitetura IMPACTLE: Consiste em evoluir a arquitetura IMPACTLE considerando: (i) outros tipos de ferramentas de avaliação; (ii) outros tipos de ambientes de aprendizagem em complemento aos LMSs; (iii) explorando melhor avaliações e resultados combinando as funcionalidades das ferramentas de avaliação; e (iv) investigando soluções que melhorem características como segurança, desempenho, tolerância a falhas, dentre outros.

- Instanciação da arquitetura IMPACTLE: Consiste em conduzir novas instanciações dos componentes da arquitetura IMPACTLE, porém considerando outras ferramentas de avaliação para trabalhos de programação e, também, outros LMSs. Ainda, consiste na manutenção e evolução dos protótipos funcionais desenvolvidos em sistemas de software mais robustos, os quais poderão ser utilizados em larga escala.

- Realização de experimentos: Consiste na realização de experimentos sistemáticos, por exemplo, considerando: (i) um maior número de participantes; (ii) outros públicos, tais como professores em disciplinas de graduação, alunos e professores no ensino médio, entre outros; e (iii) outros contextos de ensino e aprendizagem, tais como experimentos em outras instituições de ensino superior, em disciplinas de orientação a objetos, em disciplinas de teste de software, em maratonas de programação, em exames práticos de programação, dentre outros. A ideia é complementar os resultados já obtidos e aumentar a confiabilidade dos experimentos já conduzidos.

- Estudo sobre o impacto da adoção de ferramentas de avaliação no ensino e na aprendizagem de programação: Consiste na realização de estudos mais aprofundados a fim de investigar de que forma o apoio das ferramentas de avaliação para trabalhos de programação pode beneficiar o processo de ensino e aprendizagem de programação. Por exemplo, pretende-se investigar: (i) quais as limitações associadas; (ii) como tais ferramentas devem ser inseridas no processo de ensino e aprendizagem para que os seus benefícios sejam maximizados; e (iii) que estratégias pedagógicas incluindo as ferramentas de avaliação podem ser adotadas para minimizar as dificuldades dos alunos em programação.

\subsection{Publicações}

As principais publicações resultantes das atividades conduzidas durante este doutorado são sintetizadas a seguir:

- Souza, D. M; Costa, S. L.; Duarte Filho, N. D.; Barbosa, E. F. Um Estudo Experimental do Ambiente ProgTest no Ensino de Programação. 10th Experimental Software Engineering Latin American Workshop. Montevideo, Uruguay, pág. 1-10, 2013. 
- Duarte Filho, N. D.; Souza, D. M; Costa, S. L.; Barbosa, E. F. Establishment of Microblogs for Communication and Interaction in Mobile Learning Environments. 11th CONTECSI - International Conference on Information Systems and Technology Management. São Paulo, Brazil, pág. 1-10, 2014.

- Souza, D. M; Souza, S. R. S.; Oliveira, B. H.; Maldonado, J. C.; Barbosa, E. F. Towards the use of an automatic assessment system in the teaching of software testing. 44th Annual Frontiers in Education (FIE). Madrid, Spain, pág. 1-8, 2014.

- Souza, D. M; Batista, M. H. S.; Barbosa, E. F. Avaliação de Qualidade de um Ambiente de Apoio ao Ensino de Programação. RENOTE - Revista Novas Tecnologias na Educação, 12(2):1-10, 2014.

- Souza, D. M; Isotani, S.; Barbosa, E. F. Teaching Novice Programmers using ProgTest. International Journal of Knowledge and Learning, 10(1):60-77, 2015.

- Souza, D. M.; Batista, M. H. S.; Barbosa, E. F. Problemas e Dificuldades no Ensino de Programação: Um Mapeamento Sistemático. Revista Brasileira de Informática na Educação. 24(1):39-52, 2016.

- Souza, D. M.; Felizardo, K. R.; Barbosa, E. F. A Systematic Literature Review of Assessment Tools For Programming Assignments. In Proceedings of the 29th IEEE Conference on Software Engineering Education and Training (CSEE\&T 2016). Dallas, TX, USA, pages 147-156, 2016.

Além disso, o seguinte artigo foi elaborado e submetido, encontrando-se atualmente em processo de avaliação:

- Souza, D. M; Kölling, M.; Barbosa, E. F. The most common fixes students do to increase the correctness of their programs. Frontiers in Education (FIE 2017). Indianapolis, IN, pág. 1-10, Outubro, 2017.

Por fim, o seguinte artigo encontra-se em elaboração para submissão em uma revista de relevância na área:

- Souza, D. M; Kölling, M.; Barbosa, E. F. IMPACTLE architecture: Integration of assessment tools for programming assignments in LMSs. Computers and education., p. 1-15, 2017. 


\section{REFERÊNCIAS}

ABID, S. H.; ZEHRA, S.; IFTIKHAR, H. Using computer aided language software for teaching and self-learning. In: 2011 14th International Conference on Interactive Collaborative Learning. Piešt' any, Slovakia: Setembro, 2011. (ICL '11), p. 102-106. Citado na página 35.

AFFANDY; HERMAN, N. S.; SALAM, S. B.; NOERSASONGKO, E. A study of tracing and writing performance of novice students in introductory programming. In: Software Engineering and Computer Systems: Second International Conference. Kuantan, Pahang, Malaysia: Junho, 2011. (ICSECS '11), p. 557-570. Citado na página 36.

AJAYI, A. O.; OLAJUBU, E. A.; NINAN, D. F.; AKINBORO, S. A.; SORIYAN, H. A. Development and testing of a graphical fortran learning tool for novice programmers. Interdisciplinary Journal of Information, Knowledge, and Management, v. 5, n. 2010, p. 279-291, 2010. Citado na página 35.

AKAHANE, Y.; KITAYA, H.; INOUE, U. Design and evaluation of automated scoring java programming assignments. In: 2015 IEEE/ACIS 16th International Conference on Software Engineering, Artificial Intelligence, Networking and Parallel/Distributed Computing (SNPD). Takamatsu, Japan: Junho, 2015. (ACIS '15), p. 1-6. Citado na página 57.

AL-FEDAGHI, S. Conceptual framework for recursion in computer programming. Journal of Theoretical and Applied Information Technology, v. 46, n. 2, p. 983-990, 2012. Citado na página 35.

ALARIO-HOYOS, C.; BOTE-LORENZO, M. L.; GóMEZ-SáNCHEZ, E.; ASENSIO-PÉREZ, J. I.; VEGA-GORGOJO, G.; RUIZ-CALLEJA, A. Glue!: An architecture for the integration of external tools in virtual learning environments. Comput. Educ., p. 122-137, 2013. Citado nas páginas 25, 75, 76 e 90 .

ALBEROLA, J. M.; GARCÍA-FORNES, A. Achieving individual feedback through the online educational platform. In: 2012 International Symposium on Computers in Education. Andorra La Vella, Andorra: Janeiro, 2012. (SIIE '12), p. 1-6. Citado na página 37.

ALLEVATO, A.; THORNTON, M.; EDWARDS, S. H.; PEREZ-QUINONES, M. A. Mining data from an automated grading and testing system by adding rich reporting capabilities. In: Proceedings of the 1st International Conference on Educational Data Mining. Cordoba, Spain: Julho, 2008. (EDM ’09), p. 167-176. Citado na página 56.

ALLEVATO, A. J. From Intuition to Evidence: A Data-driven Approach to Transforming Cs Education. Tese (Doutorado) - Virginia Polytechnic Institute \& State University, 2012. Citado na página 57.

ALMAN, S. W.; JUMBA, J. MOOCs Now: Everything You Need to Know to Design, Set Up, and Run a Massive Open Online Cours. 1. ed. Palo Alto: Libraries Unlimited, 2017. Citado na página 26. 
AMBROSIO, A. P.; COSTA, F. M.; ALMEIDA, L.; FRANCO, A.; MACEDO, J. Identifying cognitive abilities to improve CS1 outcome. In: Proceedings of the 2011 Frontiers in Education Conference. Rapid City, SD, USA: Outubro, 2011. (FIE '11), p. F3G-1-1-F3G-7. Citado nas páginas 35 e 36.

AMBRÓSIO, A. P. L.; COSTA, F. M. Evaluating the impact of pbl and tablet pcs in an algorithms and computer programming course. In: Proceedings of the 41st ACM Technical Symposium on Computer Science Education. Milwaukee, Wisconsin, USA: Março, 2010. (SIGCSE '10), p. 495-499. Citado na página 36.

AMELUNG, M.; KRIEGER, K.; ROSNER, D. E-assessment as a service. IEEE Trans. Learn. Technol., p. 162-174, 2011. Citado nas páginas 13, 20, 74, 75, 78, 79 e 90.

ANDERSON, R. E.; ERNST, M. D.; ORDÓÑEZ, R.; PHAM, P.; WOLFMAN, S. A. Introductory programming meets the real world: Using real problems and data in CS1. In: Proceedings of the 45th ACM Technical Symposium on Computer Science Education. Atlanta, Georgia, USA: Março, 2014. (SIGCSE'14), p. 465-466. Citado nas páginas 36 e 37.

ARIS, T. N. M.; NAZEER, S. A. Object-oriented programming semantics education based on intelligent agents. In: 2011 Malaysian Conference in Software Engineering. Johor Bahru, Malaysia: Dezembro, 2011. (MySEC '11), p. 404-407. Citado na página 35.

AUFFARTH, B.; LÓPEZ-SÁNCHEZ, M.; MIRALLES, J. Campos i; PUIG, A. System for automated assistance in correction of programming exercises (sac). In: Anales del Congrés Internacional de Docéncia Universitária i Innovació. Lleida, Spain: Agosto, 2008. (CIDUI ’08), p. 104-113. Citado na página 56.

AZIZ, M.; CHI, H.; TIBREWAL, A.; GROSSMAN, M.; SARKAR, V. Auto-grading for parallel programs. In: Proceedings of the Workshop on Education for High-Performance Computing. New Orleans, LA, USA: Novembro, 2015. (EduHPC '15), p. 3:1-3:8. Citado nas páginas 23, 24 e 57.

BAIN, G.; BARNES, I. Why is programming so hard to learn? In: Proceedings of the 2014 Conference on Innovation and Technology in Computer Science Education. Uppsala, Sweden: Junho, 2014. (ITiCSE '14), p. 356-356. Citado nas páginas 31 e 36.

BAKER, K. LMS Success: A Step-by-Step Guide to Learning Management System Administration. 1. ed. Los Angeles: Resources of Fun Learning, 2015. Citado nas páginas 25 e 68 .

BARBOSA, E.; SILVA, M.; CORTE, C.; MALDONADO, J. Integrated teaching of programming foundations and software testing. In: Proceedings of the 38th Annual Frontiers in Education Conference. New York, NY, USA: Novembro, 2008. (FIE '08), p. S1H-5-S1H-10. Citado na página 56.

BARDRAM, J. E.; CHRISTENSEN, H. B.; CORRY, A. V.; HANSEN, K. M.; INGSTRUP, M. Exploring quality attributes using architectural prototyping. In: First International Conference on the Quality of Software Architectures, QoSA 2005 and Second International Workshop on Software Quality. Erfurt, Germany: Setembro, 2005. (SOQUA '05), p. 155-170. Citado na página 118. 
BARDRAM, J. E.; CHRISTENSEN, H. B.; HANSEN, K. M. Architectural prototyping: An approach for grounding architectural design and learning. In: Proceedings of the 4th Working IEEE/IFIP Conference on Software Architecture. Oslo, Norway: Julho, 2004. (WICSA '04), p. 15-24. Citado na página 118.

BASS, L.; CLEMENTS, P.; KAZMAN, R. Software Architecture in Practice. 3. ed. Westford: Addison-Wesley Professional, 2012. Citado nas páginas 79, 80, 81 e 83.

BEGOSSO, L. C.; BEGOSSO, L. R.; GONCALVES, J. R.; GONCALVES, E. M. An approach for teaching algorithms and computer programming using greenfoot and python. In: Proceedings of the 2012 IEEE Frontiers in Education Conference (FIE). Seattle, Washington: Outubro, 2012. (FIE' '12), p. 1-6. Citado na página 36.

BENSON, M. Machine assisted marking of programming assignments. SIGCSE Bull., p. 24-25, 1985. Citado nas páginas 56 e 59.

Blackboard Inc. Blackboard Learn Platform. 2017. < http://www.blackboard.com/Platforms/ Learn/Products/Blackboard-Learn.aspx>. Último acesso em: 31/01/2017. Citado nas páginas $25,68,110$ e 172 .

BLUMENSTEIN, M.; GREEN, S.; FOGELMAN, S.; NGUYEN, A.; MUTHUKKUMARASAMY, V. Performance analysis of game: A generic automated marking environment. Computers \& Education, p. 1203-1216, 2008. Citado na página 56.

BLUMENSTEIN, M.; GREEN, S.; NGUYEN, A.; MUTHUKKUMARASAMY, V. An experimental analysis of GAME: a generic automated marking environment. SIGCSE Bull., p. 67-71, 2004. Citado na página 56.

BOSSE, Y.; GEROSA, M. A. Why is programming so difficult to learn?: Patterns of difficulties related to programming learning mid-stage. SIGSOFT Softw. Eng. Notes, v. 41, n. 6, p. 1-6, 2017. Citado nas páginas 23 e 151.

BOURQUE, P.; FAIRLEY, R. E. D. (Ed.). Guide to the Software Engineering Body of Knowledge - SWEBOK V3.0. Los Alamitos: IEEE Computer Society, 2014. Citado nas páginas 80 e 83.

BRERETON, P.; KITCHENHAM, B. A.; BUDGEN, D.; TURNER, M.; KHALIL, M. Lessons from applying the systematic literature review process within the software engineering domain. J. Syst. Softw., p. 571-583, 2007. Citado na página 53.

BRITO, M. A.; SÁ-SOARES, F. de. Assessment frequency in introductory computer programming disciplines. Computers in Human Behavior, v. 30, n. 2014, p. 623-628, 2014. Citado nas páginas 36 e 37.

BROWN, N. C. C.; KÖLLING, M.; MCCALL, D.; UTTING, I. Blackbox: A large scale repository of novice programmers' activity. In: Proceedings of the 45th ACM Technical Symposium on Computer Science Education. Atlanta, GA, USA: Março, 2014. (SIGCSE '14), p. 223-228. Citado na página 38.

BRUSILOVSKY, P.; EDWARDS, S.; KUMAR, A.; MALMI, L.; BENOTTI, L.; BUCK, D.; IHANTOLA, P.; PRINCE, R.; SIRKIä, T.; SOSNOVSKY, S.; URQUIZA, J.; VIHAVAINEN, A.; WOLLOWSKI, M. Increasing adoption of smart learning content for computer science education. In: Proceedings of the Working Group Reports of the 2014 on Innovation and Technology 
in Computer Science Education Conference. Uppsala, Sweden: Junho, 2014. (ITiCSE-WGR '14), p. 31-57. Citado nas páginas 24, 25, 26, 72, 73, 76, 78, 79, 85, 86 e 151.

BUFFARDI, K.; EDWARDS, S. H. A formative study of influences on student testing behaviors. In: Proceedings of the 45th ACM Technical Symposium on Computer Science Education. Atlanta, Georgia, USA: Março, 2014. (SIGCSE '14), p. 597-602. Citado na página 57.

Reconsidering automated feedback: A test-driven approach. In: Proceedings of the 46th ACM Technical Symposium on Computer Science Education. Kansas City, Missouri, USA: Março, 2015. (SIGCSE'15), p. 416-420. Citado nas páginas 36 e 57.

CAMBRANES, E. Supporting novice programmers with natural language in the early stage of programming. In: 2013 IEEE Symposium on Visual Languages and Human Centric Computing. San Jose, CA, USA: Setembro, 2013. (VL/HCC '13), p. 173-174. Citado na página 35.

CAMP, O.; WOODWARD, R. Ict enhanced learning experience for an introductory object oriented programming course - a case study. In: International Conference on Computer Supported Education. Noordwijkerhout, Netherlands: Maio, 2011. (CSEDU '11), p. 16-25. Citado nas páginas 34 e 37.

CAO, A.; CHINTAMANI, K. K.; PANDYA, A. K.; ELLIS, R. D. NASA TLX: Software for assessing subjective mental workload. Behavior Research Methods, v. 41, n. 1, p. 113-117, 2009. Citado nas páginas 133 e 145.

CHANG, C.-C.; CHEN, I.-C.; LIN, H.-C. K. How to teach software programming? using affective teaching method and social network to enhance the learning motivation in programming courses - an example on facebook. In: Proceedings of the 20th International Conference on Computers in Education. Denpasar Bali, Indonesia: Novembro, 2012. (ICCE '12), p. 345-351. Citado na página 37.

CHEANG, B.; KURNIA, A.; LIM, A.; OON, W.-C. On automated grading of programming assignments in an academic institution. Computers \& Education, p. 121-131, 2003. Citado na página 56.

CHOU, C.-Y.; CHENG, Y.-C. Developing program grading suggestion mechanism by reusing teacher grading records. In: Proceedings of the 20th International Conference on Computers in Education. Singapure: Janeiro, 2012. (ICCE '12), p. 115-117. Citado na página 57.

CHOY, M.; LAM, S.; POON, C. K.; WANG, F. L.; YU, Y. T.; YUEN, L. Design and implementation of an automated system for assessment of computer programming assignments. In: Proceedings of the Advances in Web Based Learning. Edinburgh, UK: Agosto, 2008. (ICWL '07), p. 584-596. Citado na página 56.

CHRISTIAN, M.; TRIVEDI, B. A comparison of existing tools for evaluation of programming exercises. In: Proceedings of the Second International Conference on Information and Communication Technology for Competitive Strategies. Udaipur, India: Março, 2016. (ICTCS '16), p. 134:1-134:6. Citado nas páginas 24 e 151.

ČISAR, S. M.; PINTER, R.; ČISAR, P.; RADOSAV, D. Teaching computer science in a webbased environment. In: 2013 IEEE 11th International Symposium on Intelligent Systems and Informatics. Subotica, Serbia: Setembro, 2013. (SISY '13), p. 415-418. Citado na página 36 . 
Claroline Community. Claroline - learning management system (LMS). 2012. <http://www. claroline.net/>. Último acesso em: 31/01/2017. Citado na página 77.

CORNEY, M.; TEAGUE, D.; THOMAS, R. N. Engaging students in programming. In: Proceedings of the Twelfth Australasian Conference on Computing Education. Brisbane, Australia: Janeiro, 2010. (ACE '10), p. 63-72. Citado na página 37.

COSTA, C. J.; APARICIO, M. Evaluating success of a programming learning tool. In: Proceedings of the International Conference on Information Systems and Design of Communication. Lisboa, Portugal: Maio, 2014. (ISDOC '14), p. 73-78. Citado na página 31.

COULL, N. J.; DUNCAN, I. M. M. Emergent requirements for supporting introductory programming. Innovations in Teaching and Learning in Information and Computer Sciences, v. 10, n. 1, p. 78-85, 2011. Citado na página 35.

CURY, A. Organização e Métodos - Uma Visão Holística. 8. ed. São Paulo: Atlas, 2005. Citado na página 129.

DAWSON-HOWE, K. M. Automatic submission and administration of programming assignments. SIGCSE Bull., p. 40-42, 1996. Citado nas páginas 56 e 59.

DE-CAMPOS, C. P.; FERREIRA, C. E. Boca: um sistema de apoio a competições de programação. In: Workshop de Educação em Computaçãa. Salvador, BA, Brasil: Julho, 2004. (WEC '04), p. 1-11. Citado nas páginas 56, 110 e 172.

DE-OLIVEIRA-BRANDÃO, L.; RIBEIRO, R. da S.; BRANDÃO, A. A. F. A system to help teaching and learning algorithms. In: Proceedings of the 2012 IEEE Frontiers in Education Conference. Seattle, Washington, USA: Outubro, 2012. (FIE '12), p. 1-6. Citado na página 35.

Doodle. About Doodle. 2017. <https://doodle.com/about-doodle>. Último acesso em: 31/01/2017. Citado nas páginas 25 e 75.

EDWARDS, S. H. Rethinking computer science education from a test-first perspective. In: Companion of the 18th annual ACM SIGPLAN conference on Object-oriented programming, systems, languages, and applications. Anaheim, CA, USA: Outubro, 2003. (OOPSLA '03), p. 148-155. Citado na página 56.

Work-in-progress: Program grading and feedback generation with web-cat. In: Proceedings of the First ACM Conference on Learning @ Scale Conference. Atlanta, Georgia, USA: Março, 2014. (L@ S '14), p. 215-216. Citado nas páginas 24, 57, 110 e 172.

EDWARDS, S. H.; nONES, M. A. P.-Q. Experiences using test-driven development with an automated grader. J. Comput. Sci. Coll., p. 44-50, 2007. Citado na página 56.

EDWARDS, S. H.; PEREZ-QUINONES, M. A. Web-CAT: automatically grading programming assignments. SIGCSE Bull., p. 328-328, 2008. Citado na página 56.

ENSTRÖM, E. Dynamic programming - structure, difficulties and teaching. In: 2013 IEEE Frontiers in Education Conference. Oklahoma City, Oklahoma: Outubro, 2013. (FIE '13), p. 1857-1863. Citado na página 35.

ERL, T. Service-Oriented Architecture (SOA): Concepts, Technology, and Design. 1. ed. Crawfordsville: Prentice Hall, 2005. Citado na página 82. 
FALKNER, N.; VIVIAN, R.; PIPER, D.; FALKNER, K. Increasing the effectiveness of automated assessment by increasing marking granularity and feedback units. In: Proceedings of the 45th ACM Technical Symposium on Computer Science Education. Atlanta, Georgia, USA: Março, 2014. (SIGCSE'14), p. 9-14. Citado na página 23.

FLEMING, W. H.; REDISH, K. A.; SMYTH, W. F. Comparison of manual and automated marking of student programs. Information and Software Technology, p. 547-552, 1988. Citado na página 56.

FONTE, D.; BOAS, I. V.; OLIVEIRA, N.; CRUZ, D. da; GANçARSKI, A. L.; HENRIQUES, P. R. Partial correctness and continuous integration in computer supported education. In: Proceedings of the 6th International Conference on Computer Supported Education - Volume 2. Barcelona, Spain: Abril, 2014. (CSEDU '14), p. 205-212. Citado na página 57.

GARCÍA-PEÑALVO, F. J.; FORMENT, M. A. Learning management system: evolving from silos to structures. Interactive Learning Environments, v. 22, n. 2, p. 143-145, 2014. Citado na página 26.

GEORGOULI, K.; GUERREIRO, P. Incorporating an automatic judge into blended learning programming activities. In: Proceedings of the Advances in Web-Based Learning. Shanghai, China: Dezembro, 2010. (ICWL'10), p. 81-90. Citado nas páginas 57 e 77.

GOLDWASSER, M. H. A gimmick to integrate software testing throughout the curriculum. SIGCSE Bull., p. 271-275, 2002. Citado na página 56.

GOMES, A.; MENDES, A. J. Studies and proposals about initial programming learning. In: 2010 IEEE Frontiers in Education Conference (FIE). Arlington, Virginia, USA: Novembro, 2010. (FIE '10), p. S3F-1-S3F-6. Citado na página 36.

Google. Google Docs - create and edit documents online, for free. 2017. <https://www.google. com/docs/about/>. Último acesso em: 31/01/2017. Citado nas páginas 25 e 75.

GOSLING, J.; JOY, B.; STEELE, G.; BRACHA, G.; BUCKLEY, A. The Java Language Specification - Java SE 7 Edition. 2013. Disponível em: <https://docs.oracle.com/javase/ specs/jls/se7/html/index.html >. Útimo acesso em: 18 de agosto de 2017. Citado nas páginas 39 e 40 .

GOTEL, O.; SCHARFF, C.; WILDENBERG, A. Teaching software quality assurance by encouraging student contributions to an open source web-based system for the assessment of programming assignments. SIGCSE Bull., p. 214-218, 2008. Citado na página 57.

HAATAINEN, S.; LAKANEN, A.-J.; ISOMOTTONEN, V.; LAPPALAINEN, V. A practice for providing additional support in CS1. In: Proceedings of the 2013 Learning and Teaching in Computing and Engineering. Macau, Macau: Março, 2013. (LATICE '13), p. 178-183. Citado nas páginas 36 e 37.

HARTANTO, B.; REYE, J. Incorporating anchored learning in a c\# intelligent tutoring system. In: Proceedings of the 21st International Conference on Computers in Education. Denpasar Bali, Indonesia: Janeiro, 2013. (ICCE '13), p. 5-8. Citado na página 37.

HASAN, H. M. Assessment of student programming assignments in COBOL. Education \& computing, p. 99-107, 1988. Citado nas páginas 56 e 59. 
HELMINEN, J.; MALMI, L. Jype - a program visualization and programming exercise tool for python. In: Proceedings of the 5th International Symposium on Software Visualization. Salt Lake City, Utah, USA: Outubro, 2010. (SOFTVIS '10), p. 153-162. Citado nas páginas 35 e 36.

HEWITT, E. Java (SOA) Cookbook. 1. ed. Sebastopol: O’Reilly Media, 2009. Citado na página 82.

HIDALGO-CÉSPEDES, J.; MARÍN-RAVENTÓS, G.; LARA-VILLAGRÁN, V. Playing with metaphors: A methodology to design video games for learning abstract programming concepts. In: Proceedings of the 2014 Conference on Innovation and Technology in Computer Science Education. Uppsala, Sweden: Junho, 2014. (ITiCSE '14), p. 348-348. Citado nas páginas 23, 31,34 e 35 .

HOLTON, C.; WALLACE, S. A. Investigating the use of an online assignment submission and assessment system in the cs classroom. J. Comput. Sci. Coll., v. 29, n. 1, p. 123-129, 2013. Citado nas páginas 24 e 57.

HORVÁTH, R. Teaching one language in more depth is better than many languages superficially. In: 2011 9th International Conference on Emerging eLearning Technologies and Applications. Stara Lesn, Slovakia: Outubro, 2011. (ICETA '11), p. 71-74. Citado na página 35 .

HU, L.-L.; TSENG, S.-S.; LEE, T.-J. Towards scaffolding problem-solving implementation process in undergraduate programming course. In: Proceedings of the 2013 IEEE 13th International Conference on Advanced Learning Technologies. Beijing, China: Julho, 2013. (ICALT'13), p. 417-418. Citado na página 36.

HU, Q.; HUANG, Y.; LIU, C. The design and implementation of learner models in online peer assessment to support learning. In: 2012 2nd International Conference on Consumer Electronics, Communications and Networks. Three Gorges Yichang, China: Abril, 2012. (CECNet '12), p. 2961-2963. Citado na página 36.

HUANG, Y.; MEYERS, J.; DUBOW, W.; WU, Z.; ; EISENBERG, M. How to teach software programming? using affective teaching method and social network to enhance the learning motivation in programming courses - an example on facebook. In: International Conference on Cognition and Exploratory Learning in Digital Age. Rio de Janeiro, RJ, Brazil: Novembro, 2011. (CELDA '11), p. 195-202. Citado na página 37.

HUIZINGA, D. M. Identifying topics for instructional improvement through on-line tracking of programming assignments. SIGCSE Bull., p. 129-132, 2001. Citado nas páginas 56 e 59.

IBM staff. Rational Unified Process: Best practices for software development teams. 2005. Disponível em: <http://www.ibm.com/developerworks/rational/library/253.html>. Útimo acesso em: 18 de agosto de 2017. Citado na página 81.

IBRAHIM, R.; SEMARAK, J.; LUMPUR, K.; JAAFAR, A. Using educational games in learning introductory programming: A pilot study on students' perceptions. In: 2010 International Symposium on Information Technology. Kuala Lumpur, Malaysia: Junho, 2010. (ITSim '10), p. 1-5. Citado nas páginas 36 e 37.

JACKSON, D. A semi-automated approach to online assessment. SIGCSE Bull., p. 164-167, 2000. Citado nas páginas 56 e 59. 
JANTAN, S. R.; ALJUNID, S. A. An experimental evaluation of scaffolded educational games design for programming. In: 2012 IEEE Conference on Open Systems. Kuala Lumpur, Malaysia: Outubro, 2012. (OCS '12), p. 1-6. Citado na página 36.

JOY, M.; LUCK, M. Effective electronic marking for on-line assessment. SIGCSE Bull., p. 134-138, 1998. Citado na página 56.

JOY, M. S.; LUCK, M. A user-friendly on-line submissions system. In: Proceedings of the Fourth Annual Conference on the Teaching of Computing. Dublin, Ireland: Maio, 1996. p. 92-95. Citado na página 56.

JUnit. JUnit Cookbook. 2016. Disponível em: <http://junit.org/junit4/cookbook.html>. Útimo acesso em: 18 de agosto de 2017. Citado na página 38.

KARAPINAR, Z.; SENTURK, A.; ZAVRAK, S.; KARA, R.; ERDOGMUS, P. Binary apple tree: A game approach to tree traversal algorithms. In: 2012 International Conference on Information Technology Based Higher Education and Training. Istanbul, Turkey: Junho, 2012. (ITHET '12), p. 1-3. Citado na página 37.

KARAVIRTA, V.; IHANTOLA, P.; KOSKINEN, T. Service-oriented approach to improve interoperability of e-learning systems. In: Proceedings of the 2013 IEEE 13th International Conference on Advanced Learning Technologies. Washington, DC, USA: Julho, 2013. (ICALT'13), p. 341-345. Citado nas páginas 24, 26, 75, 86 e 151.

KAUČIČ, B.; ASIČ, T. Improving introductory programming with scratch? In: 2011 Proceedings of the 34th International Convention MIPRO. Opatija, Croatia: Janeiro, 2011. p. 1095-1100. Citado na página 35.

KAUSHAL, R.; SINGH, A. Automated evaluation of programming assignments. In: Proceedings of the 2012 IEEE International Conference on Engineering Education: Innovative Practices and Future Trends. Kottayam, India: Julho, 2012. (AICERA '12), p. 1-5. Citado na página 57.

KHALEEL, F. L.; ASHAARI, N. S.; MERIAM, T. S.; WOOK, T.; ISMAIL, A. The study of gamification application architecture for programming language course. In: Proceedings of the 9th International Conference on Ubiquitous Information Management and Communication. Bali, Indonesia: Janeiro, 2015. (IMCOM '15), p. 17:1-17:5. Citado na página 37.

KITCHENHAM, B. A.; CHARTERS, S. Guidelines for performing systematic literature reviews in software engineering. Keele, UK, 2007. Citado na página 30.

KO, E.; LEE, K. Using music notation for teaching computer programming. In: Proceedings of the 21st International Conference on Computers in Education. Bali, Indonesia: Novembro, 2013. (ICCE' '13), p. 1-3. Citado na página 35.

KÖLlinG, M.; QUIG, B.; PATTERSON, A.; ROSENBERG, J. The bluej system and its pedagogy. Computer Science Education, v. 13, n. 4, p. 249-268, 2003. Citado nas páginas 38 e 123 .

KOLLMANSBERGER, S. Helping students build a mental model of computation. In: Proceedings of the Fifteenth Annual Conference on Innovation and Technology in Computer Science Education. Bikent, Ankara, Turkey: Janeiro, 2010. (ITiCSE '10), p. 128-131. Citado na página 35. 
KRUCHTEN, P. Architectural blueprints - the " $4+1$ " view model of software architecture. IEEE Software, v. 12, n. 6, p. 42-50, 1995. Citado nas páginas 81, 85 e 105.

KURNIA, A.; LIM, A.; CHEANG, B. Online judge. Computers \& Education, p. 299-315, 2001. Citado na página 56.

KURVINEN, E.; HELLGREN, N.; KAILA, E.; LAAKSO, M.-J.; SALAKOSKI, T. Programming misconceptions in an introductory level programming course exam. In: Proceedings of the 2016 ACM Conference on Innovation and Technology in Computer Science Education. Arequipa, Peru: Julho, 2016. (ITiCSE’16), p. 308-313. Citado nas páginas 24 e 151.

LAHTINEN ESSI ALA-MUTKA, K.; JÄRVINEN, H.-M. A study of the difficulties of novice programmers. SIGCSE Bull., v. 37, n. 3, p. 14-18, 2005. Citado na página 34.

LAW, K. M.; LEE, V.; YU, Y.-T. Learning motivation in e-learning facilitated computer programming courses. Computers \& Education, p. 218-228, 2010. Citado na página 57.

LEAL, J. P.; MOREIRA, N.; MOREIRA, L. N. Automatic grading of programming exercises. Porto, Portugal, 1998. Citado na página 56.

LEAL, J. P.; SILVA, F. Mooshak: a web-based multi-site programming contest system. Software: Practice and Experience, v. 33, n. 6, p. 567-581, 2003. Citado nas páginas 56, 59 e 77.

LÓPEZ, A. R.; GARCÍA-PEÑALVO, F. J. Relationship of knowledge to learn in programming methodology and evaluation of computational thinking. In: Proceedings of the Fourth International Conference on Technological Ecosystems for Enhancing Multiculturality. London, United Kingdom: Novembro, 2016. (TEEM ’16), p. 73-77. Citado na página 23.

LUCK, M.; JOY, M. Automatic submission in an evolutionary approach to computer science teaching. Computers \& Education, p. 105-111, 1995. Citado na página 56.

MATT, U. v. Kassandra: the automatic grading system. Zürich, Switzerland, 1998. Citado na página 56.

MATTHÍASDÓTTIR, Á.; ARNALDS, H. Rethinking teaching and assessing in a programming course a case study. In: Proceedings of the 16th International Conference on Computer Systems and Technologies. Dublin, Ireland: Junho, 2015. (CompSysTech '15), p. 313-318. Citado na página 23.

MAXIMIANO, A. C. A. Introdução à Administração. 8. ed. São Paulo: Atlas, 2011. Citado na página 129.

Moodle Community. Moodle 2.2 documentation. 2016. < http://docs.moodle.org/>. Último acesso em: 31/01/2017. Citado nas páginas 25, 26, 68, 110 e 172.

MORRIS, D. Automatically grading java programming assignments via reflection, inheritance, and regular expressions. In: Proceedings of the 32nd Annual Frontiers in Education Conference. Boston, Massachusetts, USA: Novembro, 2002. (FIE '02), p. T3G-22. Citado na página 56.

Automatic grading of student's programming assignments: an interactive process and suite of programs. In: Proceedings of the 33rd Annual Frontiers in Education Conference. Westminster, CO, USA: Novembro, 2003. (FIE '03), p. S3F-1-6. Citado na página 56. 
NG, S.-C.; LUI, A. K.-F.; WONG, L.-S. Tree-based comparison for plagiarism detection and automatic marking of programming assignments. In: Proceedings of the International Conference on ICT in Teaching and Learning. Hong Kong: Julho, 2012. (ICT '12), p. 165-179. Citado na página 57.

Oracle Corporation. MySQL. 2017. Disponível em: <https://www.mysql.com/>. Útimo acesso em: 18 de agosto de 2017. Citado na página 120.

OZEL, S. A.; KAYA, M. An online compiler module for grading programming assignments on Moodle distance education system. AWERProcedia Information Technology and Computer Science, p. 715-720, 2012. Citado na página 78.

PANWONG, P.; KEMAVUTHANON, K. Problem-based learning framework for junior software developer: Empirical study for computer programming students. Wireless Personal Communications, v. 76, n. 3, p. 2014, 603-613. Citado na página 31.

PARALIC, M.; MARTONCIK, J. Support for management of programming assignments automated grading. In: Proceedings of the 2012 IEEE 10th International Conference on Emerging eLearning Technologies Applications. Stará Lesná, Slovakia: Novembro, 2012. (ICETA '12), p. 285-289. Citado na página 57.

PARLANTE, N.; ZELENSKI, J.; HUG, J.; NICHOLSON, J.; DENERO, J.; LAAKSONEN, A.; VIHAVAINEN, A.; MCCOWN, F.; WAYNE, K. Nifty assignments. In: Proceedings of the 45th ACM Technical Symposium on Computer Science Education. Raleigh, North Carolina, USA: Março, 2014. (SIGCSE '14), p. 621-622. Citado na página 23.

PEREZ, B. A. Choosing the Right Learning Management System. 1. ed. North Charleston: CreateSpace Independent Publishing Platform, 2011. Citado na página 25.

PETTIT, R.; HOMER, J.; GEE, R.; MENGEL, S.; STARBUCK, A. An empirical study of iterative improvement in programming assignments. In: Proceedings of the 46th ACM Technical Symposium on Computer Science Education. Kansas City, Missouri, USA: Fevereiro, 2015. (SIGCSE'15), p. 410-415. Citado na página 57.

PITEIRA, M.; COSTA, C. Computer programming and novice programmers. In: Proceedings of the Workshop on Information Systems and Design of Communication. Lisbon, Portugal: Junho, 2012. (ISDOC '12), p. 51-53. Citado na página 31.

Learning computer programming: Study of difficulties in learning programming. In: Proceedings of the 2013 International Conference on Information Systems and Design of Communication. Lisboa, Portugal: Julho, 2013. (ISDOC'13), p. 75-80. Citado nas páginas 31,34 e 35 .

PRESSMAN, R. S.; MAXIM, B. Software Engineering: A Practitioner's Approach. 8. ed. New York: McGraw-Hill Education, 2014. Citado na página 81.

RAJAGURU, D.; RAJESWARI, A.; BHUVANESHWARI, V.; VAGHEESAN, K. E-assessment of programming assignments in web service. In: Proceedings of the 2012 International Conference on Advances in Engineering, Science and Management. Nagapattinam, Tamil Nadu, India: Janeiro, 2012. (ICAESM '12), p. 484-489. Citado na página 57. 
RöSSLING, G.; JOY, M.; MORENO, A.; RADENSKI, A.; MALMI, L.; KERREN, A.; NAPS, T.; ROSS, R. J.; CLANCY, M.; KORHONEN, A.; OECHSLE, R.; ITURBIDE, J. A. V. Enhancing learning management systems to better support computer science education. SIGCSE Bull., v. 40, n. 4, p. 142-166, 2008. Citado nas páginas 26 e 71.

RÖSSLING, G.; MCNALLY, M.; CRESCENZI, P.; RADENSKI, A.; IHANTOLA, P.; SÁNCHEZ-TORRUBIA, M. G. Adapting moodle to better support cs education. In: Proceedings of the 2010 ITiCSE working group reports. Ankara, Turkey: Junho, 2010. (ITiCSE-WGR '10), p. 15-27. Citado nas páginas 24, 25, 26, 71, 72, 86 e 151.

ROZANSKI, N.; WOODS, E. Software Systems Architecture: Working With Stakeholders Using Viewpoints and Perspectives. 2. ed. Westford: Addison-Wesley Professional, 2011. Citado na página 80.

Sakai Project. About Sakai CLE. 2012. <http://www.sakaiproject.org/sakai-cle>. Último acesso em: 31/01/2017. Citado na página 78.

SANT, J. A. "Mailing it in": email-centric automated assessment. SIGCSE Bull., p. 308-312, 2009. Citado nas páginas 57 e 59.

SCHULTE, C.; BENNEDSEN, J. What do teachers teach in introductory programming? In: Proceedings of the Second International Workshop on Computing Education Research. Canterbury, United Kingdom: Setembro, 2006. (ICER '06), p. 17-28. Citado nas páginas 34 e 35 .

SETTLE, A.; VIHAVAINEN, A.; SORVA, J. Three views on motivation and programming. In: Proceedings of the 2014 Conference on Innovation and Technology in Computer Science Education. Uppsala, Sweden: Junho, 2014. (ITiCSE '14), p. 321-322. Citado na página 23.

SHAFFER, S. C.; SHAFFER, C. Automated generation and grading of programming assignments (abstract only). In: Proceeding of the 44th ACM Technical Symposium on Computer Science Education. Denver, Colorado, USA: Março, 2013. (SIGCSE '13), p. 745-745. Citado na página 24.

SIRKIÄ, T.; HAARANEN, L. Acos server: Towards smart learning content interoperability. In: Proceedings of the 15th Koli Calling Conference on Computing Education Research. Koli, Finland: Novembro, 2015. (Koli Calling '15), p. 169-170. Citado nas páginas 24, 25, 26, 73, 77,86 e 151.

SOMMERVILLE, I. Software Engineering. 8. ed. Westford: Addison-Wesley, 2007. Citado na página 82.

SORVA, J.; KARAVIRTA, V.; MALMI, L. A review of generic program visualization systems for introductory programming education. Trans. Comput. Educ., v. 13, n. 4, p. 1946-6226, 2013. Citado na página 23.

SOUZA, D.; MALDONADO, J.; BARBOSA, E. ProgTest: An environment for the submission and evaluation of programming assignments based on testing activities. In: Proceedings of the 2011 24th IEEE-CS Conference on Software Engineering Education and Training. Honolulo, HI, USA: Maio, 2011. (CSEE\&T'11), p. 1-10. Citado na página 57. 
SOUZA, D. M.; FELIZARDO, K. R.; BARBOSA, E. F. A systematic literature review of assessment tools for programming assignments. In: 2016 IEEE 29th International Conference on Software Engineering Education and Training. Dallas, TX, USA: Abril, 2016. (CSEET' 2016), p. 147-156. Citado nas páginas 24, 37, 38 e 151.

SOUZA, D. M. D.; ISOTANI, S.; BARBOSA, E. F. Teaching novice programmers using progtest. International Journal of Knowledge and Learning, v. 10, n. 2, p. 60-77, 2015. Citado nas páginas 36 e 37.

SOUZA, D. M. de; OLIVEIRA, B. H.; MALDONADO, J. C.; SOUZA, S. R. S.; BARBOSA, E. F. Towards the use of an automatic assessment system in the teaching of software testing. In: 2014 IEEE Frontiers in Education Conference (FIE) Proceedings. Madrid, Spain: Outubro, 2014. (FIE '14), p. 1-8. Citado nas páginas 57, 110 e 172.

SPACCO, J.; PUGH, W.; AYEWAH, N.; HOVEMEYER, D. The marmoset project: an automated snapshot, submission, and testing system. In: Companion to the 21st ACM SIGPLAN symposium on Object-oriented programming systems, languages, and applications. Portland, Oregon, USA: Outubro, 2006. (OOPSLA ’06), p. 669-670. Citado na página 56.

ŠPAČEK, F.; SOHLICH, R.; DULÍK, T. Docker as platform for assignments evaluation. Procedia Engineering, v. 100, n. 2015, p. 1665-1671, 2015. Citado na página 57.

SPINELLIS, D.; ZAHARIAS, P.; VRECHOPOULOS, A. Coping with plagiarism and grading load: Randomized programming assignments and reflective grading. Computer Applications in Engineering Education, p. 113-123, 2007. Citado na página 56.

STAUBITZ, T.; KLEMENT, H.; TEUSNER, R.; RENZ, J.; MEINEL, C. Codeocean - a versatile platform for practical programming excercises in online environments. In: 2016 IEEE Global Engineering Education Conference (EDUCON). Abu Dhabi, UAE: Abril, 2016. (EDUCON '16), p. 314-323. Citado nas páginas 26 e 57.

SULEMAN, H. Automatic marking with sakai. In: Proceedings of the 2008 annual research conference of the South African Institute of Computer Scientists and Information Technologists on IT research in developing countries: riding the wave of technology. Wilderness, South Africa: Outubro, 2008. (SAICSIT '08), p. 229-236. Citado na página 78.

The Chamilo Association. www.chamilo.org I open source e-learning and collaborative software. 2017. <http://www.chamilo.org/>. Último acesso em: 31/01/2017. Citado nas páginas 25, 68,110 e 172 .

THIÉBAUT, D. Automatic evaluation of computer programs using moodle's virtual programming lab (vpl) plug-in. J. Comput. Sci. Coll., v. 30, n. 6, p. 145-151, 2015. Citado nas páginas 26 e 57.

TREMBLAY, G.; GUERIN, F.; PONS, A. A generic and extensible tool for marking programming assignments. In: Proceedings of the IASTED International Conference on Education and Technology. Calgary, Canada: Julho, 2005. (ICET '05), p. 55-60. Citado na página 56.

TREMBLAY, G.; GUERIN, F.; PONS, A.; SALAH, A. Oto, a generic and extensible tool for marking programming assignments. Journal of Software - Practice and Experience, p. 307-333, 2008. Citado na página 57. 
TREMBLAY, G.; LESSARD, P. A marking language for the oto assignment marking tool. In: Proceedings of the 16th annual joint conference on Innovation and technology in computer science education. Darmstadt, Germany: Junho, 2011. (ITiCSE '11), p. 148-152. Citado na página 57.

WANG, T.; SU, X.; MA, P.; WANG, Y.; WANG, K. Autolep: An automated learning and examination system for programming and its application in programming course. In: Proceedings of the 1st International Workshop on Education Technology and Computer Science. Wuhan, China: Março, 2009. (ETCS ’09), p. 43-46. Citado na página 57.

Ability-training-oriented automated assessment in introductory programming course. Computers \& Education, p. 220-226, 2011. Citado na página 57.

WATSON, C.; LI, F. W. Failure rates in introductory programming revisited. In: Proceedings of the 2014 Conference on Innovation and Technology in Computer Science Education. Uppsala, Sweden: Junho, 2014. (ITiCSE '14), p. 39-44. Citado nas páginas 23 e 151.

Wikimedia Foundation. Manual: What is MediaWiki? 2017. <https://www.mediawiki.org/ wiki/Manual:What_is_MediaWiki\%3F>. Último acesso em: 31/01/2017. Citado nas páginas 25 e 75 .

WOHLIN, C.; RUNESON, P.; HöST, M.; OHLSSON, M. C.; REGNELL, B.; WESSLéN, A. Experimentation in Software Engineering. 1. ed. New York: Springer, 2012. Citado nas páginas 129, 130, 132 e 142.

YUSOF, N.; ZIN, N. A. M.; ADNAN, N. S. Java programming assessment tool for assignment module in moodle e-learning system. Procedia - Social and Behavioral Sciences, p. 767-773, 2012. Citado na página 57.

ZHANG, J.; FENGJIAN, P.; JHA, M. S.; MARLA, P.; LEE, K. W.; NELSON, D. B.; LU, Y.-H. A system for analysis of code on cloud as an educational service to students. In: Proceedings of the 123rd ASEE Annual Conference \& Exposition. New Orleans, LA: Junho, 2016. (ASEE '16), p. 1-14. Citado nas páginas 57 e 59. 

APÊNDICE

\section{A}

\section{A ARQUITETURA IMPACTLE - VISÕES LÓGICA E DE PROCESSOS}

\section{A.1 Visão lógica detalhada}

A visão lógica está relacionada com os requisitos funcionais do sistema, ilustrando quais as funcionalidades que o sistema deve fornecer aos usuários.

Diferentemente dos demais subsistemas, apenas uma instância do middleware deve existir. O middleware recebe requisições de vários LMSs e envia requisições para os vários adaptadores, que por sua vez, estão associados às ferramentas de avaliação que adaptam. Cada ferramenta de avaliação tem o seu adaptador associado à ela.

$\mathrm{Na}$ arquitetura IMPACTLE, a visão lógica (Figura 46) envolve quatro tipos de subsistemas: (1) os LMSs, nos quais os alunos e professores realizam as atividades de ensino e aprendizagem; (2) o middleware, responsável pela comunicação entre os diferentes LMSs e as diferentes ferramentas de avaliação; (3) os adaptadores, que proveem uma interface de comunicação padrão entre o middleware e as ferramentas de avaliação; e (4) as ferramentas de avaliação para trabalhos práticos de programação, que proveem as funcionalidades relacionadas à avaliação dos trabalhos. No Quadro 37 são sumarizados os quatro tipos de subsistemas que a arquitetura IMPACTLE envolve. A visão lógica detalhada de cada um dos subsistemas é apresentada a seguir.

\section{A.1.1 LMSs}

Na Figura 47 é ilustrada a visão lógica dos componentes necessários nos LMSs para a comunicação com as ferramentas de avaliação. Tais componentes são sumarizados no Quadro 38. Basicamente, os LMSs devem conter uma extensão que implemente um conjunto de operações definidas pela arquitetura. 
Figura 46 - Arquitetura IMPACTLE: Visão lógica detalhada (Subsistemas)

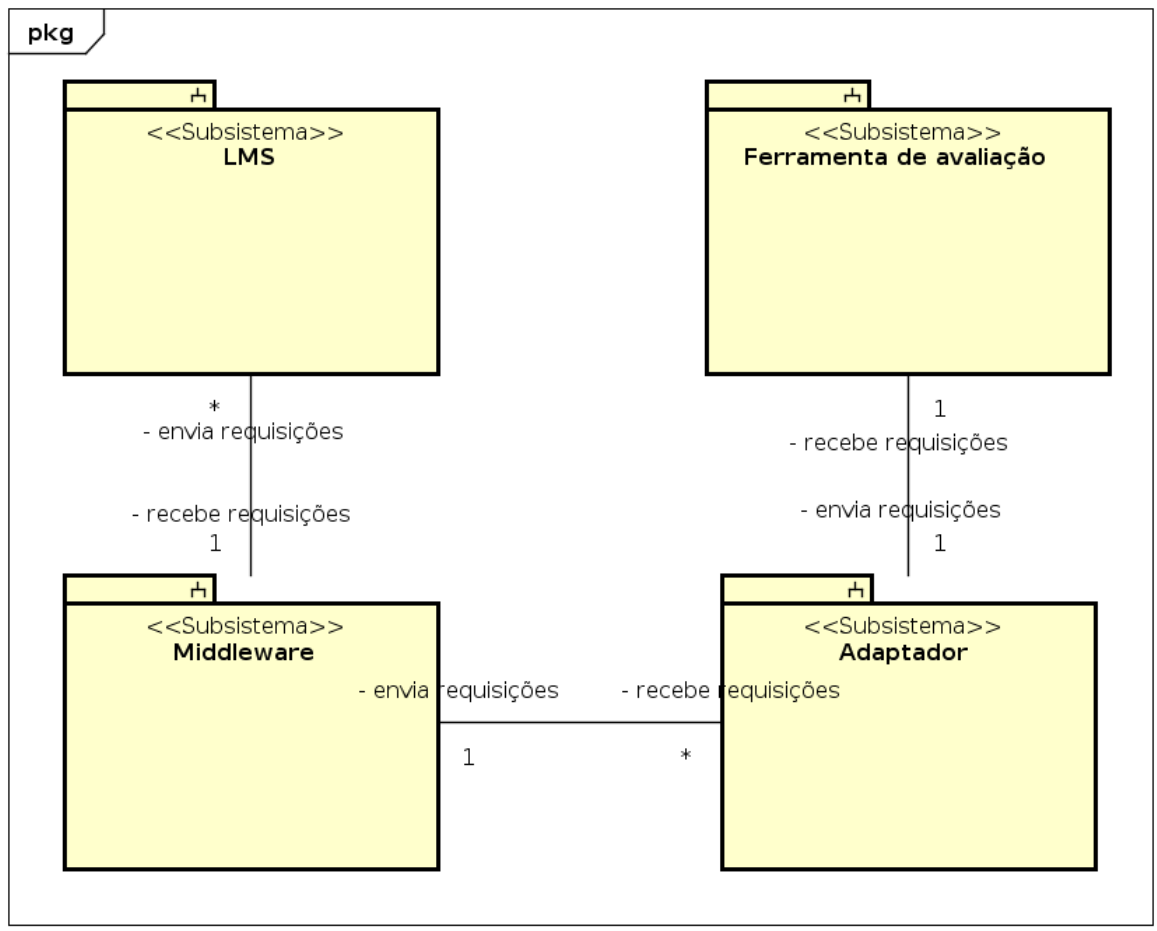

Fonte: Elaborada pelo autor.

Quadro 37 - Arquitetura IMPACTLE: Visão lógica detalhada (Subsistemas)

\begin{tabular}{|l|l|}
\hline Subsistema & Descrição \\
\hline \hline LMS & $\begin{array}{l}\text { Sistemas de gestão de aprendizagem, com funcionalidades que apoiam o processo de apren- } \\
\text { dizagem em geral. Exemplos são o Blackboard (Blackboard Inc., 2017), o Chamilo (The } \\
\text { Chamilo Association, 2017) e o Moodle (Moodle Community, 2016), entre outros. }\end{array}$ \\
\hline Middleware & $\begin{array}{l}\text { Sistema central responsável em gerenciar a comunicação e a troca de dados entre os LMSs } \\
\text { e as ferramentas de avaliação. }\end{array}$ \\
\hline Adaptador & $\begin{array}{l}\text { Adapta uma ferramenta de avaliação, provendo uma interface padrão para acesso às funcio- } \\
\text { nalidades da ferramenta. }\end{array}$ \\
\hline Ferramenta de avaliação & $\begin{array}{l}\text { Ferramenta de avaliação para trabalho de programação. Exemplos são a ferramenta } \\
\text { BOCA (DE-CAMPOS; FERREIRA, 2004), a ProgTest (SOUZA et al., 2014) e a Web- } \\
\text { CAT (EDWARDS, 2014), entre outras. }\end{array}$ \\
\hline
\end{tabular}

Fonte: Elaborada pelo autor. 
Figura 47 - Arquitetura IMPACTLE: Visão lógica detalhada (LMSs)

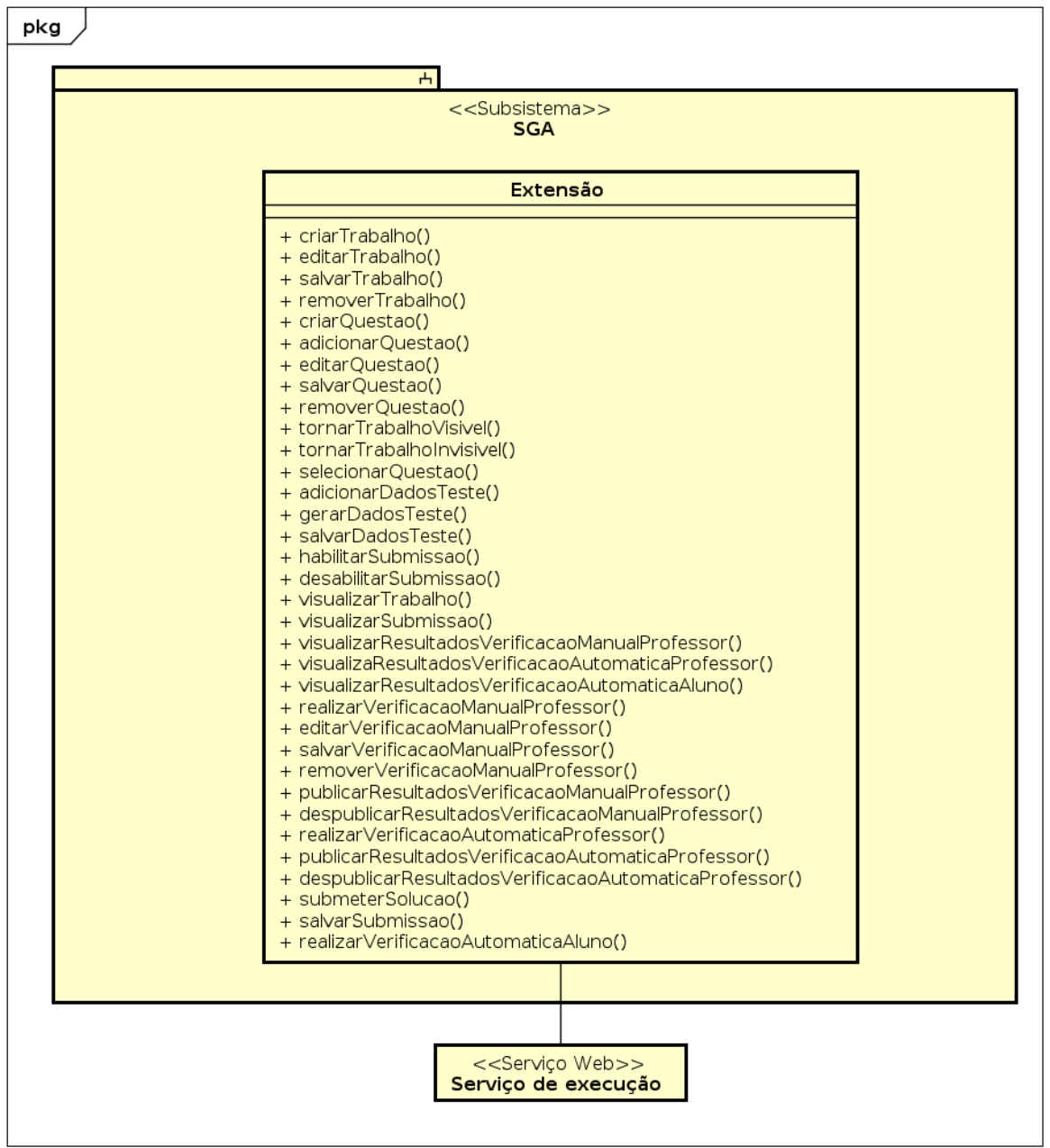

Fonte: Elaborada pelo autor.

No Quadro 38 são sumarizados os componentes necessários nos LMSs. Basicamente, os LMSs devem conter uma extensão que implemente um conjunto de operações definidas pela arquitetura. A extensão deve ser capaz de acessar o serviço de execução, componente lógico do subsistema middleware.

Quadro 38 - Arquitetura IMPACTLE: Visão lógica detalhada (Componentes dos LMSs)

\begin{tabular}{|l|l|}
\hline Componente & Descrição \\
\hline Extensão & $\begin{array}{l}\text { Estende um LMS, incluindo as funcionalidades de definição, submissão e avaliação de trabalhos de } \\
\text { programação. De acordo com as especificidades de cada LMS, pode ser um serviço web, um plugin } \\
\text { para o LMS, uma nova aplicação ou até mesmo um conjunto de funcionalidades adicionadas à uma } \\
\text { nova versão do LMS. }\end{array}$ \\
\hline
\end{tabular}

Fonte: Elaborada pelo autor.

A extensão pode ser implementada como parte das funcionalidades do LMS, como um plugin/módulo, um serviço web, dentre outras possibilidades. Tal decisão de projeto deve ser tomada de acordo com a especificidade de cada ambiente considerado. 
Deve ser possível, a alunos e professores acionar a execução das operações públicas definidas para cada um deles, enquanto outras operações são privadas e devem ser acionadas em situações específicas. A autenticação e a forma que os usuários irão acionar tais operações também devem ser definidas conforme a especificidade de cada LMS. Tais operações são sintetizadas no Quadro 39.

Por fim, a extensão deve ser capaz de acessar o serviço de execução, componente lógico do subsistema middleware.

\section{A.1.2 Middleware}

Na Figura 48 é ilustrada a visão lógica dos componentes do middleware. Em síntese, o middleware é basicamente composto pelo serviço de administração e o serviço de execução, bem como as entidades conta de usuário, ferramenta e requisição, que definem os dados que os serviços manipulam. No Quadro 40 é sintetizado o propósito de cada um desses componentes.

O serviço de administração tem por finalidade o gerenciamento do registro dos adaptadores no middleware. Por meio desse registro, o middleware consegue informar aos LMSs as ferramentas de avaliação disponíveis e encaminhar as avaliações para os adaptadores das ferramentas de avaliação.

Nesse sentido, outros dois tipos de atores foram definidos: os administradores de adaptador e os administradores do middleware. Os administradores de adaptador são os mantenedores de ferramentas de avaliação que desejam disponibilizá-las para serem acessadas pelos LMSs. Por meio do serviço de administração eles podem manter uma conta de usuário e registros de ferramentas no middleware. Já os administradores do middleware são responsáveis pela administração do middleware. Por meio de uma conta de usuário privilegiada, eles podem visualizar, adicionar, editar e remover todas as contas de usuário e todos os registros de ferramentas presentes no middleware. No Quadro 41 são sintetizadas as operações do serviço de administração.

O middleware deve conter apenas uma única instância do serviço de administração, que gerencia várias instâncias de contas de usuário e ferramentas. Nos quadros 42 e 43 são sintetizados os principais atributos das contas de usuário e ferramentas que devem ser armazenados pelo middleware.

Por outro lado, o serviço de execução tem por finalidade receber e responder as requisições das extensões dos LMSs, em alguns casos, encaminhando-as para o componente serviço adaptador do adaptador da ferramenta de avaliação em questão e recuperando os resultados retornados por ele. Para isto, o serviço de execução tem acesso aos registros de ferramentas do middleware.

No Quadro 44 são sintetizadas as operações definidas para o serviço de execução. 
Quadro 39 - Arquitetura IMPACTLE: Visão lógica detalhada (Operações da extensão)

\begin{tabular}{|c|c|}
\hline Operação & Descrição \\
\hline criarTrabalho & $\begin{array}{l}\text { Exibe ao professor o formulário para criação de um tra- } \\
\text { balho. }\end{array}$ \\
\hline editarTrabalho & $\begin{array}{l}\text { Exibe ao professor o formulário para edição de um tra- } \\
\text { balho. }\end{array}$ \\
\hline salvarTrabalho & $\begin{array}{l}\text { Salva os dados dos formulários para criação e edição de } \\
\text { um trabalho. }\end{array}$ \\
\hline removerTrabalho & Remove os dados de um trabalho. \\
\hline adicionarQuestao & $\begin{array}{l}\text { Exibe ao professor o formulário para adição de uma } \\
\text { questão. }\end{array}$ \\
\hline editarQuestao & $\begin{array}{l}\text { Exibe ao professor o formulário para edição de uma } \\
\text { questão. }\end{array}$ \\
\hline salvarQuestao & $\begin{array}{l}\text { Salva os dados dos formulários para criação e edição de } \\
\text { uma questão. }\end{array}$ \\
\hline removerQuestao & Remove os dados de uma questão. \\
\hline tornarTrabalhoVisivel & Torna um trabalho visível aos alunos. \\
\hline tornarTrabalhoInvisivel & Torna um trabalho invisível aos alunos. \\
\hline selecionarQuestao & $\begin{array}{l}\text { Carrega os dados de um trabalho de programação dispo- } \\
\text { nível no repositório de uma determinada ferramenta. }\end{array}$ \\
\hline adicionarDadosTeste & $\begin{array}{l}\text { Exibe ao professor o formulário para geração de dados } \\
\text { de teste. }\end{array}$ \\
\hline gerarDadosTeste & $\begin{array}{l}\text { Salva os dados do formulário para geração de dados de } \\
\text { teste e aciona a geração automática de dados de teste. }\end{array}$ \\
\hline editarDadosTeste & $\begin{array}{l}\text { Exibe ao professor o formulário para edição dos dados } \\
\text { de teste. }\end{array}$ \\
\hline salvarDadosTeste & $\begin{array}{l}\text { Salva os dados do formulário para edição de dados de } \\
\text { teste. }\end{array}$ \\
\hline habilitarSubmissao & Libera a submissão de soluções para um trabalho. \\
\hline desabilitarSubmissao & Bloqueia a submissão de soluções para um trabalho. \\
\hline visualizarTrabalho & $\begin{array}{l}\text { Exibe ao professor ou aluno as informações de um tra- } \\
\text { balho. }\end{array}$ \\
\hline visualizarSubmissao & $\begin{array}{l}\text { Exibe ao professor ou aluno as informações de uma so- } \\
\text { lução. }\end{array}$ \\
\hline visualizarResultadosVerificacaoManualProfessor & $\begin{array}{l}\text { Exibe ao professor e aluno os resultados de uma verifi- } \\
\text { cação manual realizada pelo professor. }\end{array}$ \\
\hline visualizarResultados VerificacaoAutomaticaProfessor & $\begin{array}{l}\text { Exibe ao professor os resultados de uma verificação au- } \\
\text { tomática acionada por ele. }\end{array}$ \\
\hline visualizarResultadosVerificacaoAutomaticaAluno & $\begin{array}{l}\text { Exibe ao professor e aluno os resultados de uma verifi- } \\
\text { cação automática acionada pelo aluno. }\end{array}$ \\
\hline realizarVerificacaoManualProfessor & $\begin{array}{l}\text { Exibe ao professor o formulário para verificação ma- } \\
\text { nual. }\end{array}$ \\
\hline editarVerificacaoManualProfessor & $\begin{array}{l}\text { Exibe ao professor o formulário para editar os dados de } \\
\text { uma verificação manual. }\end{array}$ \\
\hline salvarVerificacaoManualProfessor & $\begin{array}{l}\text { Salva e aciona o processamento dos dados do formulá- } \\
\text { rio de verificação manual. }\end{array}$ \\
\hline removerVerificacaoManualProfessor & Remove os dados de uma verificação manual. \\
\hline publicarResultados VerificacaoManualProfessor & $\begin{array}{l}\text { Torna visível aos alunos os resultados de uma verifica- } \\
\text { ção manual. }\end{array}$ \\
\hline despublicarVerificacaoManualProfessor & $\begin{array}{l}\text { Torna invisível aos alunos os resultados de uma verifi- } \\
\text { cação manual. }\end{array}$ \\
\hline realizarVerificacaoAutomaticaProfessor & Aciona a verificação automática pelo professor. \\
\hline publicarResultadosVerificacaoAutomaticaProfessor & $\begin{array}{l}\text { Torna visível aos alunos os resultados de uma verifica- } \\
\text { ção automática acionada pelo professor. }\end{array}$ \\
\hline despublicarResultadosVerificacaoAutomaticaProfessor & $\begin{array}{l}\text { Torna invisível aos alunos os resultados de uma verifi- } \\
\text { cação automática acionada pelo professor. }\end{array}$ \\
\hline submeterSolucao & $\begin{array}{l}\text { Exibe ao aluno o formulário para submissão de uma so- } \\
\text { lução. }\end{array}$ \\
\hline salvarSubmissao & $\begin{array}{l}\text { Salva os dados do formulário para submissão de uma } \\
\text { solução. }\end{array}$ \\
\hline realizarVerificacaoAutomaticaAluno & Aciona a avaliação automática centrada no aluno. \\
\hline
\end{tabular}

Fonte: Elaborada pelo autor. 
Figura 48 - Arquitetura IMPACTLE: Visão lógica detalhada (Middleware)

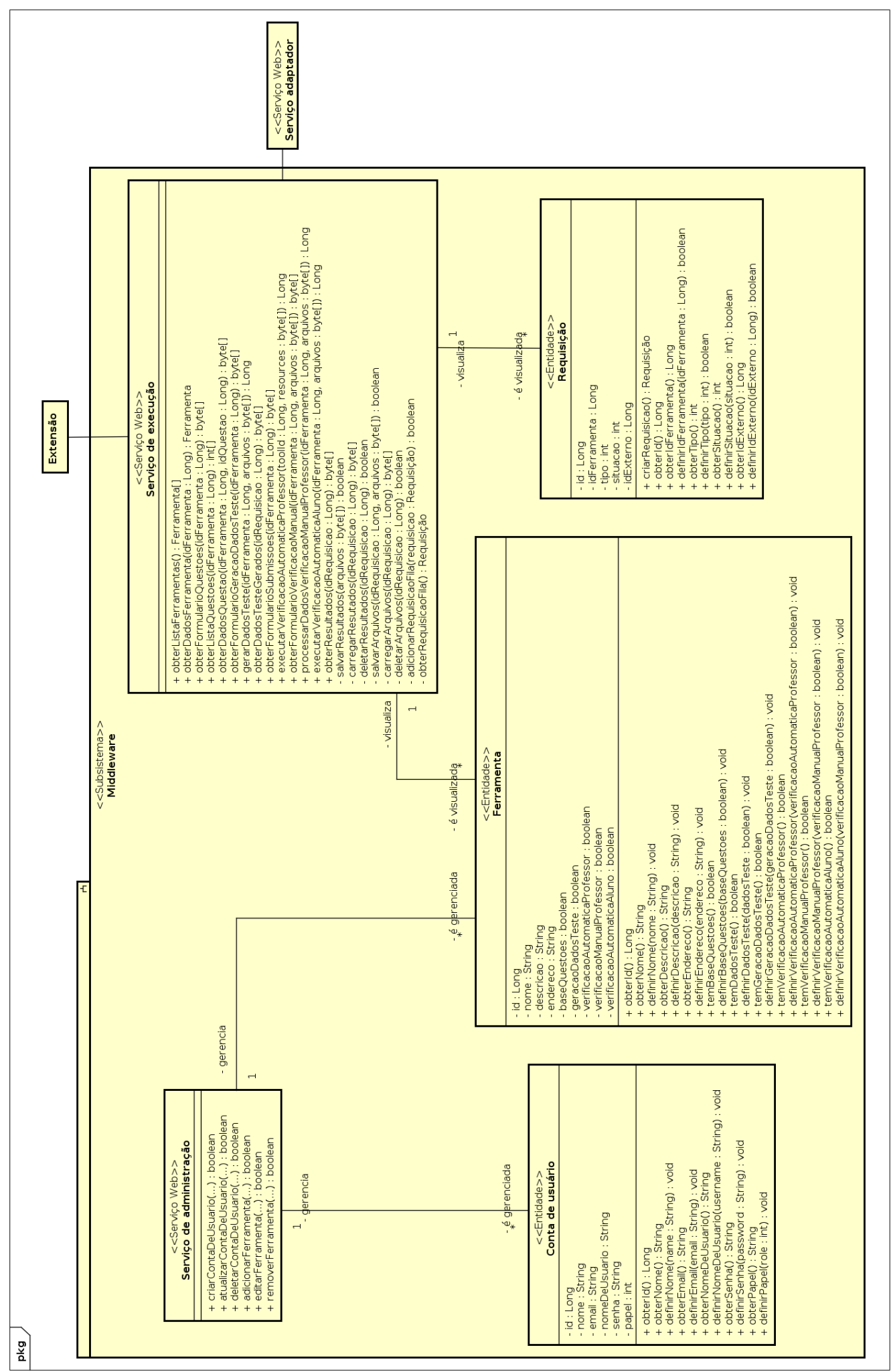

Fonte: Elaborada pelo autor. 
Quadro 40 - Arquitetura IMPACTLE: Visão lógica detalhada (Componentes do middleware)

\begin{tabular}{|l|l|}
\hline Componente & Descrição \\
\hline Serviço de administração & $\begin{array}{l}\text { Serviço web pelo qual administradores podem realizar a manutenção do middleware. Em es- } \\
\text { pecial, permite que mantenedores de ferramentas registrem as suas ferramentas e respectivos } \\
\text { adaptadores para serem disponibilizados aos LMSs. }\end{array}$ \\
\hline Serviço de execução & $\begin{array}{l}\text { Serviço web responsável por receber e processar as requisições provindas dos LMSs e } \\
\text { encaminhando-as, quando necessário, para o adaptador de uma ferramenta de avaliação. }\end{array}$ \\
\hline Conta de usuário & Entidade para manipulação e persistência dos dados dos administradores. \\
\hline Ferramenta & $\begin{array}{l}\text { Entidade para manipulação e persistência dos dados das ferramentas e respectivos adaptadores } \\
\text { registrados no middleware. }\end{array}$ \\
\hline Requisição & $\begin{array}{l}\text { Entidade para manipulação e persistência dos dados das requisições recebidas pelo serviço de } \\
\text { execução. }\end{array}$ \\
\hline
\end{tabular}

Fonte: Elaborada pelo autor.

Quadro 41 - Arquitetura IMPACTLE: Visão lógica detalhada (Operações do serviço de administração)

\begin{tabular}{|l|l|}
\hline Operação & Descrição \\
\hline \hline criarContaDeUsuario & Cria uma conta de usuário no middleware. \\
\hline atualizarContaDeUsuario & Atualiza uma conta de usuário no middleware. \\
\hline deletarContaDeUsuario & Deleta uma conta de usuário no middleware. \\
\hline adicionarFerramenta & Adiciona os dados de uma ferramenta de avaliação no middleware. \\
\hline editarFerramenta & Edita os dados de uma ferramenta de avaliação no middleware. \\
\hline removerFerramenta & Remove os dados de uma ferramenta de avaliação no middleware. \\
\hline
\end{tabular}

Fonte: Elaborada pelo autor.

Quadro 42 - Arquitetura IMPACTLE: Visão lógica detalhada (Atributos de uma conta de usuário no middleware)

\begin{tabular}{|l|l|}
\hline Atributo & Descrição \\
\hline \hline id & Identificador único. \\
\hline nome & Nome para contato. \\
\hline e-mail & E-mail para contato. \\
\hline nomeDeUsuario & Nome de usuário para autenticação. \\
\hline senha & Senha para autenticação. \\
\hline papel & $\begin{array}{l}\text { Defini as permissões do usuário. Pode assumir os valores ADMINISTRADOR_- } \\
\text { MIDDLEWARE e ADMINISTRADOR_ADAPTADOR. }\end{array}$ \\
\hline
\end{tabular}

Fonte: Elaborada pelo autor.

Quadro 43 - Arquitetura IMPACTLE: Visão lógica detalhada (Atributos de uma ferramenta no middleware)

\begin{tabular}{|l|l|}
\hline Atributo & Descrição \\
\hline \hline id & Identificador único \\
\hline nome & Nome da ferramenta para ser apresentada aos usuários. \\
\hline descricao & Descrição da ferramenta para ser apresentada aos usuários. \\
\hline endereco & Endereço web de acesso ao serviço do adaptador da ferramenta. \\
\hline baseQuestao & Registra se a ferramenta possui um repositório de problemas. \\
\hline geracaoDadosTeste & Registra se a ferramenta realiza geração automática de dados de teste. \\
\hline verificacaoAutomaticaProfessor & Registra se a ferramenta realiza avaliação automática centrada no professor. \\
\hline verificacaoManualProfessor & Registra se a ferramenta realiza avaliação manual centrada no professor. \\
\hline verificacaoAutomaticaAluno & Registra se a ferramenta realiza avaliação automática centrada no aluno. \\
\hline
\end{tabular}

Fonte: Elaborada pelo autor. 
O resultado de requisições simples são enviados às extensões por meio do valor de retorno das operações. Requisições mais complexas são mantidas em uma fila de processamento. Os resultados das requisições complexas deve ser recuperados posteriormente pela extensão que as gerou. No Quadro 45 são sintetizados os atributos das requisições que devem ser armazenados pelo middleware.

Quadro 44 - Arquitetura IMPACTLE: Visão lógica detalhada (Operações do serviço de execução)

\begin{tabular}{|l|l|}
\hline Operação & Descrição \\
\hline \hline obterListaFerramentas & Retorna a lista de ferramentas registradas. \\
\hline obterFerramenta & Retorna os dados de uma ferramenta. \\
\hline obterFormularioQuestoes & Retorna o formulário para criação e edição de uma questão. \\
\hline obterListaQuestoes & $\begin{array}{l}\text { Retorna a lista de questões do repositório de problemas de uma fer- } \\
\text { ramenta. }\end{array}$ \\
\hline obterDadosQuestao & $\begin{array}{l}\text { Retorna os dados de uma questão do repositório de problemas de } \\
\text { uma ferramenta. }\end{array}$ \\
\hline obterFormularioGeracaoDadosTeste & Retorna o formulário para geração de dados de teste. \\
\hline gerarDadosTeste & Cria uma requisição para uma geração automática de dados de teste. \\
\hline obterDadosTesteGerados & $\begin{array}{l}\text { Retorna o formulário para edição de dados de teste o formulário } \\
\text { para edição de dados de teste. }\end{array}$ \\
\hline obterFormularioSubmissoes & Retorna o formulário para submissão de uma solução. \\
\hline executarVerificacaoAutomaticaProfessor & $\begin{array}{l}\text { Cria uma requisição para executar uma avaliação automática cen- } \\
\text { trada no professor. }\end{array}$ \\
\hline obterFormularioVerificacaoManualProfessor & Retorna o formulário para avaliação manual centrada no professor. \\
\hline processarDadosVerificacaoManualProfessor & $\begin{array}{l}\text { Cria uma requisição para processar os dados de uma avaliação ma- } \\
\text { nual centrada no professor. }\end{array}$ \\
\hline executarVerificacaoAutomaticaAluno & $\begin{array}{l}\text { Cria uma requisição para executar uma avaliação automática cen- } \\
\text { trada no aluno. }\end{array}$ \\
\hline obterResultados & Retorna os resultados de uma requisição. \\
\hline salvarResultados & Salva os resultados de uma requisição. \\
\hline carregarResultados & Carrega os resultados de uma requisição. \\
\hline deletarResultados & Deleta os resultados de uma requisição. \\
\hline salvarArquivos & Salva os arquivos associados à uma requisição. \\
\hline carregarArquivos & Carrega os arquivos associados à uma requisição. \\
\hline deletarArquivos & Deleta os arquivos associados à uma requisição. \\
\hline adicionarRequisicaoFila & Adiciona uma requisição da fila de processamento. \\
\hline obterRequisicaoFila & Retira uma requisição da fila de processamento. \\
\hline & Elaborada pelo autor. \\
\hline
\end{tabular}

Fonte: Elaborada pelo autor.

Quadro 45 - Arquitetura IMPACTLE: Visão lógica detalhada (Atributos de uma requisição)

\begin{tabular}{|l|l|}
\hline Atributo & Descrição \\
\hline \hline id & Identificador único da requisição. \\
\hline idFerramenta & Identificador da ferramenta de avaliação que será utilizada para processar a requisição. \\
\hline tipo & $\begin{array}{l}\text { Define a operação que deverá ser realizada pela ferramenta de avaliação. Pode assumir os valores GE- } \\
\text { RACAO_DADOS_TESTE, VERIFICACAO_AUTOMATICA_PROFESSOR, VERIFICACAO_MA- } \\
\text { NUAL_PROFESSOR, VERIFICACAO_AUTOMATICA_ALUNO. }\end{array}$ \\
\hline situacao & $\begin{array}{l}\text { Registra a situação atual do processamento da requisição. Pode assumir os valores EM_ESPERA, EM_- } \\
\text { PROCESSAMENTO, PRONTA. }\end{array}$ \\
\hline idExterno & $\begin{array}{l}\text { Identificador da requisição no adaptador da ferramenta de avaliação. É utilizado para obter os resultados } \\
\text { da operação, após ser processada pela ferramenta de avaliação. }\end{array}$ \\
\hline
\end{tabular}

Fonte: Elaborada pelo autor.

Assim como o serviço de administração, o middleware deve conter somente uma instância do serviço de execução, que pode acessar as várias instâncias de registros de ferramentas e gerencia várias instâncias de requisições. 


\section{A.1.3 Adaptadores}

Na Figura 49 são ilustrados os componentes lógicos dos subsistemas adaptadores. Basicamente, um adaptador é composto por um único serviço adaptador que implementa as operações de várias interfaces pré-definidas. As interfaces que o serviço adaptador deve implementar variam de acordo com as funcionalidades oferecidas pela ferramenta de avaliação sendo adaptada.

No Quadro 46 são sumarizados os componentes lógicos dos adaptadores. Assim, o serviço adaptador de um adaptador deve implementar as interfaces definidas de acordo com as funcionalidades da ferramenta de avaliação que ele adapta. Todos os serviços de adaptador devem implementar a interface adaptador e pelo menos uma das interfaces verificação automática pelo professor, verificação manual pelo professor e verificação automática pelo aluno. No Quadro 48 são sintetizadas todas as operações definidas pelas interfaces, que podem ser implementadas pelo serviço adaptador.

Quadro 46 - Arquitetura IMPACTLE: Visão lógica detalhada (Componentes do adaptador)

\begin{tabular}{|l|l|}
\hline Componente & Descrição \\
\hline \hline Serviço adaptador & $\begin{array}{l}\text { Serviço web responsável em receber requisições do middleware, processá-las, e retor- } \\
\text { nar os resultados, utilizando as ferramentas de avaliação associadas quando necessário. }\end{array}$ \\
\hline Adaptador & $\begin{array}{l}\text { Interface que define os métodos essenciais que devem ser implementados pelo serviço } \\
\text { adaptador. }\end{array}$ \\
\hline Base de questões & $\begin{array}{l}\text { Interface que define os métodos a serem implementados pelo serviço adaptador, quando } \\
\text { a ferramenta de avaliação associada possui uma base de questões. }\end{array}$ \\
\hline Geração de dados de teste & $\begin{array}{l}\text { Interface que define os métodos a serem implementados pelo serviço adaptador, quando } \\
\text { a ferramenta de avaliação associada permite a geração de dados de teste para serem } \\
\text { utilizados na verificação das soluções a serem submetidas pelos alunos. }\end{array}$ \\
\hline $\begin{array}{l}\text { Verificação automática pelo } \\
\text { professor }\end{array}$ & $\begin{array}{l}\text { Interface que define os métodos a serem implementados pelo serviço adaptador, quando } \\
\text { a ferramenta de avaliação associada permite que o professor acione uma verificação } \\
\text { automática das soluçoses submetidas pelos alunos. }\end{array}$ \\
\hline $\begin{array}{l}\text { Verificação manual pelo profes- } \\
\text { sor }\end{array}$ & $\begin{array}{l}\text { Interface que define os métodos a serem implementados pelo serviço adaptador, quando } \\
\text { a ferramenta de avaliação associada permite que o professor realize uma verificação } \\
\text { manual das soluções submetidas pelos alunos. }\end{array}$ \\
\hline $\begin{array}{l}\text { Verificação automática pelo } \\
\text { aluno }\end{array}$ & $\begin{array}{l}\text { Interface que define os métodos a serem implementados pelo serviço adaptador, quando } \\
\text { a ferramenta de avaliação associada permite que o aluno acione uma verificação auto- } \\
\text { mática de uma solução submetida por ele. }\end{array}$ \\
\hline Questão & $\begin{array}{l}\text { Entidade para manipulação e persistência dos dados das questões disponibilizadas na } \\
\text { base de questões da ferramenta associada. }\end{array}$ \\
\hline
\end{tabular}

Fonte: Elaborada pelo autor.

Quadro 47 - Arquitetura IMPACTLE: Visão lógica detalhada (Interfaces no adaptador)

\begin{tabular}{|l|l|}
\hline Interfaces & Ferramentas de avaliação \\
\hline \hline Adaptador & Todas \\
\hline Base de questões & Ferramentas com repositório de problemas \\
\hline Geração de dados de teste & Ferramentas com geração automática de dados de teste \\
\hline Verificação automática pelo professor & Ferramentas com avaliação automática centrada no professor \\
\hline Verificação manual pelo professor & Ferramentas com avaliação manual centrada no professor \\
\hline Verificação automática pelo aluno & Ferramentas com avaliação automática centrada no aluno \\
\hline
\end{tabular}

Fonte: Elaborada pelo autor.

Em especial, quando um adaptador implementa a interface base de questões, que permite a utilização de uma base de problemas mantida pela ferramenta de avaliação adap- 
Figura 49 - Arquitetura IMPACTLE: Visão lógica detalhada (Adaptador)

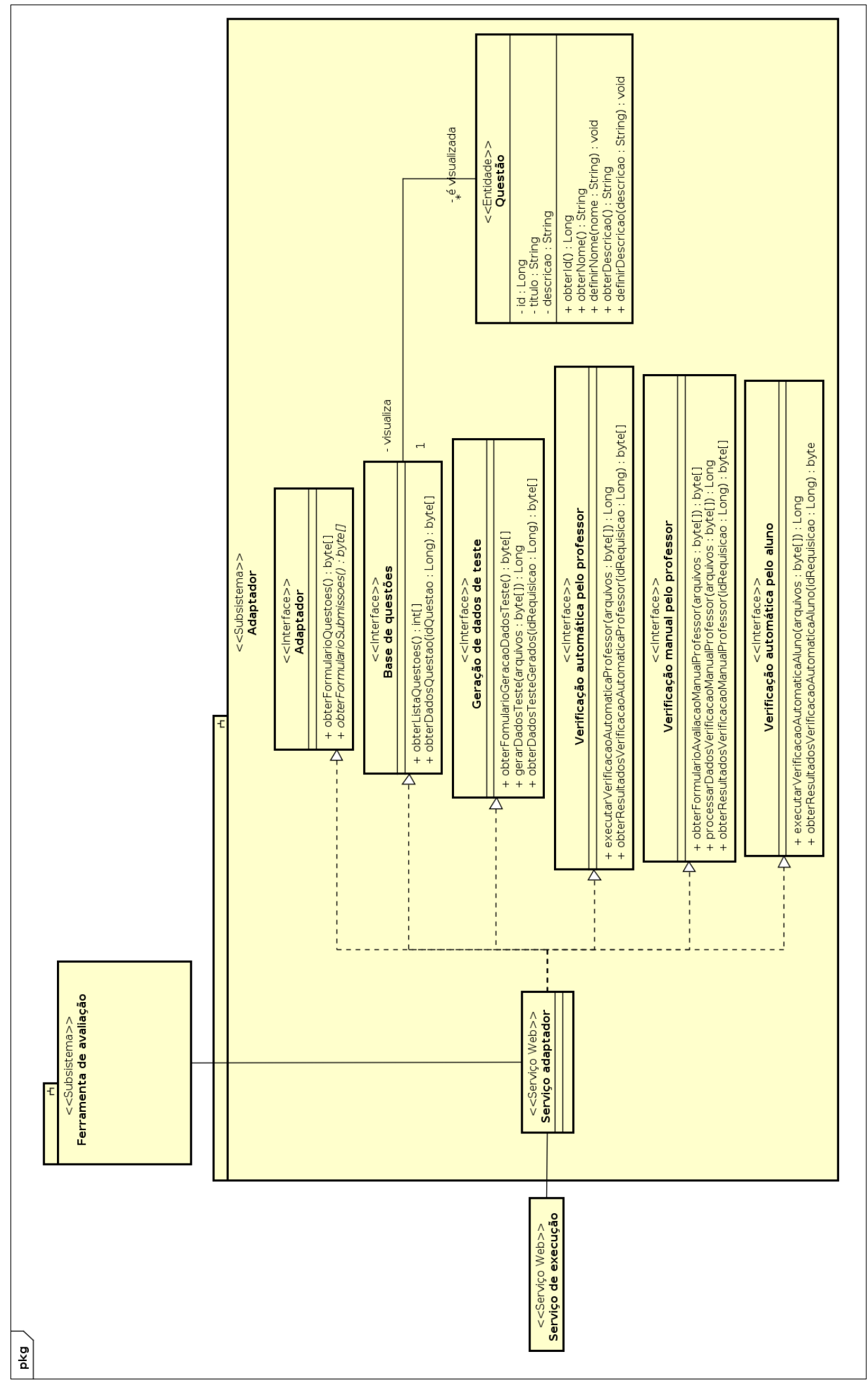

Fonte: Elaborada pelo autor. 
Quadro 48 - Arquitetura IMPACTLE: Visão lógica detalhada (Operações do serviço adaptador)

\begin{tabular}{|l|l|}
\hline Operações & Descrição \\
\hline \hline obterFormularioQuestoes & Retorna o formulário para criação de uma questão. \\
\hline obterFormularioSubmissoes & Retorna o formulário para submissão de uma solução. \\
\hline obterListaQuestoes & $\begin{array}{l}\text { Retorna a lista de questões disponíveis na base de problemas da } \\
\text { ferramenta. }\end{array}$ \\
\hline obterDadosQuestao & $\begin{array}{l}\text { Retorna os dados de uma questão da base de problemas da fer- } \\
\text { ramenta. }\end{array}$ \\
\hline obterFormularioGeracaoDadosTeste & Retorna o formulário para geração de dados de teste. \\
\hline gerarDadosTeste & Realiza a geração de dados de teste. \\
\hline obterDadosTesteGerados & Retorna os dados de teste gerados. \\
\hline executarVerificacaoAutomaticaProfessor & Realiza a avaliação automática centrada no professor. \\
\hline obterResultadosVerificacaoAutomaticaProfessor & $\begin{array}{l}\text { Retorna os resultados da avaliação automática centrada no pro- } \\
\text { fessor. }\end{array}$ \\
\hline obterFormularioVerificacaoManualProfessor & $\begin{array}{l}\text { Retorna o formulário para avaliação manual centrada no profes- } \\
\text { sor. }\end{array}$ \\
\hline processarDadosVerificacaoManualProfessor & $\begin{array}{l}\text { Processa os dados de uma avaliação manual centrada no profes- } \\
\text { sor. }\end{array}$ \\
\hline obterResultadosVerificacaoManualProfessor & $\begin{array}{l}\text { Retorna os resultados do processamento dos dados de uma ava- } \\
\text { liação manual centrada no professor. }\end{array}$ \\
\hline executarVerificacaoAutomaticaAluno & Realiza a avaliação automática centrada no aluno. \\
\hline obterResultadosVerificacaoAutomaticaAluno & $\begin{array}{l}\text { Retorna os resultados da avaliação automática centrada no } \\
\text { aluno. }\end{array}$ \\
\hline
\end{tabular}

Fonte: Elaborada pelo autor.

tada, o adaptador também deve manter um registro das questões disponíveis na ferramenta. No Quadro 49 são sintetizados os atributos das questões que devem ser armazenados pelo adaptador.

Quadro 49 - Arquitetura IMPACTLE: Visão lógica detalhada (Atributos de uma questão no adaptador)

\begin{tabular}{|l|l|}
\hline Atributos & Descrição \\
\hline \hline id & Identificador único da questão. \\
\hline titulo & Título da questão para ser apresentado aos usuários. \\
\hline descricao & Descrição da questão para ser apresentado aos usuários. \\
\hline
\end{tabular}

Fonte: Elaborada pelo autor.

O adaptador deve se comunicar com a ferramenta de avaliação durante a execução das operações. Similarmente às extensões e os LMSs, a forma em que o adaptador e a ferramenta de avaliação se comunicam é uma decisão de projeto a ser tomada de acordo com a especificidade de cada ferramenta de avaliação considerada.

\section{A.1.4 Ferramentas de avaliação}

Por fim, é importante observar que a arquitetura IMPACTLE não define mudanças na estrutura das ferramentas de avaliação. A ideia é que qualquer ferramenta de avaliação para trabalhos práticos de programação possa ser integrada ao sistema sem ser modificada, considerando apenas a presença de um adaptador que possibilite a comunicação entre o middleware e a ferramenta de avaliação por meio de uma interface padrão. 


\section{A.2 Visão de processos detalhada}

A visão de processos está relacionada com os aspectos dinâmicos do sistema, ilustrando o comportamento do sistema em tempo de execução. Os principais processos definidos para a arquitetura IMPACTLE são detalhados a seguir.

\section{A.2.1 Definição de um trabalho prático}

Na Figura 50 é ilustrado o comportamento da arquitetura durante a definição de um trabalho prático de programação. Em síntese, quando o professor seleciona a opção para criar um trabalho de programação, o LMS exibe à ele um formulário para obtenção dos dados do trabalho e a lista de ferramentas de avaliação disponibilizadas pelo middleware.

Figura 50 - Arquitetura IMPACTLE: Visão de processos detalhada (Definição de um trabalho)

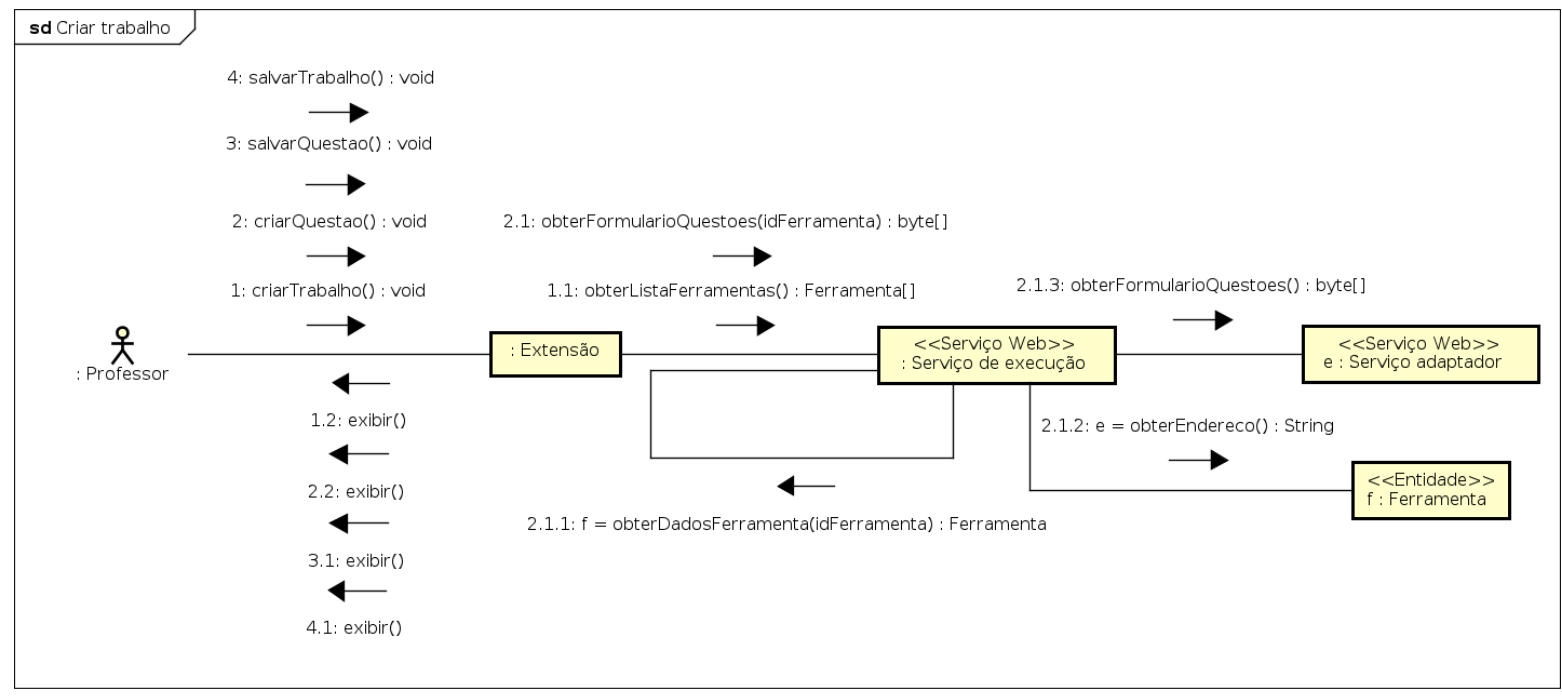

Fonte: Elaborada pelo autor.

Além de preencher o formulário, repetitivamente, o professor pode adicionar questões ao trabalho, informando a ferramenta que deverá avaliar as soluções enviadas à questão. Cada vez que o professor seleciona a opção para adicionar uma questão, o ambiente obtém e exibe a ele o formulário para obter os dados que a ferramenta necessita do professor para avaliar as soluções. Tal formulário é mantido pelo adaptador da ferramenta em questão.

Após preencher o formulário, o professor pode salvar os dados da questão, que serão armazenados no LMS. Encerrada a adição de questões e o fornecimento dos demais dados relacionados ao trabalho, o professor pode salvar os dados do trabalho, que também será armazenado no LMS.

Assim, o comportamento da arquitetura durante a definição de um trabalho é o seguinte: 
1. O professor seleciona a opção de criar um trabalho, disponibilizada pela extensão do LMS.

a) A extensão requisita ao serviço de execução do middleware a lista de ferramentas disponíveis.

b) A extensão exibe ao professor um formulário para a criação de um trabalho com as opções de acordo com o LMS em questão, bem como a opção de adicionar questões ao trabalho considerando as ferramentas de avaliação disponíveis.

2. O professor seleciona a opção para adicionar uma questão ao trabalho, informando a ferramenta que será considerada na avaliação da questão.

a) A extensão requisita ao serviço de execução o formulário de questões, enviando o "id" da ferramenta de avaliação selecionada pelo professor.

i. O serviço de execução instancia o registro da ferramenta de avaliação.

ii. O serviço de execução obtém o endereço web do serviço adaptador da ferramenta.

iii. O serviço de execução encaminha a requisição ao serviço adaptador da ferramenta, retornando o resultado da requisição à extensão.

b) A extensão exibe o formulário ao professor.

3. O professor preenche o formulário e salva a questão por meio da extensão.

4. Opcionalmente, o professor pode repetidamente adicionar, editar e remover questões por meio da extensão.

5. O professor salva o trabalho por meio da extensão.

\section{A.2.2 Seleção de questão de uma base de questões}

Na Figura 51 é ilustrado o comportamento da arquitetura durante a seleção de uma questão da base de questões de uma ferramenta de avaliação. Tal processo pode ser acionado durante a criação ou edição de um trabalho. Em síntese, quando o professor seleciona a opção para adicionar uma questão de uma determinada ferramenta, o LMS, por meio do middleware, obtém do adaptador da ferramenta a lista de questões da base da ferramenta. Em seguida, o professor pode selecionar uma questão da lista. O LMS, novamente por meio do middleware, obtém do adaptador os dados da questão, que podem ser visualizados, editados e salvos como uma questão para o trabalho.

Assim, o comportamento da arquitetura durante a definição de um trabalho é o seguinte:

1. O professor seleciona a opção de adicionar uma questão, disponibilizada pela extensão do LMS. 
Figura 51 - Arquitetura IMPACTLE: Visão de processos detalhada (Seleção de questão de uma base de questões)

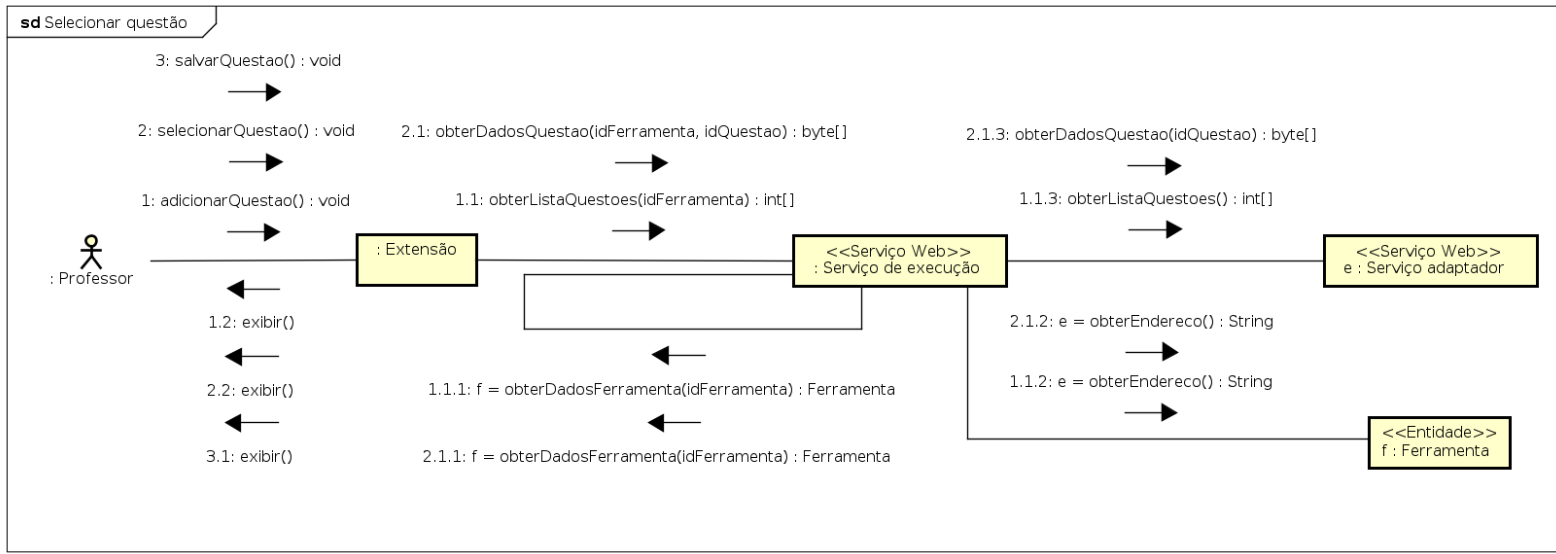

Fonte: Elaborada pelo autor.

a) A extensão requisita ao serviço de execução do middleware a lista de questões, enviando o "id" da ferramenta de avaliação associada.

i. O serviço de execução instancia o registro da ferramenta de avaliação.

ii. O serviço de execução obtém o endereço web do serviço adaptador da ferramenta.

iii. O serviço de execução encaminha a requisição ao serviço adaptador da ferramenta, retornando o resultado da requisição à extensão.

b) A extensão exibe ao professor a lista de questões.

2. O professor seleciona uma questão da lista.

a) A extensão requisita ao serviço de execução os dados da questão, enviando o "id" da questão e da ferramenta de avaliação selecionada pelo professor.

i. O serviço de execução instancia o registro da ferramenta de avaliação.

ii. O serviço de execução obtém o endereço web do serviço adaptador da ferramenta.

iii. O serviço de execução encaminha a requisição ao serviço adaptador da ferramenta, retornando o resultado da requisição à extensão.

b) A extensão exibe o formulário para edição de uma questão preenchido com os dados da questão.

3. O professor edita o formulário e salva a questão por meio da extensão. 


\section{A.2.3 Geração de dados de teste para uma questão}

Na Figura 52 é ilustrado o comportamento da arquitetura quando a geração de dados de teste para uma questão é acionada. Inicialmente, a extensão obtém e exibe ao professor um formulário para a adição dos dados de entrada. $\mathrm{O}$ formulário é mantido pelo adaptador da ferramenta associada à questão e é obtido pelo ambiente por meio do middleware. Quando o professor salva os dados de entrada, a extensão requisita ao middleware o processamento dos dados preenchidos pelo professor, enviando todos os dados e arquivos associados, bem como informando a ferramenta que deverá ser utilizada para a geração. O middleware, por sua vez, adiciona a requisição em um fila de processamento e retorna à extensão um identificador, para que a extensão recupere os resultados posteriormente.

Figura 52 - Arquitetura IMPACTLE: Visão de processos detalhada (Geração de dados de teste para uma questão)

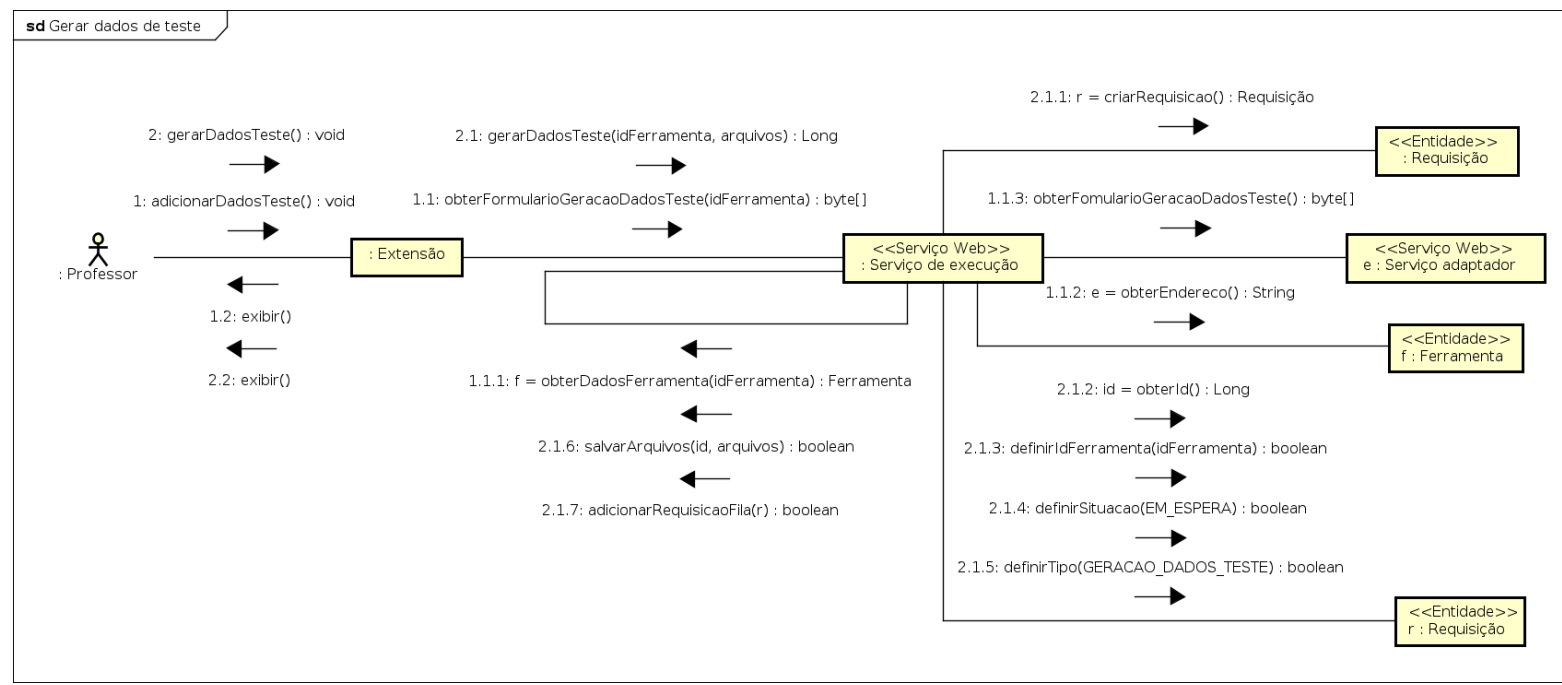

Fonte: Elaborada pelo autor.

Assim, o comportamento da arquitetura durante a geração de dados de teste para uma questão é o seguinte:

1. O professor seleciona a opção de gerar dados de teste para uma questão, disponibilizada pela extensão do LMS.

a) A extensão requisita ao serviço de execução do middleware o formulário para geração de dados de teste, enviando o "id" da ferramenta de avaliação.

i. O serviço de execução instancia o registro da ferramenta de avaliação.

ii. O serviço de execução obtém o endereço web do serviço adaptador da ferramenta.

iii. O serviço de execução encaminha a requisição do formulário ao serviço adaptador da ferramenta, retornando o resultado da requisição à extensão. 
b) A extensão exibe o formulário ao professor.

2. O professor preenche o formulário e salva os dados da geração por meio da extensão.

a) A extensão requisita ao serviço de execução o processamento dos dados da geração, enviando os arquivos e dados associados e o "id" da ferramenta de avaliação associada, bem como recebendo um "id" associado à requisição, para que possa posteriormente recuperar o resultado do processamento.

i. O serviço de execução cria uma nova requisição.

ii. O serviço de execução recupera o "id" da nova requisição para retorná-lo à extensão.

iii. O serviço de execução adiciona à requisição o "id" da ferramenta associada.

iv. O serviço de execução define o estado da requisição como "Em espera".

v. O serviço de execução define o tipo da requisição como "GERACAO_DE_DADOS_DE_TESTE”.

vi. O serviço de execução armazena os arquivos associados à requisição.

vii. O serviço de execução adiciona à requisição na fila de processamento.

b) A extensão exibe ao professor uma resposta sobre resultado da operação.

\section{A.2.4 Submissão de uma solução}

Para ilustrar, na Figura 53 é apresentado o comportamento da arquitetura durante a submissão de uma solução desenvolvida por um aluno para uma questão. Em síntese, o LMS obtém e exibe ao aluno um formulário de submissão, para que o aluno informe os dados da submissão. O formulário é mantido pelo adaptador da ferramenta associada à questão e é obtido pelo LMS por meio do middleware. Em geral, os dados da submissão consistem em um arquivo com o código fonte do programa desenvolvido pelo aluno, mas pode incluir arquivos de teste desenvolvidos pelos alunos, arquivos de documentação, resultados de uma verificação offline, dentre outros.

Assim, o comportamento da arquitetura durante a submissão de uma solução é o seguinte:

1. O aluno seleciona a opção de submeter uma solução para uma questão, disponibilizada pela extensão do LMS.

a) A extensão requisita ao serviço de execução do middleware o formulário de submissão, enviando o "id” da ferramenta de avaliação.

i. O serviço de execução instancia o registro da ferramenta de avaliação.

ii. O serviço de execução obtém o endereço web do serviço adaptador da ferramenta. 
Figura 53 - Arquitetura IMPACTLE: Visão de processos detalhada (Submissão de uma solução)

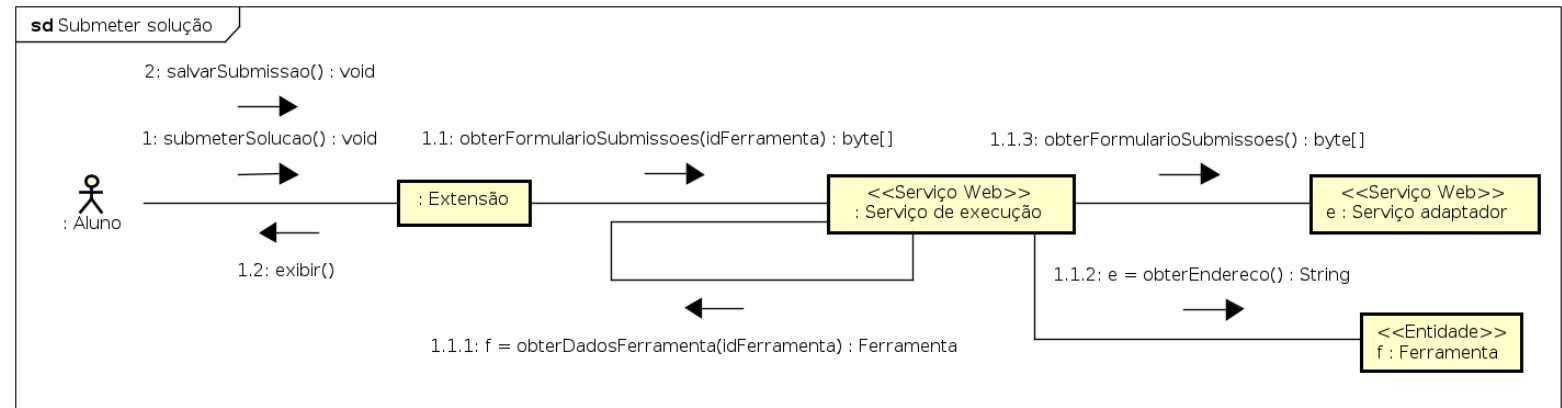

Fonte: Elaborada pelo autor.

iii. O serviço de execução encaminha a requisição do formulário ao serviço adaptador da ferramenta, retornando o resultado da requisição à extensão.

b) A extensão exibe o formulário ao aluno.

2. O aluno preenche o formulário e salva a submissão por meio da extensão.

\section{A.2.5 Avaliação automática centrada no professor}

Na Figura 54 é ilustrado o comportamento da arquitetura quando uma verificação automática centrada no professor é acionada. Em síntese, a extensão requisita ao middleware a realização da avaliação, enviando todos os dados e arquivos necessários, bem como informando a ferramenta que deverá ser utilizada para a avaliação. O middleware, por sua vez, adiciona a requisição em um fila de processamento e retorna à extensão um identificador, para que a extensão recupere os resultados posteriormente.

Assim, o comportamento da arquitetura durante o acionamento de um avaliação automática centrada no professor é o seguinte:

1. O professor aciona a avaliação automática centrada no professor para as soluções de uma questão.

a) A extensão requisita ao serviço de execução a avaliação automática das soluções, enviando os arquivos e dados associados e o "id" da ferramenta que deverá executar a avaliação, bem como recebendo um "id" associado à requisição, para que possa posteriormente recuperar o resultado da avaliação.

i. O serviço de execução cria uma nova requisição.

ii. O serviço de execução recupera o "id" da nova requisição para retorná-lo à extensão.

iii. O serviço de execução adiciona à requisição o "id" da ferramenta associada.

iv. O serviço de execução define o estado da requisição como "Em espera". 
Figura 54 - Arquitetura IMPACTLE: Visão de processos detalhada (Avaliação automática centrada no professor)

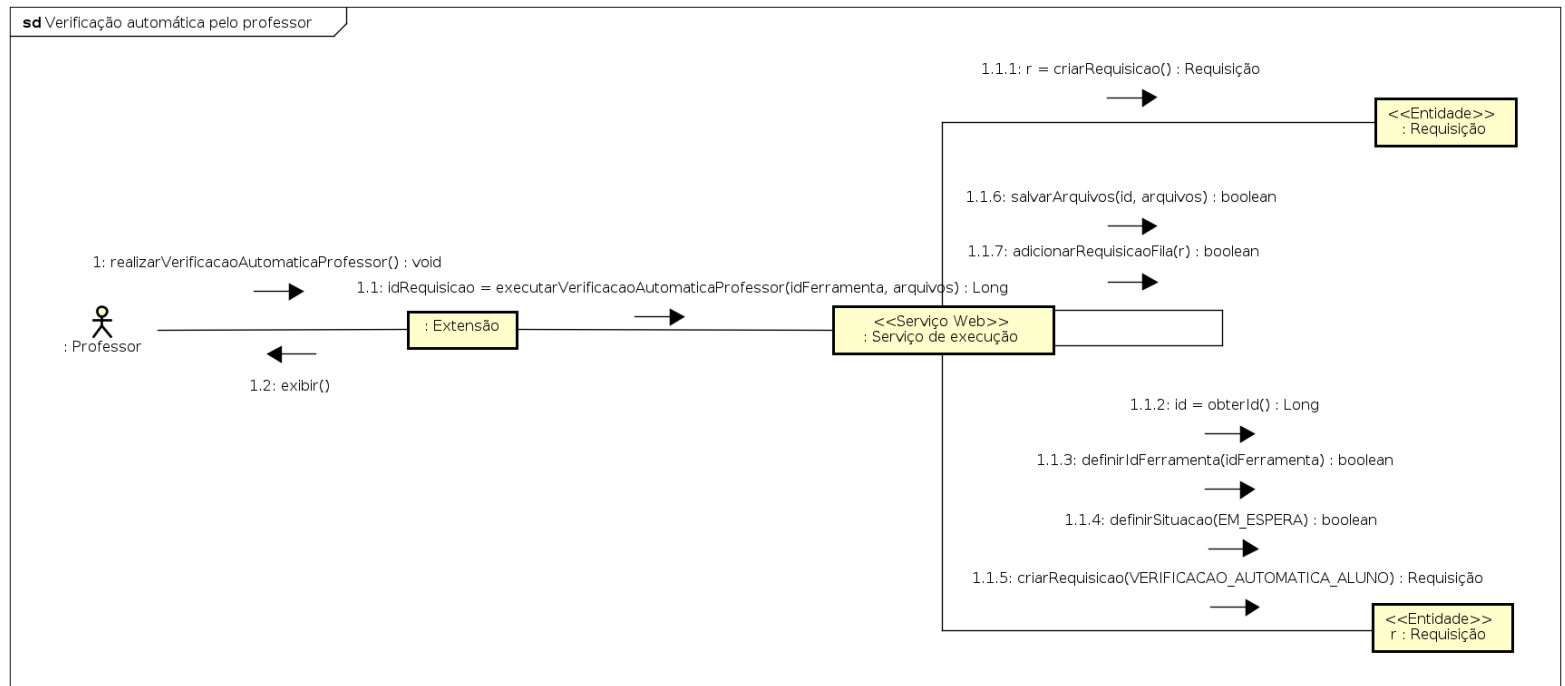

Fonte: Elaborada pelo autor.

v. O serviço de execução define o tipo da requisição como "Avaliação Automática pelo Professor".

vi. O serviço de execução armazena os arquivos associados à requisição.

vii. O serviço de execução adiciona à requisição na fila de processamento.

b) A extensão exibe ao professor uma resposta sobre resultado da operação.

\section{A.2.6 Avaliação manual centrada no professor}

Na Figura 55 é ilustrado o comportamento da arquitetura quando uma verificação automática centrada no aluno é acionada. Inicialmente, a extensão obtém e exibe ao professor um formulário para a avaliação manual. $\mathrm{O}$ formulário é mantido pelo adaptador da ferramenta associada à questão e é obtido pelo ambiente por meio do middleware. De forma análoga à avaliação automática, quando o professor salva os resultados da avaliação, a extensão requisita ao middleware o processamento dos dados preenchidos pelo professor, enviando todos os dados e arquivos associados, bem como informando a ferramenta que deverá ser utilizada para a avaliação. O middleware, por sua vez, adiciona a requisição em um fila de processamento e retorna à extensão um identificador, para que a extensão recupere os resultados posteriormente.

Assim, o comportamento da arquitetura durante a avaliação manual centrada no professor é o seguinte:

1. O professor seleciona a opção de avaliar manualmente uma solução, disponibilizada pela extensão do LMS. 
Figura 55 - Arquitetura IMPACTLE: Visão de processos detalhada (Avaliação manual centrada no professor)

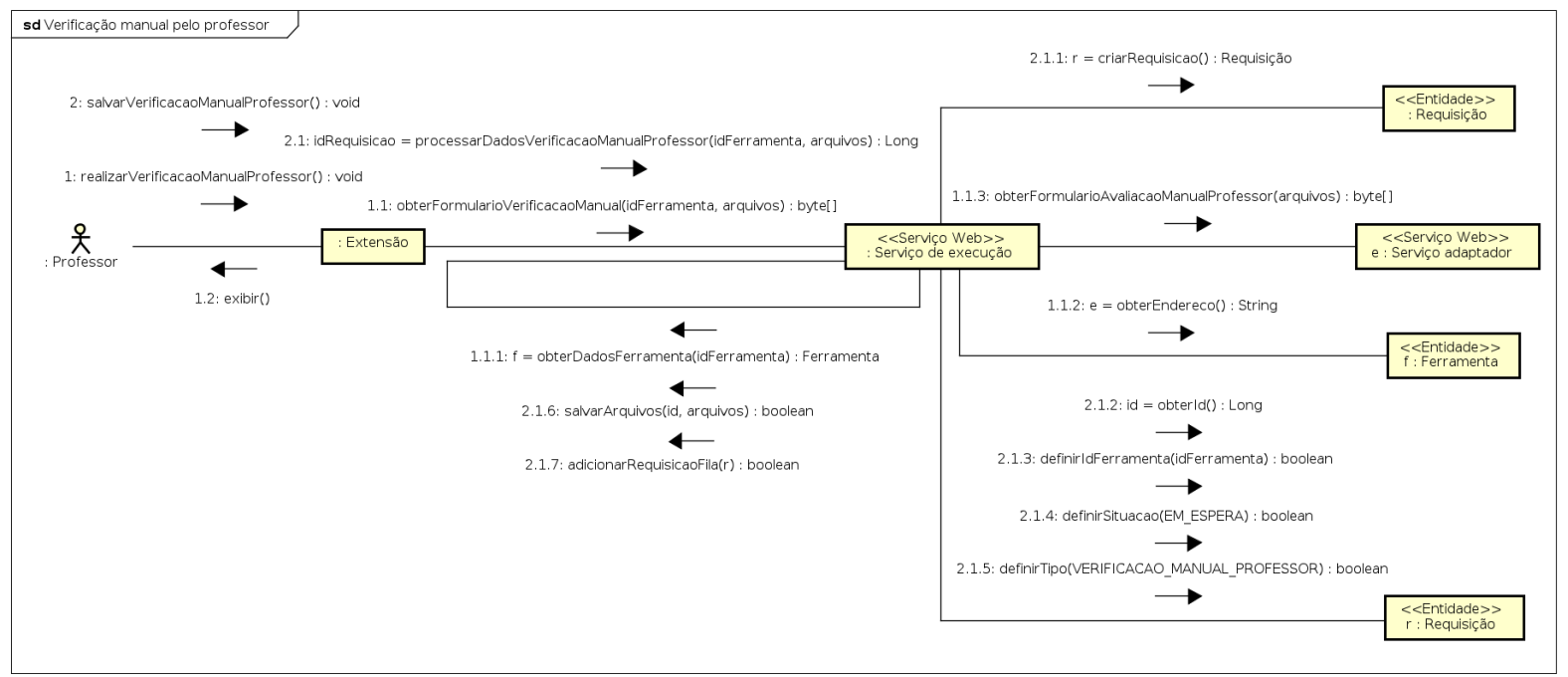

Fonte: Elaborada pelo autor.

a) A extensão requisita ao serviço de execução do middleware o formulário para avaliação manual, enviando o "id" da ferramenta de avaliação.

i. O serviço de execução instancia o registro da ferramenta de avaliação.

ii. O serviço de execução obtém o endereço web do serviço adaptador da ferramenta.

iii. O serviço de execução encaminha a requisição do formulário ao serviço adaptador da ferramenta, retornando o resultado da requisição à extensão.

b) A extensão exibe o formulário ao professor.

2. O professor preenche o formulário e salva os dados da avaliação por meio da extensão.

a) A extensão requisita ao serviço de execução o processamento dos dados da avaliação manual, enviando os arquivos e dados associados e o "id" da ferramenta de avaliação associada, bem como recebendo um "id" associado à requisição, para que possa posteriormente recuperar o resultado do processamento.

i. O serviço de execução cria uma nova requisição.

ii. O serviço de execução recupera o "id" da nova requisição para retorná-lo à extensão.

iii. O serviço de execução adiciona à requisição o "id" da ferramenta associada.

iv. O serviço de execução define o estado da requisição como "Em espera".

v. O serviço de execução define o tipo da requisição como "Avaliação Manual pelo Professor".

vi. O serviço de execução armazena os arquivos associados à requisição. 
vii. O serviço de execução adiciona à requisição na fila de processamento.

b) A extensão exibe ao professor uma resposta sobre resultado da operação.

\section{A.2.7 Avaliação automática centrada no aluno}

Na Figura 56 é ilustrado o comportamento da arquitetura quando uma verificação automática centrada no aluno é acionada. De forma análoga à avaliação automática centrada no professor, a extensão requisita ao middleware a realização da avaliação, enviando todos os dados e arquivos necessários, bem como informando a ferramenta que deverá ser utilizada para a avaliação. O middleware, por sua vez, adiciona a requisição em um fila de processamento e retorna à extensão um identificador, para que a extensão recupere os resultados posteriormente.

Figura 56 - Arquitetura IMPACTLE: Visão de processos detalhada (Avaliação automática centrada no aluno)

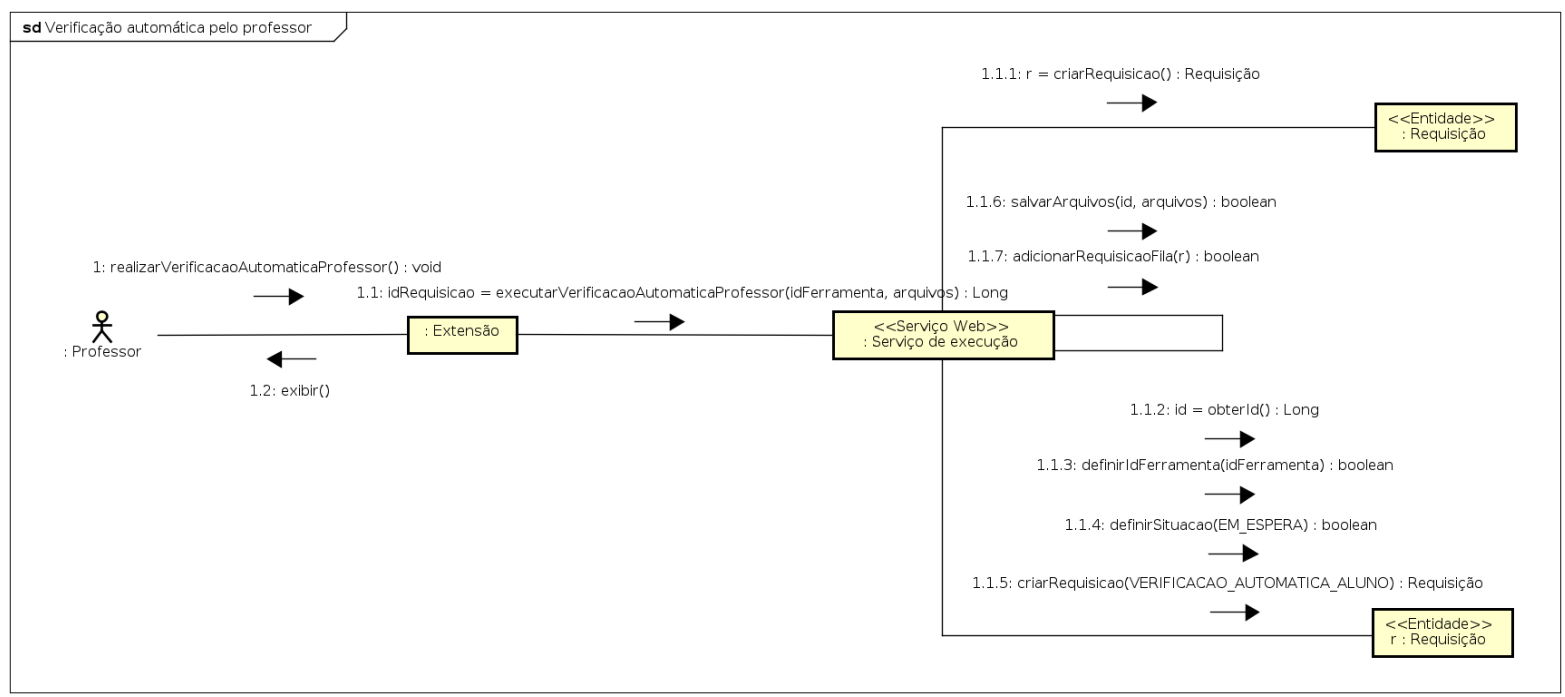

Fonte: Elaborada pelo autor.

Assim, o comportamento da arquitetura durante o acionamento de um avaliação automática centrada no aluno é o seguinte:

1. O aluno aciona a avaliação automática centrada no professor para as soluções de uma questão.

a) A extensão requisita ao serviço de execução a avaliação automática da solução, enviando os arquivos e dados associados e o "id" da ferramenta que deverá executar a avaliação, bem como recebendo um "id" associado à requisição, para que possa posteriormente recuperar o resultado da avaliação.

i. O serviço de execução cria uma nova requisição. 
ii. O serviço de execução recupera o "id" da nova requisição para retorná-lo à extensão.

iii. O serviço de execução adiciona à requisição o "id" da ferramenta associada.

iv. O serviço de execução define o estado da requisição como "Em espera".

v. O serviço de execução define o tipo da requisição como "Avaliação Automática pelo Aluno".

vi. O serviço de execução armazena os arquivos associados à requisição.

vii. O serviço de execução adiciona à requisição na fila de processamento.

b) A extensão exibe ao aluno uma resposta sobre resultado da operação.

\section{A.2.8 Processamento de uma requisição em espera}

Na Figura 57 é ilustrado o comportamento da arquitetura durante o processamento de uma requisição em espera no middleware para avaliação automática centrada no professor. Em síntese, o middleware remove a requisição da fila de processamento, carrega os dados da requisição, verifica qual ferramenta está associada à requisição e aciona a avaliação por meio do adaptador da ferramenta. $\mathrm{O}$ adaptador da ferramenta retorna um identificador externo para que o middleware possa recuperar os resultados posteriormente. Por fim, o middleware atualiza os dados da requisição e a adiciona novamente na fila de processamento.

Assim, o comportamento da arquitetura durante o processamento de uma requisição em espera para avaliação automática centrada no professor é o seguinte:

1. O serviço de execução remove a requisição da fila.

2. O serviço de execução obtém o "id" da ferramenta de avaliação associada.

3. O serviço de execução obtém o estado da requisição.

4. O serviço de execução obtém o tipo da requisição.

5. O serviço de execução obtém os arquivos associados à requisição.

6. O serviço de execução instancia o registro da ferramenta de avaliação.

7. O serviço de execução obtém o endereço web do serviço adaptador da ferramenta.

8. Se o estado da requisição for "Em espera" e o tipo da requisição for "Avaliação Automática do Professor" e o serviço de execução aciona a execução da avaliação por meio do serviço adaptador da ferramenta associada, enviando os arquivos associados e recebendo um "id" externo enviado pelo serviço adaptador para a posterior obtenção dos resultados.

9. O serviço de execução deleta do middleware os arquivos associados à requisição. 
Figura 57 - Arquitetura IMPACTLE: Visão de processos detalhada (Processamento de uma requisição em espera)

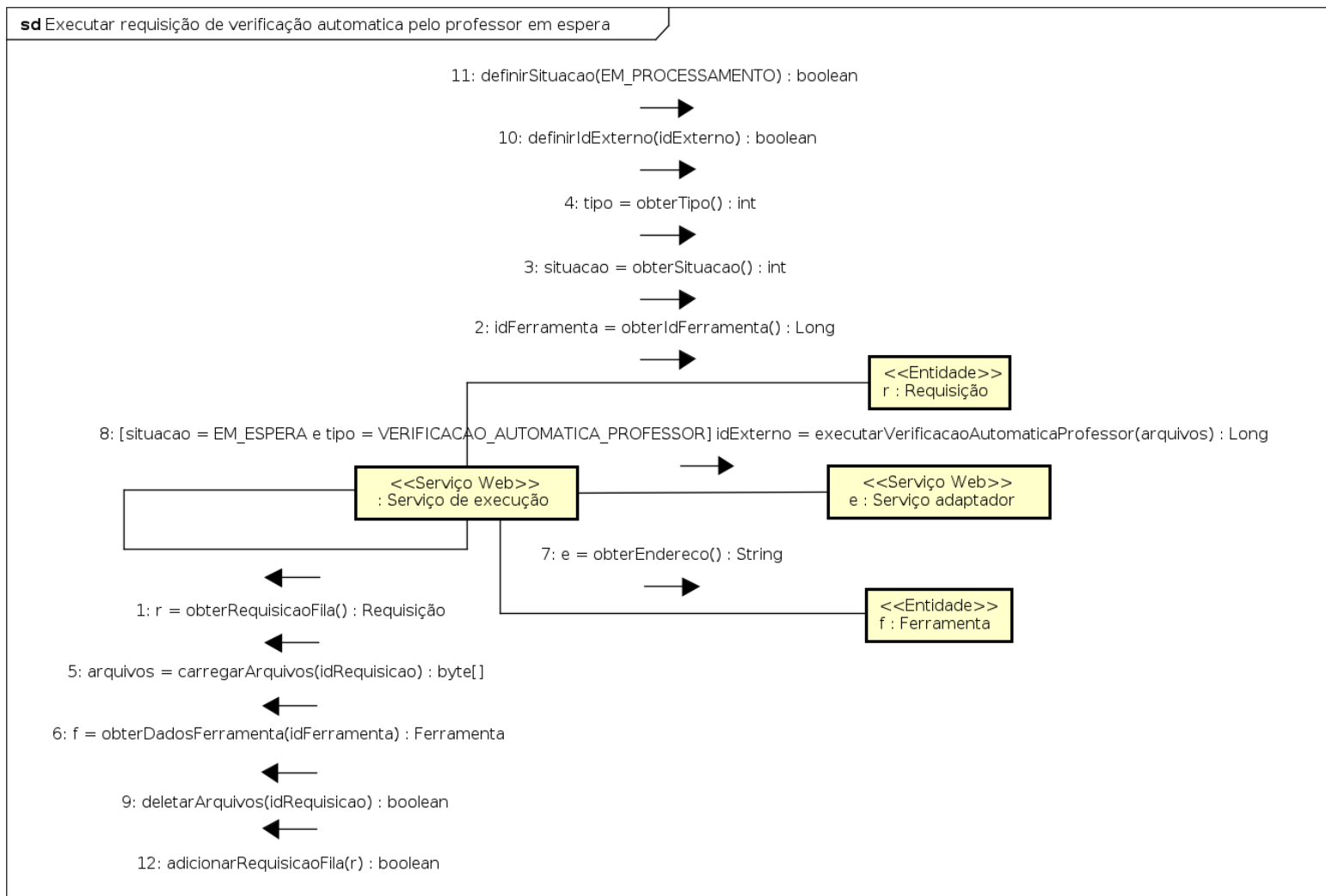

Fonte: Elaborada pelo autor.

10. O serviço de execução adiciona à requisição o "id" externo.

11. O serviço de execução define o estado da requisição como "Em processamento".

12. O serviço de execução adiciona novamente a requisição na fila.

Os processos para os demais tipos de requisições são similares, diferenciando-se apenas na operação do serviço adaptador, no qual o middleware aciona. No Quadro 50 são sintetizadas as operações acionadas em cada tipo de requisição.

Quadro 50 - Arquitetura IMPACTLE: Visão de processos detalhada (Operações acionadas no processamento de uma requisição em espera)

\begin{tabular}{|l|l|}
\hline Tipos de Requisição & Operações \\
\hline \hline Geração de dados de teste & geracaoDadosTeste(byte[] arquivos) : Long \\
\hline Verificação automática pelo professor & executarVerificacaoAutomaticaProfessor(byte[] arquivos) : Long \\
\hline Verificação manual pelo professor & processarVerificacaoManualProfessor(byte[] arquivos) : Long \\
\hline Verificação automática pelo aluno & executarVerificacaoAutomaticaAluno(byte[] arquivos) : Long \\
\hline
\end{tabular}

Fonte: Elaborada pelo autor. 


\section{A.2.9 Obtenção dos resultados de uma requisição em processamento}

Na Figura 58 é ilustrado o comportamento da arquitetura durante a obtenção dos resultados de uma requisição em processamento no serviço adaptador para avaliação automática centrada no professor. De forma análoga ao processamento de uma requisição em espera, o middleware remove a requisição da fila de processamento, carrega os dados da requisição, verifica qual ferramenta está associada à requisição e recupera os resultados da avaliação por meio do adaptador da ferramenta. O middleware salva os resultados, atualiza os dados da requisição e a adiciona novamente na fila de processamento.

Figura 58 - Arquitetura IMPACTLE: Visão de processos detalhada (Obtenção dos resultados de uma requisição em processamento)

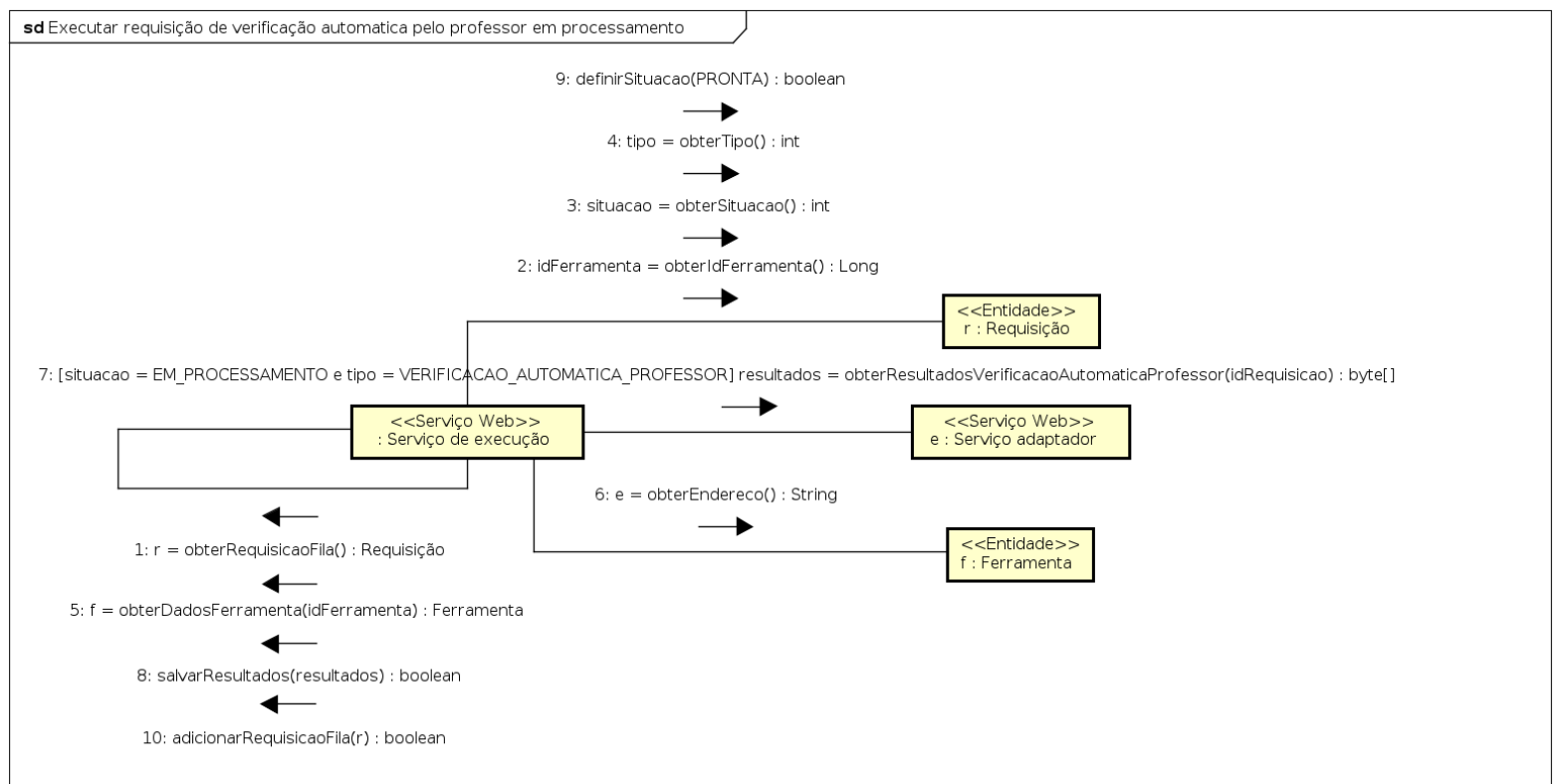

Fonte: Elaborada pelo autor.

Assim, o comportamento da arquitetura durante a obtenção de resultados de uma requisição em processamento para avaliação automática centrada no professor é o seguinte:

1. O serviço de execução remove a requisição da fila.

2. O serviço de execução obtém o "id" da ferramenta de avaliação associada.

3. O serviço de execução obtém o estado da requisição.

4. O serviço de execução obtém o tipo da requisição.

5. O serviço de execução obtém o "id" externo da requisição.

6. O serviço de execução instancia o registro da ferramenta de avaliação.

7. O serviço de execução obtém o endereço web do serviço adaptador da ferramenta. 
8. Se o estado da requisição for "Em processamento" e o tipo da requisição for "Avaliação Automática do Professor". O serviço de execução obtém os resultados da avaliação por meio do serviço adaptador da ferramenta associada, enviando "id" externo da requisição.

9. O serviço de execução salva os resultados requisição.

10. O serviço de execução define o estado da requisição como "Pronta".

11. O serviço de execução adiciona novamente à requisição na fila.

Os processos para os demais tipos de requisições são similares, diferenciando-se apenas na operação do serviço adaptador que o middleware aciona. No Quadro 51 são sintetizadas as operações acionadas em cada tipo de requisição.

Quadro 51 - Arquitetura IMPACTLE: Visão de processos detalhada (Operações acionadas na obtenção dos resultados de requisições em processamento)

\begin{tabular}{|l|l|}
\hline Tipos de Requisição & Operações \\
\hline \hline Geração de dados de teste & obterDadosTesteGerados(Long idExterno) : byte[] \\
\hline $\begin{array}{l}\text { Verificação automática pelo profes- } \\
\text { sor }\end{array}$ & obterResultadosVerificacaoAutomaticaProfessor(Long idExterno) : byte[] \\
\hline Verificação manual pelo professor & obterResultados VerificacaoManualProfessor(Long idExterno) : byte[] \\
\hline Verificação automática pelo aluno & obterResultadosVerificacaoAutomaticaAluno(Long idExterno) : byte[] \\
\hline
\end{tabular}

Fonte: Elaborada pelo autor.

\section{A.2.10 Obtenção dos resultados de uma requisição pronta}

Na Figura 59 é ilustrado o comportamento da arquitetura durante a obtenção dos resultados de uma requisição armazenados no middleware. Em síntese, a extensão obtém os resultados ao serviço de execução e os armazenam no LMS.

Figura 59 - Arquitetura IMPACTLE: Visão de processos detalhada (Obtenção dos resultados de uma requisição pronta)

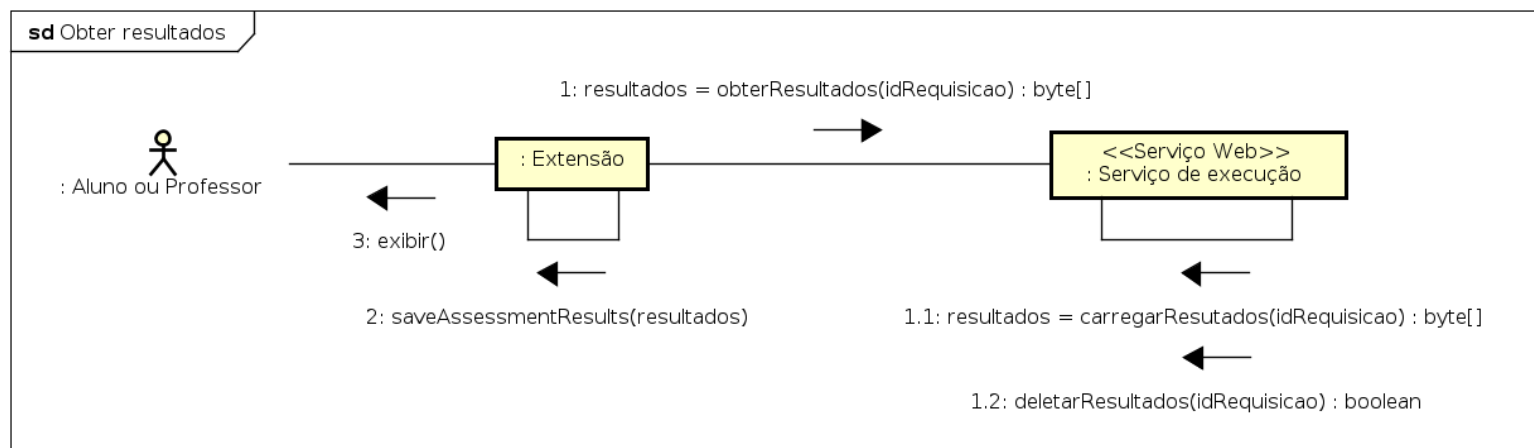

Fonte: Elaborada pelo autor.

Assim, o comportamento da arquitetura durante a obtenção dos resultados é o seguinte: 
1. A extensão requisita ao serviço de execução o resultado de uma requisição, informando o "id" da requisição e recebendo os arquivos associados.

a) O serviço de execução carrega os resultados armazenados no middleware.

b) O serviço de execução deleta os arquivos associados do middleware.

2. A extensão armazena os resultados no LMS.

3. A extensão notifica o aluno ou professor sobre o resultado da operação. 


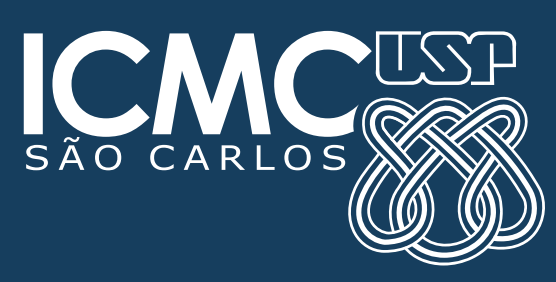

